

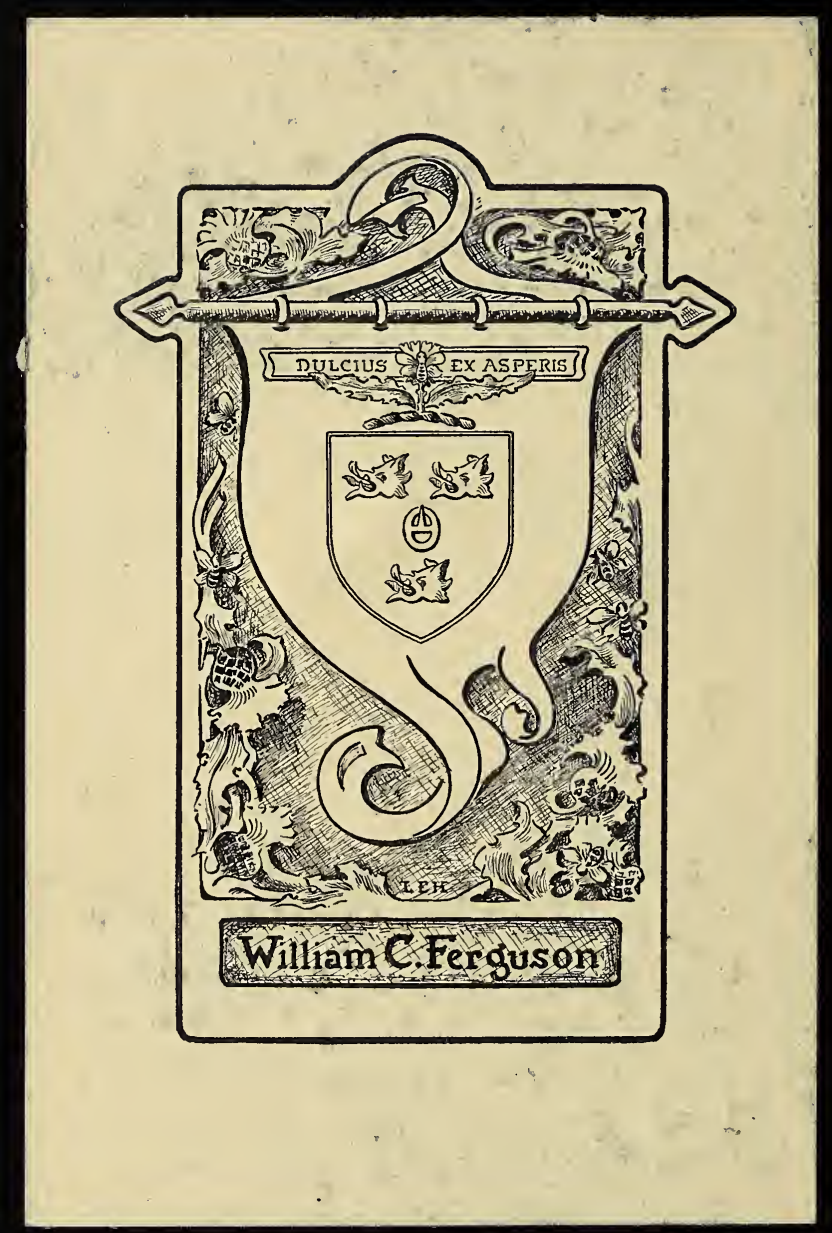


Smithsonian Institution Sibraries

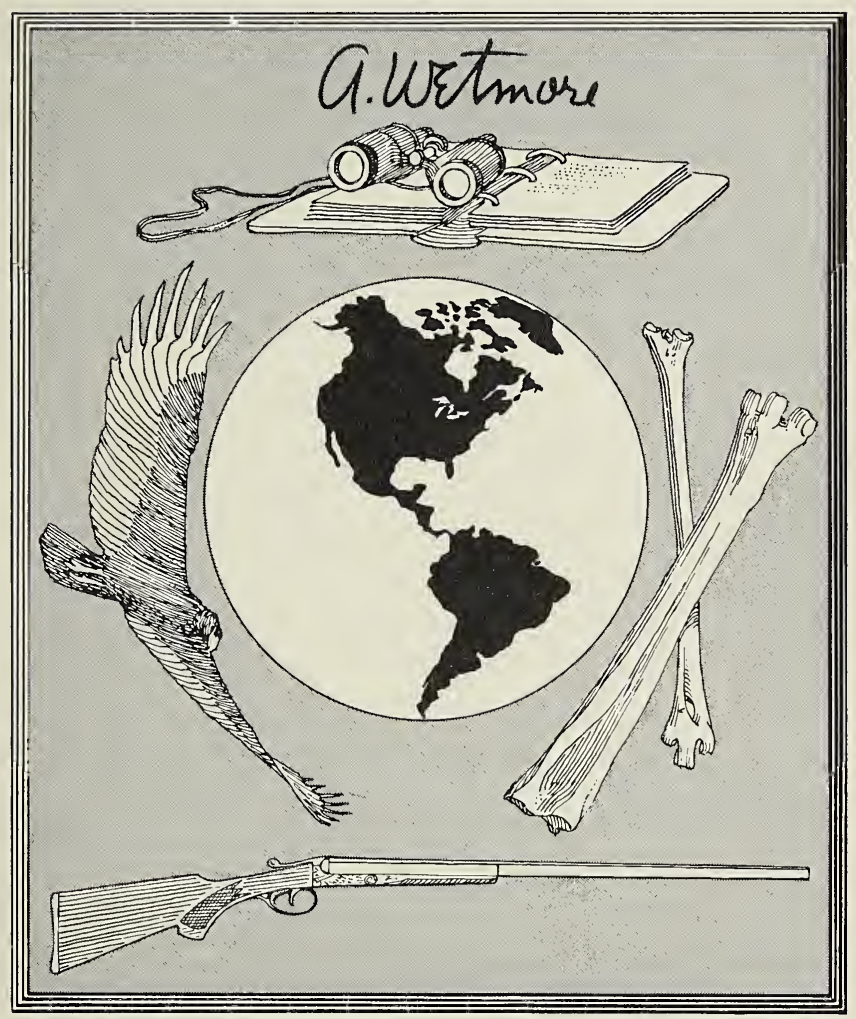

Alexander Wetmore 1946 Sixth Secretary 1953

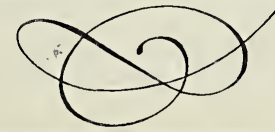




$$
5 \%
$$


A. Wratmore 2,5 


\section{I.-BIRD-LIFE OF THE BORDERS.}

Records of Wild Sport and Natural History by Moorland and Sea. ( $5+$ Illustrations.)

London: Gurney \& Jackson. 1889.

\section{II.-THE ART OF WILDFOWLING.}

With Appendix of Reminiscences, and 39) Illustrations. London: Horace Cox. 1896.

\section{III.-WILD SPAIN-ESPAÑA AGRESTE.}

(By A. C. and WAITER Buck.)

Records of Sport with Rifle, Rod, and Gun, Natural History and Exploration. With 174 Illustrations.

London: Gurney \& Jackson. 1893.

\section{IV.-WILD NORWAY.}

With Chapters on Spitsbergen, Denmark, etc., and $6: 3$ Illustrations.

London: Edward ARNold. 1897. 


\section{WILD NORWAY.}






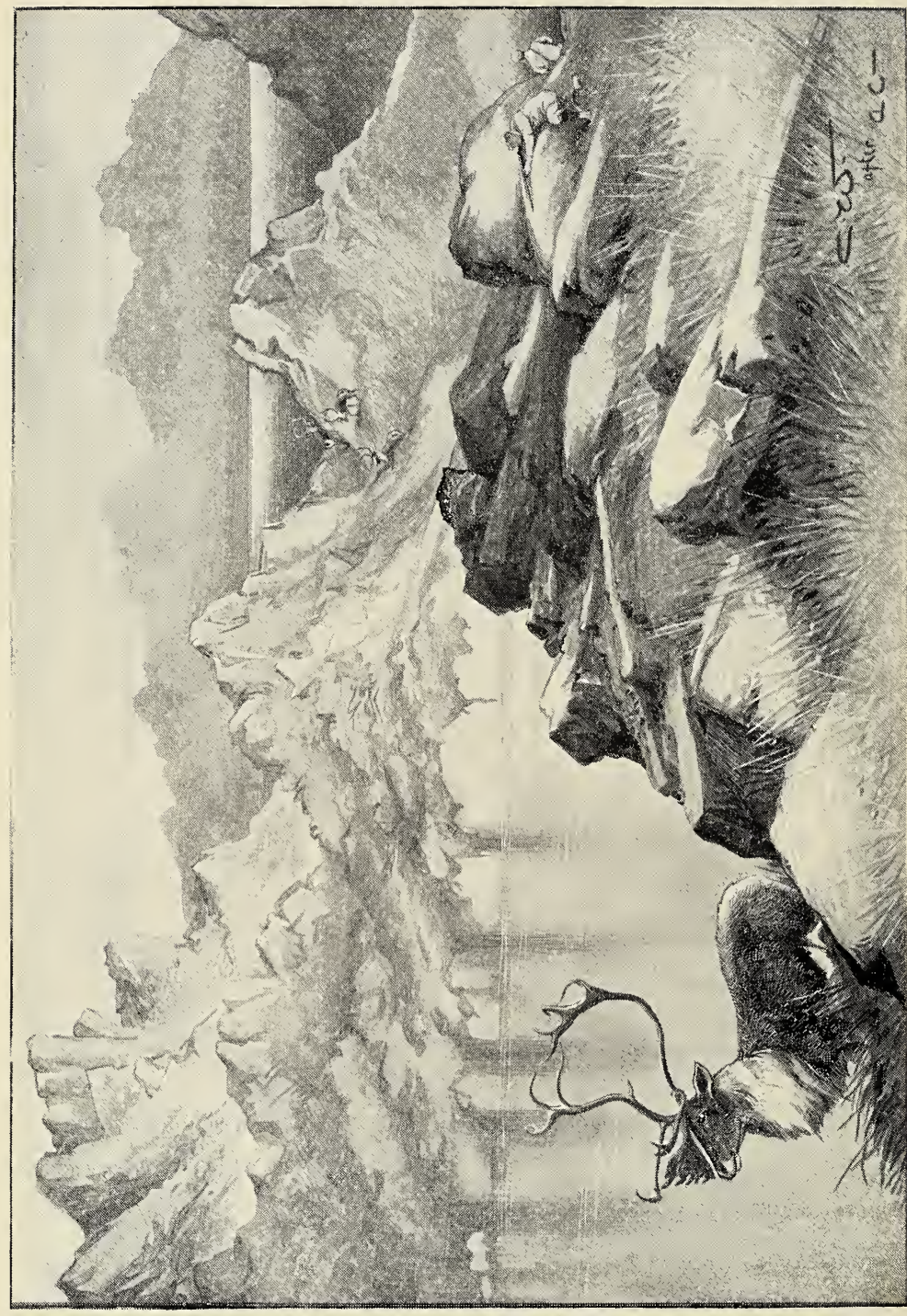

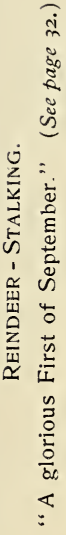




\title{
WILD NORWAY:
}

WITH CHAPTERS ON

\author{
SPITSBERGEN, DENMARK, Eтc.
}

BY

\section{ABEL CHAPMAN,}

JOINT-AUTHOR OF "WILD SPAIN," AUTHOR OF "BIRD-LIFE OF THE BORDERS,"

"THE ART OF WILDFOWLING," ETC.

ILLUSTRATED BY THE AUTHOR,

ASSISTED BY CHAS. WHYMPER AND P. CH. TRENCH.

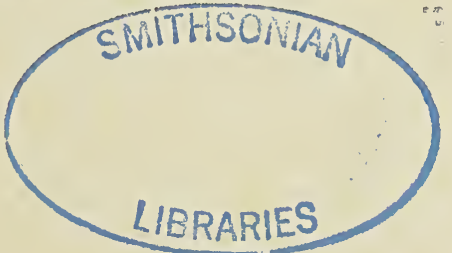

EDWARD ARNOLD,

积ublisher to the Frndia Office.

LONDON :

37, BEDFord StREeT.
NEW YORK :

70, Finth Avenue.

1897. 



\section{PREF A CE.}

Eigнт years ago, in the preface of my first book ("Bird-Life of the Borders"), I ventured to forecast the possibility of my publishing the results of similar experiences in foreign lands. Thanks to the kindly reception of that and each of my succeeding works, I now complete the series then indicated, with this volume on Scandinavia.

During sixteen years (since 1881), I have regularly visited Northern Europe; but, inasmuch as Norway has been exploited by British sportsmen for at least forty years, it seems desirable to define my qualification to write. Many old Anglo-Norsemen have enjoyed longer opportunities-particularly in special localities and in special branches of sport; but not many have taken a wider field with rod, gun, and rifle, or a broader scope of research. And all, I hope, will forgive me if, in one quality, I claim to yield place to none-that is, in keenness.

As regards salmon-fishing, I write as an amateur, and the chapters thereon should be read as the impressions of an enthusiast, rather than of an expert. In big-game hunting, having graduated in the craft since boyhood, I write with more confidence; while the subjects of trouting and small-game shooting, though briefly treated, are believed to be reliable, and will, I trust, prove of use to the tyro in Norway. 
The love of natural history, especially of ornithology, has ever been a mainspring with me, and has formed the sole object of many journeys, incidentally of all. The results I have endeavoured to compress into the smallest compass, although, personally, I regard them as the most valuable section of this book.

Illustration of wild-life becomes ever increasingly difficult. Ten years ago nothing that was artistic was correct, and vice versâ. Of late years, art has broadened its border, and some recent drawings of bird-life are the best the world has ever seen. Birds have surrendered to the pencil, but big-game (in Europe) remain outside the pale. Co-operation is still necessary; but I believe that several of Mr. Whymper's drawings in this book, based on my own rough but careful sketches from the life, approach the real with a fidelity not before attained.

In completing this, the last of my four volumes, I may take a retrospective pride in surveying the wide area covered-bardly an appreciable extent of really wild land in Western Europe, from Southern Spain to Spitsbergen, but has been inspected, if not explored. From the first chapter in 1888 , to the last in 1897, every line represents work at first-hand, and all has undergone the supervision of my friend Mr. Howard Saunders, to whose sound advice and unsparing criticism, both my readers and I are indebted to a degree that would be difficult to define and impossible to exaggerate.

A. C.

South Bailey, Durhai,

March 31, 1897. 


\section{TABLE OF CONTEN'TS.}

\section{CHAP'TER I.}

THE LAND OF FJELD AND FJORD.

I. Introductory

II. Norway as a Sporting-field

III. The Avifauna of Norway

IV. The Norsk People

$\begin{array}{rrrr} & & & \\ \ldots & \ldots & \ldots & 1 \\ \ldots & \ldots & \ldots & 8 \\ \ldots & \ldots & \ldots & 14 \\ \ldots & \ldots & \ldots & 17\end{array}$

\section{CHAP'TER II.}

REINDEER-STALKING IN RYFYLKE.

"There's many a Slip" ...

$\ldots$

CHAP'IER III.

REINDEER-STALKING-continued.

"A glorious First of September" ...

$\begin{array}{lll}\ldots & \ldots & 32\end{array}$

CHAPTER IV.

NOTES ON THE FIRST PRINCIPLES OF SALMON-FISHING.
I. Fly-Fishing
...
$\begin{array}{llll}\ldots & \ldots & \ldots & 49 \\ \ldots & \ldots & \ldots & 59\end{array}$
II. Harling 
CHAP'TER V.

SALMON-FISHING IN SÖNDHORDLAND.

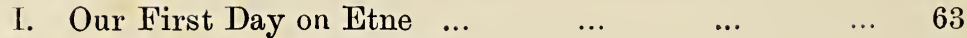

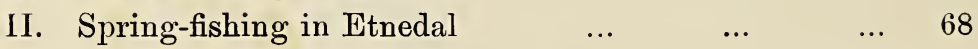

CHAPTER VI.

$\begin{array}{llllllll}\text { MEMOIRS OF MONSTERS } & \ldots & \ldots & \ldots & \ldots & \ldots & 78\end{array}$

CHAPTER VII.

SALMON-FISHING IN SŬRENDAL.

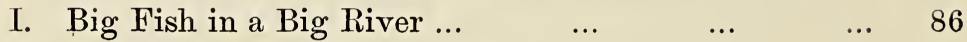

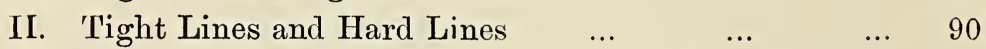

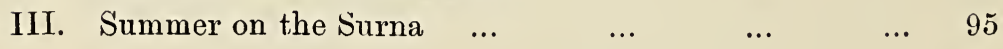

\section{CHAP'TER VIII.}

SUMMER RAMBLES ON THE SŬRENDAL FJELDS.

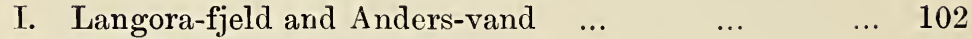

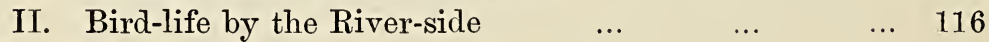

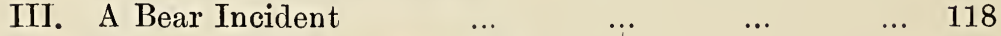

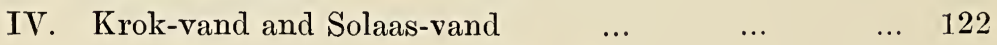

CHAP'TER IX.

NOTES ON TWO MORE SALMON-RIVERS.

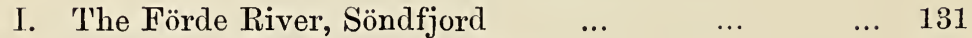

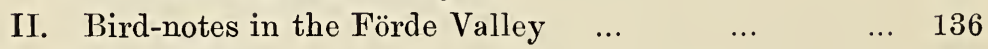

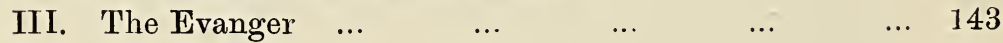

\section{CHAPTER X.}

TROUTING FOP TOURISTS.

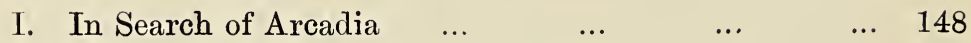

$\begin{array}{llllll}\text { II. A Reminiscence } & \ldots & \ldots & \ldots & \ldots & 156\end{array}$ 


\section{CHAPTER XI.}

TROUTING IN THE TELEMARK

\section{CHAPTER XII.}

AUTUMN IN NORWAY.

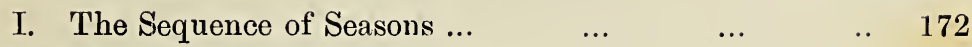

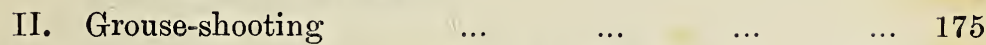

III. Specific Notes on Grouse and Ptarmigan $\quad \ldots \quad \ldots \quad \ldots 184$

CHAPTER XIII.

HUNTING-CAMPS ON HARDANGER VIDDEN (REINDEER-STALKING).

$\begin{array}{llllll}\text { I. Under Difficulties } & \ldots & \ldots & \ldots & \ldots & 187\end{array}$

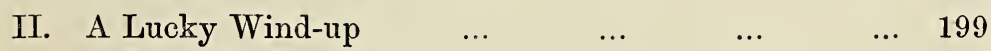

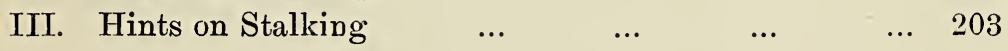

CHAPTER XIV.

ELK-HUNTING IN INDERÖEN.

$\begin{array}{llllll}\text { Our Forest of Furudal } & \ldots & \ldots & \ldots & \ldots & 207\end{array}$

CHAPTER XV.

ELK-HUNTING IN NAMDALEN.

The White Bull of Rognvas-fjeld ... $\quad \ldots \quad$... 225

CHAPTER XVI.

$\begin{array}{llllll}\text { THE HIGHLANDS OF THE SWEDISH DIVIDE } & \ldots & \ldots & \ldots & 242\end{array}$

\section{CHAPTER XVII.}

THE HIGHLANDS OF THE SWEDISH DIVIDE-continued

Lövsjoli and the Luru River $\quad \ldots \quad$... $\quad \ldots \quad 261$ 


\section{CHAPTER XVIII.}

WILD-LIFE IN FOREST AND FJELD.

PAGE

Studies of some Few of the Chief Typical Species Characteristic of the Scandinavian Fauna

\section{CHAPTER XIX.}

IMPRESSIONS OF DENMARK.

I. The Cornlands and Heaths $\quad \ldots \quad \ldots \quad \ldots \quad \ldots \quad 301$

II. The Fens of West Jutland $\quad \ldots \quad \ldots \quad \ldots \quad \ldots \quad 305$

\section{CHAP'TER XX.}

THE MARINE LAgOONS AND SALT-MARSHES OF WEST JUTLAND $\ldots 317$

\section{CHAPTER XXI.}

THE NORTH SEA.

Notes on Bird- and Insect-Migration, observed during

$\begin{array}{lllllll}\text { Twenty-four Voyages } & \ldots & \ldots & \ldots & \ldots & 327\end{array}$

\section{CHAP'TER XXII.}

SPITSBERGEN.

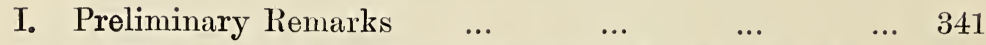

II. A Winter in the Eightieth Degree. By Arnold Pike 343 


\section{LIS'T OF ILLUSTRATIONS.}

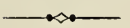

PAGE

Reindeer-STaLking in Ryfylike

... Frontispiece.

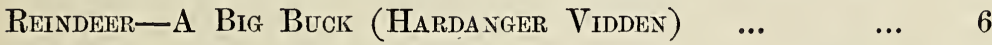

Bull-elk at Hone (MŬRŭ Forest)...

... To face 8

Stalker's Camp (Opstryn)

Our only Neighbours (Magpies)

Pelicans, Gulls, and Grey Geese

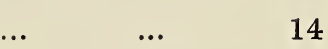

Reindeer-Stalker's Hut (Breiava)...

To face 20

Ptarmigan ...

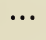

The Sentinel (Reindeer) ...

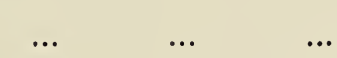

35

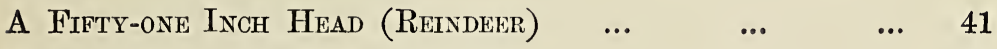

Salmon-Fishing-" Begginning to Yield" ...

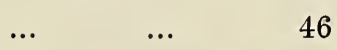

A Salmon-Pool, showing Casting-stages

... To face 66

Osprey (Tana River)

$\begin{array}{lll}\ldots & \ldots & 70\end{array}$

"Boring" (Salmon)

... $\quad$... 76

"Played out" (Salmon)

GŭLAa（SŬRENDAL)

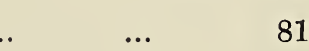

"Half as Deep as he was Long"

\section{(Satmon)}

$\ldots \quad \ldots 83$

The Ferry on Galten Pool

"Kidded" into By-Strean, and killed in Eight Minutes 


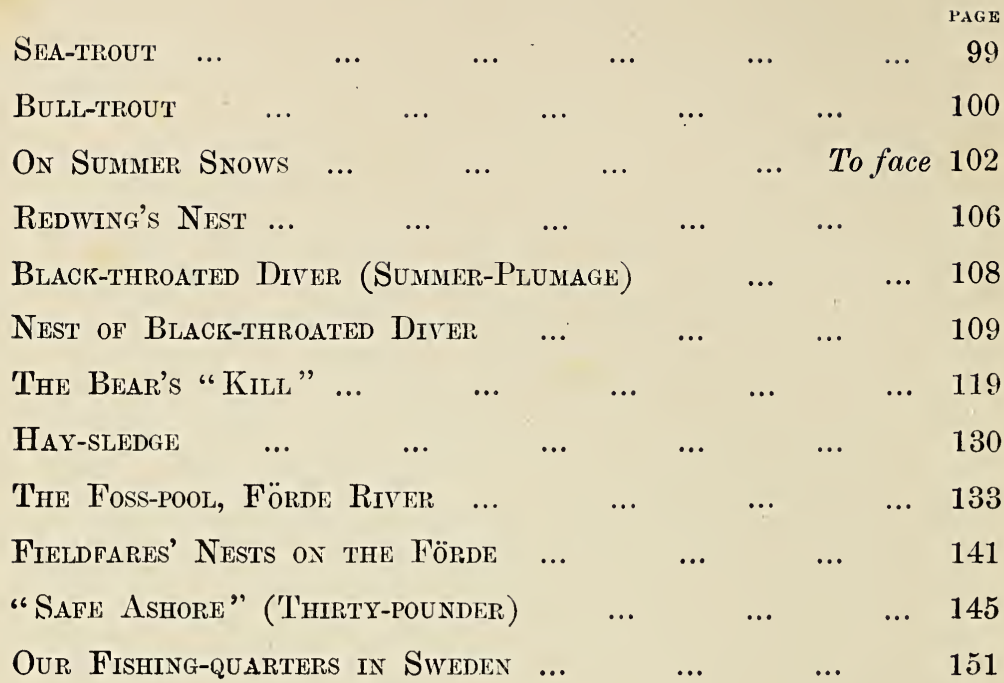

“A Lively Double" ('T'rout) ... $\quad \ldots \quad$... $\quad$ To face 154

$\begin{array}{llllllll}\text { "UNRESISTING } & \ldots & \ldots & \ldots & \ldots & \ldots & 159\end{array}$

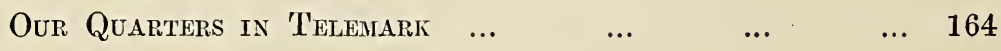

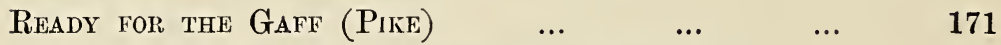

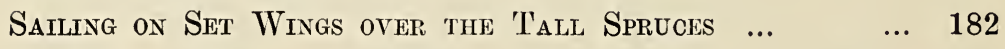

Our Camp on Hardanger Vidden ... $\quad \ldots \quad$ To face 188

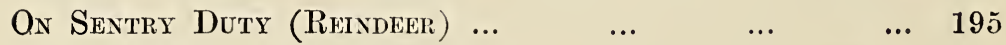

ReINDEer RESTING AT MID-DAY $\quad \ldots \quad$... $\quad$ To face .196

"Struck StifF" (Thirty-Three Points) $\quad \ldots \quad \ldots 201$

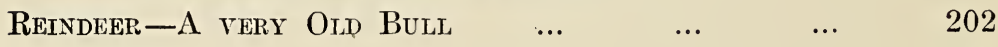

$\begin{array}{lllllllll}\text { HAWK-OWL } & \ldots & \ldots & \ldots & \ldots & \ldots & \ldots & 209\end{array}$

HAWK-OWL-“ "WATCHING AND WONDERING $" \quad \ldots \quad \quad \ldots \quad 212$

Tengmamm's OwL-"ON the Spike of a Sprdce" $\quad \ldots 214$

"Cackling and Becking for all they are worth" $\ldots \quad 217$

Hoofs of Elik, Reindeer, and Red Deer $\quad \ldots \quad$... 218

Our Forest-home in Furudal $\quad \ldots \quad$... $\quad$ To face 222 


\section{LIST OF ILLUSTRATIONS.}

xiii

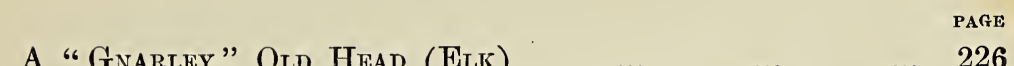

BULL-ELK, BRoWSING

To face 228

The White Bull of Rognvas-fjeld $\quad \ldots \quad \ldots \quad \ldots \quad$, 232

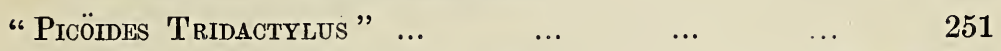

A Straight-away Stern Shot (Elk) $\quad \ldots \quad$... To face 254

The Biggest Game-beast in Europe $\quad \ldots \quad$ „.. 258

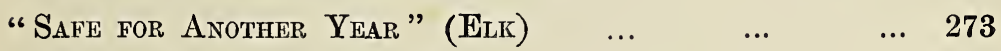

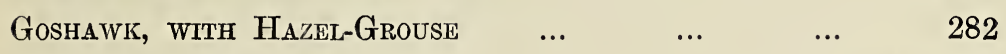

$\begin{array}{llllllll}\text { ROUGH-LEGGED BuZZARD } & \ldots & \ldots & \ldots & \ldots & 288\end{array}$

A Study in Vigilance (Godwit) $\quad \ldots \quad \ldots \quad \ldots \quad \ldots \quad \ldots \quad 295$

In the Skjergaard (Cormorants and Eiders) $\ldots$ To face 296

$\begin{array}{lllllll}\text { A Danish Farm-House } & \ldots & \ldots & \ldots & \ldots & 302\end{array}$

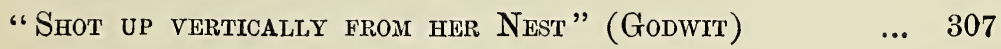

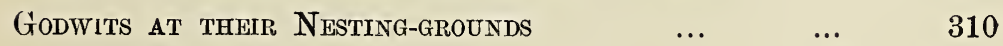

Avocets (West Jutland, $\quad \ldots \quad$... $\quad \ldots \quad$ To face 322 



\title{
WILD NOR W A Y.
}

\author{
CHAPTER I. \\ THE LAND OF FJELD AND FJORD. \\ I. INTroductory.
}

Norway must attract those who appreciate what is grand and wild. There is a boldness and a sense of desolation in her metamorphic mountains with their robe of clinging birch and prehensile pines, and in the infinity of those winding fjords, a tithe of which it would take a lifetime to explore. The traveller is constantly confronted with what, in our days, appear anachronisms in nature. I do not refer to the electric light in the arctic-a sort of counter-blast to the "midnight sun"-nor to telephone-wires stretched afar through primæval forest, where the old-world elk still wanders, wondering at lustrous insulators. No ; it is rather the sentiment that one is here face to face with the genesis of creation, with glacial epochs and eocene forms of life surviving contemporaneous and, it may be, in juxtaposition with later nineteenth-century conditions and developments. The latter, in Norway, are 
fairly well up to date. But the earth is unfinishedwithout form and void-its matter and material only emergent from embryonic stages. One enters, in short, the green-room of geology.* I can understand, though I do not endorse, the complaint that her scenery is monotonous; but a sentiment, once overheard, that "Norway is dull," seems indicative of intellectual poverty.

Norwegian scenery may be said to begin where that of other lands leaves off. Nature here arrays herself on giant scale. There is nothing small, even by way of contrast; though there is infinite softness in the half-lights of the north and the subdued colouring of the fjords. The general aspect may be-aye, isof gloomy type; but the extremity of sternness is relieved, in spring, by the brilliant emerald of the foreshores and light, feathery foliage of the birch. Then, in August, masses of heather bloom purple even down to sea-level. In the forests the glory of autumnal tints can nowhere be rivalled, while russet and crimson mosses and fell-grasses of every hue clothe the lower slopes. These pleasing colour-reliefs grow gradually less and less marked as one voyages northwards; and beyond the polar circle but little of softness survives in a landscape composed of black rock-mountains, of glaciers, and eternal snow-always impressive, often almost appalling, when cloud-masses half shroud frowning precipices, and a glint of sunlight impinging on some snow-field far above, enhances the effect. For fantastic grandeur of form there is nothing in Europe

* I am not a botanist, but believe the Norwegian flora is largely of that early order " whose seed is in itself." 
(nothing accessible, at any rate) that will compare with the serrated outlines of Lofoten in wildness and sublime desolation,-while the arctic idea is intensified by the shoals of whales and grampus that gambol in the narrow seas.

Still further north, in Spitsbergen, no vestige of colour remains to relieve the terrible asperity of a contemporary "glacial epoch" in full present operation, and which seems likely to survive for many more æons before retiring within the limits of a geological definition.

But "scenery" will not be described. It is too big for epithets, and superlatives are played out. In Norway it must be taken without saying. Nor, if difficult to describe, is it easier to depict, for pencil cannot portray that which impends; while the scale and the nearness of the point of view alike forbid such subjects being focussed upon puny paper-that is, as seen from the level. Though less impressive, perhaps the most imposing Norsk landscapes are those seen from above. Truly charming subjects are afforded looking down glen or corrie at a thousand or fifteen hundred feet; but beyond such limited range, the power of art has yet to catch the full breadth of this big land, to realize its ideals of spirit and space in a crystal atmosphere, where distance is often all but annihilated. As for photography, in landscape it is caricature, false alike in perspective and proportion.

The Norsk fjelds rise abrupt and direct to their full height. Hence, though few exceed seven thousand feet, and none reach nine thousand feet, they look bolder than loftier ranges in other lands where gradients are more prolonged. One's eye enjoys in Norway chronic 
gratification, with frequent surprises ; but, in a book, it is inconvenient to be ecstatic, so we will now leave "scenery" and, as before proposed, take it for granted.

Travelling along the main routes, but little is seen except the wall-like slopes of the fjelds. Some tourists, perhaps, conclude that these are unscalable. Few, at any rate, attempt the ascent, or see what lies above and beyond. There is something, it is true, in the character of the fjeld-sides-perhaps it is the bold and serrated contour of the sky-lines-which suggests that they lead merely to knife-edged ridges, falling away on the reverse with equal abruptness as from the visible apex. But that is not so. Norway lies up there:

One may have read (and overlooked amidst dry statistics) in faithful Bennett or Baedeker, a statement that "one half of Norway lies at an elevation exceeding two thousand feet." Within that little fact are comprehended very large results. Those mural precipices that he sees are but the walls of vast table-lands, stretching for twenty, thirty, it may be fifty miles, and even more, before another deep valley breaks their continuity. It is up here, on these glorious highlands, that the Norway of the hunter and stalker, of the sportsman, naturalist, and mountaineer is to be found. The people, it is true (and the salmon!), live down below, in the valleys; but to see Norway, to realize what the word means, you must get on the top-out on the roof.

The high fjeld is worth the ascent. The tourist will not be disappointed. On the contrary, he will find himself, in the course of a ten or twelve hours' walk, amidst scenes that he will not forget during life, 
and will have acquired a new and impressive idea of this grand wild land which is now becoming a chief summer playground of the touring world. It is a characteristic of hills in all lands, not excluding Norsk (though of the latter in a modified degree), that they appear worse than they really are. Go to work with stiff neck and a set purpose, and the summit will be found to have been gained with less labour than was anticipated.

The highlands - the roof of Norway - vary infinitely in character. Many of moderate elevation (say, under three thousand feet) are of moor-like aspect, rolling, broken ground clad for miles around with wiry scrub of dwarf birch, creeping willow, and such-like alpine plants, with numerous tarns and patches of bog interspersed. Snow only lies here in patches on the northern faces; whereas, on the higher fjeld, it remains in wreaths (or snæfonds) and unbroken sheets throughout the year. On really high fjeld, snow seems to alternate only with naked faces of bed-rock, black as Erebus, or chaos of tumbled boulders. Plant-life is restricted to lowly forms, such as reindeer-moss and lichen, with the puniest of stunted shrubs and cryptogams. Yet even here are scattered oases of fell-meadow and pasturage where, in some sheltered glen, one finds grass and wildflowers quite luxuriant. These (if within reach of the nearest valley) are occupied by sæters, the summer sheilings of the peasantry, who during July and August ascend thither to graze their cattle and goats, to make butter and cheese, and to gather into stacks or sheds, as hay, the crop of grass and mountainplants. The produce is afterwards conveyed on sledges 
to the valley, when the first snows permit. But during some ten months out of the twelve the fjeld is deserted by man; while there are yet higher regions, and others whose extent precludes even this intermittent form of agriculture, and which are abandoned to the sole possession of an alpine fauna.

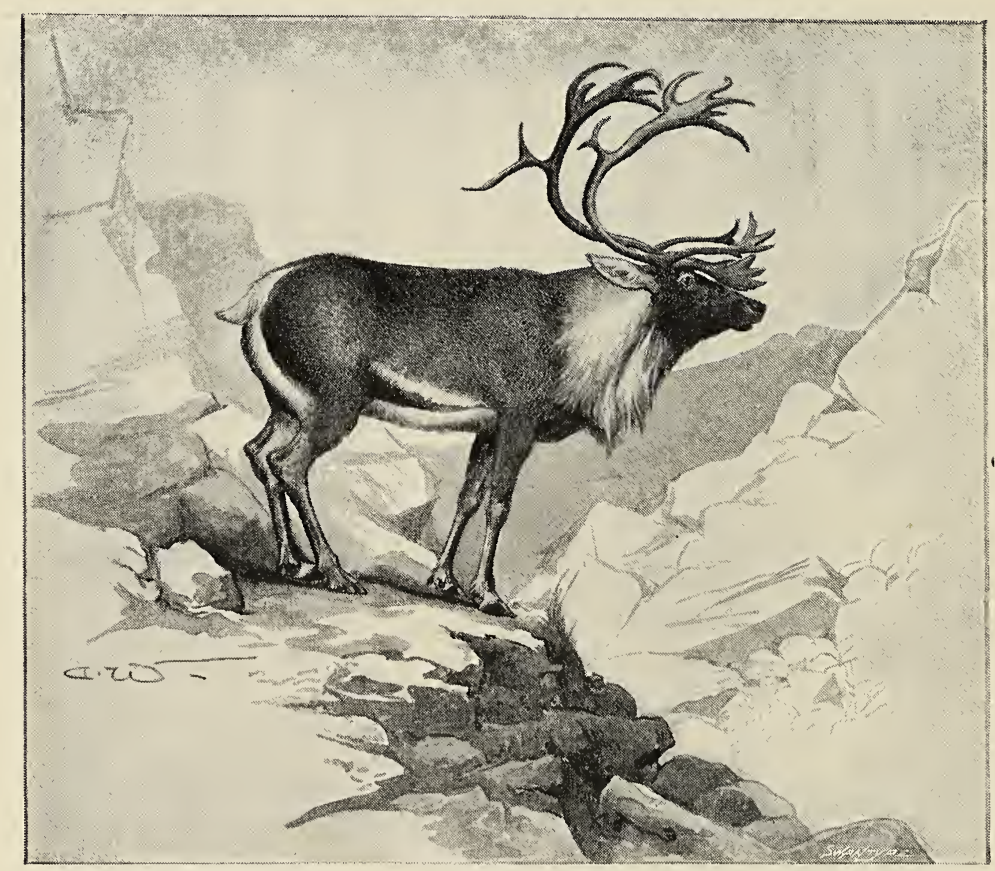

REINDEER-A BIG BUCK.

(Slietched August 29, 1895.)

Many different types of fjeld will be described in the succeeding chapters. It is upon those of more moderate elevations-say, under two thousand feetthat one finds the greatest variety of animal-life, and upon such, among the sæters, I have spent much time. But I have also enjoyed (if that is the right word) 
camping-out on those higher regions of eternal snows, beyond the limits of sæters or signs of human existence: where the wild reindeer wander in peace amidst some of the rudest scenes on earth-more akin to lunar landscape-and where the unsophisticated ptarmigan perk and crane as one passes within arm's-length, no doubt mistaking the unwonted apparition of a man for some new species of deer carrying an express rifle in lieu of antlers.

Passing from snowfjeld to forest, we enter a very different region. Commencing about the Arctic circle, and trending southwards, a vast area of central Norway is clad with dense pine-forest, stretching across to the borders of Sweden, and lying chiefly to the eastward of the main mountain-range. The timber line varies from fifteen hundred to two thousand feet, and many a hundred miles of pathless primæval forest lies between Nordland on the north and the Telemark and Wenern on the south. Amidst these I have spent several seasons, hunting the elk and bear in Namdalen and Sandöla-dalen, under the deep spruces of Inderöen and the Nordenfjeldske, and on the highlands of the Swedish divide.

The inland waters of Norway are stated to cover one-twentieth of her entire superficial area, and by many that twentieth is regarded as of more importance than all the ninety-five per cent. beside. I have not neglected it, having passed glorious springtides on the great salmon-rivers, as hereinafter recorded; while, in their seasons, I have landed bull-trout and sea-trout, with yellow trout, grayling and char, in a hundred Scandinavian lakes and streams. 
One physical fact has already been mentioned-that one-half of Norway lies at an elevation of two thousand feet and upwards. I will venture to add the few following statistics, which are eloquent of the rugged, primæval character of the land :-

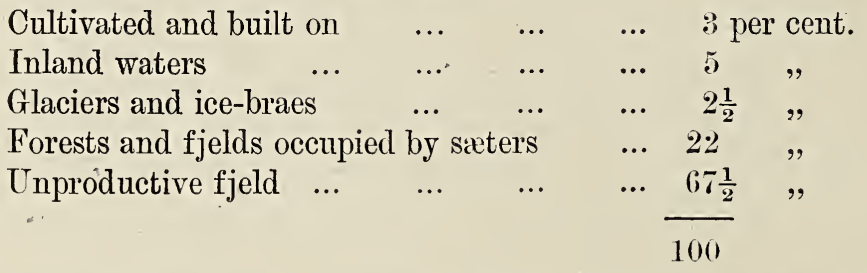

Not even Spain, my first love among wild lands, will compare with this. There the total area " without cultivation of any kind" reaches $42 \cdot 8$ per cent. of the whole superficies," while in Norway the unproductive proportion is no less than seventy per cent.

It will thus be seen that, small as Norway looks on the map, it is a big country to tackle. For it is all "hunting"; with the exception of an insignificant three per cent., there is no break in the wild, and no obstructions to the hunter, such as corn-growing, cattle, and cultivation offer in more normal lands.

\section{Norway as a Sporting-Field.}

Regarded purely as a sporting country, Norway must be classed among the "hard-rendering" sortthat is, every head of game brought to bag therein represents a maximum of labour. Troutlets, it is true, may be "chucked out" in scores; but with large trout in large rivers the case is different, and some degree

* See "Wild Spain," p. $23 \%$. 


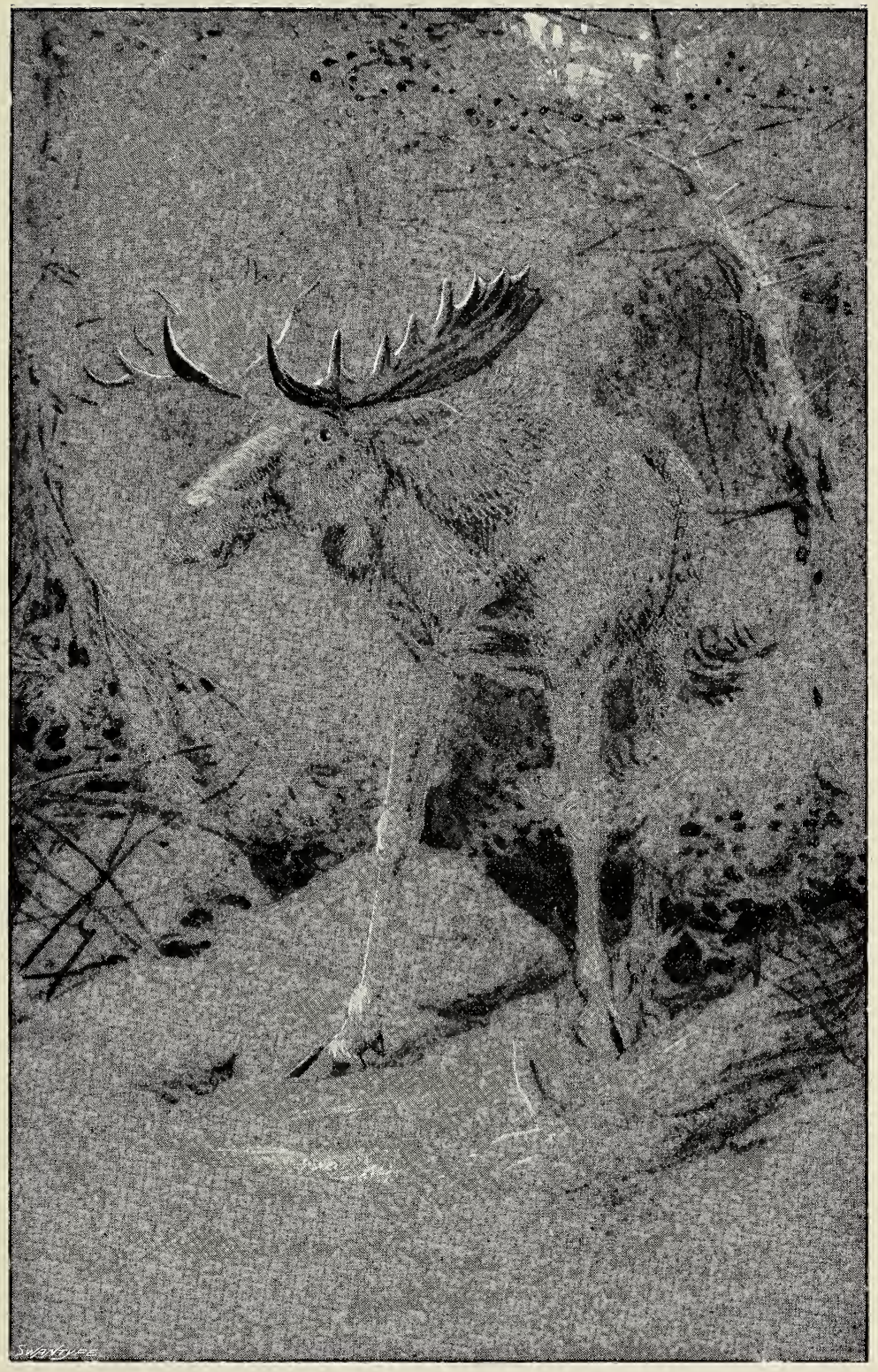

BULL-ELK AT HOME.

(Muru Forest, September $\mathrm{x} 8,1895$. ) 

both of skill and of resource are required to attain the "best possible." The sport, indeed, with such fish, need hardly rank second to any other, and a fair average performer may easily find himself outelassed. I refer here to angling in rivers amply large enough for salmon, but which, through some fosse or obstruction below, are not accessible to sea-going fish. Such waters can only be commanded by a double-handed rod, and are at present "free;" though of late years I have had offers of exclusive rights on lease. Even the owners of lakes now begin to dream of "rents;" but it is not difficult to foresee danger ahead in any attempt to close such waters.

Salmon-fishing is commonly supposed to yield abundant sport; and so it truly does, with these two allimportant provisos, namely, that you hit off the right season on a first-rate river. Unless the happy combination can be relied upon (and no exact prediction of the first is possible), the only certainty is that there will be a stiff rent to pay. Norsk salmon-rents already stand far beyond the intrinsic value of the rights secured, while each year new men are found willing to pay whatever may be asked; until one may fairly ask intending lessees to pause before rushing to exchange a pound sterling for a pound avoirdupois.

Of small game, there are five kinds of grouse; nevertheless, owing to their scarcity and the steep and rugged nature of the fjelds, with their trailing horizontal herbage tripping one's step, grouse-shooting is quite three times as hard work as it is at home, while the bag diminishes in inverse ratio. The most abundant grouse-shooting is in Nordland and its islands; the 
fjelds that will yield thirty to forty brace a day in southern and western Norway are few and far between. The willow-grouse are really the only thoroughly sporting game-birds in August, though the ptarmigan improve as the season advances, and the blackcocks are ready by September. The hazel-grouse can never be rated as a really sporting bird-good as he is to eat; while it is more the misfortune than the fault of the capercaillie that we cannot place that noble game-bird in the first class; for his haunts in the dense spruceforest, wildness, and relative scarcity, render his sole pursuit rarely worth following. Of snipe, on average fjelds, one sees about three in two days, with woodcock in but slightly larger numbers. Wildfowling as a sport does not exist.*

Turning to large game, this pursuit demands infinite sacrifices. None but the hardier sort should essay the forest-hunting : the men who count no cost, and are careless of hardships, hard work, rough living, and disappointments without end. Rough as it is, however, the forest compares favourably with the fjeld. In the former, the elk-hunter has at least the shelter of sæter or a woodman's log-hut; whereas, on the high fjeld, the deer-stalker must live under canvas or in a "cavedwelling" (stein huset), albeit it freezes hard by night and perhaps rains in torrents every day! Taking my own experience in the northern forests, the average is very nearly nine days' work to each bull-elk brought to bag. The average with reindeer works out considerably better: not because the latter are, in any sense, easier to shoot, but because, being met with in herds

* I write in general terms, and there are local exceptions. 
and on open mountain-tops, the deer will often afford two, three, or more shots at a single stalk. This is never possible in the forest, where the bull-elk roams in solitude, or only accompanied by a cow and calf. The cow, by the way, may legally be shot, and always is shot by native hunters whenever a chance offers.

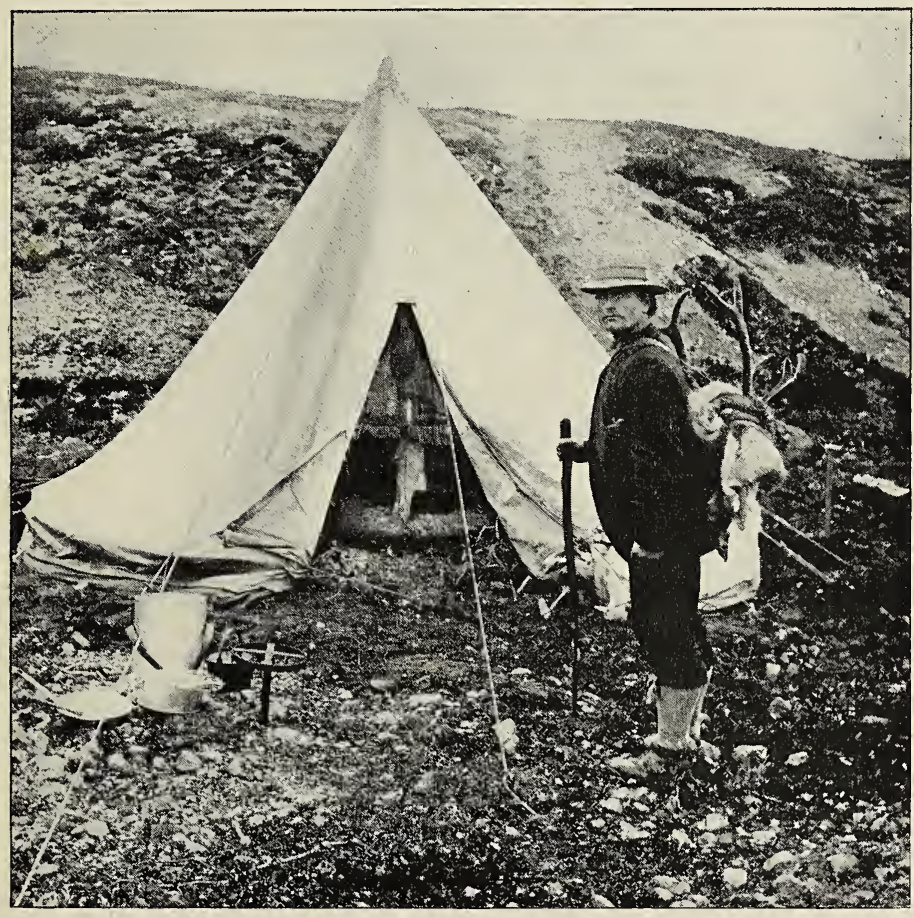

STALKER'S CAMP (OPSTRYN).

English hunters, on the other hand, confine themselves exclusively to the bigger bulls, and spare all cows and young beasts. The same difference exists on the high fjeld, where the object of the native is meat; whereas with the foreign stalker it is the trophy of "the best 
head in the herd." These facts may, perhaps, weigh in our favour when next the Norsk legislature reviews the game-laws. At present we foreigners pay two hundred kroners (over £11) for a license which only entitles us to compete with hosts of unlicensed natives, many if not most of whom are pot-hunters of the worst typethat is to say, they shoot mercilessly for meat, sparing neither age nor sex. There is also the further question of the Lapps, of whom anon.

I am not grudging the two hundred kroner-nor four hundred either. It is a broader question. The Crown of Norway, possessing the whole vast area of her "alpine regions," is the largest owner on earth of deer-forests, and those within easy reach of the richest country on earth, whose sportsmen are prepared to pay handsomely for sporting privilege. But it must be privilege. The question I respectfully submit to the consideration of the Norsk authorities is, whether their vast domains might not more advantageously be reserved for those who will pay-and pay handsomelyrather than allow the stock of deer to be exterminated within a few decades by rent-free, tax-free and unlicensed pot-hunters.

My apologies are due to my old friends, the pothunters aforesaid. Of course, they are pot-hunterstheir poverty compels them to be-and they shoot to lay in a winter's stock of provision. We were all pot-hunters in the first instance; the sportsman is merely the latest development. But, for all that, the pot-hunter is utterly out of date, and, if wisdom prevails, he should be superseded. The country is flooded to-day with cheap "repeating rifles," sighted up to unknown 
hundreds of yards, at about fifty shillings apiece; and with these my Norsk friends "brown" the herds, "pumping in lead" as far as they can see. The result is suicidal. In a few years there will be no herds to " brown," no meat for the pot, no kroner for the crown.

The reindeer, it should here be added, is a really fine sporting beast. His habits and habitat (as fully explained later) place him quite in the first rank of European big game. In her herds of wild reindeer, Norway possesses an extremely valuable property, one which deserves (and will amply repay) more care, forethought, and protection than it now receives.

Another feature of the high fjeld deserves passing note. The nomad Lapps keep ever trending southward, and the advent of their tame herds is notice to quit to wild deer. Whether these half-human vagrants enjoy prescriptive rights of free pasturage over all the length and breadth of the roof of Norway or to encamp at their own (not sweet) will, are questions beyond my knowledge. But a reluctance to resent Lapp intrusion is evident among Norsk bonders-however much they dislike it. Conceivably such fly-away savages might, if provoked, prove awkward neighbours in a pastoral country; still, the latitude allowed them seems curious to outsiders. I remember the chief of a Lapp tribe explaining to me that "he and his forefathers had occupied the land long before the Norwegians came there, or a crown of Norway had existed." This (in Nordre Trondhjem's Amt) was certainly untrue; but nothing a Lapp says is ever true. 
III. The Avifauna of Norway.

Norway is popularly believed to be the summer home of many of our British winter birds and wildfowl. An old gamekeeper recently asked me, with crescendo. indignation, "Isn't it true, sir, that they furriners just. live on woodcock eggs?" Old Anglo-Norsk fishermen, on the other hand, have exclaimed :- "Birds! There are no birds in Norway, except magpies and grey crows!" Truth lies in the middle. Scandinavian ornithology re-

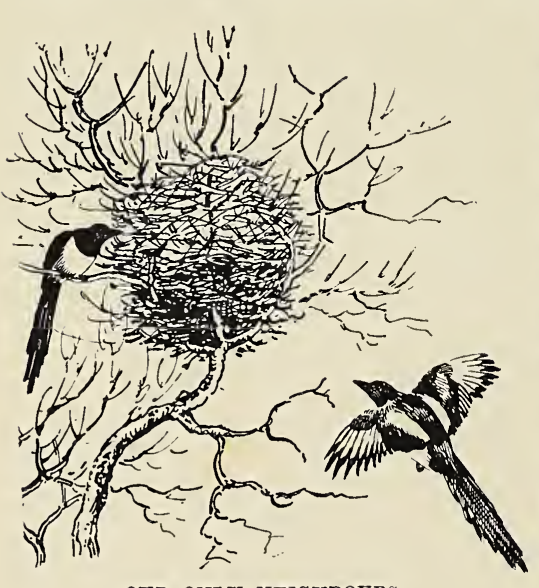

OUR ONLY NEIGHBOURS.

quires extremelyclose and careful attention - very different from that which the casual fisherman or tourist bestows upon it. The immense extent of mountain-land and snowy alpine region is adverse to the general distribution or diffusion of birdlife, which is scattered sporadically over the huge area ; or perhaps it would be more accurate to say, is localized and circumscribed to certain suitable spots which occur only at wide intervals. These favoured spots, amidst infinite space, like oases in a desert, one may or may not have the luck to "hit off." Briefly summarized, the Norsk avifauna may thus be described:-On the high snowfjeld there is no variety at all; on the lower fjeld, though one may search over hundreds of miles almost 
in vain, there do occur those scattered oases of exceptional interest, some of which are hereinafter described. These, in my opinion, are yet but little known, and their exploration offers the highest promise of ornithological reward. Thirdly, there are the low-lying, sheltered valleys, where bird-life is hardly less varied than at home, where warblers sing, and the most tender forms find abundant insect-food and a congenial home. An essential element is found in the fact that birdmigration to Norway sets from the east, not from the west - that is, her feathered population arrives each spring rather by way of the Baltic and Russian territories than across the North Sea. This fact also explains the presence in North Norway of several species which are scarce or unknown in the south, and imparts an eastern or east-Arctic quality to the feathered population.

The Norsk avifauna is not of that northern type that the relatively high latitude would suggest. Its characteristic species are all birds of temperate tastes. This is explained by the influence of the Gulf Stream which, along the whole western coast, maintains an equable temperature and an ice-free winter sea. Compare the two sides of the Atlantic. Though opposite Bergen, South Greenland is smothered with glaciers, the like of which are not found in cis-Atlantic latitudes till one reaches Spitsbergen fifteen hundred miles north, and in Canada, the estuary of the St. Lawrence, though opposite the British Channel and north French coast, is ice-bound for half the year; yet Tromsö and Hammerfest, two thousand miles north, rejoice in an open sea. 
In Norway the Gulf Stream is a governing factor both as to climate and ornithology. None of the purely ice-loving fowl remain here. The wild geese of Norway are all greylags: her characteristic ducks are pintail and wigeon - all three being species of essentially temperate tastes. The ice-loving brents and bernacles, on the other hand, with the bean- and pinkfooted geese, the wild swans, northern divers, and true hyperborean fowl, pass right beyond the whole Norsk coast, and seek congenial homes in Spitsbergen, Novaya Zemlya, or Siberia, where no warm current from the tropic tempers the frigid zone or troubles their incredible love of cold.* On the other hand, one finds breeding throughout Norway many millions of the tiniest and most delicate of the summer-songsters-such as the bluethroat and redstart, the icterine, blackcap, and garden-warblers, chiff-chaff, willow-wren, whinchat, swift, all our British Hirundines, and both species of flycatchers, as far up as Lapland; at least a thousand miles north of the point at which their representative and congeneric species cease to exist under transatlantic conditions.

Of familiar bird-forms which are chiefly conspicuous by their absence may be mentioned the stonechat and corn-bunting, wood-wren, reed- and sedge-warbler (the latter very rare in the south), the partridge and white owl; while the peewit, skylark, and waterhen are extremely scarce and local.

Another illustration of climatic mildness is afforded by the butterflies. The Scandinavian list includes one

* Here, again, I write generally, and omit notice of exceptions to the general rule laid down. 
hundred and eleven species, of which number Arctic Lapland claims no fewer than fifty-two, besides owning eight species peculiar to itself-in all, sixty species in the Arctic census as compared with sixty-five in the British.

A few really warm days at the end of May produce an abundance and a variety of insect-life of every denomination-winged, creeping, crawling, and hopping - the like of which I have not seen at home. The Norsk list includes many of the handsomest of European Rhopalocera, as, e.g., Apollo, Antiopa, Paphia, Adippe, and many other fritillaries, Virgaureæ, Comma, ete. But at the same time, it also comprises those insect horrors, the gadfly and clegg (of sorts) - these due about mid-June; and, two weeks later, the mosquito.

\section{The Norsk People.}

To describe a country without even alluding to its inhabitants may seem discourteous. It is not so meant in my case, for I admit that (whether in Scandinavia or elsewhere) the human race are to me of minor interest as compared with the "lower orders" of creation. Hence I am no judge; and, besides, it has always seemed to me to border on presumption to criticise on brief experience a people whose language the censor can hardly speak. The brotherhood of sport I have found strong enough to dissipate all difficulties of tongue, and to secure me firm friendships in every quarter. The peasant-proprietor, or bonder of the backwoods (from whom one's hunters or gillies are drawn), is by nature a gentleman: quiet and reserved, 
but anxious, as a rule, to render service, and instinct with a sympathy and simple honesty that are rare and refreshing. He is self-respecting, resolute, and resourceful in a crisis. With such men the comradeship of a month or two begets feelings of friendship and respect, and it is a source of legitimate pride when such are found to be reciprocated.

I know I have elsewhere called some of these men pot-hunters (and excused the term), for they are pothunters, and I cannot overlook it, much as I like them. The Norseman often shows a stolid and phlegmatic exterior ; yet his heart is in the right place, and governs his actions, which spring thence rather than from the lips outward.

The two characteristics that have struck me (I refer to remote rural districts) are their poverty and their contentment. The former, in distant dales, can hardly be exaggerated, and to us is incredible. Money simply does not exist. What a man cannot make with his hands or hatchet he does without and doesn't even seem to want. Their lives are of the hardest-like their native rocks; they know not comfort, nor recognize its reverse, and under circumstances that to many would represent abject misery, they are contented and even happy. Perhaps, after all, such conditions are incorrectly described as "poverty."

I will not omit mention of the other sex, albeit my experience must be largely limited to the handmaidens who have accompanied us in hunting expeditions. Women in Norway work as hard as the men. One sees them in twos and fours, pulling, without rest, across leagues of open water, or carrying what looks 
like a ton of hay up steep pathways. One feels inclined to proffer assistance, but is restrained by a conviction of sheer inability to essay the job! Last year we employed a girl as cook, etc., and during a month's sojourn in the backwoods, really feared we had worked her too hard. Yet, while busy with this chapter, I received the following message, which, I believe, the Norwegian gentleman, who deciphered its somewhat obscure caligraphy, took for a love-letter !

"A thousand thanks, kind Chapman" [Note: no prefixes in Norway], "for the time we spent last autumn, and for our travels through the forest. I long for your return, and hope I may come with you when you go to fish in the $\mathrm{S}$ - river. If you will not take me, I shall be very sorry, kind Chapman. I hope I may come and prepare your coffee and food while you are fishing, and if not, I shall be very, very sorry. Welcome back to Norway and to big fish and big bull-elks!"

So much for my peasant friends-not a word but what is good. Of the "classes"- to use the modern cant-I know nothing, beyond the fact that my small business relations in the matter of renting shooting and fishing rights have been marked by unvarying fairness and good faith.

I have omitted some chapters descriptive of my two journeys in Sweden, inasmuch as the parts of that country which I visited, both as regards their character and fauna and the sport enjoyed therein, so closely resemble the adjacent districts of Norway, that a description of the one almost suffices for both.

Denmark, on the other hand, is the antithesis of Norway in every respect; hence I include a brief 
account of two voyages thither. To the naturalist, Denmark, as a whole, presents a dreary monotony of pettiness and poverty; but there are certain richer nooks, and in out-of-the-way corners of Jutland we came across a variety of bird-life which I have thought worthy of record herein. On our second visit, it befell my brother Alfred and myself to meet with a species which we should least have expected, and which forms a new and truly remarkable addition to the Scandinavian avifauna-I refer to the Pelican (Pelecanus onocrotalus), a bird whose ordinary habitat is in the south-east of Europe. Certain ornithologists in Copenhagen were not only sceptical, but waxed sarcastic over our pelicans, hinting that we had been deceived by the hildring, or "false view" (mirage), common on all such low-lying coasts, and had mistaken sect-gulls for birds of ten times their bulk. I have attempted, in the rough sketch opposite, to portray what we really did see that May morning on the sand-spits of the Jutland coast. 


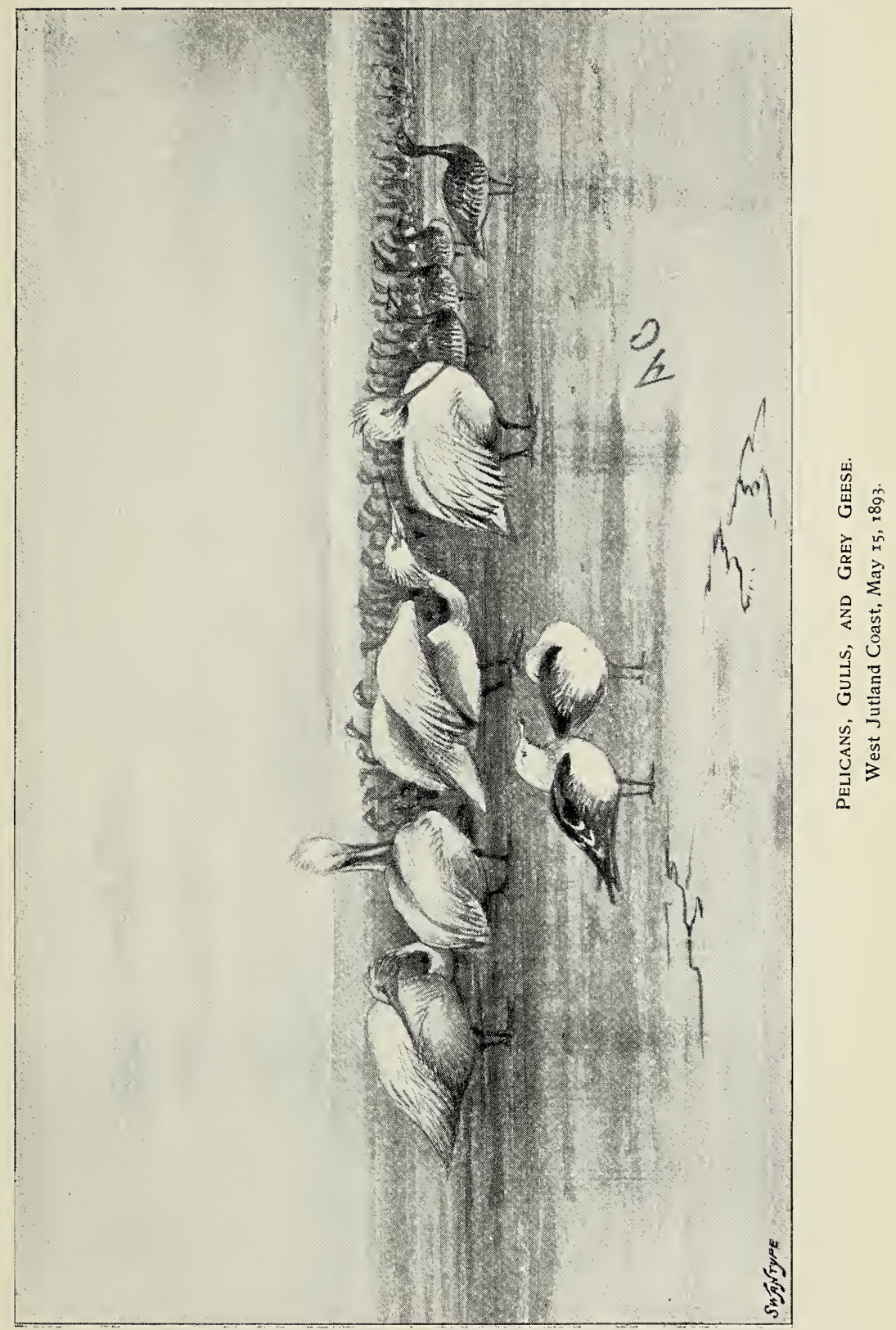


I 


\section{$(21)$}

\section{CHAPTER II.}

REINDEER-STALKING IN RYFYLKE.

“There's mavy a Slip.”

AuIDsT rude boulders which formed a primitive pier, lay scattered our belongings-bundles of bedding, baggage, preserved provisions, etc.- -while the last link with the world, the steam-launch we had chartered to convey us to this remote spot, was disappearing behind a pine-clad promontory. By the shore stood huts, and, hitched to them, our two pack-animals-cream-coloured ponies, shapely as zebras, yet docile withal. There, too, stood our stalkers, men we had engaged beforehand; but we knew not which was which, and neither party spoke the other's tongue. Such perplexities, however, are but momentary; the brotherhood of sportsmen bridges the gulf, and soon we are all busied with ropes and running-gear, making fast the loads on horse-back by cunningly-contrived cleats and willowwoven frames. To the latter the various packages were secured by merciless straps and loops, doubleburtons, and diamond-hitches. "Rough on dress-coats," groaned W.; but it was useless to repine, and the cavalcade was under way.

Our destination was a log-hut, situate three Norsk 
miles across the fjeld, and erected expressly for reindeer shooting by a Norwegian friend, who had kindly placed it at our disposal. As we tramped slowly upwards, two things occurred to us:-First, that among the multifarious arrangements of the previous night we had forgotten one thing-luncheon; secondly, that three Norsk miles equal twenty-one English, to say nothing of the five thousand feet ascent which these particular three included. We therefore called a halt at the highest of the three farms that occupied the lower valley. Here the hospitable bonder, with his wife and daughters, provided us with breakfast of boiling coffee, potato-bread, sundry sorts of cheese, and delicious möltebcer and tutibor (fell-berries) with cream. We also put some of the said potato-bread (which is of the consistency of half-melted gutta-percha) and cheese in our pockets, and thus fortified, made a second start in earnest.

The ascent proved an easy one. Up to the level of the highest sæters was a fairly defined track following the contour lines of various converging glens, and commanding glimpses of a mountain torrent whose cascades and cataracts rivalled in romantic beauty many of the "show" things one sees in Norway. This track brought us out at two thousand feet, without encountering difficult ground or having any climbing at all. The next thousand feet were more abrupt-no track, all path-finding through tangled scrub and bog, where the placid ponies were at one moment struggling girth-deep in mire, the next calmly snatching a mouthful of heather. Here we left behind us the zone of tree-growth and willow-grouse; and on the next ridge above, we 
flushed a covey of ptarmigan, which, after circling around with irregular pigeon-like flight, pitched close behind us, the old cock as usual on the top of a rock, the rest among broken stones, where they speedily made themselves invisible, though only sixty yards away. We decided to "outspan" here, both to rest the ponies and to lay in a stock of ptarmigan as a basis for our larder. We soon learned a useful lesson; for, rambling on after the ptarmigan, which seldom flew far, in half an hour we found ourselves hopelessly lost amidst chaos of stony slopes and rock. After this we never again lost sight of our guides.

From here we proceeded direct to five thousand feet, across a rock-region whose awesome sterility passes words to describe-the naked backbone of the planet. For miles, men and horses traversed bare bed-rock, here inclined in smooth steep slopes, there rent and contorted into chasms and ravines, their depths half-choked with snow and the débris of avalanches. All around lay Stygian lakes, whose waters reflected the glaciers that fringed their shores, and the whole scene reminded us of those terrible landscapes that astronomers see in the moon. Probably but little change has occurred here since the age when the molten earth "went off the boil."

Yet even here, where no blade of grass or green thing grew, the hardy "fjeld-ryper" (ptarmigan) rose from beneath the ponies' noses, or ran from sight at amazing speed. From the crest of the pass we could survey our prospective hunting-ground, which lay before us at a rather lower level. Big enough, at any rate, was the vast fjeld plateau before us, extending some forty miles straight ahead, and an unknown 
distance to right and left. In aspect it appeared hardly less barren and forbidding than the lunar landscape we were now traversing.

From these "mountains of the moon" we descended through gloomy arctic glens and snow-filled gullies, that recalled the valleys of Spitsbergen, where, twelve years before, I had first hunted the wild reindeer. Thence hours of steady tramping across the fjeld; two broad, shallow torrents had to be forded, each of us hanging on the pony's stern, behind its load, nor were matters made rosier by a snowstorm driving down the valley, luckily in our backs. It was already dark ere the second river was passed, and we rejoiced to observe that our men did not replace their boots-a sign that the end of our journey was near. Then, through the gloom, loomed the outline of a hut; but oh, horrors! it is occupied. From the open door issue three stalwart hunters ; moreover, they had slain deer, as sundry skins laid out on the rocks attested. Poachers, villains, scoundrels!- how we hated them with a fierce hate. It is difficult in a moment to subdue the spirit of exclusiveness, the bye-product of British sport and its conditions. Reflection served to show that it was we, the foreign intruders, who might reasonably be regarded as poachers. W., promptly diagnosing the situation, harangued our new-found friends at length, expressing our joy at meeting them thus, our sorrow at not being able better to entertain them, etc. Not one syllable, of course, could they understand; but cordiality was established, and the scoundrel-in-chief was soon busy unloading our ponies, cleaning rifles, etc., everything being thickly coated with snow. 


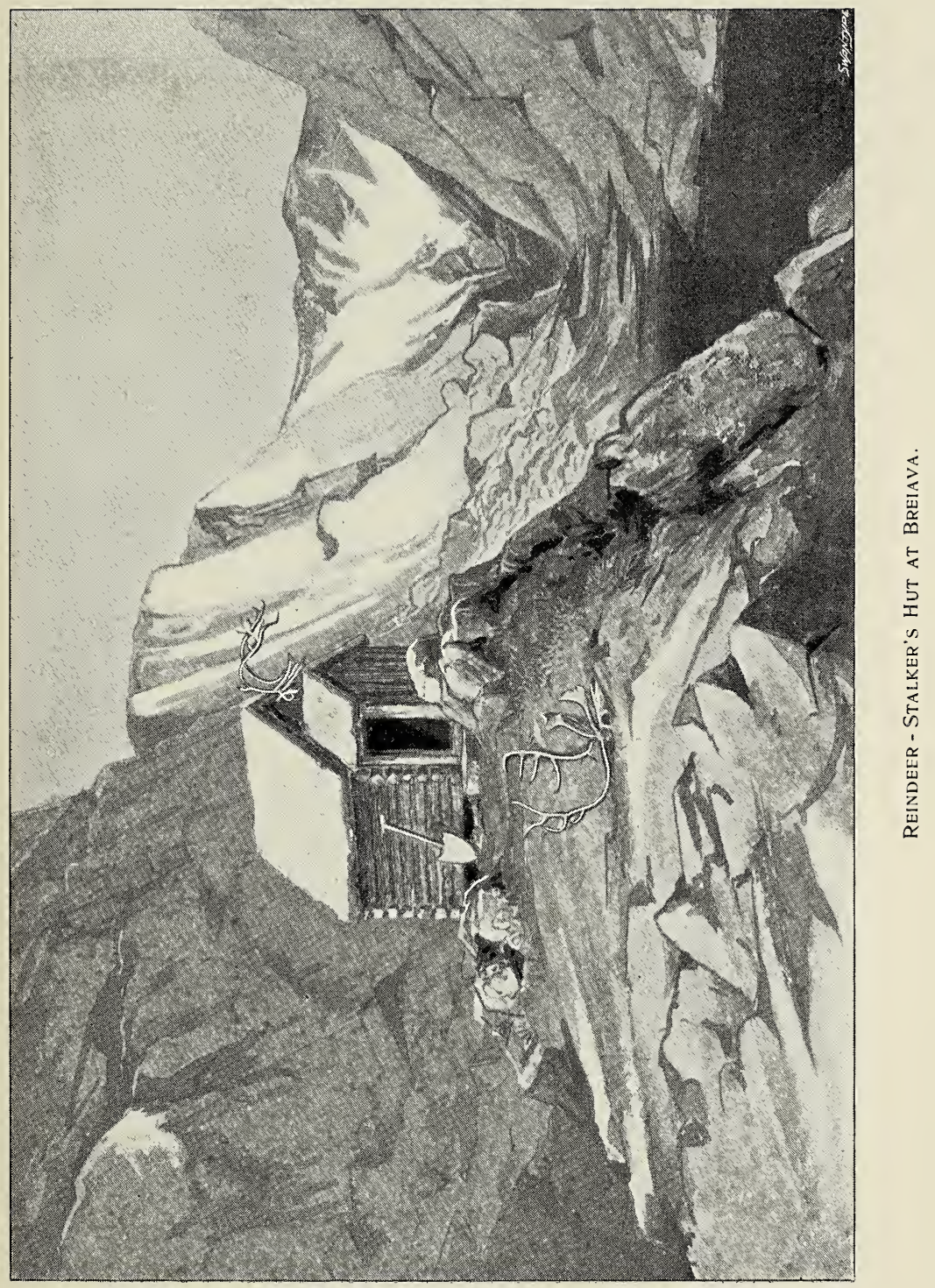



Our hut measured twelve feet by ten, and contained a table and a bench, some empty packing-cases for chairs, two shelves and a tiny iron cooking-stove. Numerous long nails in the wall proved invaluable furniture. Across the rafters from side to side was carried a half-roof or ceiling, and on this open shelf, reached by a ladder like a hen-roost, we slept on damp hay. We had, of course, brought waterproof ground-sheets, blankets, and rugs, besides kettle and frying-pan, canteen, with bread, coffee, candles and such-like necessaries.

The off-loading completed, order presently replaced chaos; we boiled our coffee, dined on corned beef and ptarmigan, and over a reflective pipe wondered where we were all seven going to sleep. Fortunately this difficulty was presently solved by our three friends withdrawing to a turf-covered hovel there was hard by. We inspected this cave-dwelling in the morning; it was three-parts underground, dug into the hill, the rest built up of big stones all thickly covered with turf. The door was eighteen inches square, and on crawling inside, one perceived a dark space of about seven feet by five, and some three in height. Next morning the three hunters departed at dawn, carrying their meat homewards.

Our own quarters were not luxurious, since four of us lay huddled on a hay-shelf twelve feet by five, W. and I occupying one end, head to head with Lars and Paul, who shared the other. These worthies always came to bed pipe in mouth - so did we, in selfdefence-but they beat us, for they seemed to possess the faculty of smoking asleep; aye, and spitting too, 
all over the tiny space. The cold at night was penetrating, and at an early hour $(4$ a.m.) an excruciating noise aroused us. Lars was grinding coffee by crushing the roasted berries under a beer bottle. Sleep being impossible, we turned out, and found that ablutions were equally so. The ground lay white with snow, and every pool and stream was frozen, though we were still in August. The burn that last night danced hard by our hut had ceased to be; every evening it was there when we returned from stalking, but every morning it was gone. The night frosts were fatal to its existence. Not till midday was a dip possible; and to finish off the subject at once, let us confess that during our whole sojourn at Breiava we never were undressed nor enjoyed a decent wash.

A word as to our living. Having only one kettle, it was necessary first to boil our trout (having previously caught them), before the coffee could be similarly treated; then the little stove was called upon to fry a ptarmigan or venison-steaks, and, when extra luxurious, sardines or tinned peaches or pine-apple wound up the feast. Dinner was necessarily constructed on precisely the same lines as breakfast, though beer replaced coffee as long as our stock of "öl " lasted.

At half-past five we were off, Lars and I, in the keen morning air. The wind having shifted during the night, and now blowing fresh from the eastward, we took that direction. To me, in big-game hunting, fortune had ever been chary; with two or three grateful exceptions, arduous expeditions in foreign lands had been but ill-rewarded, and hard-earned trophies secured more by solid work and "sticking-in" than by any 
special turn of luck. And my first day's experience on Ryfylkan heights proved no exception. For three hours we scrambled and climbed over rocks and snow, balancing on boulders or crawling up ragged biting crags; anon crossing screes which sloped from underfoot into bottomless abyss or lake, without seeing deer. Then Lars' eyes were focussed on a distant snow-slope. I could see nothing, but seven deer had crossed the snow that morning. The deer were going due east, following the change of wind, as Lars explained; hence their course was nearly straight, and we had but little difficulty in picking up the trail again and again after the game had traversed wide intervals of high bed-rock where, of course, no spoor could be seen. We had followed their break-neck course for some hours, when Lars became perplexed by the seven tracks having increased to nine. He left me sitting on the edge of a small glacier while he cast back, presently returning to report that he had found the spoor of the two, which had evidently joined the original herd, all nine proceeding together.

We followed with increased caution, "spying" every glen and corrie, and at frequent intervals searching out the more distant slopes with the glass. It was now noon, and Lars remarked, "the rens will not be much further off, for they will now be lying down to rest." No habit in wild animals is more fixed and regular than this midday siesta of reindeer. It lasts from one to two hours, and I have never seen them neglect it. Still, the most careful scrutiny revealed no living creature upon the wastes of rock, snow, and stony ridges, when, on our front and not a mile ahead, 
there resounded the crack of a rifle. The shot was followed at short intervals by four more, and we knew our game was up. Here we were, more than thirty long miles from the nearest human habitation, and close up to our coveted quarry, when by sheer bad luck a Norsk hunter emerges from some stone-built den beneath the rocks, wherein he had passed the night, and snatches the prize from our very grasp. And he only got one small deer after all. It was now midday. Before us, to windward, lay our rival's territory ; to the right we could not take fresh ground by reason of a chain of lakes which lay on that side, and I knew our chance was gone. In his zeal to show me sport, Lars continued to "speer" and tried a few more miles towards the left; but it was useless, the ground being all bare rock, and we reached the hut about 6 p.m. without having seen game. W. had returned half-an-hour earlier and reported similar luck. Paul and he had found plenty of new spoor, but seen no deer.

The country traversed is about as bad "going" as can well be. Though the main plateau lies fairly level, it is intersected in every direction by innumerable chasms and ravines, mostly precipitous, and three to five hundred feet in depth, into and out of which one is continually climbing, scrambling, and glissading. Between them rise barren rock-ridges and peaks of about equal elevation. The glens and corries, on their southern aspects, are fairly clad with grass and pasturage for deer. Here, amidst the rocks, grew blue harebells and ferns of two sorts, the common and the parsley fern (Cryptogamma crispa); while on the grassy slopes bloomed a sort of dandelion and the golden-rod (Solidago 
virgaurea), the rock-rose (Sedum rhodiola), tormentil and alpine campion (Lychum alpina), with many heaths and mosses. The northern slopes were mostly buried in snow and glacier, or carpeted with that peculiar substance-half moss, half soil, but wholly slimewhich forms beneath and around eternal snow, and from which, when pressed underfoot, there wells forth a spurt of crystal water in drops bright as mercury. Many of the rocks showed beautifully variegated striationparallel bands of interjected strata, or larva, sometimes straight, often curiously twisted and contorted.

Innumerable lakes filled the hollows of the hills, but these were absolutely lifeless-not a water-bird broke their surface, * nor indeed were there many birds of any kind on the high fjeld. A pair of ravens would now and then come croaking round, deeply interested, for private reasons of their own, in our success. Once we watched a merlin chasing a wheatear; another day we came on a rough-legged buzzard dining on a lemming, and Paul almost wept at the loss of the two kroner reward. Besides these, a very few titlarks and wheatears, a chance white wagtail or dipper, and the ptarmigan, were literally all the birds we saw.

A few words as to the ptarmigan and their autumn habits out here. When first found they were usually tame enough, their proximity only indicated by a low croak from among the rocks. Here a careful scrutiny might detect several of the covey cowering amidst the

* Once, in September, we observed a big diver (Colymbus) on a fjeld lake at three thousand five hundred feet, but he was probably only resting on migration. There were, however, trout in several of the lakes, though by no means in all. 
broken stones-an exquisite harmony in colours. They would sit thus while one approached within a few yards, when curious necks craned up erect among the crags -many hitherto unseen-and away they all dashed in rapid flight, twisting round rocks or diving over some projecting point, smart as woodcock, but seldom

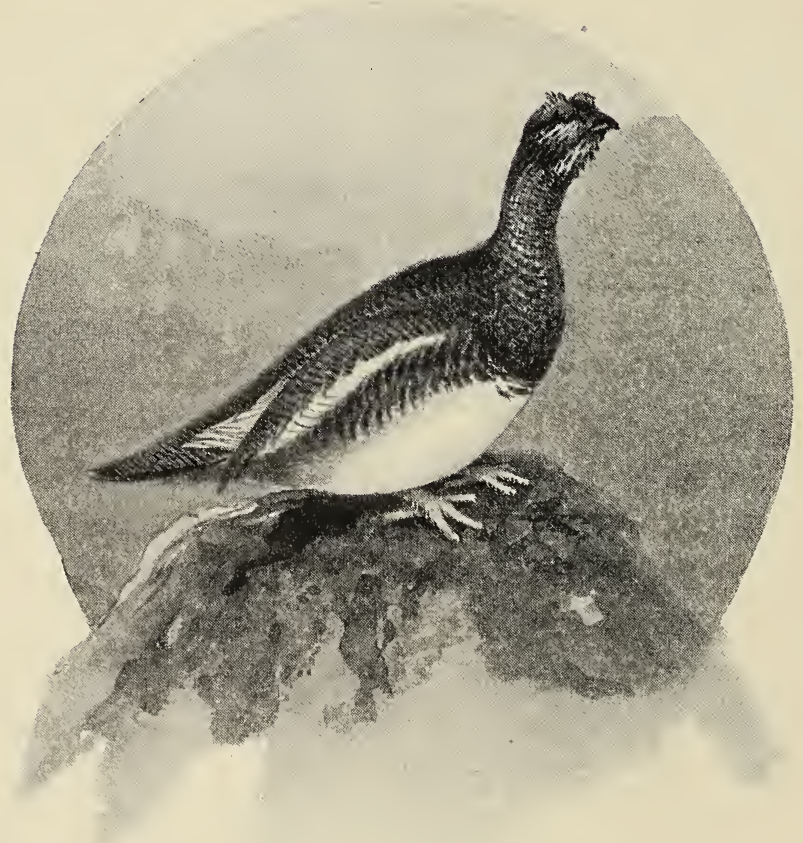

PTARMIGGAN.

flying far. One fine old cock ptarmigan sat so immovable that I made the annexed sketch from life within ten yards, all the feathers of crown and chin erected, and the wind playing with the very long coverts and tertiaries. He then allowed Lars to have three or four 
pot-shots at him with stones, merely crouching as each struck hard by, till at length he took wing with loud execrations. As elsewhere mentioned, I believe that in these remote spots the ptarmigan have hardly learned to distinguish man from deer or other harmless animals; and of course the hunter rarely molests them.

Towards evening the Ryper were busy feeding, moving rapidly about on the sheltered slopes of the glens, where heath and crowberry-ling grow. Among the latter humble covert (not three inches high) I found a nest of the previous summer containing an addled egg and the hatched-out remains of the rest. I noticed. that the nestling quills of the young ptarmigan shot in September were speckled brown, like those of fledgling grouse, and not white, as in the adults.

To return to our deer. I have now described a blank day, and others followed. As Sunday drew near, we became anxious as to possible Sabbatarian tendencies in our companions, and approached the subject with diplomatic circumlocution. But Lars' view, as we understood it, was simple: there is no Sunday above three thousand feet! Certainly there are no churches. The final days of August yielded no special incident worthy of record, and for an illustration of the opposite picture, success, we must pass on to a glorious First of September. 


\section{CHAPTER III.}

\section{REINDEER-STALKING-Continued.}

\section{"A glorious First of September."}

THE ground selected for to-day's operations lay far to the south-west, beyond a long chain of lakes which extended in that direction, and on which, fortunately, was a boat, dragged out thither on a sledge in winter. We were astir with the sun, and an hour's walk brought us to the boat hidden in a hollow of the rocks. Having several miles to pull, we set up the rods, and a small blue phantom extracted three trout weighing four and a half pounds, the "spoon" being ignored as an article of diet.

Landing at the south end, we continued in that direction over a range of country which was more open and of richer pasturage than any we had hitherto seen. Grass and herbage clothed the valleys and minor ridges, even extending some distance up the loftier heights, leaving comparatively but small areas of naked rock and snow-fjeld. There can be no doubt that such ground would afford fair summer grazing; but its vast extent and remoteness forbids the existence of sæters. For some hours we spied lovely glens and fjeld-meadow without seeing game; and I had fallen back for a 
moment, tempted by a clump of golden-ripe möltebœr, when I perceived from Lars' movements that something had occurred. In a moment I was at his side. Yes; there they are at last! About a mile away a herd of deer were slowly emerging, one by one, from a glen, and feeding along its rock-strewn ridge. There were four or five calves, smaller and conspicuously lightercoloured than the rest, which were of a darker grey, but the horns of all were still in the velvet. Then behind them, there emerged from the glen a finer beast carrying clean white antlers with a forest of points. But even he was presently to be dwarfed by the real monarch of Rannœs-fjeld. For a long time we lay watching them with the binoculars-one of those truly entrancing spectacles, a herd of wild animals still roaming in absolute security. Lars kept urging a forward movement; but as the glass still swept lovingly over the scene, all at once they rested on a new object-were they indeed horns, or the sheltered, weather-blanched skeleton of a pine? From behind a rock projected such a pair of antlers as I had never before seen in life. The beast was lying down, his whole body concealed by the rock, and some hundred and fifty yards away from the herd. "Meget, meget stor Ren!" whispered Lars, as he closed the glass, and off we set at top speed down a glen which ran in their direction. The first half-mile presented no difficulties-beyond a wide and rushing torrent which, however, delayed us not an instant-and we reached a second ridge which commanded a clear view of the game, distant about seven hundred yards on the opposite hill. We could now see that they numbered. twenty-one as they moved, feeding, along the crest. 
But from no point could we discover an "advantage" for a further advance. Three broken gullies we tried, but each proved useless-one turned the wrong way, the other two terminated less than half-way down the face. The ground was dangerous, since one or other of the widely scattered deer opposite commanded a full view of all the intervening slopes. A shallower couloir led direct towards the centre of their position, and at the moment no deer were in view from it. Lars thought this might cover an approach. I strongly dissented; but Lars was confident. Hardly, however, had we progressed a hundred yards than the horns of a deer on the sky-line ahead demonstrated the error in tactics. Before his whole head came in view we both lay prostrate on our backs. Fortunately a profusion of grass, bleaberry-ling, and scattered stones rendered us all but invisible; still we now lay in full view, and passed an uncomfortable quarter of an hour. "Forsigtig" (be careful), Lars kept muttering, though I never moved a muscle, albeit a cruelly sharp stone nestled in the small of my back. "Presently they will lie down," whispered Lars; and presently they did, though the word has a relative significance. Then, by slowest movements, we crawled like serpents to the shelter of a big rock a few yards to the left. Here, at least, we were free to move in some limited degree; but the error of Lars' tactics was even more clearly apparent, since we could now see that a lake intervened between us and our game, which would effectually have prevented our "getting in" from that direction.

The big bull, I now rejoiced to see, had joined the herd; the meeting, I imagine, had been quite casual. 
Most of the deer were lying down, but both the big stags stood upright in dreamy, inert postures. I now fully realized what a truly magnificent animal I had before me. Both in body and horn he was a giant, and his coat was no less remarkable; the neck was pure white, and beneath it a shaggy mane hung down a foot

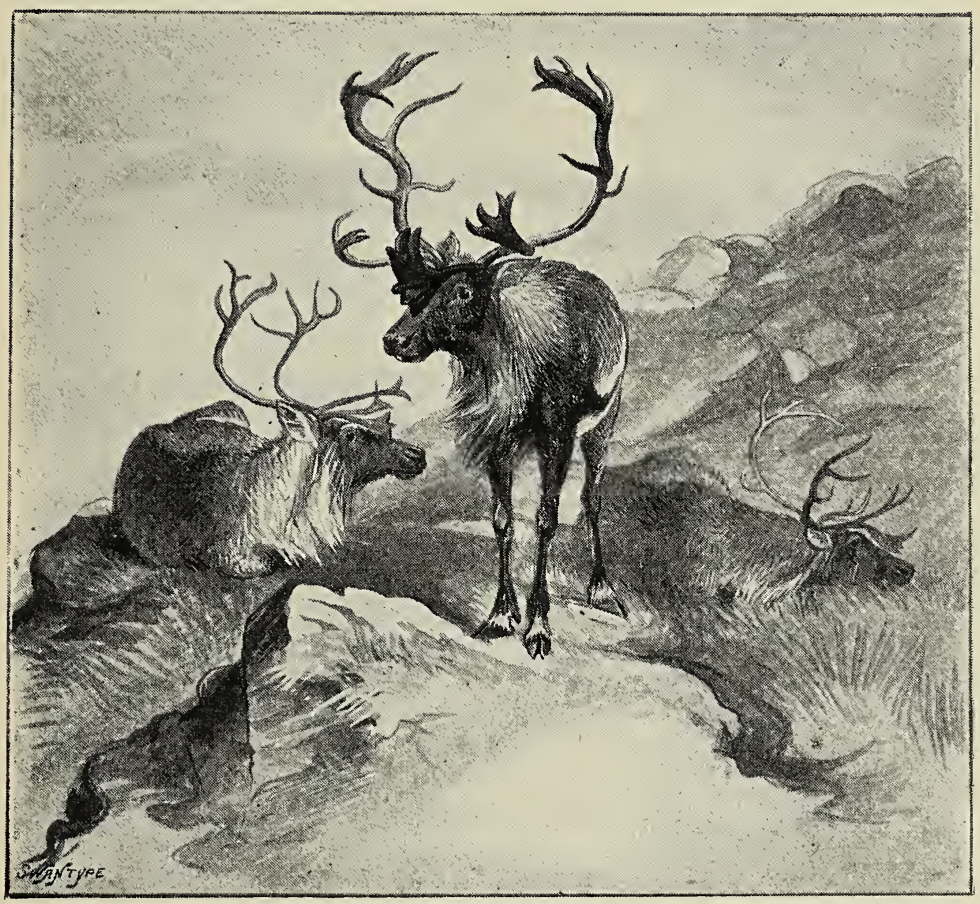

THE SENTINEL.

(Sketched September 1, 1893.)

in length. This white neck was set off by the dark head in front and the rich glossy brown of his robe behind. Besides this, the contrasting black-and-white bars on flanks and stern were conspicuously clean-cut and defined, and the long and massive antlers showed 
a splendid recurved sweep, surmounted by branch-like tines, all clean.

At either flank of their position stood a smaller buck on sentry duty. For full half an hour the nearer vedette stood rigidly motionless, as shown in the sketch, and with a steadfast glance directed straight towards us. Even when relieved from duty, though he moved a few yards away, he still maintained that steadfast gaze, and a terrible fear oppressed me that he had seen something.

For nearly an hour and a half continued this state of affairs: the deer enjoying their midday siesta, we lying watching them from behind our rock, at less than six hundred yards. Never was there a better opportunity for studying wild animals at home. With spyglass and sketch-book in hand, I tried to eatch their various characters, poses, and attitudes, as represented, from the life, in the accompanying drawings. Now a well-grown buck approached the second lord of the herd as he dreamily ruminated. For some seconds they stood face to face, then the master reared, struck out straight from the shoulder, and the impudent youngster vanished. "They will begin to feed at half-two," $(=1.30$ p.m.) said Lars; so we produced our lunch, and silently drew the cork of the öl. Then, more silently still, I lit a match and revelled in a few delicious pulls at the pipe-a precaution, I thought, against possible "buck-fever" or flurried nerves, when the crisis should arrive.

Within a few minutes of the time predicted, there was evident commotion among the deer. The whole herd were on their legs, feeding rapidly from point to 
point, and twice a regular stampede among the younger beasts caused infinite anxiety in our breasts. They started at first to feed towards our left, threatening to pass out of reach, beyond the lake, but presently changed their route, and in zigzag courses made towards the head of the lake. It was curious to notice their hurried, petulant movements, very different from the casual, lethargic demeanour of the morning. Now they seemed to feed at a run, heads down, but hardly stopping to snatch the herbage. The big beast alone seemed deliberate, spending minutes on some succulent patch; and he was the last to disappear from our view in the grassy corrie at the head of the lake.

The instant he was out of sight, we ran back to the ridge whence we had essayed the faulty stalk, and hurrying along its reverse slope, reached some rocks which overlooked the glen, but at too great a distance. One hundred yards ahead, and on a lower level, lay a single big boulder, and I saw that if we gained this we should command the further slope of the corrie at about one hundred and fifty yards. There was some risk, for the intervening ground was open : but we tried and succeeded, though the last few yards of the "crawl" was executed in presence of three deer that had already appeared in view, feeding away from us up the opposite slope. Others followed, and soon that rock-strewn bank was full of deer, peacefully grazing at about one hundred and fifty yards range. Soon many of these deer had fed forward over the ridge and out of our sight. Lars grew impatient, hissing, "Shoot, shoot!" in my ear. I knew that, for once, our sentiments disagreed-" meat" was naturally his idea; while, for me, 
nothing but that big bull should draw first shot. Still he came not. Where was he-indeed where were both the big beasts?

Only two small deer now remained in view. Lars was in despair. Then, right round on our left, something caught my eye. That something was the tips of those grand palmated antlers just appearing over the broken ridge, and on our side of the lake! Luck was indeed about to make a noble amend for any sorry tricks played us in the past. The big beast, that for three long hours I had watched with almost fiendish yearning, was actually going to give me a standing shot at less than one hundred yards. Half a dozen forward steps and his white neck and dark shoulder were beautifully exposed. Already, ere his head had appeared, the rifle had been shifted over, and now the foresight dwelt lovingly on a thrice-refined aim. (See frontispiece.) The $\cdot 450$ bullet struck to an inch, just where the shaggy mane joined the brown shoulder. The beast winced all over, but neither moved nor fell. A moment's survey and I knew by the swaying of his head that he was mine, and turned to look for number two. Curiously, some of the smaller deer, either mistaking the echo or unable to cross a second gorge beyond, came running back towards the main corrie, meeting the second stor bock as he galloped out of it. Him, as he struggled up the steep ascent, sending the stones flying behind, my second bullet caught fair on the back, though a foot lower than intended. He dropped on his haunches, and when I next looked up was dead, rolling down the rocks.

Both leaders being down, I turned attention to 
the rest, and as they galloped past, broadside on, just under the opposite crest, I gave them two double shots at about 180 yards. Two deer dropped to shot, never to move again; a third fell, but recovered and followed the herd. The survivors had now disappeared beyond the further hill, where a deep corrie hid them from view; but five, turning short, reappeared galloping in single file along the same hill-face by which they had come in. It was a very long shot, right across the lake, apparently about 300 yards ; but I put up the longrange flap, tried both barrels, and was surprised to see the leading buck fall dead to the first. The ball had passed through his neck, literally "cutting his throat," and he never gave a kick. The distance (as afterwards verified by W.) was 270 yards. The big bull was still standing on his legs, but his head hung down, swaying violently. Just after my eyes had returned to him, he fell over, dead, with a crash. Five deer now lay prostrate before us, but even this did not complete the tale; for, while we were busy gralloching No. 4, my eyes caught, on the sky-line above, the swaying horns of a deer in extremis. Leaving Lars to his gruesome business of butchering, I proceeded to stalk the disabled animal, which however gave some trouble. The poor beast, terribly shattered in the stomach, could only walk short distances; but, constantly keeping the ridge, and always lying down behind a rock, it was an hour ere he gave me a chance to finish him by a shot at a hundred yards.

Thus terminated the most successful interview I had ever enjoyed with big game. The whole affair, from first shot to last, I suppose had not occupied 
hàlf a minute; nor had I ever moved from behind the shelter of my original rock. The net resultnearly a ton of meat secured by less than three ounces of lead!-was gratifying to me, but brought infinite satisfaction to numerous humble Norwegian cots where fresh meat is all but unknown, but which were now set up in supplies for the winter. Not a morsel was wasted. It must be admitted that I had singular good fortune in thus getting a herd of deer, within shot, in a spot so intercepted with impassable ravines and lakes. I have no pretension whatever to being a crack shot with the rifle, but to kill six deer in almost consecutive shots-all (save the first) at long ranges and full gallop-is a good performance. Whether (as I fear) it arose from a merely passing " inspiration," or whether I may hope to do such work again, time only can show. And it is fair also to remember the wonderful power and precision of that beautiful weapon, the modern Express rifle.

We now walked over the scene of operations. The big bull, which lay 88 yards away, differed from any deer I have ever seen. His broad neck and frame rather resembled those of a bullock in massive strength, and his weight, as near as I could make it out in English measure, was $450 \mathrm{lbs}$., or 32 stones. $^{*}$ He carried 25 points (of which 9 were on the snow-scraper), and his

* I give this weight with extreme diffidence, the means of weighing big game in wild countries being so very rough. To my eye, the beast looked like it, and the weight may be correct, though (if so) 32 stones is probably a record. The second buck, on a similar calculation, weighed $25 \frac{1}{2}$ stones. I am unaware if accurate records of the weights of Norwegian reindeer exist. In Spitsbergen the deer are a smaller race and scarcely exceed 22 stones. 
horns measured 51 inches in extreme length, by 29 inches beam. No. 2 stag, though of no such bulk, carried a fine clean head of 23 points, with horns measuring 36 inches by $27 \frac{1}{2}$ beam. The third proved, unfortunately, to be an old hind with long single-switch horns, while the others were two-year old bucks, all three in the velvet.

It was five o'clock ere the obsequies were performed and we started, each burdened with a skin, head, and horns, and a supply of venison-steaks, on the three-hours' tramp homeward. Darkness overtook us, and not even the triumph of the day wholly reconciled us to the terrible labour of that night. To begin with, I got a nasty fall crossing the river. The fording of that torrent in the

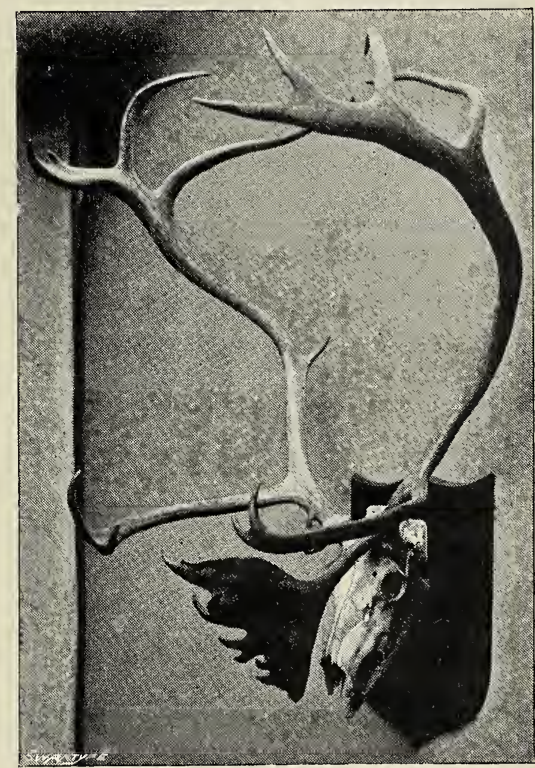

A FIFTY-ONE INCH HEAD.

(Ticenty-five points-shot September 1, 1893.) morning, with deer before us, had seemed a simple affair; but now, with these same deer on our backs, it resulted in an awkward accident. A submerged boulder towards which I had jumped, though it lay in full four feet of rushing water, rolled over, and in a moment I was down. Luckily there was a protruding rock beyond to fall on, so I escaped with a ducking, two bad knocks on the 
rifle-stock, several more on shins and elbows, and a severe shaking. I even saved my deer-skin as it swept past towards some rapids immediately below. Then for long leagues we scrambled in and out of black ravines, across cruel rocks whose angles we could no longer see, feeling a way down moraines or along rock-shelves, or through the clinging slime below the snow-slopes. Nature had well nigh given way that night ere the welcome light of Breiava twinkled across its gloomy tarn.

Including W.'s contribution, our united bag for this "First of September," comprised :-6 reindeer ; $4 \frac{1}{2}$ brace ptarmigan ; 312 brace trout ( $8 \frac{1}{2}$ lbs.) ; 1 lemming.

Next day, by general consent, was "an easy." Strict orders were given that no coffee-crushing should take place before 6 a.m., at which hour we turned out to a sumptuous breakfast of boiled trout, pink as salmon, fried reindeer-cutlets, coffee, and yellow-ripe peaches (from California). Even then we emptied one of our much-prized flasks of öl, ere again we "took the fjeld." The men carried hatchets, sacks, ropes, and a kettle with coffee-berries, we our rods and guns. The general order was to bring in as much meat as the men could carry, while we supplemented the larder with ptarmigan and trout. From the south end of the lakes we shot our way towards the scene of yesterday's operations, picking up a brace of ptarmigan here and there, but not troubling to follow the coveys unless they flew straight ahead.

Then the butchering business commenced, and the men, in truly scientific style, cut up the deer into quarters and joints, haunches, loins, and so forth. Two 
facts struck us. First, that the ravens, which, before a kill, had circled round inquiringly within thirty yards, were now extremely wary. Perhaps this arose from evil conscience, for they had purloined one deer's tongue and done other mischief. No other birds or beasts of prey had touched our meat. The second phenomenon was the swarms of bluebottle flies that had assembled. Hitherto we had seen no insect-life out here; even the mosquito was absent, and a careful census kept for the last ten days only included two small gnats, one spider (a big fellow with red spots), and one blue-bordered carabus, besides a few house-flies in the hut. Yet now whole swarms of bluebottles had apparently sprung into being from nothing; and on some half-digested grass disgorged by one of the deer, were congregated a host of another kind-the common yellow dung-fly.

The skilfully-carved joints being piled in a huge mass beneath an overhanging rock, Lars and Paul each shouldered a heavy sack-full (about 150 lbs.), with which, plus a skin apiece, we set out homewards. Hard by the hut, we observed an ominous apparition-a stranger; but he proved to be quite harmless, merely a messenger sent out (twenty-one miles) with an unimportant telegram for me. We had to put him up, but utilized him next morning to send a message to the valley concerning the meat. Two days later, six men arrived to carry it off, quite content to do the tremendous walk-in all, some sixty miles across the mountains-for the sake of the hundredweight of venison which each carried off on his back. For days this gory traffic continued, till not an ounce of meat remained. The gratitude expressed was profuse and sincere; but 
we could not help observing that the simple folk regarded us rather as reckless spendthrifts, living out here at monstrously extravagant expense (about twelve shillings per day, all told, for the two), to shoot deer which we could not use when we got them. But it is pleasant to find an absolutely unsophisticated region.

During the next ten days, we had some examples of fjeld-veir (fell-weather), when storms of rain, sleet, and flying scud drove across the hills. Weary days. Nothing could be done but eat and smoke and sleep, and read again and again our fortnight-old newspapers. Each day seemed to drag itself out to double its normal length, partly through the early hours we keep, for we find it impossible to retard coffee-crushing a minute beyond 6 a.m. Rifle-practice at a mark was tried, but even that involved getting wet, so our hunters fell to asking the prices of everything we had, and were intensely interested in our battery, which they regarded with due respect.

Then it cleared, and we recommenced stalking. The first morning we set out together, crossing a big lake to the west. In some very deep corries beyond was abundant pasturage, and close down to the water we fell in with the spoor of two big bucks. They had gone off at speed, down wind, perhaps having seen the boat. We were obliged by the wind to make long detours, but each time picked up the track. The deer were now going slowly, feeding; but we failed to get to leeward, and in the afternoon a storm of sleet drove us off the hill. These were large deer, and as I had resolved to kill none but big heads, we continued hunting their 
country for two days, and at any rate these old stor bocks taught us a lesson.

In reindeer-stalking one sets out full of hope and keenness, and with the favouring wind. But towards evening, when one begins the long tramp back, tired and empty-handed, and conscious too that the traitor breeze is now disclosing our presence to every deer for two miles in advance, then that intense keenness is apt to relax. This was our case to-night when, after ten hours' fruitless hunting, we came suddenly right on these two big bucks in the depths of a rocky ravine. They had seen us just as we saw them, and were off like grey shadows. Lars had the rifle, and ere it could be unslung and loaded, the deer had vanished. These deer, it should be noted, had been directly to leeward of us, but in that deep gorge the human scent had been carried high over their heads. Had we spied the glen with due care, the stalk would have presented no difficulty, indeed we were already within long shot. But, of course, I did not know the ground or of the existence of this ravine, which opened upon us with the usual abruptness.

One other incident will I relate. Towards the end of our sojourn on the fjeld, Lars and I had separated to spy the corries on either side of a high ridge, agreeing to meet on the lake beyond. I had crossed the apex of a sort of double moraine, when I heard the rattle of hoofs behind, and a fine rein-buck was galloping up within thirty yards. In an instant, with a tremendous bound, he turned and fled. Inside that same instant the rifle was pitched up and a snap-shot fired as though at a rabbit-every resolve forgotten, no apology for an aim taken. The deer winced, but away 
he went down that moraine, faster than ever; while so sick and humiliated did I feel-missing a beast as big as a donkey at thirty yards - that I was too ashamed to use the other barrel, and turned away. Again a rattle on the rocks attracted attention, and looking round, the buck was pitching headlong, stone dead, down the steep moraine. The bullet, after all, had gone right through

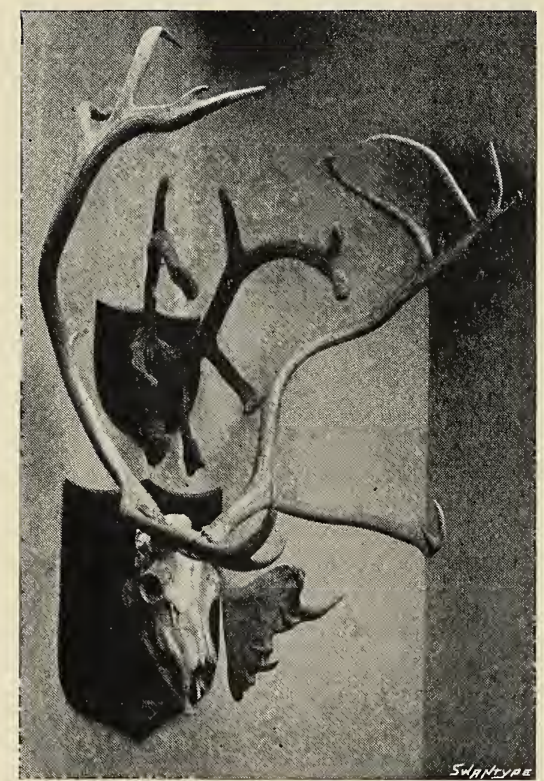

MEMENTOS OF THE HIGH FJELD. both shoulders, and I could not have made a better shot had I dwelt ten seconds on the aim.

This proved to be my last deer of 1893 . The next day was very wet, and on the morrow we set out, in a gentle drizzle, on our return. The swollen rivers we crossed in safety; but in the region of cloud which overspread the "mountains of the moon," we lost the way. Vainly we cast to right and left. Nothing but precipice and glacier confronted us on every side. Lars left me with the pony while he sought a path. That wise little beastie knew all about it, and while I lighted a consolatory pipe, moved off to show us the way. Ere I could catch him, he was crossing a steep snow-slope. Here his instincts, too, were at fault, for the undermined snow gave way, and amidst an avalanche of rocks, ice 
and frozen snow, the pony disappeared in the lake below. Then I saw antler-tips and corners of my baggage, as the beast swam across and began calmly to feed on three blades of grass, the saddle broken and all the pack and horns hanging beneath. It cost an hour's work to repair damages.

The rain was falling solid, and, in the cloud, I dare not leave the track; but, before passing the ridge, shot four brace of ptarmigan without leaving the pony's side -half at one double shot: and added a brace of willowgrouse by a right and left in the birch-scrub below cloud-level. Lower down, but still above the highest sæter, the last shot of the season added an old blackcock to the bag.

Three hours' row down the lake brought me to the spot where I expected to find dry clothes; but W., who had come down a few days before, had taken on our joint portmanteau. It requires more time than I could spare to dry things by hanging them out in the rain, so I was obliged to "weather it out," as I was ; and only mention the circumstance as a caution to the improvident, since the result was a severe chill which cost me no small trouble to throw off. In succeeding seasons, paying due attention to clothing and commissariat, I have hunted longer, staying on the fjeld till later in the season, without "turning a hair." Three hours in a rowing-boat, a day and a half's carioling, then a day and a night in a fjord steamer, brought us to Bergen in time to catch the Nordenfjeldske steamer Kong Harald for the Tyne-so fine, indeed, had we run it, that we had to tranship from one steamer to the other by boat in the fjord; the obliging Norsk captains 
each stopping their vessels while we and our luggage were transferred.

Postscript.-Here is a copy of a letter from a Norwegian friend:- "It may interest you to hear that the day after you left, two brothers, hunters of Kjendal, left Breiava to look for deer, and lost their way. Search parties were arranged, who scoured the mountains for three days without finding the missing men. They had left the hut on the Thursday morning, and on Tuesday it was reported that they had arrived at the sæters above Rannœs-fjord on the other side of the fjeld-the place whence I proposed you should start next year. The men had found no shelter, and had to walk continuously, night and day, the cold being so intense. They were in very poor condition when they reached the sæters at Rannœs. So, you see, reindeer-shooting in Norway is not without its dangers."

[NoTE.-Further details of Reindeer-shooting will be found in chap. xiii.- - while hints on stalking, on camp-outfit, equipment, and so forth, are given at pp. $203 \mathrm{et} \mathrm{seq.} \mathrm{and} \mathrm{p.} \mathrm{189.]}$ 


\section{CHAPTER IV.}

NOTES ON THE FIRST PRINCIPLES OF SALMON-FISHING.

\section{Fly-Fishing:}

THese notes are not indited as emanating from one highly skilled or experienced in the art of salmonfishing, but rather the reverse. There are born anglers, as there are brilliant shots, who seem to inherit an innate skill and attain proficiency almost without effort. But these, perhaps, hardly realize the difficulties that beset the less gifted aspirant-difficulties that the latter alternately fights and fears, at times deems insuperable, yet finally vanquishes, or, at least, overcomes in such minor degree that he can then from the threshold, as from the top of Pisgah, survey the realms of higher art, to him, it may be, forbidden for ever.*

The art of salmon-fishing differs in its essential principle and in its rationale from that of trout-fishing. The two kinds of fish are distinct in habit and economy. Trout take the artificial fly because they mistake it

* Though coming myself under this second category, yet I have had the advantage of angling on both sides of the North Sea with those who belong to. the first class. To Mr. Fraser Sandeman, in particular, a true craftsman and observant of the life-history and hidden habits of the salmon-tribe, I am indebted for much, both in precept and practice. 
for the natural $\mathrm{Hy}$, which in summer forms the bulk of their food. Hence there is infinite scope for skill in dressing trout-flies to imitate as exactly as may be, a known natural object.*

But it is of less importance how the fly is presented to the trout-floating, drowned, or otherwise-provided that no suspicion of danger or deceit is conveyed before, or along with the lure.

Salmon, on the contrary, never take a fly as suchthat is, as an insect-nor as food at all. For salmon do not require to feed in fresh waters. They may, and do, from sheer idleness, mischief, or curiosity, or possibly to keep the digestive organs in working order, snatch at and swallow some darting creature or living object they may chance to see passing by or overhead - say a "blue doctor," or an "angel." But that is not feeding; they do not feed in the sense of nourishing their bodies. What nourishment they need during their sojourn in rivers, is derived from the abundant reserve of fat, or "curd," with which high living at sea has interlarded the flakes and overlaid the flanks of a new-run salmon.

If there are those who still hold that salmon "feed" while in fresh water, let them consider what the hypothesis involves. Salmon ascend favourite streams in shoals; they are by nature rapacious and voracious-their build and equipment show this, as well as the rapidity with which they recover condition and put on flesh at sea. What is there in any river to

* That is, the imitation must exactly follow the natural throughout the latter's progressive stages towards maturity. It follows that the former (whether fished dry or sunken) must correctly mimic the real insects, perfect or imperfect, under the same conditions as those in which their prototypes would then be existing. 
satisfy hundreds of such appetites? If they required to be so satisfied, a single week's ravages would clear out every living thing in the water. Aquila non capit muscas, nor does a salmon use his armed vomer or double rows of back-set teeth to catch animalculæ and small crustaceans.

No ; every trout, smolt, or eel, every duck, moorhen, and water-rat, would speedily be swept up-in a week small boys would hardly be safe. Consider also that a salmon loses condition, strength, and fightingpower from the moment he enters fresh water, while his stomach and digestive organs shrivel away with disuse.

Why salmon take a fly, or what they mistake it for, are perennial problems. But all that is immaterial to our present point. Certainly there is no form of life in fresh water that in any degree resembles a "salmon fly," and the assumption therefore is not unreasonable that the fish take the fly or other lure for some object on which they have been accustomed to prey while in salt water.*

The tinsel and gaudy feathers, it may be, recall pleasant memories of the week or month before, and Salmo salar, with reawakened rapacity, but without pausing to consider the anomaly of thus finding a prawn inland, or a starfish stemming a rapid, dashes at the intruder - and gets the hook.

Whether this be a solution of the problem or otherwise, and, if not, what the true answer may be, is, as already stated, immaterial to the angler.

* No doubt a salmon fly may at times resemble a small fish. Trout frequently seize a large fly in a big water, or when out of condition. Unquestionably they mistake it for small fish. 
But it is highly material, and of the first importance, to recognize that nothing more nor less than a living, moving creature (or the semblance thereof) will ever serve to move a salmon or attract him to the lure. No drowned fly drifting on the current, or towed tail foremost by a slack line, will secure a second glancenothing, in short, but these active, darting creatures (call them what you will) that salmon flies simulate when deftly "worked" across the current by skilled hand and limber rod. See it from the fish's point of view.

Deep down there, revelling in that rush of aërated waters, hard by the main stream, but slightly sheltered by some big boulder or rock-ridge from its fullest force, lies the big salmon, fresh last night from sea. Sticks or twigs, withered leaves, larvæ or libellulæ, ill-fished "flies"-the flotsam and jetsam of the stream-swirl by or circle in the eddies, all unheeded. Smolts and small fry in the shallows attract not-but, hulloa! what comes here? There, in the very vortex of the strongest stream, appears an object that at once arouses our erewhiles inert friend. His attention is riveted. To and fro in the current darts that bright-winged thing, now poising for an instant on feathered oar, anon with collapsed wing shooting sidelong from sight. Is it gone? No; there it is again, and nearer this time. The strength and activity of that thing, rivalling his own, its power of stemming the stream, the alternate opening and closing of those glittering wings-these points clinch his attention, its flashing hues (discreetly selected) excite his admiration and cupidity. What is that thing? To himself thus Salar: "Starfish, I fear ; shrimp, I think; herring, I hope." (Goes for it with 
a bang.) "No; it's that . . Jock Scott again, size 3.0, I fancy - and this time it's fast right in the roots of my tongue, so help me Dagon!"

From the above it will be apparent that it is of less importance to discuss biological theories that cannot be solved, than to keep the fly ever "working" in that enticing, exasperating style that first excites, then arouses the watching salmon below.

Another essential point in the life-history and habits of the salmon must be taken into account by those who would compass his capture. Unlike the trout, the salmon always lies at the bottom-he rests on the river-bed. I do not mean to attribute eel-like propensities to the king of fish, nor to infer that he lies whole-length like a $\log$; for that he does not. Trout, being furnished with air-bladders which they can inflate at will, are thereby enabled to hang poised in mid-water, on the look-out for food. But in the salmon (which does not feed so) these air-glands are wanting, or at least obsolete, and the fish, therefore, being incapable of floating without exertion in mid-water, necessarily rests on the bottom, though supported only at one point. That point can readily be seen in spring fish (after a week or two in fresh water) by the discoloured mark below the throat, or just aft of the pectoral finsthe point at which he balances, the head being relatively the heaviest part.*

* In Northern Spain, salmon are regularly captured by expert divers while lying thus on the river-bed. The position of each fish being accurately marked in the crystal-clear water, the diver, swimming up cautiously from behind, slips a running noose over its head. The noose being drawn tight, when the salmon begins to run, an attached line is hauled upon by a second fisherman on the bank. 
It will thus be obvious that the angler's lure must, speaking generally, be presented to the salmon deeper in the water than is necessary with trout-varying of course with the depth of the stream. This effect is obtained by holding the rod-point low while working the fly-in deep streams, within a few inches of the surface.

Again, I doubt if the salmon can avail his full powers of sight to any such degree as does the trout. Lying deep beneath the surface, the comparative absence of light must tend to neutralize his eye-power. Just as in the half light and rifted shade of the forest, the elk has learned to rely more on the senses of scent and sound than on that of sight, so too does Salmo salar in the depth of his swirling pool; and in each case nature, ever prompt to supply an equipoise, comes to aid. The broad, palmated antlers of the elk serve (as elsewhere suggested) to concentrate the least vibrations of sound-waves, and direct them into the cavernous ear behind; while in the salmon (which has neither ears nor sense of smell) there is provided an apparatus that intensifies the fish's sensitiveness to every external change. On the top of his skull are placed two oblong, bony plates, perhaps three inches in length, one on either side, each covering, and, as it were, closing with a valve a small circular aperture in the cranium-say half an inch in diameter-and leading to the brain. Thus there is communicated to the brain, magnified in the ratio of at least six to one, the faintest wavesound or vibration in the waters above. The moral is that the angler may fish without fear down-stream; he need not use that extreme care to conceal himself 
that is imperative in trout-fishing, but he will do wisely to avoid any unnecessary disturbance of the water.

A landed salmon, by the way, is killed most easily and expeditiously by a smart blow with a staff or stone across the frontal bone-plates aforesaid.

Salmon in all streams, at home and abroad, have certain fixed and favourite resting-places. If the young angler does not know these (and has no one that can tell him), he must first fish the places he thinks look likely. Secondly, some he thinks unlikely, then those he had missed before. Should none give response let him try again with a change-fly, and make a final effort with the first fly of two sizes smaller.

But, in Norway at least, he will rarely-that is, in a good river and under reasonably favourable conditions of time, wind, weather, and water--find fish so recusant.

Casting being the first step, I will say a word on that. The cast is made by the rod, not by the angler, whose function it is so to use the rod that its full strength and elastic power are exerted in impelling the line. When the latter floats perpendicularly down stream, the rod should be lifted till the fly is within a few inches of the surface, which action is sufficient to impart to the rod the requisite power for the back cast. The whole line is then projected behind, the fly leaving the water with a "pop" like a champagne-cork and returning thereto with a flop like a dead sparrow as the forward impetus of the rod drives the line straight out with a margin of force still unexhausted.

A clean straight back-cast is more than half the battle and is facilitated by dropping the rod-point down stream as each cast is fished out. 
The cast being made down stream at an angle to the current of $45^{\circ}$ and the fly placed a yard or two beyond the furthest presumed lie of the fish, it should (if a straight line has been thrown) already be "fishing" before it comes within the salmon's ken.

The "working" of the fly is accomplished by vertically raising and dropping the rod-point-more or less according to the strength of stream. In strong currents a few inches of play is sufficient; in "log" or slack water, the absence of current may be counteracted by giving a foot or two of "play" to the rod. But in either case, it is essential that the rod, while "fishing" the cast, be held straight across at right angles to the stream and, as a rule, low on the water. Trout-fishers (and most novices with salmon have already served an apprenticeship to trout) are apt to forget this and to work the rod round with the fly. This is a fatal error, for it at once deprives the fly of that active, lifelike character-opening and closing its wings alternatelythat I have striven to show is of such vital importance in salmon-fishing.

It will thus be seen that the trout-fisher has something to unlearn in acquiring the new art.

The several mechanical movements thus enumerated : (1) recovering the line, (2) the back-cast, (3) pause, (4) forward cast, and (5) "working" the fly, become with practice almost automatic; but it may be useful to remind the beginner (and thus save flurry), that at the completion of No. 5 the cast is finished, nor is there any need for haste in commencing a new one. The fly is then hanging straight down stream, doing neither good nor harm, and the angler has time to 
look around while he walks or wades a step or two downwards.

Each cast should be "fished right out"- that is, the fly should be "worked" across till it hangs straight down stream from the rod point, even should the water there be shallow. For, though no salmon would be lying there, it is always possible that a fish may have followed the fly from the deep and, if opportunity be afforded, will seize it in the shallow. This, of course, does not apply where a back-set current exists on the angler's side.

Striking.-Sooner or later the hour will come, and the fish. The latter fact is conveyed to the angler's knowledge either by his feeling the fly suddenly arrested in its course, or by his seeing the break on the surface-often a tremendous lunge with which, in rapid rivers, a salmon captures his prey. As soon as the hook is inside the fish's mouth, it is essential that the barb be driven home. To effect this with safety, and certainty, demands some judgment. The force required varies. It may roughly be defined thus: in slack water, where the fly has been seized deep under, and with long line out, it is safe to drive the hook home by a fairly smart stroke of the rod. On the other hand, in strong streams where the swirl on the surface (and probably the fish itself) has been seen, no action on the angler's part may be needed, the-salmon hooking himself as he turns to dive. These are the two extremes, intermediate cases requiring a middle method, often merely raising the rod point. A salmon may hook himself; but it is surer work for the angler to do it for him by driving the barb right home. 
There is danger in striking too hard, especially in heavy water, the double force thus applied simultaneously by angler and fish respectively putting a severe strain on the tackle. It has occurred to me to lose a large fish through this mistake, the hook (having probably struck a bone) breaking off short at the barb. The hold seemed all right till the captive turned to run down stream, when the injured fly at once flew free. On the other hand, in slack water, should the stroke not be smart and well-timed, there is great risk that only a slight and insecure hold will be obtained, which in the event of a prolonged fight, will very likely give way.

As to striking from the hand (that is, with the line included in one's grasp of the rod), or from the reel, I prefer the former. Striking from the reel no doubt provides a safety-valve against the use of excessive force. But if an angler exerts a force to drive home a half-inch barb that would suffice to uproot a sapling, he deserves the smash that will ensue.

The loss of two or three fish thus will prove a valuable object-lesson, and serve to inculcate the virtues of coolness and control of the nerves.

Some men say they neither "work" their flies nor strike their fish; the former may be right; but on watching the latter, when a fish takes, the upward movement of the rod on feeling the pull will be seen to be analogous to what others call striking, though perhaps not hitting a fish. As above remarked, though a fish may hook himself, it is workmanlike to leave nothing to chance, but to make sure of a good hold and a buried barb. 
Gaffing.-This, to my mind, is a very pretty part of the operation, requiring a quick eye and dexterous hand. It seems a pity to relegate the final stroke to a gillie or gaffer. The angler cannot well gaff his own fish, unless he has practically killed it first; but where two men are fishing together, each may gaff the other's fish and derive no small satisfaction from smart work.

The gaff itself should be a plain, strong ash stick, five feet long, with steel cleek, costing only four or five shillings. Avoid the smart-looking, brass-mounted toys of the tackle-makers (with spare top inside!), which are certain to come to grief at the critical moment.

Gut.-Waste no money on the gaff, but be as extravagant as you can afford on the gut. Have the best, if it cost a pound a cast, for one good length will outlast many inferior, and be actually cheaper in the long run ; while of infinitely greater importance is the mental comfort that good gut assures to the angler when it comes to "putting on steam," or stopping the career of a wayward fish at all hazards.

\section{HarLing.}

The salmon-rivers of Norway vary infinitely, alike in size, season, and the sources of their water-supply. Many fulfil one's early ideal, when fancy conceived nothing but turbulent torrents with seething fosses, mountain-born masses of disrupted waters fretting and fuming in cataract or cascade amidst obstructing rock and precipice.

There are rivers in Norway that are torrential enough, but the majority of Norsk streams glide in vast volume 
of wondrously translucent water through green valleys, a mile or more in width, and flanked by the forest-clad slopes of the fjeld. In these larger rivers it is not always easy at a superficial glance to distinguish exactly the gradual alternation of salmon-holding pool and fishless rapid, so imperceptibly does the one merge into the other. The depth is often uniform from bank to bank, save where the main current has scoured away its gravel bed. There are, of course, pools whose existence and extent are more clearly defined, those, for example, where the river impinges on the rock-walls of its valley, or where a sharp bend gives fuller scope to the erosive action of the water. Yet it is sometimes difficult to distinguish, this a pool, that a rapid, in these broader Scandinavian streams, though every pool and eddy, its back-sets and "holds," are intimately known to the local fishermen, and each stretch has its name.

Very large rivers are necessarily unsuitable for flyfishing, since such breadths of water cannot be commanded by casting-as well stand on the North Cape and angle for whales. Moreover, their rapid currents, the extreme clearness of the water, and, lastly, its depth, render surface-fishing, in such streams, uncertain and unreliable. It is on the smaller rivers, and on the upper waters of the larger, that fly-fishing for salmon is practised in Norway. On many of the larger rivers and lower reaches, mid-water fishing is the only means of thoroughly commanding the whole streamthat is, harling with fly or spinning lures, angel, spoon, or phantom, in their various forms.

On great rivers, such as Alten and Tana in Arctic Norway, Namsen and Vefsen, harling is the exclusive 
form of fishing, and it is also available on the lower waters of the Gaula, Surna, Förde, Evanger, and many other rivers which also afford fly-fishing on their upper reaches.

Harling a swift salmon-river and trolling a currentless loch are very different things, though there are stay-at-home sportsmen who, with a singular mixture of ignorance and insular prejudice, affect to believe them the same. Effectively to harl a large river--that is, to attain the best possible results - both fisherman and boatmen must thoroughly understand their work and their water, and pay constant attention to each.

With two rods at work (and sometimes three) there is occupation for the angler in attending to the respective lengths and depths of his lines, varying either according to the varying strength and depth of the current, the nature of the river-bed in each pool, etc., so that, while keeping clear of fouls, shallows, or obstructions, every nook and corner from bank to bank that may possibly hold a salmon, is fished out in the most enticing and effective way. Skill in handling the oars and an intimate knowledge of the likely " catches" are of the first importance. While passing directly above the latter, the boat may be "held up" for a moment or two, and one watches with intense anxiety the neighbourhood of the lures as they sweep to and fro, spinning invitingly over the submerged boulders of some well-known " holt."

The length of line out need not exceed twenty-five to thirty yards, and it will be found convenient to mark that length by tying a bit of coloured silk upon the reel-line as a guide. When two lures are being used, one should be fished a yard or two further out than the other. In 
harling with a fly, it should be borne in mind that the fly must be "worked" in the water precisely the same as in casting. By this means fish may sometimes be raised that have refused the other lures.

When a salmon seizes a spinning bait, and the reel rings out an intimation of the fact, it is always necessary to strike-and that quickly. Then follows a period of some anxiety, while the angler is engaged reeling up the other lures, so as to clear the lines and avoid a foul. It is safer, after striking, to be at first easy on the fish, merely holding him till the other lines are safe aboard, rods passed forward, and decks cleared for action. And even then, I opine, it is prudent, in waters where fish run large, to be gentle for a time, to invite the captive to exhaust himself rather than, by undue force, to provoke a display of his unimpaired strength and running powers. Especially is this the case where the banks present difficulties in the way of killing, or in the event of any untoward circumstance occurring.

It is generally supposed that fish fight less freely when held on a compound lure than by a fly, and this may possibly be so ; but it is hardly my own experience, for I have enjoyed as long and severe tussles, and as determined runs with fish captured on spoon or phantom as on Jock Scott or the deadly Doctor. Indeed to some of those byegone days spent in broad-beamed salmon-boat, with fifteen-foot trolling-rods out astern, I look back for memories of as glorious sport as angler need desire. 


\section{$(63)$}

\section{CHAPTER V.}

SALION-FISHING IN SÖNDHORDLAND.

\section{Our First Day on Etne.}

Our chartered steamer, brilliant in bunting, came alongside as the mail-boat anchored in Bergen harbour. Rod boxes and baggage were transhipped, and in half an hour we were speeding merrily down the fjords, where already, on May 21st, terns dashed headlong on the shoals of sand-launce, where tysties splashed and stately eider-drakes paddled aside, while porpoises, with an occasional whale, rolled heavily in the wavelets till the ping of an express bullet disturbed their daydreams.

The Etne river, in Söndhordland, lies eight hours' steaming south of Bergen, and by 7 p.m. we were on the riverside. At midnight we returned homewards empty-handed, having tried several of our best pools without moving a fin, though the water was in splendid order. Not pride, but hope had suffered a fall, and terrible anxieties oppressed our minds: while deep doubts of our powers and skill forbade all sleep that night. Moreover, having caught no fish, we had nothing for breakfast.

A word here as to our quarters. Our four-roomed 
chalet of Solbakken, perched on a birch-clad slope hard by the riverside, overlooked all the lovely Etnedal, a verdant valley now glorious in the new-born foliage of spring, redolent of the blossom of bird-cherry and rowan, and resonant with the chorus of summer warblers.* Beyond rose fjelds, encircling our Elysian dale as with a mural amphitheatre, and rising ridge upon ridge to snow-flecked summits where, with the spy-glass, we recognized the bare bed-rock beloved of ptarmigan. The whole valley was but a mile in width by four in length, broken by foothills and old-time moraines. A quarter-mile away the hamlet of Etne nestled betwixt river and fjord, and, by way of touch with the outer world, was twice in each week visited by little steamers which sometimes brought us letters. The telegraph office was at Skonvik, eight miles away, over a mountain which we found to be 2150 feet in height; yet that aggravating wire, climbing the obstruction on prehensile poles, elected to cross our river at the centre of its best pool, and afterwards traversed the road at five points, thus causing five separate anxieties when carioling with eighteen-foot rods up.

In the morning our grey-haired gaffer, Lars, warned us that it was useless to fish before 4 p.m. But initial

* Here is a list of the chief species noticed immediately about our house and garden at Solbakken in May : Pied flycatchers, two pairs in orchard : ortolan and yellow buntings, redstart, whinchat, wheatear, sedge- and garden-warblers, blackcap, willow-wren, great and marsh-tits, goldcrest, white wagtail, sand-martins (arrived 25th), cuckoo, corncrake and woodcock, besides starlings, grey crows and magpies in swarms. On the green haughs in front were various gulls, herons, redshanks, peewits, sandpipers ; and, high overhead, golden plovers sang their vernal song. On the hills behind preyed buzzards and ravens, ring-ouzels piped, and blackcocks crooned. 
enthusiasm, impatient of delay, spurned counsel of wisdom, and preferred even certain failure to the misery of inaction. The day, moreover, was dull and cloudy, and we thought there might be a chance. Having well " messed" our home pool by the bridge ("Enge-broen"), easily cast from a level sward, I proceeded to the next, Busketieg. Here the stream runs strongest under the angler's feet, but a high gravel bank at his shoulder at first presents some difficulty in the back-cast. This, however, is soon overcome (in all such cases) by returning the fly straight up-stream, afterwards impelling it outwards during the forward movement.* Five yards below the stream-head there came the glorious swirl, a plunge of a pointed fin, and the Black Doctor went home in response. Ten minutes later Lars had gaffed the first-a ten-pounder fresh from sea. The next pool, Lydskar, is also easy, but requires a rather longer cast, the main stream running in the centre while the "catch" lies beyond, and a backwater on the hither side demands a wide berth. $\dagger$ Here, again, I was soon fast in a heavier fish which, after twenty minutes' smart running to the verge of the rapids below, registered 23 lbs. The sun now glinting through the clouds, the two next pools fished blank, and we set out to return to

* There are four methods of fishing such pools:-(1) as described; (2) by bringing the fly out over one shoulder, returning it over the other ; (3) by a perpendicular cast ; (4) by the Spey cast ; the latter only in heavy water. The choice of the other three depends on the wind, etc.

$\dagger$ This pool should, of course, be fished from the other side; but the river was impassable, and neither boat nor bridge for a mile or two. The same remark applies to other pools described passim; while in others, again, thick forest or high rocks compel one to fish from the "wrong side." 
lunch; but, under a passing cloud, I had the luck to take a twenty-pounder out of Broen-pool on our homeward way.

The afternoon brought a blazing sun and cloudless sky. Nothing could be done but shelter under the birches and wild-cherry trees, nor were operations possible till past nine o'clock. An hour later we were still " unfished," and darkness coming on. Then, leaving W. with Lars at Busketieg, I hurried on alone to Broen, where, almost at the first cast, the Black Doctor again lured a fastrunning fish. Willingly would I have been easy on him and fought gently, awaiting the arrival of the gaff, but not so my gallant foe, who from the first insisted on forcing the game, racing hither and thither, running and jumping alternately, buzzing off line till the reel hummed again, and soon obliged me, with nigh a hundred yards out, to follow him down the flat. Down the delta we raced in mad career, recovering some line meanwhile, till the open waters of the fjord glistened in the moonlight within two hundred yards. Here the river, I now observed, divided into three channels, down the largest and farthest of which my lively friend had evidently elected to run the rapids. Not knowing the water nor whether the two intervening streams were wadable, it became imperative to assume the offensive, and I put on full steam to check his fatal intent. Anxious moments followed, while by the dim mystery of the moonlight, I could just see by the distant swirl on the shallows and at times by the roll of a rounded back and dorsal fin, that the fish was dropping ever nearer and nearer to the lip of the broken water. To gain that lip to him meant safety; to me a catastrophe. 


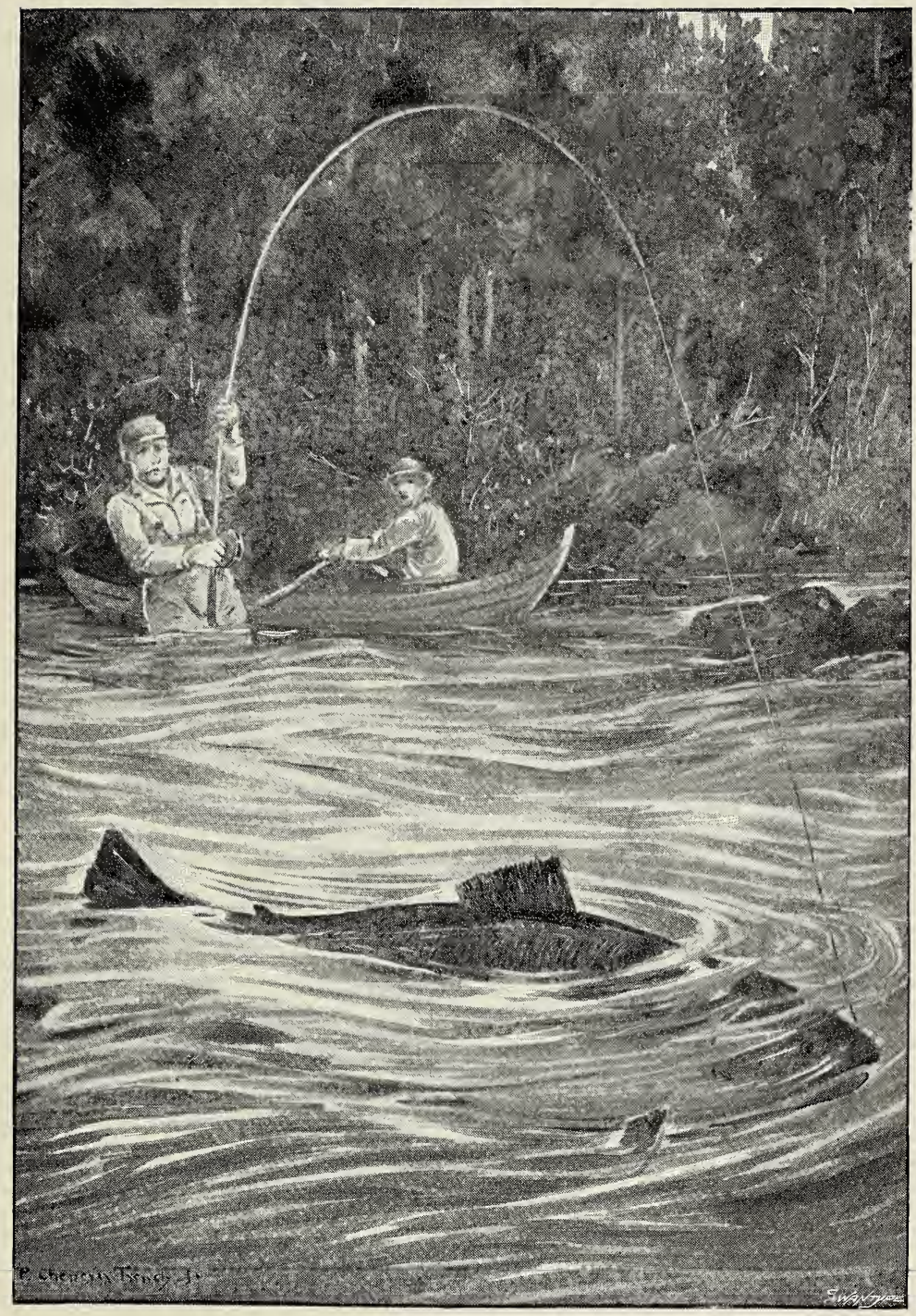

SALMON - FISHING.

"Beginning to yield.", 

Still full eighty yards away, and in a bight beyond the two nearer stream-heads, it looked six to four on the fish, when at length the pressure slackened and he came fast up the flat once more. Then I knew he was mine, and, holding him hard up stream, in a few more minutes he was rolling in distress in safe waters hard by my shore. Still no signs of the gaff, and deep water to the very brink. What should I do? I decided to take him into the smaller stream below, and this fortunately proving quite shallow, all doubts were dispelled as the played-out fish, in last resource, sought shelter beneath a grassy bank. A friendly native, attracted by my "siren" signals, here "tailed" as shapely a fish as ever swam, a perfect torpedo in form, fresh from sea, and scaling 21 lbs. The fight had lasted thirty minutes, and ere I had dragged the victim up to the bridge, the cariole drove up and I found that W. had been engaged in a simultaneous struggle and added a fifth fish to the day's bag. This, a ten-pounder, had taken a small Jock Scott literally at the last cast of the night.

Joy replaced the carking cares of the morn. Our first day's total was five fish, all cocks, and bright as burnished silver, weighing 10, 23, 20, 10, $21=84$ lbs., and we felt we had deserved them.

"And the night was filled with music, and the cares that infested the day

Folded up their tents like the Arabs and as silently stole away."

Having ventured to send the last-named fish to the Præst-gaard of Etne, next morning the good pastor's pretty daughter called and presented us with a lovely bouquet of white narcissi and lilies of the valley- 
typical, as we tried to explain, of her sweet little self, a true flos campi liliumque convallium.

That morning we found to our chagrin that the river had fallen full six inches during the night. The wind, moreover, was north, with heavy mist hanging on the hills. Skud meget slem = " mist very bad," augured Lars; yet, casting from the stage at Gravelset, W. hooked and I gaffed a nice $8 \frac{1}{2}$ pounder, and we got another fish at night.

\section{Spring-Fishing in Etnedal.}

Day by day we arose only to find our river lower and yet more low. The preceding winter had been unusually mild in Norway, and the spring was early and warm. What little snow had fallen on the fjelds, by mid-May had already melted, leaving but scant patches scattered on their northern faces. Hence the blazing heat of midday no longer swelled the midnight stream, and not a drop of rain fell during our stay. Adverse climatic conditions we tried to counteract by extra hard work, sticking in at all hours, and fishing, day or night, whenever opportunity served. We had our reward, for not a single blank was recorded. We came very near it, but W. saved the game with a tenpounder when close on midnight.

The Etne is but a small stream and very short, its total course being under six miles to the Storfos, a sheer waterfall which no salmon can surmount, and beyond which the river opens out into a series of lakes extending seven or eight miles to the foot of the fjelds which encircle its basin and form the watershed. 
In spring, even this short length is curtailed, since a second waterfall, the Lilfos (one mile below Storfos), is also unsurmountable to salmon in the strong waters of May. Hence the upper water is useless for salmon fishing before the summer-time. We tried it down for trout, and had evidence of the presence of salmon in the dried remains of the largest fish $I$ ever saw, alive or dead. As far as measurements could be taken, the skeleton exceeded four feet in length, while the ghastly gape appeared better proportioned to a shark or maneating crocodile than to a sport-giving salmon. One shuddered at the possibility of finding one's self engaged some evening in personal conflict with so ferocious a fish.

It is a curious circumstance that many very large fish only succeed in escaping capture by man, to meet thus with a natural death at this-the weakest period of their lives, that is, just after spawning.

During the midday interlude, the trout in these upper waters (being much sheltered by trees), as well as in the lakes above, afforded some little sport, but naturally the fish yet lacked condition. The best trout, we found, frequented the lowest pools of the delta, right down to the fjord - handsome brown fellows, free-taking, and averaging half-a-pound apiece.

The Lilfos being, at this season, the terminus of their upward career, the pool below naturally held several of the earlier-run fish awaiting a first opportunity to ascend. Some of these we induced, reluctantly, to " come out of the wet." Lilfos, indeed, was a glorious pool, my ideal of all Scandinavian salmon-fishings, before I came out to see. Immediately behind the angler 
roared the foss, where the whole volume of Etne thundered down in majestic ruin over black rock-barriers, swirling and fretting, to the troubled pool beneath. In the gloomy ravine, birch-surmounted and halfobscured by reek and spray, the angler's vision was none too clear: especially was this the case in the dim mysterious twilight-what time woodcocks flew piping

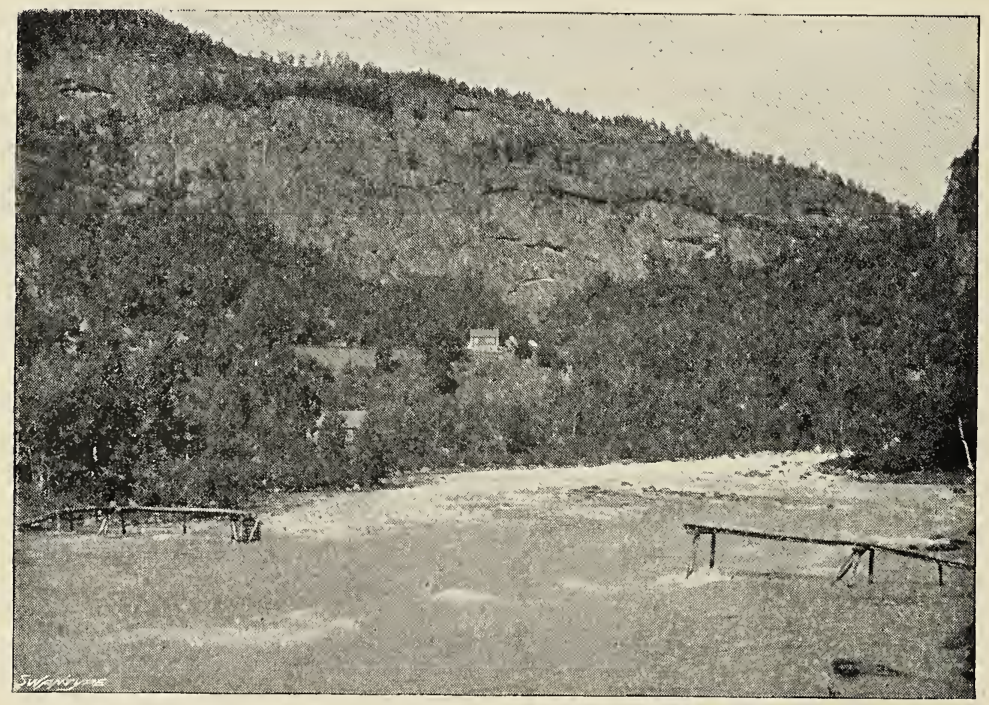

A SALMON-POOL, SHOWING CASTING-STAGES.

overhead. Hence, after fishing down the pool, I was hardly surprised when Lars, perched fifty feet above, came down to tell me I had moved a salmon-a "meget stor lax," close below the neck. Half an hour later I tried him again. This time the roll of back and dorsal fin, and the plunge of a shovel-shaped tail as he dived, were clearly seen amidst the boiling waters. The fish was firm hooked, and I held him hard, fearing a run 
down the chaos of cataracts below. He fought gallantly, but his race was run. The strong stream helped me. After some anxious moments of desperate fighting amidst swirl and seething spray, the pressure told, and W. put in the cleek. Weight $26_{2}^{1}$ lbs.; duration of fight, nine minutes-smart work. During the tussle I had felt the sickening sensation of the hold dragging, and for the last minute had held him more gently. He proved to be lightly hooked in the lip ; the first hold had failed, and the faithful hook secured a second grip-good luck, that.

This fish had been some ten days in the river. In those new-run, direct from sea, the broadside has the hue of burnished silver, except the narrow flat of the back; a week or two in fresh water, and a darker shade of steel-blue extends downwards, half-way to the median line. At the end of a fortnight the pristine silvery effulgence of the scales is also seen to be perceptibly tarnished.

One morning after breakfast (we had already put in three hours' work at dawn) a cloudless sky suggested "nothing to-day but trout." Then, just as we were setting out with single-handed rods, the wind, which for a week had been nailed to the north, shifted at last, flying right round to the south, and in half an hour the sky was overcast. Then two drops of rain, worth their weight in thrice-refined gold, were actually felt to fallthey were quite wet! Joy filled our hearts ; the weather, we felt sure, was breaking at last, and the mercury of hope ran up to the top of the scale. We had but a few days left, and we already feasted, in mental anticipation, on a grand finale. While Lars went to 
catch the pony, we hurried to the home pools, and I had already gaffed a cock-fish of $11_{2}^{1}$ lbs. (time, five minutes) when the stolkjær pulled up. A few more scattered rain-drops, few and far between, still further stimulated hope, and at full speed we pushed on direct to Lilfos. Here I killed a ten-pounder, and was soon fast in a second salmon, which seemed resolved to ascend the foss right away; but those terrible streams told their taleafter a grand effort, he perforce fell back, and a straight pull brought him to gaff in seven minutes, weight $14 \frac{1}{2} \mathrm{lbs}$. This was a good beginning; but now, alas! before our small white pony could trot down to Gravelset, the sun was already glinting through crevices of his cloudy canopy. Another half-hour, and he shone in a cloudless vault. One dull hour had given us three fish; but never again did we receive one shred of assistance from the weather.

The size of the fly used in fine water is an important consideration, as the following incident shows. One evening we fished down Gravelset with a Jock Scott, No. 3, without response; but on trying the pool a second time with the same pattern two sizes smaller, a fish of 22 lbs. was secured. The short twilight in May is a drawback to early-spring fishing. The sun remains on all pools till 8.30 - on some till 9 p.m. We combated his malevolence, and made the most of the two hours till half-past ten (when it is as dark as the night will ever be), by keeping our stolkjær, or pony-cart, in waiting, hitched on to a tree hard by. After finishing a pool, we jumped in, rattled off full speed to the next, and leaving Lars to anchor the pony, or tie his legs if no tree grew handy, got to work without a moment's delay. 
No. 1 rod first fished down the pool, then hurried forward to the next, while No. 2 tried it down a second time with a change-fly. True, this was fishing "at a run"-at top pressure; but it served a temporary purpose. Towards midnight we wished to send old Lars home, but he refused, saying, "I am old in years, but young in spirit when sport is in view," and the fine old Norseman did enjoy a nip of cognac, and curled himself on the rocks to snatch a few minutes' sleep while we finished the pool.

As the river fell in and its volume daily decreased, it was curious to observe the intense anxiety of the salmon to surmount the barrier of the Lilfos. The main foss still forbade all attempts; but among the broken rapids and minor falls below, were rock-pockets or cauldrons of seething water-half-way houses, so to speak, which the fish now eagerly occupied. It seemed almost incredible that any living creature could long maintain a position there, and avoid being dashed to fragments in that rush of disintegrated water. Yet the salmon were there; for by ascending the lateral rocks and "trickling" the fly on these cauldronsthat is, making the "insect" dance along the surface, skipping through the spray-it generally resulted that either the head or the huge tail of a salmon showed up almost under the rod-point, though we could never induce these impatient pilgrims to take a fly. Possibly, a spoon or "angel" might have succeeded, but it did not occur to us at the time to try those lures.

Occasionally, in the very focus of the best salmon pool, a trout of insignificant size would seize the fly. This was always a fatal omen, indicating that the 
salmon were lethargic. Once, just at midnight, something rose, and for a few seconds fought hard, then at once collapsed. A two-pound trout had taken a big Jock Scott. Up to the penultimate day of May, all our fish had been cocks, with an average weight of just under 16 lbs. apiece. But on May 30th, the run of hens commenced, and we got two that night, rather under $10 \mathrm{lbs}$. each. These little she-fish were desperate fighters, rushing in mad and reckless flurry all over the pool, jumping half a dozen times in succession now above, then below, thus slacking the line, then bringing it up taut with a bang-in short, one never knew where we had them. One of them fairly beat me, going off at racing speed from right underfoot, thus succeeding in breaking the gut by the jerk when the slack was taken up. Though she was only a ten-pounder, she carried off a brand new Jock Scott, and a foot of best single gut-the only fish, by the way, that fairly secured a trophy! Of course, I should have held back some loose line in hand, but-well! these she-tactics puzzle one, and besides it was 2 a.m., and we had fished continuously since five the morning before. Another henfish ran herself right ashore, and I gaffed her jumping about among the stones full three feet above water-level, and barely a couple of minutes after she was hooked.

It is, I believe, an axiom that running fish will not take; we, however, raised several and hooked two (both hens) in the small hours of June 1st, hanging in the slack water at the pool-tails, and evidently resting after struggling up the stream below-at any rate these fish were not there a few hours before. At three o'clock that morning we twice observed heavy fish in 
the act of running, and an hour later the sun rose behind the grey crags of Haglerstein-Nut.

The favourite spring flies on Etne were (1) Black Doctor, best of all, (2) Jock Scott, (3) Butcher, (4) Blue Doctor, on dull days. For change-flies, Durham Ranger, Silver-grey, and Bull-dog, proved useful, while the Blue Doctor with silver body did best at night. Hooks in no case larger than No. 3, and all might well be dressed on double hooks (in duplicate). Several of our fish were killed (in very fine water) on hooks as small as No. 5 .

I cannot leave Etnedal without adding a few words on its feathered inhabitants. I have already referred to the variety of summer-birds which by day and night serenaded us in our little garden at Solbakken. The marshy haughs and hazel-coppices by the riverside afforded congenial homes to all these in numbers. The corncrakes arrived before there was any growth of grass to hide them. I had never before seen these skulking birds running about, like partridges, on quite bare ground; yet they seemed neither disconcerted nor ashamed of their nakedness. But the lightninglike way in which they "streaked off" horizontally when alarmed was striking. The herons that fished our backwaters had established their colony in the face of a sheer rock-escarpment of six hundred feet overhanging the fjord, their nests being placed either on the rocks or the small birches that clung to the cliff. I thought this curious at the time, but (as happens with many "discoveries" one makes abroad) I find the habit duly set out by Mr. Saunders in his all-inclusive "Manual of British Birds." Very singularly, a pair of ravens occupied an upper ledge in the same crag. 
Lower down the fjord a pair of ospreys had their eyrie in a broken cliff, and almost daily paid our river a visit, possibly on the look out for a late-lingering kelt, though not a single gammle fisk remained, to our knowledge, in those pellucid streams, a few sea-trout kelts alone still hanging about the brackish waters by

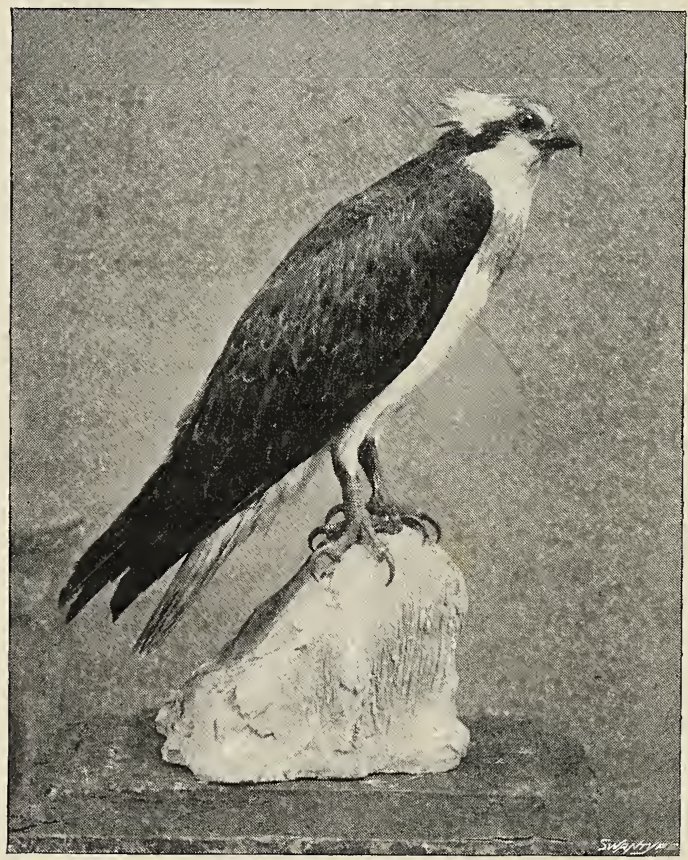

OSPIREY.

('Tana River, June 7, 1884.)

the river mouth. The graceful, though somewhat unstable poise of the osprey is a pretty sight, typical of these inner Norwegian fjords; one morning while W. played and I gaffed a twelve-pounder in the home pool, the fisher-eagle hung overhead the whole time and watched the performance with curious eye. Probably 
she felt she was quite equal to putting in the cleek, but would admit that the preliminary feat lay beyond her powers.

To sum up-the Etne is a charming little river, very early and very easy; each of its dozen pools, from Lilfos downwards, is commanded from the bank, except one (Straake-pöl), which must be waded. There is no harling, nor a single boat on the river. On the other hand, the season on Etne, as on most small rivers, is liable to be extremely short-one good week, it may be two, and it is over. In the year above described, we were decidedly in luck's way in exactly hitting off to a day the most favourable period. Nothing had been done previous to our arrival; while in June, with continued hot weather, the river ran almost dry, and sport became impossible. The following year, the main run of fish began about ten days later, May was a blank, and the first ten days of June proved to be the most productive period of the season.

"Big rivers, big floods ; small rivers, short season." 


\section{CHAPTER VI.}

\section{MEMOIRS OF MONSTERS.}

ONE result of former experience in Scandinavian salmonfishing had been to instil a belief that the largest old male fish ran early-earlier, that is, than we had previously arrived in the country. With the object of trying conclusions with these in May, we came out this season ten days before the usual date. That the premises were correct, the sequel proved. Whether the latter was entirely satisfactory we leave others to judge.

Samkomme pool is formed by the junction of the Sŭr river with the main stream. It is easily commanded by wading the Surr; but when the latter is too deep and strong to wade, the pool presents some slight difficulty, owing to the opposite bank being inaccessible and the main current running in at an angle of $45^{\circ}$ towards the angler. Hence, in the temptation to cover the whole water, he is apt to lose control of his fly, which then drifts drowned and useless.

I had fished it down carefully with as long a line as I can manage, leaving untried the dangerous bit at the top, and proceeded to the pool below, while W. tried Samkomme again with a change-fly. He, wisely 
reversing my attack and using a short line, almost at the first cast, a monster salmon lunged along the surface and seized the small Jock Scott in the strongest stream-head. I had hardly commenced casting below ere a syren-signal, startling the echoes, summoned me back to Samkomme. This fish, while evidently convinced that safety lay in the strongest stream (whence he had first emerged), made continuous runs, short and sharp, down or across the pool, taking off twenty to thirty yards of line with a screech, but always returning to the heavier water close at hand. Again and again during these excursions he "flowsed" or plunged along the surface, sending the water flying and exposing his formidable proportions-full four feet long by estimate, with massive shoulders, and a depth that seemed disproportionate. But he never tried to leave the pool, which was about sixty yards in length. At the end of half an hour's fight, he hung more in the slack water, and once seemed disposed to go down the rapids below, the main stream of which ran far away under the opposite shore. But if ever that desperate intent was in his mind, an equally desperate countereffort dissuaded him, and for twenty minutes longer the struggle continued without respite or breathing time, but within its original limits ; yet after fifty minutes of this, there were few, if any, signs of submission-indeed it appeared an open question whether angler or quarry were in the more parlous state. Distress there certainly existed, and Erik now crept forward beneath the willows. Twice the gaff moved out in readiness, but the fish again sought the middle depths. Fifty-five minutes, and he once more came sailing round below the bushes- 
still on even keel, and no inducement could bring him quite within reach. Then, without a moment's notice, the rod sprang upright, the line twirled backward among wild-cherry blossoms, and the fish was gonegone for ever! The little Jock Scott hung unharmed on the gut; its hold, firm as its puny size could grasp, had simply worn itself out, and the strong gristle and sinews of the big beast's mouth had given way under the strain and stress of the struggle, and of a threepound pressure maintained continuous during an hour all but five minutes. Those five minutes would probably have served to kill this grand fish, had only the hold held good.

It was a Sunday evening. As the end of the week drew near, we had been anxious as to local customs in regard to Sunday fishing-these varying in different parts of Norway. Erik told us we might fish after dinner; and Gjertrud, our laughter-loving handmaiden, who happily seemed to find something comical in almost everything we said or did, propounded the brilliant idea :- "Yes, but you can dine at ten and begin fishing at eleven o'clock!" There was a subtlety about this capable of infinite development, but it struck us as too refined, so we delayed starting till four in the afternoon; the greater part of the population of the village, we observed, accompanying our stolkjær or making short cuts through the woods. When I commenced to cast Stein-pool from the platform, there was an audience of thirty-four folks, lads and lassies, old men and maidens, assembled on the bank behind.

Stein-pool is dead and deep, with a moderate stream running in beyond mid-river, and the fish lying well in 
towards the opposite bank, which was heavily wooded down to the brink. The nearer half of the river is (in fine water) a deep back-set where the line, if allowed to enter, is instantly drowned. This combination necessitates not only long casting, but rapid-long throws and quick returns, which means hard work, especially as a high bank, twenty yards behind, involved lifting the line well up in air.

Visum veniunt, paventque videntes! The swish of the fly in their faces so on cleared off the spectators to safer distances, and about half way down the pool, there came that tug-no, it is not a tug, but a sudden inflexible resistance as of a tree-trunk or of solid rock. But I knew that a big fish had annexed the fly, deep-under and without showing, and delayed not to drive

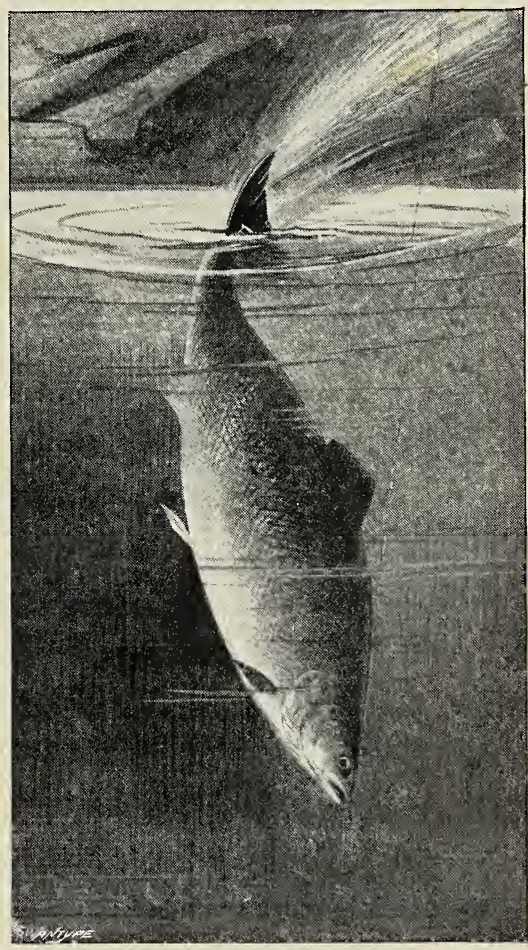

"BORING." the small double hook well home in his jaws.

Five minutes later, after a prolonged period of bottom-fighting, jagging and sulking, alternated with subaquatic gymnastics and contortions that kept me trembling for my tackle, the captive came up with a 
sudden rush to the surface, ploughing along flat on his bent broadside for twenty yards. Then we saw that this fish was even bigger than our lost monster of Samkomme. Was it possible to subdue such a salmon on that paltry hook? True, it was double; that reflection seemed inspiring. But then the hooks were even smaller than that which had already failed, being actually the smallest (No. 5) in all my collection, and therefore specially selected for fine water in a streamless pool.

In salmon-fishing, as, I presume, in managing a ministry, it becomes occasionally necessary to possess a policy, or to decide for better or worse upon a set course of action. In the present instance, having the above considerations in view, I determined (rightly or wrongly) to play for safety, to act solely on the defensive, and to leave the fish to kill himself, even though it involved my spending the night with him in the process.

I pass over details which would involve repetition. Suffice it that eventually the fish, persistently dropping down-stream, obliged me to follow. This, for some distance, was easy enough; but lower down, trees grew to the water's edge. Still it was necessary to follow, having some fifty yards of line out. The fish was now in the shallows, rolling heavily at intervals with short sullen runs, during one of which I felt a slight "draw" - perhaps the hold of one hook had failed. W., going down through the trees to reconnoitre, reported the fish meget tret - " tired." For almost minutes at a time he lay inert in mid-stream, suffering himself to be towed ahead in the slack pool-tail without resistance. Had it now been possible to incline the rod inland, an opportunity to gaff might, it seemed probable, be 
secured. But the thick-set branches, projecting far across the stream, forbade this, and two alternatives remained. One was to drop still lower down stream, trusting to find shallows and to get in the cleek at the foot of the pool. This, however, I rejected, first because the fish was as yet in no sense under control, and the danger in the stronger stream obvious: nor was there any reasonable certainty of gaffing there.

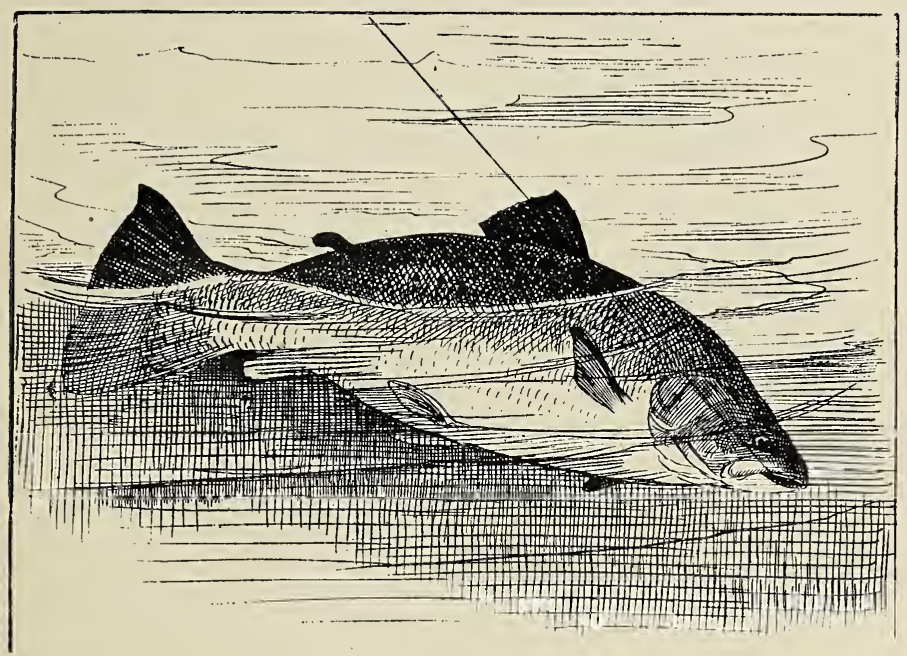

"PLAYED OUT."

Secondly, because I knew nothing of the depths or nature of the water below, beyond seeing that there was a strong rapid at least two hundred yards long, with an island in mid-stream and thick wood on either bank. Hence I elected the other course, and endeavoured slowly to tow the half-beaten fish up-stream, and thus clear the trees.* While thus engaged, though exerting

* A stone thrown in a little below the fish's tail at this point might have served the purpose. But we did not think of that at the time. 
no special pressure-indeed humouring the captive in all his little runs and lunges - the rod flew up, and the fly came home, unharmed. The fight was over and the fish the victor.

A few days afterwards, in the same Stein-pool, I hooked a third monster. I felt him come, struck at the right moment, yet in rather less than a minute, for some reason unexplained, the hook came away. During his short captivity he had made one long surface-run, thus showing us his size.

The conclusions we came to are these: that these very heavy fish, given the best of holds on single gut, may take an hour to kill and possibly more; and that, during so prolonged a pressure, the hold of a small hook (and in fine water no other is of any use) must almost necessarily wear itself out.

I give for what it may be worth, the quality and rank of the two above-named fish, these points being set down by estimate of the local experts as (1) the Samkomme fish, 40 lbs., fresh from sea the night before. (2) Stein-pool-a larger salmon, probably from 45 to 50 lbs., but of some fourteen days' sojourn in the river. These estimates I take to be fairly near the mark. After handling heavy fish, one comes to know the strength and style of the twenty-pounder, and of fish ranging between that and 30 lbs. These two, as well as that other monster of Nedre-Baksnyden, whose fight for life is described later, presented an altogether different problem.

There are among anglers, as in other sports, experts and "old hands," who never fail or lose a fish. They may smile at this record of disaster, pointing out things 
done that should have been avoided, or neglected that should have been tried. Well, to criticize is easy; so, too, it is to haul out heavy but ill-conditioned autumn fish from the depths of some sluggish hole. But with fresh-run springers in strong Scandinavian streams the case is different, and the difficulty greater and more varied. Possibly before these notes appear in print, I may have held the spring-balance in the snout of a fifty-pounder; but freely admit that these misfortunes of the past do not greatly enlighten me as to a safer course in the future.

As to "pulling fish out by the roots," well, that cannot be done, even with a ten-pounder; nor is it either skilled work or politic, though severe measures are at times imperative.

Incidentally it may be remarked that the mechanical advantage appears to lie on the side of the fish; since, while the strain on the human arm and back feels like half a hundredweight, the utmost pressure actually applied to the fish by an eighteen-foot rod barely reaches three pounds, or four pounds with a twentyfoot rod.*

But the memory of defeat tends to ill-humour, so I will wind up this chapter of accidents.

* The 15-ft. harling-rods, though apparently so much stiffer and stronger than fly-rods, will, I find, only pull about $2 \frac{1}{2} \mathrm{lbs}$. 


\section{CHAPTER VII.}

\section{SALMON-FISHING IN SŬRENDAL.}

\section{Big Fish in a Big River.}

The summer of 1892 in Norway proved cold and wet, hardly affording a single warm and balmy day-in marked contrast to our previous season, when all through June and July the heat was tropical, with scarce a drop of rain. Now, we turned out morning after morning only to see mist-wreaths and scud still coursing along the fjelds, fresh snow on their summits. at midsummer, and the river in frequent flood. 'Ninetytwo, nevertheless, marked an epoch: for then, at Gŭla, in beautiful Sŭrendal, I enjoyed my first experience of big fish in a big river.

The Sŭrna that first morning was pronounced to. be too big-the index-stone in Galten being just awash, instead of standing a good foot clear ; and operations, till things had shaken down into shape, were more or less casual and tentative. Moreover, the roll of the North Sea was hardly out of our heads. F. landed a bull-trout kelt of 5 lbs., casting from bank, and in the evening I hooked a fish which caused a flutter of excitement as his silvery sides were seen, lashing out, some forty yards away; but Ivar never treated him with 
any ceremony, presently hauling him ashore by the line-a bright-coloured kelt of 7 lbs.

Next morning (June 7th) was dull and cold, with strong north wind driving fleecy clouds low across the glen. The water was in good ply, and I fished carefully down three long and lovely pools as far as they could

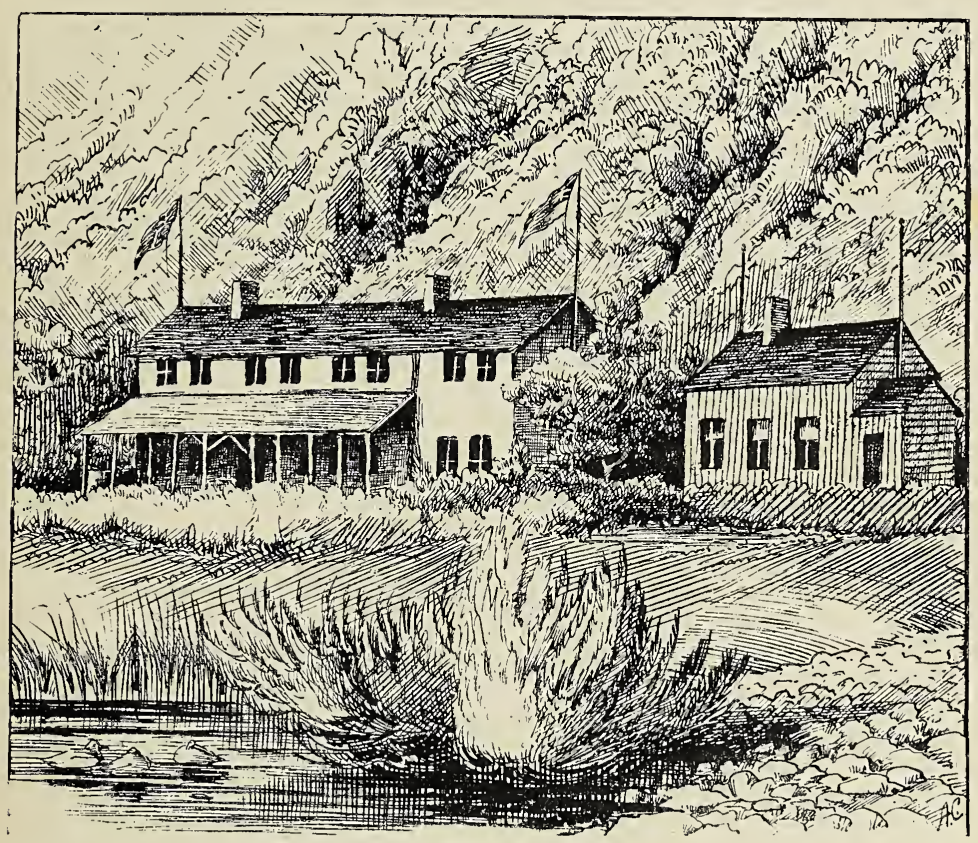

GǔLA.

be commanded from the bank; but no response could be elicited with fly, nor had a second attempt with the phantom any better success.

So intense was the cold, that even at midday we noticed the newly-shorn sheep huddling together under the banks for shelter from the icy blast. Signs of summer were few; swallows and sand-martins, it is 
true, coursed over the river; but the grass and wildflowers had hardly awakened from their winter's sleep, and the foliage even of the hardy birches was scarce fully unfolded. Yet I observed to-day a single orangetip (Cardamines), and found a white wagtail's nest with six eggs already half-incubated, in a rough stone embankment by the riverside; while chattering fieldfares had hatched out some few young in the hazelcoppice where we lunched. Presently Ivar got up, took off his hat, and shook hands, saying, "Tak for" maden," according to the pretty and courteous Norsk custom.

Our next pool was Mogstad, a very long stream formed by the junction of the river at the foot of a big gravel islet. At first sight I had not thought it a very likely resting-place for fish, since, despite its length, only the upper part was deep, the current running very fast and clear, and of uniform depth, except in the strong central stream. But I was wrong, for hardly had I got the four-inch blue phantom set spinning than a fish came at it with a bang that well-nigh jerked the rod out of hand, and hooked himself as firm as two triangles well inside, with another on the cheek, can hold. I felt his weight, and realized that I was fast in a fish the like of which $I$ had not held before. For hitherto my small experience had been in comparatively puny rivers and slow-running streams which afford scant scope to the salmon to develop his powers or to use his speed. In such waters there is but little running -it is merely a case of "hold him hard." But here, in the huge swirling salmon-rivers of Norway, it is a different affair. Often as I had read descriptions, I 
never till now realized the splendid dash, resource, and fighting power of a big fish in a big stream.

With a single impulse the captive ran obliquely across the river, heading for the farther shore, while Ivar pulled hard to the nearer. The reel hummed rather than screamed, and as the boat touched the ground, I noticed that three-fourths of the line had left its barrel. With a foolish idea of checking the rush, I put my left hand over the running line, and simultaneously two fingers were cut-or rather, burned to the quick, and at the same moment we saw the fish fling himself clear of the water close in to the far shore, and nearly a hundred yards away. It was scarcely possible to believe that any effective control could be exercised from such a distance. That jump, however, indicated the end of the first rush, and ere we had landed and run down the bank, a certain amount of the lost line had been regained. Only momentary were the pauses; again and again the hardly-recovered line was lost in an instant in another frantic rush, as the fish continued running down stream, always close under the far bank, and keeping us going at top speed to overhaul him. At the end of a quarter of a mile my arms ached and trembled with the strain; but our adversary also felt the results of his grand effort.

The second stage of the struggle consisted of a series of "lie-ups," each behind the shelter of a sunken boulder in strong water, and lasting about a minute, till a steady down-stream strain put a period to that, and presently a silvery gleam denoted distress-the fish was rolling on his side. So far the nature of the bank had offered. no obstruction; we had had, in fact, a perfectly open 
level meadow all the way down. But now, just below, a belt of thick young birch-scrub grew right down to the water's edge, and I resolved to finish the fight here. The final scene occupied some minutes; but each successive effort of our gallant foe was less vigorous than the last, and each run ended nearer to our shore, till at length, while I walked backwards into the meadow, Ivar crept up from below, and, deftly seizing his opportunity, the gallant salmon was borne ashore on the gaff. Oh, the relief to aching arms to lay down the rod, and for a few minutes to lie resting on the grass and sweet-scented thyme!

Our fish was a clean-run hen-salmon of 22 lbs., with several sea-lice still sticking to her silvery flanks and tail, and measured forty inches in length by twenty in girth. The whole operation, from hooking to gaffing, had only lasted twenty minutes, but the impressions left on the tablets of memory are indelible.

Our host, we found, had also landed a fish of $21 \mathrm{lbs}$.; killed on large Namsen fly, and we sat down to dinner at 10 p.m.

\section{Tight Lines and Hard Lines.}

Sunday in Sŭrendal, by local custom, commences at six o'clock on Saturday evening, when secular pursuits are relinquished for just twenty-four hours.

Our first Sunday-that which fell on the 12th of June-proved to be one of the very few really warm summer days enjoyed during the whole season. The sun shone with semi-tropical heat, and the new-fallen snow on the three thousand feet peak of HaanstadKnyken opposite our windows, contrasted strangely 
with an azure background. New snow, by the way, fell on these heights at intervals up to the beginning of July. In the evening the fjeld was merely streaked and patched; by morning it lay in unbroken white.

The morning was spent in a scramble up the steep, hanging woods of the fjeld, by zigzag cattle-pathseach, to-day, a miniature water-fall-leading upwards through pine to brushwood and, above, to the zone of an alpine flora. Curiously, though by night these woods were vocal with a chorus of infinite redwingsand on dull, wet days they sang at all hours-yet in the bright sunshine to-day not a "Nattergal" was in evidence; though the efforts of cuckoo, willow-wren, northern tit, and woodlark, together with the ubiquitous sound of falling waters, forbade all fear of stillness. Under the first warm sun-rays the woods gleamed with insect-life-brilliant commas and fritillaries of three species, wood-whites, orange-tips, and many morewhile grass-green hairstreaks vied in hue with an emerald flying-beetle.

The rapid advance of summer and the effect of the first few hours of warmth in those higher latitudes are indeed marvellous. Leaf bursts forth on tree and shrub while one watches; on all sides is heard the cracking of the buds on birch and plane-trees, the unfolding of fern-fronds is well-nigh visible. But we are wandering from our subject, and must hurry down to the 4.30 dinner, for the Norsk Sunday will soon be over.

By a few minutes past six we were afloat on the beautiful waters of Galten, though the sun was not yet off the river, and swarming flights of sand-martins filled the air with evening evolutions. This favourite pool, 
twice tried, proved blank; and the next belowNygaard by name - gave no better result. These long pools occupied us near three hours, and as the evening air grew crisp, a great fjeld-eagle slowly flapped across the valley, seeking his quarters for the night among the crags of the Vindöla-dal.

Our last pool lay a mile below-a deep, black, surging torrent, with a terrible, double-barrelled unpronounceable Norwegian name; such, at least, I then thought it, though at the end of a few weeks I had almost mastered this thing, and even make bold to spell it, thus:-Nedre Baksnyden. Suffice it here to say that this great pool, with its strong double current setting in towards a rock-wall, looked big enough and black enough to hold a whale. We commenced to work it with a phantom minnow, while I tried a few casts with a large Namsen fly towards the farther bank. Hardly had we cleared the rapids than there was seen a swirl even on that troubled surface. A short, heavy tug and I was fast. The fish never moving from his original position, I thought (in my ignorance) that he was a small one, and held him with one hand while I reeled in the fly-line and passed the second rod forward. We had, however, hardly got ashore ere the error of this view and the quality of our foe became apparent; for the fish developed a sudden force that was almost alarming, and in a single rush took off nearly half the reel-line (140 yards), betaking himself to the surging torrent beneath the opposite rocks. Here, with alternate short runs and long periods of heavy bottom-pulling- " jagging" at the line whenever he stopped-the fight proceeded for two hundred 
yards down-stream. Then, for the first time, we saw him. He jumped once only, barely clearing the water; but the size and build of that fish astonished me. It was not merely his length (which rarely much exceeds four feet), but that he appeared near half as deep as he was long. And another thing-the spot where he jumped was fully thirty yards above where the line was pointing at the time. Such was the depth of that eerie pool, and such the force and volume of its current, that though the stiff fifteen-foot harling-rod was pretty

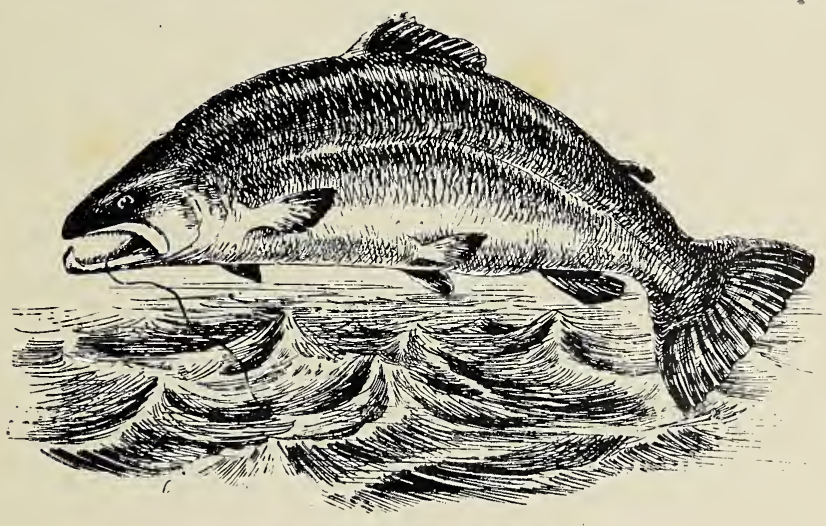

"half as DEep as he was LONG."

well doubled up, yet the line was "bagged" to onethird of a circle. The defence of this fish was rather sullen and strong than dashing. He seemed to husband his strength; hence, at the end of half an hour we had hardly moved fifty yards further, and the end seemed as far off as ever. Then, in the midst of a slow, sullen run (line going off quite gently), with a jerk, the line parted. A long hissing "welt" curved far across the pool. Ivar and I looked at each other in mute, blank despair-he was gone $!$ 
The moon, full to-night, but pale as at midday, looked coldly down on two miserable mortals. There was no sympathy in her orb, nor in the great silent snow-fjelds ; the midnight melody of the redwings and distant laughter of a loon simply mocked us - the chance of a lifetime was gone.*

"That fish will now go back to sea," presently remarked Ivar, "and in fourteen days we'll get him in Galten!" The prophecy was not fulfilled, but it evidenced my gillie's correct knowledge of the habits of salmon, as the following incident shows. In a previous year, another angler, spinning with spoon-bait from a boat, in this same pool, hooked, played and eventually lost a very large fish, whose weight, he confidently asserted, was 40 lbs. It was suggested, since no proof was possible, that the luckless angler might as well put his fish at $60 \mathrm{lbs}$., but he insisted on the correctness of his estimate, which was verified three days later, when the salmon was caught in the fjord nets with the spoon still in his mouth, and found to scale $39 \mathrm{lbs}$. The incident serves to show that salmon, if hard hit when running, do return to the sea; but this only applies to compound lures, since fish hooked and lost on fly have afterwards been killed higher up the rivers with the fly still in their jaws.

On examining the line, the treble gut was found to be broken about one foot above the hooks; and from the worn and frayed state of each of the three strands, the breakage had evidently been caused by contact with

* It will have been observed, from a previous chapter, that the same lifetime has already since afforded two similar chances : alas ! so far, with similar results. 
rock. The farther bank and the river-bed beneath are strewn in Nedre Baksnyden with blocks of rock and boulders, many of which are thrown in by the riparian owners to protect their land from the stream. Hence the catastrophe. I could not, on reflection, reproach myself with any known mistake or want of care; no jerk or jar to my knowledge had occurred. Possibly I had been too severe at first on a fish of such weight and power; but it was decidedly hard lines that I should have had my one chance with such a monster almost as an initial experience with big fish.

We finished the pool in silence-almost mechanically; and returned homewards with heavy hearts, while the peasant lads and lassies of the hamlet were dancing al fresco to the music of a fiddle at midnight.

\section{Summer oN THE SURNa.}

The following further notes, selected from my diary, serve to illustrate the incidents of sport, and of a fisherman's life in a Norwegian valley.

Midsummer day - a misty morning, but dry. Close to foot of Galten pool, I had just remarked to Ivar, "In five yards more he comes!" when come he did, and was firm hooked on spoon. After clearing the lines, put on steam ; fish responded with a rush, when, at about fifty yards, the reel stopped dead-the line having buckledand not another inch would run. The jerk near wrenched the rod out of hand, and the strain of the sudden pull-up was terrible. Gear and hold, however, stood the shock, and we abandoned offensive operations, dropping the rod-top while we tried to clear the line. 


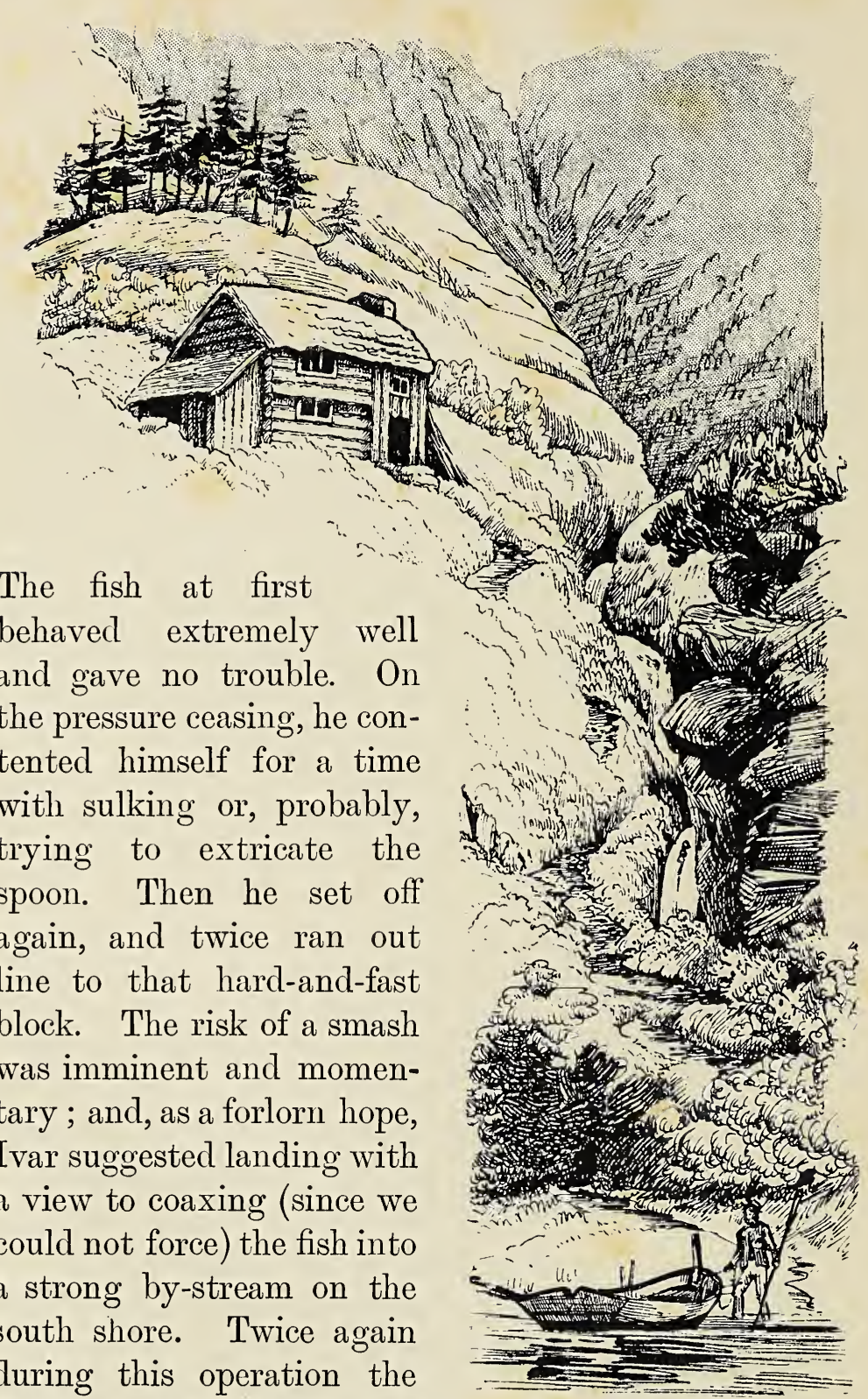
fish ran out his tether, and
THE FERRY ON GALTEN-POOL. 
the rod-top was dropped with the same lucky results, till he presently lay well in the mouth of the backwater, and by his broad tail and dorsal, now showing, we saw he was a big one. Moments of intense suspense followed, while the big fish, though in no sense played out, or even tired, obeying the joint impulse of stream and rod, slowly began to drop, tail-first, down the rapid-he was, in short, completely kidded into a trap,

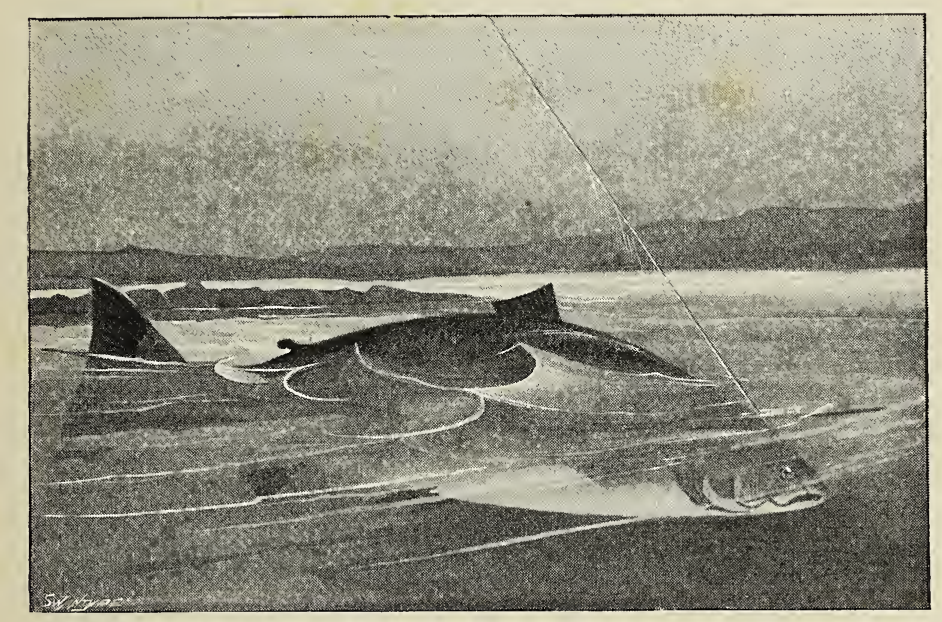

“KIDDED" INTO BY-STREAM, AND KILLED IN EIGHT MINUTES-WEIGHT, 28 LBS.

and a pretty manœuvre it was. Ivar stood knee-deep in mid-stream, and as the salmon backed down, neatly gaffed him in about eight minutes from the start-a bit of luck we had scarce hoped for. This fish weighed $28 \mathrm{lbs}$., and measured 42 inches with a girth of $21 \frac{1}{4}$.

F. to-day killed a fish of the same weight in Körsin ; but the two were of very different types-mine being of the heavy, hog-backed form, while his was a regular 
torpedo, and gave a run of five hundred yards down the rapids and to the foot of Mogstad pool below.

June 27th (Thermo. 56 $6^{\circ}$-An extraordinary day of climatic vicissitudes - snow-squall, sunshine, and shower alternately predominating, while the wind flew round to all points of the compass. Now, for a few minutes, bright and calm, followed by deluges of driving rain and sleet, rainbows in all directions, the hills appearing and disappearing amidst mist and low cloudmasses. The picturesque effects were superb, the mystery of half-seen heights, black rocks contrasting with new-fallen snow and grey cloud, all mixed and viewed above intervening nebular strata; here, through a break in the shroud, a vision of pines, indistinct as trees walking; there a confused maze of smoky vapours with half-hidden peaks, all apparently whirling away into space.

We observed to-day the first sea-trout (or bull-trout), jumping; but they would not be induced to take. Raised two salmon, but hooked neither, and the day ended blank. Next morning a hurricane from west.

June 29th (Thermo. $50^{\circ}$ )-Wind west, day bright. I had the lowest beat, and while launching the boat on Sögge, observed a fish rise. "Orret," said Ivar, meaning a sea-trout of perhaps 4 or 5 lbs., but, not being fastidious, I sent a four-inch blue phantom spinning towards him. We had not pulled ten yards from shore ere the fish took in quite shallow water. Still believing him to be a trout, Ivar lay on his oars, regardless of so insignificant an opponent. But a magnificent run right across, followed by the apparition of a silvery salmon high in air and close-in to the far bank, 
undeceived us. This fish ran in all directions, renewing his strength as an eagle, and it was twenty minutes ere the gaff could be applied to as game a fish as ever swam-weight 17 lbs., clean-run, with sea-lice still adhering.

The breeze dying away, the river fell too bright, and as a lot of logs were coming down, we could only kill time by catching trout in the backwaters and in Ranœs burn (where lively half-pounders lie below the bridge) till evening. At seven o'clock started to fish the five pools down again. In Pel-pool killed a sea-trout (the first of the season), a deep and beautifully-shaped fish

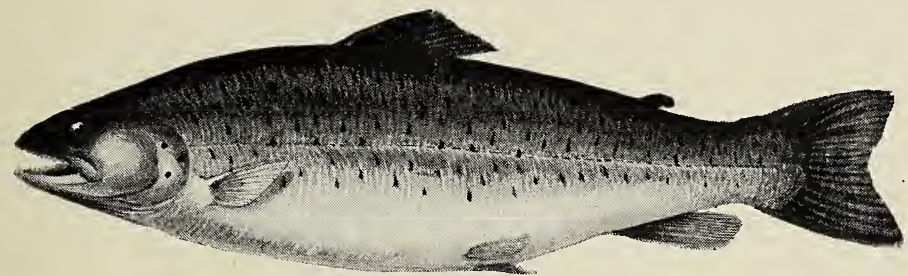

SEA-TROUT (Salmo trutta), SǓRENDAL, JUNE 29TH.

Female; weight $2 \frac{1}{4} \mathrm{lbs}$., length 17 , girth $9 \frac{1}{2}$ inches.

of $2 \frac{1}{4}$ lbs., roughly sketched above, and by 10 p.m. reached the lowest pool, Tellesbö, where I got a sixteenpounder a few days before. This fish, by the way, never ran, but kept incessantly plunging and "boring," his body held vertical, and tail frequently breaking the surface-see p. 81. I killed him from a high bank after "drifting" three hundred yards down-stream.

To-night Tellesbö again yielded us a fish, a deeprunning, sullen fighter which sought the strong water, but in due course had to succumb and fall back-weight, $14 \frac{1}{2} \mathrm{lbs}$. Total for day, three fish, $33 \frac{1}{2} \mathrm{lbs}$. 
Our host also had a sixteen-pounder, and we sat down to dinner at 10.45 p.m.

June 30th.-The river to-day was full of sea-trout, jumping in all directions, apparently at daddy-longlegs ; but they would not look at an ordinary fly, and I had no similitudes of the Tipulidæ in my collection. During the evening I twice moved a salmon, but news having been brought of a bear, I deserted rod for rifle.

July 1st.-Killed to-night in Krang-næs the first bull-trout of the season, a cock-fish of $5 \frac{3}{4}$ lbs., 24 inches

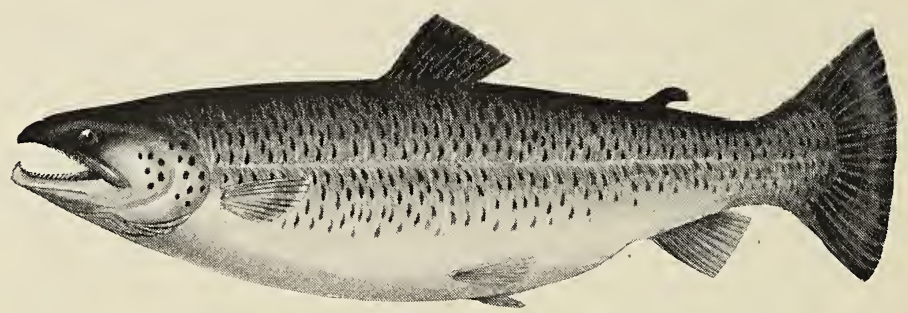

BULL-Trout (Salmo eriox), SǓRENDAL, JULY 1 st.

Male; weight $5 \frac{3}{4}$ lbs., length 24 , girth $12 \frac{3}{4}$ inches.

by $12 \frac{3}{4}$ inches girth (see sketch above), and a sea-trout of 2 lbs., $16_{2}^{1}$ inches.

July 5th.-An unlucky day. Commenced well with a 14-lb. fish in Körsin, and at the top of Mogstad pool hooked a second-apparently about 8 lbs. - but, when nearly ready to gaff, the spoon landed on the grass at my feet. Lower down the pool, killed a bull-trout of $4 \mathrm{lbs}$. and a big brown trout, missing another. Back to Körsin later, where I raised a fish in the identical spot as in morning. Struck quickly, and on feeling the hook, the fish shot right up to boat, slacking the line. I saw the silvery gleam as he turned, not three yards 
SALMON-FISHING IN SŬRENDAL.

away-but he went off free! I believe both these two lost fish were foul-hooked on short rises.

Our host had a 14-lb. fish, besides two bull-trout, and F. a salmon of $16 \mathrm{lbs}$.

July 8th.- Sailed from Christiansund in the Domino, Wilson liner, for Hull. 


\section{CHAPTER VIII.}

\section{SUMMER RAMBLES ON THE SǓRENDAL FJELDS*}

\section{Langora-FJeld and ANders-vand.}

THE business of life on a Norwegian salmon-river of course centres on the salmon, all other objects becoming subservient to the capture of that noble fish, which the nightly rises of the river (caused, in well-regulated seasons, by the daily melting of the snow on the fjelds) bring up from the sea and tidal waters of the fjords. But there is always the weekly close-time. Sunday in Sŭrendal begins at 6 p.m. on Saturday: and, in such seasons as that of 1892 , there are floods that suspend fishing-operations for days, and give opportunity for rambles on the fjelds and exploration further afield. We had, moreover, no very austere taskmaster; indeed,

* Surrendal is taken as typical, in regard to bird-life, of the lowerlying fjelds-say, under 2000 feet elevation. The nesting birds of the high snow-fjeld, 3000 feet and upwards, are extremely circumscribed in variety. There are the ptarmigan, titlarks, and wheatears ; a chance pair of plovers or sea-gulls. The dipper breeds on the burns at 4500 feet, and once we found a ring-ouzel on the 3000 foot linethe nest on quite open ground against a stone. The raven roams ubiquitous, and there is the snowy owl and other birds of prey; but one rarely sees a snow-bunting, and never a "rare" sandpiper or any of those northern forms one expects and keenly seeks. Hence I have omitted a chapter I had written on the summer-birds of the high fjeld. But see plate, "On Summer-Snows," opposite. 


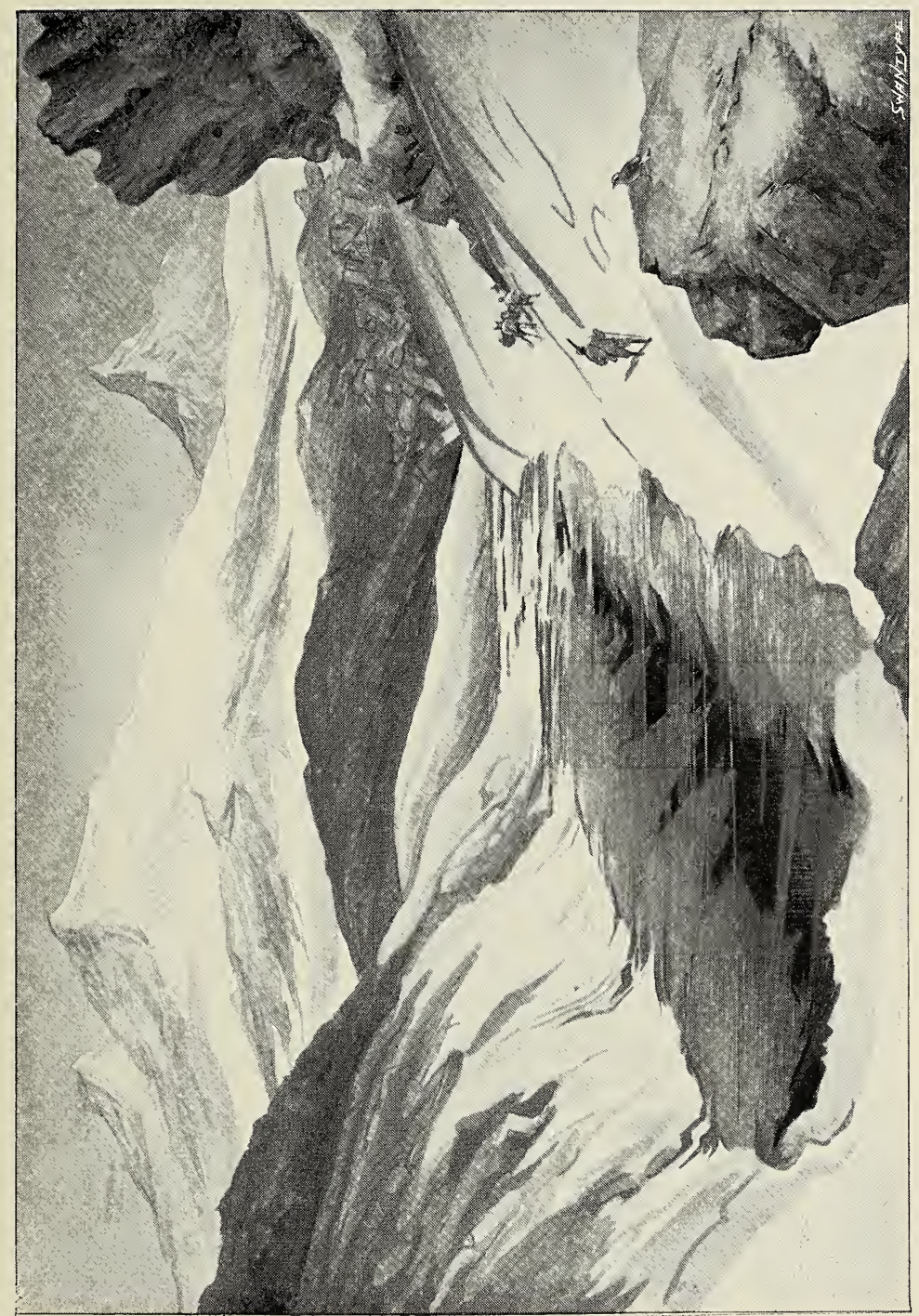

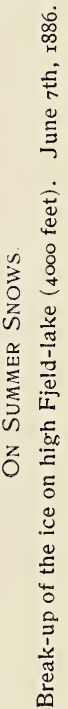



our host was one of the best-natured of men, who overlooked my occasional truancies on the fjeld, though I sometimes suspected that his kindly heart bled when the exigencies of "science" converted either birds or their eggs into specimens.

Immediately behind the house rose the wall-like slope of the Langora-Fjeld, a wild expanse of moor stretching over a vast area of broken fell-land of no great elevation, the mean level of the plateau hardly exceeding twelve hundred feet. On the early morning of June 19th, Ivar and I set out to visit a lonely lake that lies some twelve miles away upon this fjeld. Climbing out through the steep hanging woods of birch and pine, we fell in with an adder (a common reptile about the crags and in gnarled old trees), whereupon Ivar observed, "We shall have rain," and a smart thunderstorm followed soon after; though whether the reptile brought the rain, or the converse, is an open question.

Beyond Nyegaard Sæter, where a vociferous pair of whimbrels were nesting, we reached the fjeld proper -rough moor, heath-clad, and "horrid" with the stiff scrub of creeping birch. It was singular to see quite large trees trained flat on the ground by winter's snows, and merely raising their latest shoots heavenwards in a half-apologetic sort of way. Then came stretches of dry, hummocky moss, alternating with marsh and bog, where black, miry waters oozed out from under patches of snow, and where, in sheltered nooks, a few stunted pines found root-hold, and bramblings sang. Moss and moor were diversified by sterile, stony regions where great grey rocks protruded, and the snow lay in broad 
sweeps. Here we chanced on a wheatear's nest, which already contained callow young, though literally islanded amidst snowfields. At the highest point passed (two thousand feet), willow-wrens were singing, and the few other birds seen included ryper, golden plovers, and a distant-soaring buzzard.

Anders-vand is a lake of about two miles in length, lying in a fold of the fell, and almost entirely surrounded by forest, chiefly birch and alder, with a few pines. Its surface is studded with rocky islets, mostly scrub-clad, and some wooded. From a distance, imagination pictured country houses on its lonely shores, with green lawns sloping down to the water's edge; but the lawns were only boggy clearings, verdant with rank vegetation, the "halls" log-huts used in summer for storing hay. No one lives on the fjelds, nor had human foot trodden the shores of Anders-vand since the latestlingering peasant latched the door of his sæter in September. The last half-mile of our route was over snow marked by a track that, Ivar asserted, was that of a bear prowling along the side of a noisy little torrent that led to the lake. The boat, relieved from her winter covering of pine-branches, proved desperately leaky; but, with Norwegian resource, Ivar produced from his capacious pockets store of tarred felt and oakum, with which we caulked the faulty seams. During this operation I watched a gull-one of three or four that were drifting about-settle down on a rocky islet, whereon we presently (having got the boat made fairly tight) found its nest with three eggs, half incubated. I shot the owner, which proved to be Larus canus, the only species of gull we found breeding on these fells, and of 
which we subsequently found several other single nests, each on separate islets, both on this lake and others. The only other birds in sight were a pair of goldeneyes (very wild), a single goosander drake, and a big diver, which rose heavily and with as much splash and noise as a wild swan, from a long bight beyond the group of islands.

Finding nothing here, we commenced to "troll" towards the other end of the lake, and almost immediately secured half a dozen trout of about $\frac{3}{4} \mathrm{lb}$. each, in colour the deepest indigo and gold, and, for loch fish, remarkably game. The sun coming out very bright, trolling was useless, and, an hour's fly-fishing proving hardly more profitable, I was just giving it up when two trout seized the two large lake-flies, and were duly pitched on board in the bailing scoop (weight, $2 \frac{1}{4} \mathrm{lbs}$.), Ivar hardly deigning to interest himself, much less to assist, with such puny game. June is, however, too early for trouting in the fell lakes, which remain icebound till the beginning of that month; in July, the fishing-book has a record of forty-three fish, weighing $37 \mathrm{lbs}$. It is noteworthy that in this lake (and in some others), while the best trout are caught close in-shore, none can be killed from the bank-only from a boat.

While fishing along the north shore, we noticed a white wagtail executing singular aërial gyrations, apparently catching flies on the wing, then darting off behind a moss-clad cairn. On examining this, we found his mate (whom he had evidently been feeding) sitting a hard on six eggs in a crevice among the stones. We landed here for lunch, adding broiled trout (rolled in leaves or wet paper, and cooked in the embers) to the 
luxuries brought in the knapsacks. The rough wooded slope swarmed with fieldfares, whose conspicuous nests studded the birches. These birds continue nesting over a very long period. In the Sogne-Fjord I found eggs just "chipping" in May, and both there and in Telemark young were hatched out early in June (on the 3rd); yet in Lapland, as late as July 23rd (though some young birds were already on the wing), I had no trouble in finding several fresh clutches of eggs. We also found here (June 19th) two nests of redwing, both

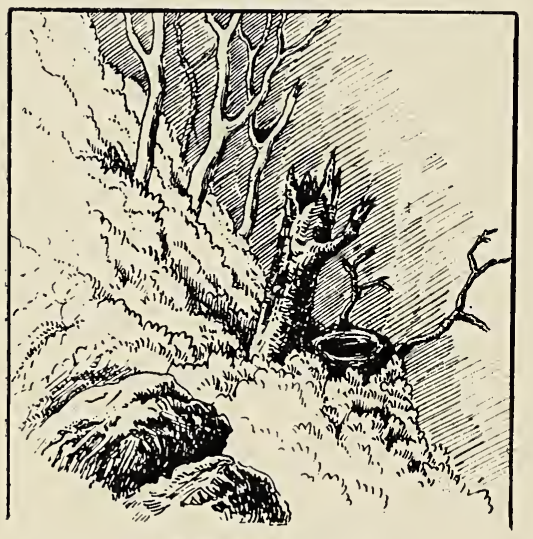

REDWING'S NEST. built among the moss at the foot of gnarled birch stumps, and each containing six eggs; also two nests of willow-wren and one of redpole. A sad episode occurred while we sat smoking our pipes. One of our friendly little wagtails was tripping along the shore, not fifteen yards away, when, from behind, a merlin swept down and carried him off before we could interfere.

Going afloat again, we observed two of the big divers; but, though they sat quite embayed, and I was anxious to secure one, they beat us easily, disappearing without a ripple and not reappearing till quite a quarter of a mile outside the boat; while at straight-ahead swimming we soon found they could give us fifty yards in a hundred. The pursuit took 
us close to a rocky islet, whereon we now landed, and, after twice walking round it among rough heather and scrub, I almost stepped upon a nesting sandpiper, which, with much outcry and solicitude, rose from her four eggs at my feet. For five or six yards she fluttered away; but, long before a shot could well be taken, dived from sight among the birch boughs and junipers, and when next seen was skimming on jerky pinions towards an adjacent island. Thither we followed, but she rose wild, and, with the same undulating flight, flew across the lake and beyond our view. This bird - visibly larger than a dunlin, which she otherwise resembled-was of a bright chestnut colour, each feather centred with black, showed a white bar across the wings, white below, and white feathers very conspicuous on either side of the tail. From the moment she rose under the gun-barrels I knew she was a Sanderling, though I do not ask other ornithologists to share that confidence. The four eggs lay in a mossy cup surrounded by moss, and overhung by heather, a few dead bleaberry leaves in the nest. We decided to leave the eggs for a few hours, to allow the old bird to resettle, and went meanwhile to explore other islets, especially in search of the big diver's nest. We soon found onea circular mound of moss, slightly raised, and with a distinct path to the water, ten feet distant. There were traces of moss having recently been gathered just above the nest; but it was empty.

The next islet had a raised central ridge, along which I walked, to command either shore. Presently, on coming to a break in the ridge, I had the intense pleasure of observing a black-throated diver squatting 
flat on her nest on the low, mossy foreshore. She lay within five yards-indeed, almost directly beneath me. Hardly had I seen her than she was in motion, her great splay feet sending the two eggs spinning backwards among the heather as she got on the wing. The nest was almost on the water's edge, which shoaled out far, and the Paradox gun cut the diver down very clean, with, luckily, only three pellets between eye and beak. This was a splendid bird, $8 \frac{1}{2} \mathrm{lbs}$. in weight, in full nuptial dress, and I admired the lovely velvet-like

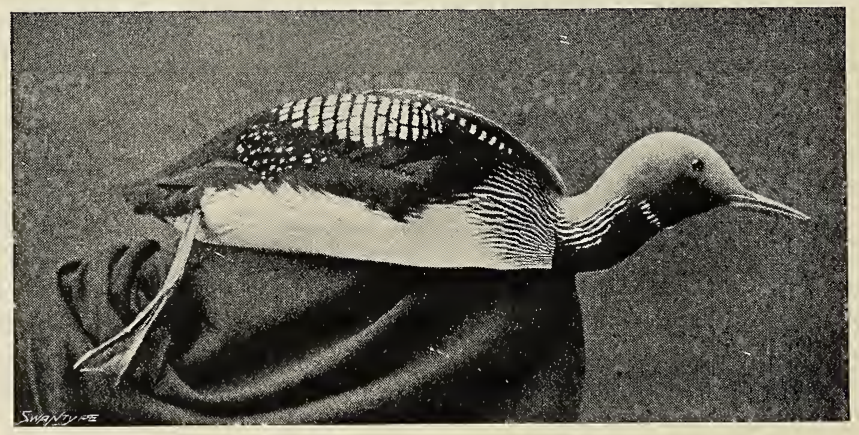

BLACK-THROATED DIVER.

(Full summer-plumage.)

sheen and bold contrasts of her plumage-especially noticeable being the peculiar pale French grey (with a tinge of mauve) of the crown and occiput, the violetpurple iridescence of the throat, and the bas-relief bars of black and white on the sides of the neck. For the benefit of those who persist in "mounting" the Colymbi bolt upright, I may add that the feet, while fresh, would not bend forward beyond the line of the legs, nor, indeed, quite so far. The nest, a mere circle of moss, twenty-one inches across, with a few dead leaves 
and some sticks (the latter probably accidental), was situate in a little mossy cove, close to the thickly growing junipers and trailing scrub, and all but overhung by the gnarled boughs of silver-birch which dipped in the water beyond. The two eggs were quite fresh.

Two larger islands proved blank; at least, they contained nothing more of interest than three grey

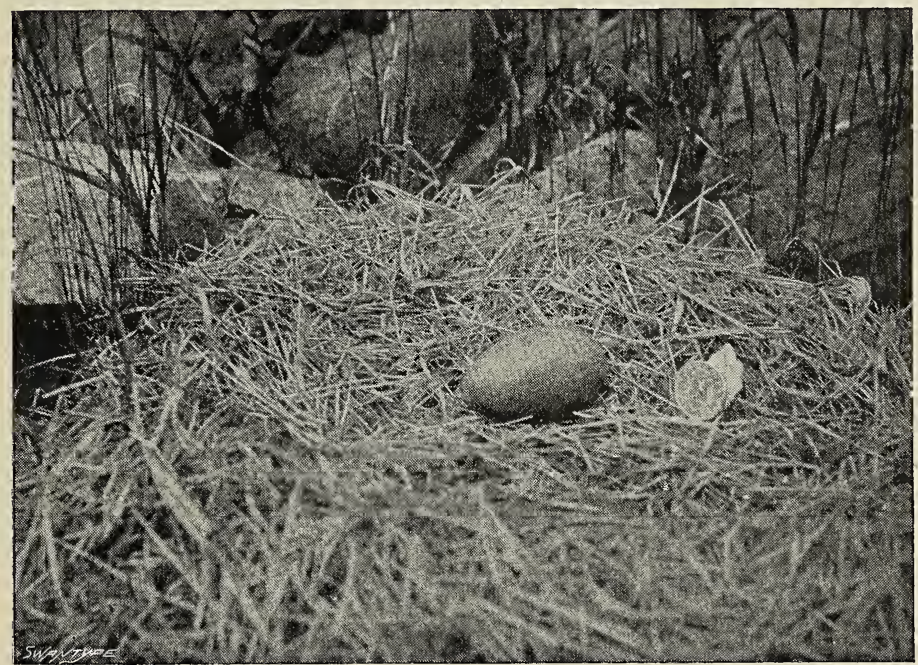

NEST OF BLACK-THROATED DIVER.

(A two-kroner piece near the egg shows relative size.)

crows' nests on pines : one of them occupied by a pair of merlins, the others by squalling broods of their original architects. Beneath the last I picked up fragments of egg-shells belonging to willow-grouse, grey hen, ducks of sorts, and one of a sandpiper-as far as I could judge, Totanus glareola. A curious incident occurred at another islet, a flat, grassy holm, with a few stunted 
pines. We had searched it carcfully to-day, and found nothing but one gull's nest; yet, a fortnight later, when we landed on this islet to tow ashore on its gravelly beach a fine "double" of lake-trout, a black-throated diver rose, with much flapping and scuffling, from her nest in the very centre. The nest then contained two eggs in the act of "chipping," and how it had escaped our eyes on the former occasion passes understanding. This diver performed a singular feat; after flying thirty yards she suddenly collapsed (though I had not fired), and fell heavily on the water, to all appearance wing-broken. There for several seconds she lay flapping helplessly on her side, and swimming round, as though paralyzed, in narrow circles. I did not molest her, and half an hour afterwards saw the pair flying fast and strong, a hundred yards high. Three weeks later (at the end of July) these birds had their young out on the water, and, curiously, were accompanied by the survivor of the other pair, whom they had apparently allowed to join them and assist in bringing up the family.

We now returned to the "Sanderling's islet," accompanied all the way by a gull-probably the bereaved one-which persistently swept past our heads with loud outcries. I was truly sorry for the poor widower. Alas! the sanderling's nest was unoccupied, though the eggs were warm. Probably the bird had just slipped off, alarmed by our noisy gull. I now laid in wait, in a position commanding the nest, till past midnight without seeing a sign of its owner. A single island remained unexplored, and to this (in order to give the sanderling one more chance) we now pulled away. It 
was a high rock-ridge, covered with juniper and birchscrub, from which presently a large duck sprang noisily, almost at Ivar's feet. In the dim, uncertain light of the northern midnight I could not be sure what she was -in colour, blue as a wood-pigeon, and with similar white wing-bars-so dropped her, a female goosander. The nest, which contained seven eggs, nearly fresh, was. completely "roofed in" beneath strong horizontal enebranches: it was formed of dead leaves of bilberry (Vaccinium myrtillus), lined with dusky-grey down, and had an ancient and fish-like smell. A yard to one side lay the broken egg-shells of a previous year, showing that these birds return again and again to the same nesting-site. A third time we now returned to the sanderling's nest, again to be disappointed. We were, therefore, obliged to take the eggs, for our time was about expired, and we still had a twelve-mile tramp before us.

These four eggs, which resemble those of the common sandpiper more than any other, I afterwards submitted to Mr. Howard Saunders, who reported that they did not correspond with the accepted type of the eggs of Calidris arenaria, a species which, moreover, in the few instances in which it has been discovered breeding, has been found in the immediate neighbourhood of the sea or salt water.* There remains, however, prominent in my mind the fact that a Sanderling rose from those eggs at my feet. There is no other Tringa known to me of that size and colour for which

* These eggs nevertheless fairly correspond with the plate of sanderling's egg, given in Seebohm's beautiful work, "The Eggs of British Birds"(1896), p. 176. 
it could well be mistaken; still, I ask no one to accept my sanderling as gospel, for, should my identification be correct, there would be no great difficulty in establishing the fact by solid proof in another year. Where one sanderling breeds, many more probably do the same. On the other hand, should this have been an isolated or exceptional case, little or no value attaches to it.*

When one comes to realize the truly boundless area of wild upland plateaux in Norway, with their unnumbered lakes, studded with islets which are never visited, and surrounded by moory wastes absolutely untrodden by human foot, much less by naturalistssave for a few weeks in summer, when the peasants drive up their cattle and secure a scant crop of hayone wonders if, after all, these vast wastes may not yet prove to be one home of those missing birds, such as the sanderling, whose breeding quarters in Europe still remain undiscovered. I am not forgetting the splendid ornithological work done by Professor Collett and others; but the region is too wide for any one man, or for fifty, however energetic. On many a remote felllake no boat has ever floated; and consider the labour of dragging one, first some thousands of feet above "civilization," then across miles of the most rugged ground, ere even a single loch can properly be investigated. At the same time, I imagine that it is those fjelds of under, rather than over, two thousand feet elevation, and especially those of marshy, moor-like character, that would best repay exploration.

* The following year my friend B. F. B. examined the whole of the islets in this lake at the same date; but no sign of a sandpiper of any species was seen. 
It was 1 a.m. when we landed, the clouds in the north already beginning to regain some of the rosy tints they had only lost two hours before. Yet the willow-wrens, redwing, and cuckoo were all singing, and the weird laughter of the big divers resounded across the loch. We observed a dipper feeding its young at the inflow of a small torrent hard by where we beached our boat. Blackcocks had been "crooning" at 11 p.m., and by two o'clock the willow-grouse began to cackle.

We had a four hours' tramp homewards, and, looking back from the highest ridge, enjoyed a lovely alpine scene. Far away to north and west the serrated snowpeaks of the Dovre-fjeld towered high above intervening strata of woolly white clouds, which hid our loch and all the middle' distance, while the foreground was superlatively wild and chaotic.

When halfway home, I proposed a rest, and Ivar, looking widely around over a prospect of some hundreds of miles of open fell and snowfield, blandly remarked, "Ja, ja, very plenty place." The contrast seemed absurd, but Ivar's English was often amusing, and the words "very plenty" comprised a large portion of his vocabulary. The opposite meanings of the Norsk "noget" and our "nothing" probably explain the exuberant glee with which, on a lovely fishing morning, my fidus Achates would invariably remark, "To-day I hope we may get nothing!"

At three o'clock a common brown hare was feeding in the dewy pastures that overlooked our valley, and a couple of hours later we were back on the river haughs, where hundreds of fieldfares fed noisily in the 
meadows, after a delightful twenty hours' ramble amid the glorious fjeld scenery of Norway.

The penultimate week of June was one of almost incessant rain, which brought the river down in opaque, blue-grey flood, seriously interfering with salmon-fishing, while it absolutely forbade all thought of al fresco existence on the fjelds. On Saturday, June 25th, the downpour easing off a little at midday, we set out for a small tarn named Bruxta-vand, which lay some six or seven miles among the hills. The writer must admit to an intense love of whatever is primeval-for things as created, whether animate or inanimate-and rarely can such conditions be found more accentuated than among the fell lakes of Norway with their wild surroundings and their unsophisticated trout. It is in their very innocence that lies the charm of these latter. I love to watch them-two or three of them-curiously following one's fly on its homeward course, the boldest presently coming at the lure with a sudden dash as it leaves the water (one can actually hear his jaws snap); or to see a bigger fellow ascend vertically from the depths to inspect that strange insect that has alighted above his "holt." A ghostly apparition he seems at first, resolving itself into a golden gleam in the dark moss-water as he nears the surface. Each fell-lake has some peculiarity of its own-some formation of bank or bed that differentiates it, as a haunt of bird or fish, from its fellows, and adds new interest to its exploration. Each one in reach deserves the trouble of a visit.

The present tarn was untenanted by water-birds, save some noisy greenshanks, a single golden-eye drake 
(his mate doubtless nesting somewhere hard by), and a pair of red-throated divers, which went away very wild and had no appearance of breeding. The nearer bank of the loch was steep and craggy, in places shaggy with rough scrub and hanging birch-woods, alternating with naked screes which descended abruptly into deep water-an awkward place to traverse with a rod. The other shore was squashy bog, very shallow at the edge, but deepening all at once a few yards out, as was ascertained on commencing to fish. No sooner was a lake-fly of approved size and pattern placed beyond the shallows than it was seized by a trout, which ascended vertically from behind this submerged bank, whose shelter he had left for ever. In a short time I had extracted forty-two, which filled my basket. It was curious that, though only small (just three to the pound) these fastidious fish refused to look at ordinary trout-flies, and insisted on having full-sized sea-trout flies, and these, too, of strictly modest and unassuming hues.

All round this lonely tarn there resounded the spring-note of the whimbrel-a note which at first rather resembles that of the curlew, but modulates into a delicious liquid ripple, an intonation of, though quite distinct from, the bird's autumnal note. On our evening walk homeward we spent some time searching for a nest of these birds, a pair of which were breeding on a stretch of very wet, miry moorland, studded with dry moss-hummocks. The solicitude of the old birds was extraordinary; they hovered and screamed within five yards, and frequently pitched down upon the heather within reach of the rod. At other times they 
perched upon big rocks, or on the topmost branches of the birches. Guided by their anxiety, my eyes presently rested on the nest: a mere circular hollow containing a young bird (newly hatched) and two eggs, the latter "chipping." The youngster was prettily mottled with grey and black, shaded fawn-colour, with dark eyes, short, dusky bill, and blue legs. While examining the nest, which was surrounded by mire and moss-pools, Ivar signalled, and on looking round I observed a fox squatted on his haunches like a dog, on a big rock some seventy yards behind me. Before a ball-cartridge could be slipped in, he whipped round and disappeared, the last I saw being the swirl of a bushy brush. On the fell-edge we chanced on a redshank's nest, coming suddenly over a ridge upon the sitting bird; and (about ten o'clock) among the topmost belts of scattered pines woodcocks were flighting hither and thither with a curious chic-chic sort of cry.

A small loch, about four miles further east, yielded larger trout, and others each had some specific characters of their own; but in none of them hereabouts did we succeed in killing char, which are so abundant further north.

\section{Bird-Life by the Riverside.}

On the evening of June 22nd, after finishing my water, having killed one sixteen-pounder, which came up with splendid dash just as I had reached the foot of the lowest pool for the third and last time, I spent an hour or two seeking for the nest of a pair of mergansers that always frequented a certain spot. In a long strip of 
thick bushes and low trees which there borders the riverside, we found two nests full of eggs placed snugly beneath thick horizontal ene-branches, embedded amidst scrub of hazel and osiers, ferns and long grass. These nests were made of dead leaves, slightly lined with down. In this small patch of cover we also found a nest of pied flycatcher, built in a crevice of a broken stump, with seven eggs, almost hatching. We had daily observed these birds on the opposite shore, and they appeared to be the only pair in our part of the valley. There were also two nests of the gardenwarbler, one incomplete; while from the other I took by hand the old bird, so closely was she brooding her six eggs. In a low thicket was a redstart's nest (seven eggs); and we also found two of willow-wren, each with about eight eggs; and, on the mossy shingle hard by, one of a sandpiper, with four eggs. We also found here two nests of white wagtail ; and a few days afterwards one of the yellow wagtail, by the side of a marshy backwater, all golden with king-cups, and into which I was just " towing" a beaten salmon; making no fewer than seven interesting species breeding within a space of a hundred yards.

Later in the season it was a pretty sight to watch these mergansers with their broods about some quiet backwater or stream-foot, or to see the old female "shooting the rapids" with half a dozen downy youngsters squatting on her back. The latter seem to require no instruction in the arts of swimming and diving; they acquire both intuitively before they get their feathers-indeed, from the moment they reach the water. 


\section{A Bear Incident.}

On the last evening of June, we were sitting in the verandah, smoking a pipe, and waiting till the sun should have "got off the water," when, about six o'clock, a letter was brought in from a farmer some three miles further up the valley, saying that a bear had "killed a sheep from him" the night before, and asking if one of the Englishmen would come and shoot it. The bear, he said, had only devoured one-third of the carcase, adding that he (Sverka) had left the remains untouched, and that Bruin would be sure to return about midnight to his "kill." All other stock had been removed from the fell; and if the Englishman would be at his house at nine o'clock, he would be ready to take him to the spot, which was four miles distant therefrom.

The Paradox, with half a dozen ball-cartridges and other small necessaries, being made ready, at seven we went to fish for one hour, being on the home-beat, and having twice that day raised a heavy salmon close by. But eight o'clock arrived with the stor lax still free, and, though I somehow felt that, given time, I should be able eventually to coax him into a taking mood, we had larger game in view, and half reluctantly abandoned rod for rifle.

Sverka was ready waiting when the cariole pulled up, and we at once set out for the climb on to the fjeld; not a difficult path, for in half an hour we were seven hundred feet up; the remaining six hundred feet were soon accomplished, and a walk of three miles across the fjeld brought us to the place. The dead sheep lay in an open grassy glade, completely decapitated and neatly 
eaten away down to the shoulder, the ribs exposed and each bone carefully picked. The carcase lay within sixty yards of a wooden hay-shed, in which I found ensconced three Norsk gunners. The right to the bear having been assigned to me by Sverka (in whom it vested as the owner of the killed sheep), the natives at once gave me precedence, though they remained in the shed "in case I should miss." I afterwards heard that my "supports" were the laughing-stock of the district. A short time previous, a bear having killed a cow on a neighbouring fell, the redoubtable trio waited up for his return. On the third night he came and finished the cow before their eyes, they asserting that as "he was as big as a horse" it was not prudent to fire.

These men having, as their habit is, converted the hay-shed into a spit-

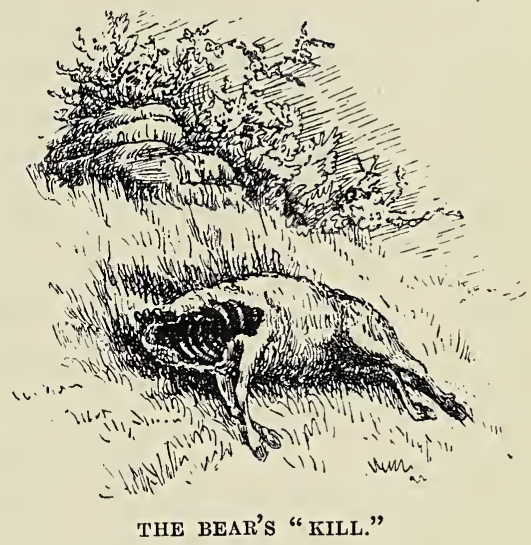
toon, and, neither caring for such close proximity nor for shooting through the chinks of rotten timbers, I decided to form an ambush outside; and, after a survey of the situation, made a screen of cut bushes by some rocks that commanded the kill to windward, at about thirty-five yards' distance. 'The bear, by the way, had pounced on his victim from the cover of some hazel-bushes about forty yards higher up the hill, and the marks of the struggle, and the track along which he had dragged his prey down the boggy grass-slope, were very distinct. 
It was a somewhat grim sensation, sitting over that grisly carcase in the dim mysterious twilight of the northern night. The sense of solitude was rather heightened than otherwise by the occasional note of a cuckoo, and by the "scree" of an unknown bird, possibly a brambling, though the note sounded too harsh. About eleven o'clock I heard a startling growl behind me, and high overhead an eagle-owl swept past with superb dash and speed. At short intervals he passed and repassed, always coming from behind, and evidently hunting a very wide circle of moorland. Never a pinion moved as he clove his way through the upper air, one hundred yards high, uttering now and again that strange growling bark, which I could still hear when he had passed far from sight. My previous acquaintance with this fine bird (in the south of Spain) had always been in daylight, when, though imposing enough in sweep of wing, he is seen at disadvantage, and never impressed me with his magnificent power of flight as on this wild northern fjeld. A smaller owl-perhaps the hawk-owl, but possibly only the short-eared-was also" hunting low around the nearer scrub: mere "pottering" work as compared with the lofty aërial sweep of his: larger relation; and woodcocks flighted to and fro among the pines, dropping down towards a marshy flat below.

The light breeze had died away to nothing, when, only a few minutes before midnight, I heard from among the belt of birch-saplings just beyond the carcase. a different sound, that set my heart off at inexcusable speed, despite every effort to control it. The sound was. a double grunt or "sniff," low, but quite distinct. Was. 
it the bear? Again the double grunt was repeated-louder; and I thought I could also detect the faint rustling among the birch-branches. No doubt it was Bruin sniffing the breeze, and perhaps scenting danger ; for though I momentarily expected his appearance, he never showed, and, after a brief period of suspense and expectancy, it was clear that he had gone, though not a sound had reached my ears since those twice-repeated grunts. Had but the breeze held fair, in all probability the bear would have presented a point-blank shot at thirty-five yards in the open; but, alas! no air moved, not a leaf was now stirring, and perhaps that second sniff had betokened his "winding" us, and assuring himself of an already-suspected danger. The light airs had betrayed us - at any rate, we neither saw nor heard anything more that night.

At four o'clock, the sun being then high, and melting the rime and hoar frost that at midnight had incrusted the grass and bushes, we arose, stiff and benumbed, and departed. The next night another gun performed the vigil, but neither on that nor on the third evening did the bear return. On that third morning, having arranged to spend the next two days on the fjeld, Ivar and I left the spot about six, and proceeded upwards from the scene of these nocturnal watches, following at first (merely for amusement) the broad slots left by the bear on the soft ground. These we soon lost in the midst of strong thicket; but about a mile or two beyond, Ivar, who was faithfully hunting for nests of the northern tit and wood-lark, chanced on the spot which had recently formed our bear's bedroom. On the outermost spur of a projecting bluff, or buttress, 
on the steep fjeldside, was formed the neatest circular lair, from which all brushwood had been forced back, and with a soft carpet of heather, all besprinkled with brown and grizzly hairs. There was also evidence that our friend had dined the night before on mutton-wool and all. This was, no doubt, the lair he had selected four nights previously, after killing the sheep; and it was admirably chosen, commanding an uninterrupted look-out in every direction, far and near, and (though Bruin had probably not considered that point) a superb view across the main valley, with the beautiful winding river far below, and the panorama of fantastic snowpeaks beyond.

\section{Krok-viand and Solaas-vand.}

The early morning of July 2nd found us (as narrated above) close to the bear's kill, and, in fact, in his abandoned bedroom. It was our intention to spend the next thirty-six hours in an expedition to two larger lakes, which lay at a somewhat indefinite distance across the rolling Langora-fjelds, called Krok and Solaasvands. The morning was very wet, and for miles after reaching the summit of the fjeld our course lay across an open expanse of springy moss-thousands of hummocks of green, grey, and yellow reindeer-mosses, varied by patches of heather, bilberry, and trailing birch. The latter, now bursting into leaf, produced a curious effect, the stratum of foliage being quite a foot from the ground beneath, with a void between. The only signs of life were an odd pair of whimbrels at intervals of a mile or two, a few golden plover (found a 
hatched-out nest of these), an occasional ryper-cock, and numerous dead lemmings. These little beasts (we saw none alive, though many half-sunk tunnels in the snow I took to be theirs). had evidently been lying dead and frozen beneath the snow since the previous autumn.

Crossing a high snow-clad ridge, we diverged to examine a nameless loch of some twenty acres that lay a mile or so to the right. There were several mallards, golden-eyes, and other ducks on this water, three of which, going off very wild, I could not identify. They pitched, however, on a smaller lake adjacent, and connected by a narrow channel; lying concealed here among the junipers, and sending Ivar round to drive, I had them, two ducks and a drake; overhead, and selected the latter. Unluckily, it proved to be only an adult goosander in eclipse, and the shot turned two pairs of other ducks of whose identity I could not be sure, though they were perhaps only scaups. These latter ducks were apparently not breeding, nor were a noisy pack of quite twenty redshanks, which kept flying round the loch. Another small bird here quite puzzled me; it was black and white, apparently of the wagtail type, but larger and heavier, with long tail, the outer feathers white. I followed it some distance through very rough, rocky ground, under a deluge of rain, but failed to secure it. The whole south shore of this lake was occupied by a huge snow-slope, perhaps two hundred feet high, only broken by a few big rocks. Along the water's edge were new tracks of an animalperhaps an otter, though it carefully avoided the water. I followed these till they led into some crags, where a couple of terriers would have been required to further 
our acquaintance. From some half-understood remarks of Ivar's, I thought the unknown beast might possibly be a wolverine.

From here we had a very long walk over the wildest fjeld ground studded with lakelets, where broods of mallards dipped and dived, and trout dimpled the surface, in the assumed direction of Krok-vand; but midday was past ere the sight of its glistening waters, embedded amongst pine and birch forest, gladdened our eyes, after a nine hours' walk. This is a lake of eight or ten miles in extent, with a shore-line about as irregular as that of Norway itself. So infinite are the ramifications of long headlands and peninsulas, with alternating bays and bights, that a straight mile along shore would probably be ten or fifteen following the sinuosities of the land. On our approach, a small grey goose rose from a patch of osier-scrub at the water's edge, and pitched, croaking, about a hundred yards out. Feeling sure she had risen from her nest, we left the place to give her time to re-settle, and had lunch in heavy rain under some pines, near to which a pair of wood-sandpipers evidently had their nest, for one of them kept flying round in great anxiety, perching on the topmost boughs and uttering its metallic "Chìrkop, chìrkop, chib, chib." I was not, however, to be beguiled into searching for this impossible nest, and presently returned to the lake. On "glassing" the water from a ridge which commanded the supposed nest, I saw the goose still afloat, but within shot of a wooded promontory, where a stalk was easy. While traversing this, I crept almost on to an old blackcock, which went off with much scuffle and 
wing-clatter, and on reaching my marks found that the goose (alarmed, no doubt) had swum out. She sat very high in water about a hundred yards away, and a lucky shot with ball appeared almost to lift her off the surface. And now we found ourselves face to face with a double disappointment. First, there was no nest of any kind in that patch of scrub, so that the poor goose had been needlessly sacrificed, which is quite against my practice; secondly, I found that my faithful guide, who had never before failed me, knew no more of the local geography of Krok-vand, nor of the position of a reputed boat thereon, than I did myself. The lake being miles in extent, to attempt a search for a hidden boat, without the least clue to its situation, amidst those labyrinths of deep-wooded bays and long peninsulas, was clearly useless. Hence, to my intense regret, the poor goose (which was of about the size of Anser albifrons) drifted uselessly on to the shore of a pine-clad islet.

This want of a boat was, of course, fatal to our plans, for it was impossible to reach the hundred and one islets with which the lake was studded, and these are always the favourite nesting-places of waterfowl. Of birds observed on this lake may be mentioned: mallards, many; pintails and golden-eye, several of each, besides other ducks of which we could not be certain as to their species-they probably included scaup, scoter, and long-tailed duck; as well as goosanders, mergansers, gulls (Larus canus), whose nests we found on the shore, with greenshank, common and wood-sandpipers, brambling, dipper, and other common kinds.

An hour's fishing from the bank supplemented our 
evening feed with a few half-pound trout, and afterwards (being rather in arrears with sleep) we coiled ourselves up on the beams of a ruined hay-shed, which, at any rate, afforded protection from the rain, and slept for a couple of hours, with an orchestra of the big divers, whose weird laughter is about as unearthly as any bird-note $I$ know, ringing in our ears.

In hopes of being able to find a boat on the larger Solaas-vand, we set out thither across a wild tract of birch-forest and brushwood, much intercepted with abrupt ravines and gullies, two or three hundred feet deep, and studded with lakes, large and small, but all abounding in trout. In one quite small pool we observed a fine fish, apparently of 3 or $4 \mathrm{lbs}$, repeatedly throwing himself out of water; but though we waited and set up a rod, neither fly nor worm would coax him. Hard by, we sprang a dunlin from her nest of four eggs, hard-sat. The variety of plant-life on the fjelds is striking, even though, as in my case, botany is a sealed book. There was the pink marsh-andromeda, drossera, and equiseti, of various kinds; butterwort, bog-asphodel, and cotton-grass, with purple and pink saxifrages, variegated mosses, lycopodium and trailing shrubs in infinite variety-their recumbent growth eloquent of the severities of winter in these uplands. Here and there the growing shoots of dwarf-birch tunnelled through superincumbent snow, or forced a way with the black oozy water from beneath its margin. In more sheltered spots grew purple vetches, mouse-ear forget-me-nots, harebells, and the pretty Cornus suecica. The cloudberry (möltebær) was still in bloom, and at midnight I noticed that the windflowers had all gone 
to sleep facing the north. At noon their heads turn due south.

We found to-day, among others, two nests of bluethroat-one with seven eggs, the other with seven young, half-feathered; also one of Lap-bunting with six eggs; and four young great snipes, newly hatched. I had previously found a nest of this bird with four fresh eggs on June 8th in Sondmör. We have twice put up jacksnipe on the fjelds, but have never found a nest.

A blood-red first-quarter moon was setting as we eventually reached beautiful Solaas-vand about 11 p.m. - beautiful indeed as a scene in fairyland, with its great dark rocks and wild forests mirrored on a rippleless surface till, in that mysterious northern night, one cannot tell where water ends or foliage begins. But that fine sheet of water, with its many possibilities, was not to disclose its ornithological secrets to us; here, again, we were confronted with the same difficulty - a boat, or boats, existed somewhere, but where we knew not, nor was there any to tell us nearer than in the distant valley, twenty miles away. Without a boat little can be done, and we were obliged to regard our venture as merely a flying survey. The great extent of these fjeld-lakes, or rather chains of lakes, and their remoteness from a base of operations, precludes their being explored in any cursory way, or in a limited time. To investigate such places necessitates a more elaborate expedition, provided with tent, canteen, and other necessaries, probably a portable boat, and at least a week or two's hard work.

The night being very cold (a white hoar frost already 
covered the ground), we sought the shelter of a sæter, which Ivar stated was in the neighbourhood, though the search for it occupied well-nigh an hour. On a bare grassy ridge stood Eriksgaard sæter, a long, low, loghut, slightly raised on rough stone pillars. Though tenantless, the door was merely latched, so we took possession-the first occupants of Eriksgaard for ten months. The sæter comprised one tiny living-room, a quarter of which was occupied by the stone-built hearth, and a longer room adjoining, evidently used for dairy-purposes, for various churns, wooden bowls, etc., stood ranged on a pine plank. There was, however, a plentiful supply of firewood-cut birch-logs-with which we soon made a grand blaze on the broad hearth, and enjoyed hot cocoa, followed by hotter grog, before turning in. The sleeping accommodation consisted of two wooden shelves about four feet square, one above the other, strewn with hay. Imagining that, as the sæter had been deserted so long, this hay would be " uninhabited," I coiled myself up on the lower shelf, Ivar above me, and slept till the fire had burned itself out, when the cold awoke us both.

They are curious places these sæters, or summer sheilings, of the Norwegian peasantry, only occupied for six or eight weeks-between July and September. The chief essentials of life appear to be a grindstone and a scythe of peculiarly crooked form. These two things are never wanting, though everything else is. No; there is sure to be a cooking-pot and a fisker-stang, or rude fishing-rod of unbarked sapling; otherwise the only useful thing to be found is the stock of cut firewood aforesaid. 
On the morning of July 3rd we turned out at five, and, leaving a kroner on the table in payment for the wood we had burned, went down to the lake to wash, etc. A bitter east wind was blowing, developing later into bright, breathless sunshine, with a degree of warmth that was decidedly " grateful and comforting," but which prevented our getting any trout for breakfast, that meal consisting of biscuits with whisky-and-water. Here, again, we were disappointed in being unable to discover any sign of a boat, which we had been told existed somewhere on the lake, and though along the shore we observed many interesting birds, including most of those already mentioned, besides rough-legged buzzard, merlin, two pintail drakes, with other ducks and divers, yet our main object was frustrated. In almost the last little bay we reached, before finally turning our faces homeward, with a rough twenty-mile tramp in prospect, we discovered a new and interesting bird. I was watching through the binoculars the morning toilet of a beautiful black-throated diver about a hundred yards away, enjoying the spectacle of the wholly unsuspicious bird as he now rolled over on one side, displaying half his snow-white breast while he daintily arranged his nether plumes, anon sitting bolt upright to shake the drops from his speckled wings, and piping out his weird, wailing cry. Presently from behind a tiny rock-islet (on which a gull sat close on her nest) emerged a beautiful adult drake of the velvet scoter, his sheeny purple-black plumage and orange neb very conspicuous in the early sunlight. For some minutes he busied himself with ablutions after the manner of his kind, sometimes diving completely under, at others 
merely splashing the water over his back. Then he returned to his island-home, on which I felt sure must be the nest. Energy, of course, proposed a swim-out (150 yards) to solve that problem; but, unluckily, a rather tired nature moved "the previous question" (whatever that may mean), which was eventually carried by a small majority.

Various other ducks and water-fowl there were on this lovely lake, to some of which, I see in my notes, I allotted names; but, these being more or less of the nature of surmises, 'twere better to omit them. These things only served to aggravate our disappointment in failing to find the boat; without this nothing further could be done, and regretfully we set our faces homewards, reaching our hospitable roof at Gŭla, after some forty hours' fjeld-tramping, in time for the Sunday's dinner and the "after six" evening with the salmon. Virtue, however, on this occasion was its own reward; for, though I raised and struck a fish in Nyegaard stream, yet, on feeling the touch of steel, he shot upwards at such speed towards the boat that the line was slacked and he was free.

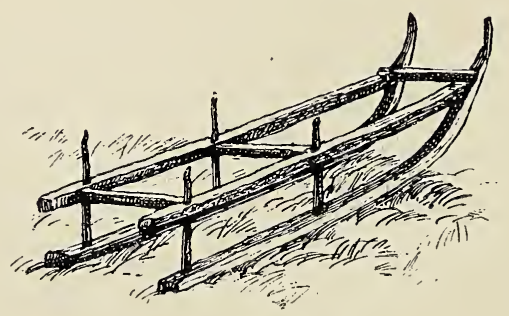

HAY-SLEDGE. 


\section{$(131)$}

\section{CHAPTER IX.}

NOTES ON TWO MORE SALMON-RIVERS.

I. The Förde River, SöndfJord.

I HAVE already described experiences on rivers which may be regarded as representing the two extremes of Norway salmon-fishing, namely-(1) a small fly-casting stream, as Etne, and (2) a large harling water, as the lower Sŭrna. In the present chapter I propose briefly to notice two other rivers of intermediate sizes and types.

The Förde drains a large area of very high-lying snowfjelds extending towards Justedal, though not fed by the great glaciers of that name. As a salmonriver, its course is very short-barely five miles from the fjord to Brulands-foss, a sheer waterfall that is always impassable to fish. The river, in this respect, resembles Etne; but there the resemblance ceases, since Förde is altogether bigger, and at first sight looked as if it would "stretch us out." After a day or two, however, we found we commanded the whole river, though the wading in parts is deep, and in a big water difficult, owing to the strength of the stream and the big rounded boulders, slippery as ice, that are strewn along its bed. 
The general system of fishing is to begin by flycasting all the pools that can be so commanded from bank, bed, boat, or stage; afterwards harling those pools and larger stretches that cannot be reached by casting.

The three topmost pools are reached by a track through the woods. The whole of the rest of the river (the various pools lying conveniently contiguous) we descend by boat, alternately fishing and shooting the intervening rapids. This latter proceeding is not in itself lacking in excitement when, in a big water, the cockle-shell craft dances amid breakers and boulders, and often ships a lot of wave. The boats are sent back to their stations each morning by cart along the road. For two rods, the river may conveniently be divided thus :-

UpPer Water.

Foss-Poor, casting only.

HODNET,

NASET, cast first, then harl.

NASVIGEN,

Gut , , , ,

GJELOREN, " "

G.J ERHOL, ", ",

STOTTE-KASTEN , , ,

SvöRET
LOWER WATER.

SvörET, cast only.

Brulandsberg, cast first, then harl.

Tutelönen, cast or harl.

BreinoluneN, cast first, then harl.

NYNeS, cast first, then harl.

Store Haugen " ,

Preste-Pul, harl.

Bridge-Pool, ,

Svöret, it will be seen, comes in both beats, and is, perhaps, the best pool on the river, the stream running beneath a lofty white gravel-escarpment on the far side. It must be cast only (wading) by the lower rod, the second man also casting it, but harling after, by which triple treatment Svöret at least receives full attention. 
The Foss-pool, according to local experts, is the sanctuary of many big fish which run up thither very early. The main pool is totally unfishable. No boat can live on its raging flood, and angling from the two rocks that project across the outflow resembles (in May) casting into a heavy Atlantic surf, with spray flying high over one's head. I paid special attention to these

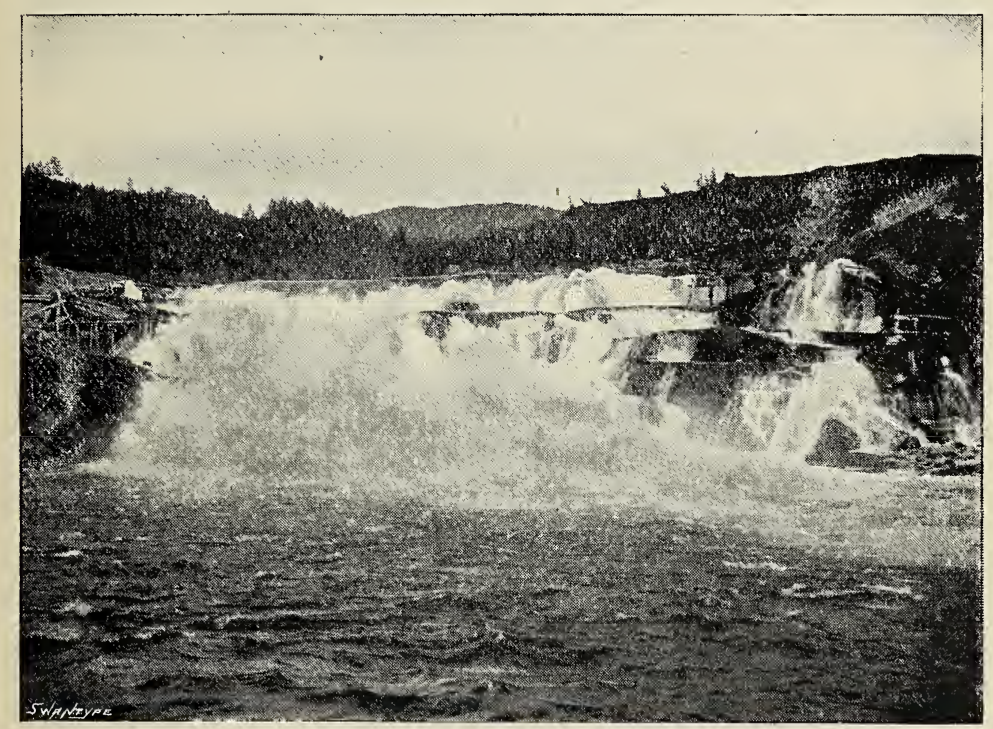

THE FOSS-POOL, FÖRDE RIVER.

rocks, for if a fish did come here, he must come up almost beneath the angler's feet, and I was most anxious to view the promised apparition of a phantom fish rising almost vertically, with open mouth, from the depths below. No such reward, however, befell. We tried all we knew to command this pool, including spinning with long lines from the top of the foss, wading from the north shore, etc., but all in vain. 
As regards sport, our own luck this last season was of the poorest. Two rods, from May 18th till 24th, killed one fish, 23 lbs., and lost another. Three rods then fished "clean" for six days (one of them, however, spending most of the time and vast energy in the pursuit of a bear that was reputed to be ravaging the flocks), and a blank week was only saved by a twelvepounder on the seventh evening. In the hope that this capture presaged the beginning of a "run" of fish, we then worked extra hard, and during the next week killed every fish we saw-and I firmly believe every one that entered the river-but then they only numbered three, of 12,10, and 9 lbs. respectively.

On June 5th heavy rain caused a flood which rendered the water unfishable, though one nine-pounder was extracted from the tail of Brulandsberg, and others were reported to be "running." Whether this was so or not, nothing more was seen of them; for, though we left Förde on the 8th, no more fish, we heard, had been taken up to the 14th. This season in Förde was late beyond the average. In other years the river has fished in May; but now the salmon had clearly delayed their advent, for none were being caught by the nets in the fjord, the first being only secured at Naustdal (outside the river mouth) as late as June 2 nd.

For two consecutive years the early fishing on Förde proved disappointing. The river, we were told, has yielded $2400 \mathrm{lbs}$. (1750 lbs. of salmon) in a season, and by appearance it ought to realize that total every year. In physical conformation it possesses all the qualities demanded by the fish. Its pools are deep and strong, with abundant "holts," and the bed alternates 
between boulders and gravel-beds of the size suitable for spawning. There is no lack of rapids or aërated water, nor of "back-sets" for the young fry. Presumably the netting business outside is greatly overdone. In rivers which are approached through twenty, thirty, or forty miles of narrow fjord-waters (as is the case with most Norsk streams), five days' netting out of seven over the whole length of those constricted water-ways is more than any river, however prolific, can stand. The nets, of course, yield the larger revenue, and so deserve consideration; still, the upper riparian proprietors (who produce and protect the fish) also have their rights, and these should not be overlooked, or both interests will soon be sacrificed. Prudence should avoid precipitating a catastrophe which can be seen to be imminent.

I will only relate one fishing incident, and that of a kind that most folks prefer to keep dark. Having received by steamer a new rod (nineteen-foot CastleConnell), and fancying that a change in gear might change the luck, I spliced it together, and in the first pool tried, rose, and $I$ thought hooked a good fish. Yet ten seconds later the rod stood upright with line all slack. On reeling-in, however, I found the fish was there - he had run up faster than I could take up the line. Hardly had we settled down to business than bang falls the reel down on the bottom-boards of the boat. Ere it was replaced, a lot of line had been lost, and in order to recover this, I directed Kristian to let the boat drop down-stream. He set off, backing water at some thirty strokes to the minute, and this, with an eight-knot current, soon placed us below our captive and the line 
all slack again. While reeling-up, the winch once more fell off, and this time I put it on the wrong side up, thus necessitating its removal and refixing for the third time. At length this was accomplished. Every possible blunder and bungle had now been committed-the category of crime seemed exhausted, and no further idiocy remained to perpetrate. I was free to attend to the other end of the line, and the complacent fish was still there, awaiting our precarious pleasure. Even he seemed to realize that a reprieve was hopeless : for, on pressure being renewed, he almost at once " turned it up," coming in quite sweetly to the gaff on the gravelbed below. He weighed 14 lbs. Virtue, after all, may lurk beneath a harmless superstition.

Helge, our gaffer on the upper water, was a firstrate performer with the rod, though not even a fortyyard cast will avail when no fish lies below. Kristian, on the other beat, though a highly picturesque old Norseman of seventy-six summers, whose grey locks and rugged features had frequently been committed to canvas, was no fisherman. Poor old Kristian! I forgave him, though he did get drunk at the pony-fair and smashed one of my rods! We then engaged Rasmus, Helge's brother, and were pleased with the change.

At odd times we killed on Förde and above the foss, 29 trout; weighing $24 \frac{1}{2} \mathrm{lbs}$, the best fish $2 \frac{1}{2} \mathrm{lbs}$. The record salmon of Förde, killed in May, 1894, weighed 51 lbs.

\section{Bird-Notes in the Förde Valley.}

For most of what is good in the following observations, I am indebted to my brother Alfred, whose 
keenly discriminating ear and accurate knowledge of the different notes, calls, and songs of birds left but little room for omission or mistake.* Not a feathered atom whistled, squeaked, or sang during our stay but its presence was instantly detected and its nest, if required, found. Hence the following (omitting the commoner kinds) may be taken as a fairly full census of the spring avifauna of the Förde dale.

Though of very circumscribed area, yet the valley of Förde, in Söndfjord (lat., $61 \frac{1}{2}^{\circ} \mathrm{N}$.), may be regarded as typical, in its bird-life, of dozens of similar dales in Western Norway. We paid constant attention to the birds during the intervals between salmon-fishing, and the following notes are the result.

These intervals included the period between breakfast —usually about noon-and an early dinner about 6 p.m.; after which we steadily "stuck in" to the business of salmon-fishing till two or three on the following morning.

The most conspicuous species was, perhaps, the pied-flycatcher; nowhere have we seen these pretty little birds so numerous - ubiquitous alike in close proximity to houses and village and in remote forests bordering on lakes and rivers miles away from habitation. It did not, however, frequent the higher levels, even where forest-growth was abundant, and where the redstart was common enough. The favourite nesting-places of this flycatcher were natural holes-

* But three short months afterwards, and before this note has gone to press, that keen eye and ear were closed for ever. Returning from Norway in June, we had shot grouse together in August, and on the 21 st of that month I had gone out to Spain; but was at once recalled by telegram, and on September srd my dear old companion died of typhoid, five days after I had reached home. 
usually in the form of a narrow vertical slit-in the trunk of thick trees and close to the ground. Wherever the cock bird was heard singing, the nest was pretty sure to be within forty yards; and by examining the trees for such an opening or hole we seldom failed to find the nest, though the eggs were always difficult to get at. The tiny hole and the toughness of the growing wood meant half an hour's work with the hatchet. The nests, in all cases, were very slight, formed of fine dry grasses, without hair or other lining. The henbird, when alarmed by our presence at her nest, uttered a hissing note, very like that of its congener, the spotted flycatcher (M. grisola), which latter species was also quite common and first observed on May 28th.

The pied flycatchers were already laying in May, and by June 5th we found full clutches of six eggs. Half a dozen pairs were sometimes breeding within a space of forty or fifty acres.

Another exceedingly common species was the northern marsh-tit (Parus borealis), which is also a very early breeder, having full clutches of eggs by May 15th. After May 25th we found nothing but young birds in the nests, and by June 6th the newly-fledged broods were seen on the wing. In some cases, natural holes are utilized for nesting-sites; in others, rotten trees are bored out to a depth of six or eight inches, the tunnel widening towards the bottom. Sometimes the eggs are laid on the dry chips without any lining or nest; in other cases we found the young ensconced in compact warm nests of fur, hair, moss, and the like, woven into a bulky structure resembling those of the blue and oxeye tits. This marked divergence puzzled 
us. Possibly (we thought), like ducks, the tits form the nest after the eggs have been laid; but, on further investigation, the solution proved to be that the nestless, excavated abodes belonged to the northern Parus borealis, while the mossy structures in natural holes were those of its southern congener P. palustris. We watched the old birds feeding their young on moths. The note of the marsh-tit, when alarmed, is much more metallic than those of either the blue, oxeye, or coal-tits, and is easily distinguishable even at a distance. This applies equally to the British and Scandinavian forms of the marsh-tit.

On May 30th, while strolling through open wood some five hundred feet above river-level, a faint squeaking noise attracted attention. Not recognizing the note, which came from among juniper bushes adjoining pine-forest, A. approached the spot. After waiting some time, somewhat confounded because, though close at hand, the notes seemed to come from several different directions, a heavy greenish bird of bunting-like build flew up, carrying food, and unconcernedly tumbled itself into the scrub. Immediately a lively chirrup indicated the feeding of young, and a chorus of hungry throats at once indicated the positions of the several youngsters. Presently the old bird flew silently off, alighting on the ground at some distance. "I watched her carefully"I quote my brother's note - "she ran on the ground smartly like a tree-pipit, and quite unlike a bunting, actively searching for food. Then returning to another part of the scrub near me, she fed another young one; but before doing so, perched on a tree close by and, seeing danger, raised her crown-feathers like a skylark, 
This was an Ortolan, whose young were fledged though still unable to fly, and we caught one for examination. The lower parts were bright sulphur-yellow; breast yellow, but streaked with brown. The back brown, streaked longitudinally with a darker shade. The ortolan, in its gait, as above remarked, is more of a lark or a pipit than a bunting, and it evidently breeds very early. In this instance, the eggs must have been laid very soon in May, and perhaps in April. After a little watching it became very cautious, and evidently conveyed its suspicions to its offspring, for they, too, became quite silent."

Another characteristic bird was the Icterine warbler. We first observed it on June 2nd. The day had been drenching wet, but cleared towards evening. We were then hurrying homewards, to get to our respective beats on the river, when the lovely song of this warbler struck on our ears. For a moment we wondered if it could be a thrush, but no: such a flow of mingled melody never poured from a throstle's throat. For five minutes more we listened in rapt attention and admiration, wondering what it could be, and turning over in our minds the whole list of European songsters. "Melodious willow-wren?" suggested one. "Well, if there's a bird of that name," replied another, "that must be it!" And so it proved to be. The blue-throated warbler is bad to beat, and hitherto we had given it the palm as the Jenny Lind of European songsters; but having now heard both, and remembering each pretty well, we incline to rank the Icterine as level with the blue-throat in splendid volume and variety of note. The Icterine warbler is, moreover, essentially a mimic. Here, where 
fieldfares are so abundant and so noisy, it was natural that this mocking-bird should imitate them to perfection; but at times the song also caught the flute-like notes of the canary, and we recognized the resemblance to the song of sedge-warbler and house-martin. Various

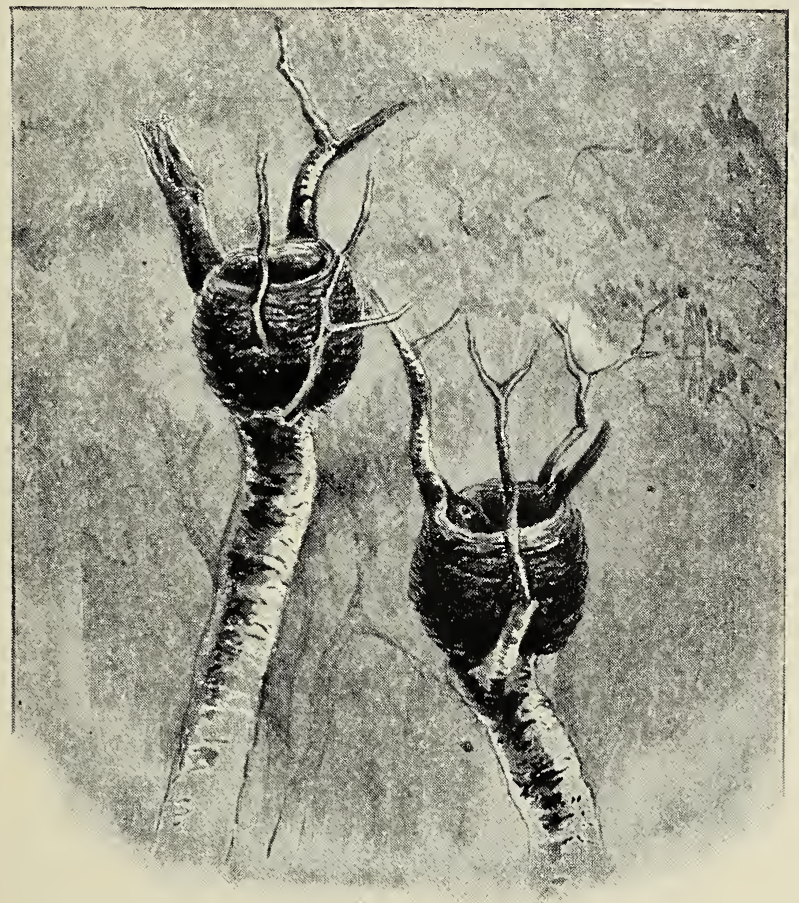

FIELDFAREs' NESTS ON THE FÖRDE.

opinions have been expressed on the singing powers of the Icterine warbler, and different ears are perhaps apt to emphasize different notes. No doubt its normal song resembles that of the thrush, and it is also probable that its highest degree of excellence is attained at the most northern points of its range. 
We found the Icterine warbler fairly common, both in the Förde valley and on the scrubby shores of Vossevangen lake, near Bergen, but failed to detect the nest, for the bird is of very rapid flight and resents being watched. Some years before, in Sogndal (Sogne fjord), a nest containing six beautiful eggs was taken in the garden adjoining our house, and brought to me in the second week of June.

Having written at some length on these four characteristic species (the pied flycatcher, northern tit, ortolan, and Icterine warbler), I will conclude with a few short notes on the commoner birds observed :-

Brambling - scarce; only a few pairs breeding here, laying before mid-May. Nests chiefly in alders and silver-birch. We found fledged young (from nest in a pine-tree) on June 1st.

Chaffinch-common; feeding fledged young on June 6th.

Tree-Pipit - common ; first heard singing on June 3rd.

Reed-Bunting-scattered pairs on each tiny patch of bog.

\section{Yellow-Hammer-fairly common.}

Longtailed Tit - northern type, with very white head ; observed once.

Oxeye Tit-common; feeding fledged young, May 30 th.

Wryneck-three pairs breeding in valley.

Great Spotted Woodpecker-observed twice or thrice.

Lesser Whitethroat-heard singing in our garden at Förde on June 4th. As we heard it no more, presume it went on northwards. 
We may "lump" the following: whitethroat, blackcap (arrived June 5th), sedge-warbler, redstart, willow-wren, chiffehaff, whinchat (sang all night)-N.B., stonechat never observed in Norway-wheatear (on high ground only), robin, wren, white wagtail, house- and sand-martins, redwing, fieldfare, dipper (young on wing, June 2nd), starling, thrush, and ring-ouzel, magpie, raven, and grey crow, merlin and kestrel, tawny owl, cuckoo, corncrake, and blackcock.

On the delta at the river mouth, six wigeon (one old drake) rested some days at end of May, and mergansers were numerous on the stream, as were also sandpipers, gulls, and a few redshanks and herons. Woodcocks "flighted" at night, and three black-throated divers were seen together on Mö-vand on June 2nd.

The tawny owl had large young ones on June 5th, which some peasants tried to palm off upon us (at halfa-crown apiece!) as genuine berg-uggla, or eagle-owls, which latter also breed on the higher fjeld. A fieldfare's nest, built inside the old abode of a crow, had large young on May 30th.

A noteworthy feature in these observations is the early date at which birds commence to breed so far north as latitude $61_{2}^{10} \mathrm{~N}$. Several species must lay in April, others early in May.

\section{The Evanger.}

Approaching from inland, the watershed of Evanger is seen to comprise an immense area of high snow-fjelds lying around Opheim-vand and beyond, towards Stalheim. Hence, in average seasons, there is little fear 
of lack of water-rather the reverse. The danger is that the stock of winter snows may be used up without regard to economy-that is, from the salmon-fisher's point of view. Thus, if the sun blazes forth like a fiery furnace in early June, the melting snows come down in one great tearing flood all that month and leave no further supplies to replenish the stream during July and August.

The Evanger is only short-some eight miles from Voss-lake to Evanger-but it is a big river; too big, in a general way, for fly-fishing. Yet the configuration of its banks happen to have produced several excellent Hy-casting pools; while others have been formed by the construction of artificial shelters in the midst of what would otherwise have been useless rapids.

Our experience last year was very short-from June 10th till 20th-and during those ten days we had the river in high flood, the result of intense heat, melting the snows above. The crack pool of Saghoug had temporarily ceased to exist, the casting-stages being submerged full three feet beneath a raging flood, and the whole river resembling a seething cataract rather than angling water.

Salmon-fishing under such conditions seemed hopeless-the very attempt savoured of ignorance; yet, at eleven o'clock on our first evening, harling the long flat below Kvile-Kval, I hooked a "big un." This fish took a four-inch brown phantom thirty yards below: but in less than three seconds was alongside-between boat and oar-point. Seeing the dip of the oar, he shot beneath our keel. These were bold tactics, but I rose to the occasion, and by plunging the rod deep under, 
was only just in time to save a smash. After fighting for twenty minutes in mid-stream, he went straight down, taking a bee-line for a strong swirl we could just discern on the south shore. This I afterwards found (by daylight) was caused by a huge boulder normally projecting from the river's brim, but now lying quite thirty yards off-shore. In the shelter of this sanctuary, despite all I could do, the captive remained for forty minutes almost stationary. To go down below was not available, and I did not care to

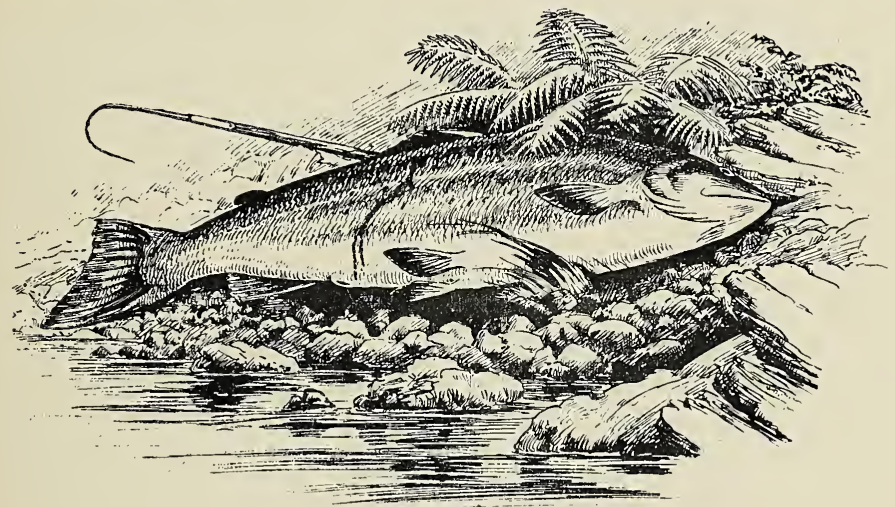

"SAFE ASHORE."

take to the boat again, as Ole Teigen had just before been smashing my line between his strong fingers and swearing it was rotten. I therefore decided to play for safety, with the result that sixty-five minutes elapsed before the fish consented to quit that swirl and cross the flooded mead between us. A. put in the gaff five minutes after midnight, and I was glad to get this fish, as his defence, if not brilliant, had been really artful, showing both local knowledge and true generalship 
- especially that first bold charge. He scaled just over $30 \mathrm{lbs}$., and measured $44 \frac{1}{2}$ inches by $23 \frac{1}{2}$ inches in girth.

Saghoug pool, as stated, was too big and held no fish during our stay. We tried it all ways, and found harling rather "creepy" work here, with the boat hanging on the lip of a half-mile rapid. "If an oar breaks, we are dead men!" "True," was the reply; " but if you consider such things, you cannot fish Norwegian rivers."

In Rörholm, the pool next below, I raised a fish the second evening and paid it special attention afterwards. The river here was one raging torrent, save for a sheltered space, some ten yards wide, lying well out in the stream. This space forms the catch; but between it and the angler swirls the intervening rapid quite fifteen yards in breadth. Hence, however skilfully the fly be placed on the middle water, unless the intervening line be held high and clear of a three-foot wave, the lure is instantaneously swept away. Three disappointments befell me here. Thrice I raised a fish on the verge of the torrent, struck quickly, and for a few moments enjoyed the rapid out-rush of line; but each time it proved to be a big trout, swept far down-stream in the swirl. That the first rise had been a salmon, we had, however, the eventual satisfaction of proving through the medium of the Black Doctor.

In a short stay we had no time to find out the lie of the fish in so big a water. The regular pools were untenantable, and our gillies, though excellent hands, had evidently paid no attention to such exceptional states of water-at least, they had no ideas on the point; and perhaps, after all, there was really no chance. Except the two main pools mentioned, and a few 
bank-casting catches, the angling on Evanger is entirely boat-fishing, and the upper water, including Flaage pool and Seim-vand, is exclusively harling. Boats are placed on each pool, and the return journey in the small hours is made by drasin on the railway which runs alongside the river. The drasin is an ingeniously contrived trolly; but with four men aboard it, with all their rods, gear, and fish, there is not much room to spare, and one has to "sit tight" amidst revolving cranks and pinions, levers and shuttles, as the machine spins along at eight miles an hour.

I will only mention one other pool-Gjetle by name, a fine sporting stretch with strong stream, though rather too big for casting. On each of our last two evenings, Gjetle offered us a chance. The first appeared to be a fish of $35 \mathrm{lbs}$., or over, but soon parted company, probably never being properly hooked; the second I killed on "spoon"-a cock-fish of 21 lbs.-and thus wound up the least lucky season I have had with Norway salmon.

We also killed, in Evanger, twenty-seven trout, weighing $32 \frac{3}{4} \mathrm{lbs}$., besides a few char. On a former visit, I had killed a number of these fish in the Evangervand. The trout were, with occasional exceptions, in poor condition, as the following measurements show :-

Trout of $3 \frac{1}{2}$ lbs., length 22 inches.

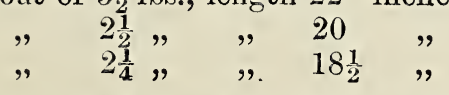

This narrow, rock-bound valley was remarkably deficient in bird-life. There were neither ducks, divers, nor even mergansers, and we did not notice a single species that calls for record. But the gadfly appeared on June 13th, and the terrible clegg two days later. 


\section{CHAPTER $\mathrm{X}$.}

\section{TROUTING FOR TOURISTS.}

\section{Iv Search of Arcadia.}

Norway is the Elysium of the wandering angler, but is not unlikely, in the first instance, to disappoint his hopes. The cause will lie in too high-flown anticipation rather than in any inherent fault in Scandinavian waters. There is an infinite choice available to the trout-fisher, and, amidst abundance, the tyro is apt to conclude that he must fall into an angler's paradise "right away." But Utopia must be sought in Norway as elsewhere. Sooner or later he will find it, and, in retrospect, will agree that there is reward in those preliminary explorations. No one who has searched out for himself the "arcana" of foreign lands, and perchance discovered spots of which the piscatorial mind may dream, but seldom realizes, cares to publish for all and sundry what has cost so much time and trouble to find out.

A twofold obstacle is encountered at the outset. First, the Norsk streams are often too rapid for flyfishing; many, in fact, are little better than rapids and cataracts, offering, even to one accustomed to highland rivers, hardly a yard of fishable water. Then, when 
eventually one finds a moderately level stretch, though trout may take freely enough, they are hardly worth the catching-poor little fingerlings of eight or nine inches at best. Sport must ever be gauged by quality before quantity, and no hecatombs of such small fry can be reckoned a fair equivalent for the pains and perils of the North Sea passage. This is the second preliminary drawback-the trout run small. It is only here and there one finds a river that yields the right sort-those deep-sided, golden fellows that run to a pound or two, and upwards; and these are the places that are nameless.

The regular salmon-rivers, it goes without saying, are reserved and forbidden ground to the casual angler. These, moreover, are not, as a rule, good trouting waters. A vast volume of crystal water, speeding fast and level over a gravelly bed, has little attraction for Salmo fario, albeit such few as it contains are often real monsters of six, eight, or ten pounds weight. There are many minor streams, and others, say those of glacial origin, which, though rarely visited by Salmo salar, are yet reserved by their owners to be let at a rental. The rivers alluded to abound in their season (that is, in July, August, and September) with seatrout and bull-trout, some of the largest hardly inferior in weight to the salmon himself-take, for example, the rivers of the Nordfjord and the watershed of the Justedals-bræer, with many more. Such streams, adding the off-chance of a salmon, together with browntrout fishing of the first class, deserve, and at home would command, rents of many dollars. Small wonder the Norseman markets such rights to best advantage. 
For an angler who may be unable to pay the high rents asked for salmon-rivers proper, and who is willing to forget the fetish of salmon-worship, such streams afford a measure of sport that is both good, varied, and cheap. But we are getting off the line, and must remember that we are endeavouring -in theory, at any rate, and in general terms - to direct the casual fisherman to the best angling waters that yet remain free.

Such, as above roughly indicated, were our initial experiences. Some streams were too rapid, in others the trout ran small. This was preserved; that, for one reason or another, failed to fulfil aspirations. The lakes I pass over for the present. References to lake-fishing will be found scattered passim throughout this book, but they chiefly afford trolling; and lake-trolling alone, I imagine, would hardly attract an angler across the sea, while nowadays almost every sheet of water of easy access along the main tourist-routes is mercilessly worked-done to death with otters, nets, and traps, to supply the numerous stations and tourist hotels in its vicinity.

Very pleasantly, nevertheless, sped those seasons of exploration. If sport was moderate, anticipation was unbounded, and that made amends. Moreover, we were younger then, and there was novelty in the glory of the mountains and of the forests, whose chequered shade was carpeted beneath with glowing hues of russet, green, and gold, and where glades opened vistas of towering crag or the distant tracery of ice-bræs. But scenery, we admit, is not sport, nor even a satisfactory substitute.

Late one summer evening we reached a remote 
station after seventeen hours' carioling. The accommodation was primitive, but we had a reason for our choice. Tables and chairs, curtains, carpet, and the like count for little when under your window surges a broad flood that, you are told, abounds in big trout.

The banks were bounded by huge, bare boulders, in places twenty feet sheer, and the river appeared one in which one might look for salmon. But, by reason of

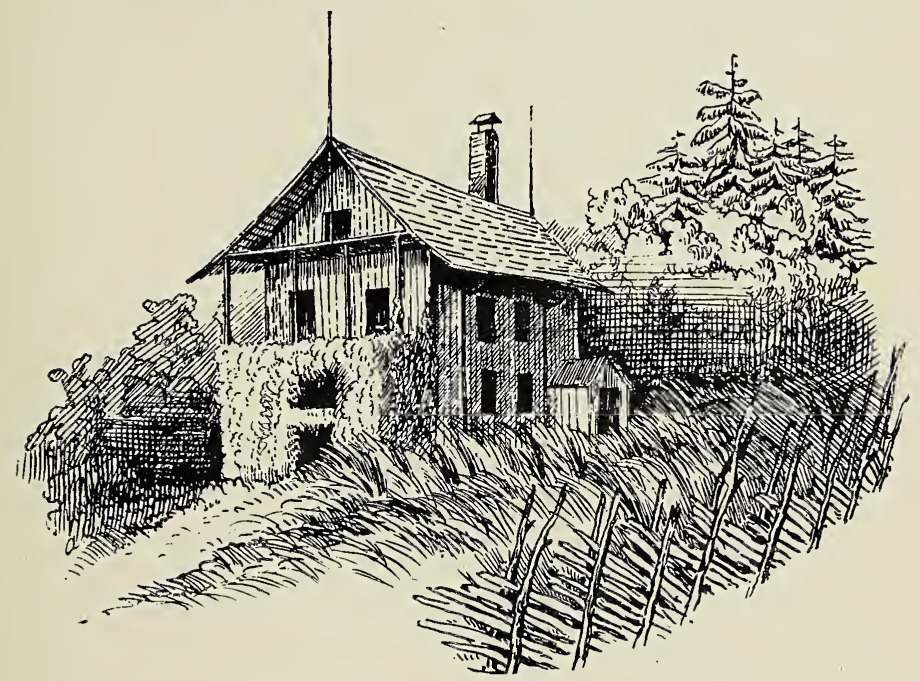

OUR FISHING-QUARTERS IN SWEDEN.

a high foss below, no sea-fish could ascend here. The circumstance, however, was the more favourable to its trout-holding capabilities.

Yet from that surging flood not a fish could we beguile. Part of the water, no doubt, was too tumultuous; but there were stiller reaches, and here and there, where some frequent monolith stemmed the torrent, were formed turn-holes and foam-flecked 
back-waters, to all appearance, the perfection of trouting waters. But even on these promising bits there came no response to the oft-changed fly, and after fishing "clean" for three miles down, I turned aside to follow a tributary that wound its devious way through thickets of pine and hazel-scrub. The lower reaches were broad and shallow, rippling over a gravel-bed, and there, as usual, the trout rose greedily at any small fly, but proved poor little things. From some deeper pools above, despite heart-breaking boughs interlaced overhead, we extracted sundry half-pounders and one really nice trout. Then, round a deep-wooded bend, we came face to face with a rock-glacis, over whose smooth, grey surface our stream came trickling down in driblets-a mere film of water spread out over hundreds of feet in width. We climbed the slope that flanked the obstacle; but above it not a sign of a stream was there. Down the steep and stony fjeld a hundred tiny rills came splashing and tumbling from the snows far above. Whimbrels whistled in tremulous key, and a buzzard soared beyond; but that was all.

Returning homewards by the river, a native angler was plying his craft most effectively in the very backwaters where, in the morning, I had failed. It was slightly humiliating, but the Norsk method was instructive. His rod a rough ash-sapling, bark and all, without reel or rings, and with tackle of the rudest; yet the trout were taking his carelessly-adjusted worm as greedily as whitings on a summer night at sea. Instantly a fish was felt, and, without regard to size or weight, he was jerked out---pitched overhead on to the rocks above, or among the branches of a pine. In the half-hour 
I watched him, our friend killed a dozen, in poor condition it is true, yet several exceeded a pound. Gladly for a few coppers he half filled my creel, for fare was scant, and sizable trout a welcome haul. Meat, in those parts, is unknown, and eggs, fladbröd and blaeberry jam, make but a poor feed after a long day on fell or riverside.

The incident conveyed a lesson. Reflection brought the conviction that success in this northern land is a question of time as well as of place. Rivers in Norway have their own special conditions, and their season, dependent in each case on the nature of the watershed, but always far later than at home. Here, in a region surrounded by high snow-fields and ice-bræs, we were still much too early. It was the second week in June. Two months before we had enjoyed abundant sport on our Border streams at home, yet here the fly was still useless and the lowly worm (in big waters) I abjure.

That the trout were there, abundant and heavy, we had had ocular evidence; and returning five weeks later (in July), we enjoyed on those dark eddies and erst recusant streams one of the finest fortnight's trouting that has ever fallen to our lot. Details are not needed if the moral has been made clear.

Another class of stream which affords some of the best river-trouting in Norway, may be described as salmon-rivers in miniature, and are, in some cases, the head-waters of salmon-rivers obstructed lower down by foss or fall. In Norway, I imagine (though I am very far from asserting it as a fact), salmon are not invariably so resolute in pushing up to the very spring-heads (where their ova would almost certainly be destroyed 
by ice), as we know is their habit in our more temperate clime. In some rivers, salmon do push right up (and their ova are destroyed), but in others they seem content to spawn in the relatively lower reaches, and leave the highest waters to trout. In such rivers, clear as glass, there are smooth-running stretches that afford the very cream of fly-fishing, the trout averaging half a pound or more apiece, and running up to two and three pounds and upwards, those feeding just off the heavy streams, and at the tail of gravel-beds, as strong and game as can be found or desired. A fair-sized fish will often commence with a burst of twenty yards as straight and clean as a salmon, while two taking together produce sensations that make the nervous say their prayers.

For these larger waters I prefer a double-handed rod of fourteen or fifteen feet-not from any desire to mete out lynch law, but simply in respect of the greater area thus commanded. The water, which is intensely clear and rapid, is best fished down-stream-exactly as in salmon-fishing: hence fine gut is necessary. The flies should be larger than those usually used at home - such as are called by tackle-makers "sea-trout" sizes ; but they must be specially tied on fine gut, the same as the cast.

The patterns for trout are not of such vital importance as for salmon. Among effective lures may be mentioned the mallard-wing, Zulu, March-brown, tealand bustard-wing, etc. Winged flies are preferable to hackles, with bold or gaudy colours, and tinsel ribbing; while a touch of red on tag or tail is always attractive.

Fishermen labour under an ill-repute-perhaps nọt 


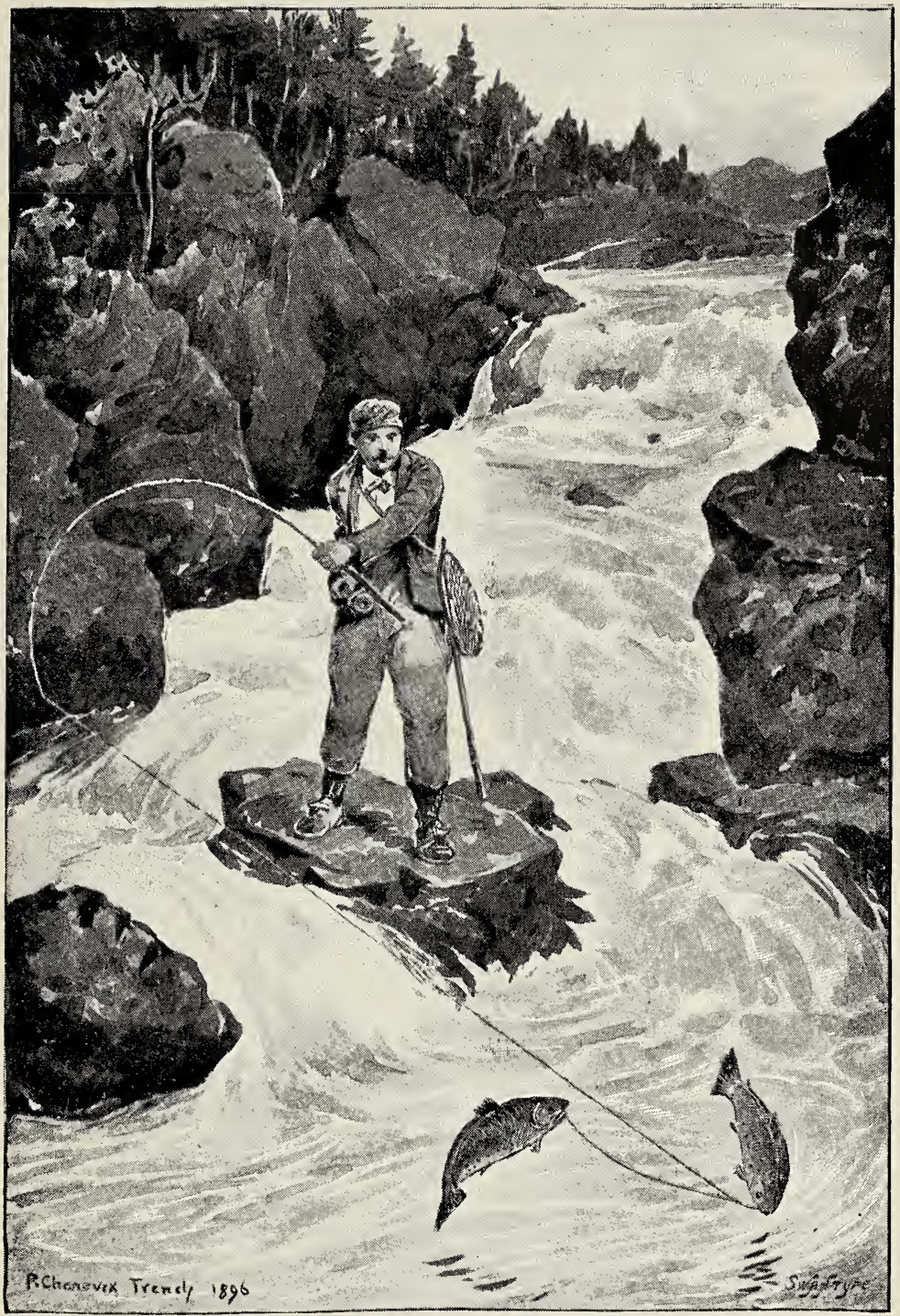

"A Lively Double. 

entirely undeserved-that of (to put it mildly) habitual exaggeration. No one believes them. I don't ask to be believed myself. But on re-reading what I had written above, I see I actually understate the case. There is trouting in Norway far better than this. There are waters that dwarf such description. These, I admit, are remote, involving days of carioling from any known base, with the rudest surroundings when reached. None but keen anglers care to undertake such risks, nor would others reap the reward: since really big trout (however remote their haunt) are not " unsophisticated." Wisdom, with them, comes with age, and they will not be had for the asking. Their habits must be studied, and their haunts identified. Recently I had thoroughly enjoyed a day's trouting, and even felt proud of a basket averaging nearly $1 \mathrm{lb}$. apiece. Not so my host, friend Knud. Next day, accompanied by this local expert, the creel contained few so small, while nearly a score weighing between 2 and $5 \mathrm{lbs}$. each lay in ranks on the dark green grass. These were half killed on fly (long casting with fifteenfoot rod), the rest by casting phantom. My companion assured me he had taken many of 8 to $10 \mathrm{lbs}$, and not a few even larger, in this water.

Two other game-fish deserve passing notice, though neither afford any great measure of sport to the flyfisher. The grayling is found in most suitable streams; but, reversing ordinary seasons and spawning in summer, this fish is then in such poor condition that it should be left out of account. Then there are the chars. In the north, in Lapland, they run large and rise freely to fly; but I have never myself so taken them in south or 
central Norway, where they seem to be confined exclusively to lakes, or lake-like waters. I first met with them in the Evanger, where a small spoon captured a dozen in an hour's trolling. These averaged half a pound, with one larger, and were lovely objects, herring-shaped, their backs dark green, shading off through orange and salmon-colour to bright crimson below, the whole spangled with pink or white spots. The gill-covers showed golden reflections; the lower fins and half the tail bright red, banded black and tipped with white.

I have seen several char of between 2 and 3 lbs. weight (besides some large trout) taken on set lines in an alpine lake at 2400 feet, which, at the time (June 6 th), was still three-fourths covered with ice, and appeared an impossible place for fish-life.

Char abound in many of the hill-lakes of the Nordenfjeldske, and sea-char in the rivers of Nordland.

\section{A Reminiscence.}

As the month of June wore on, and the northern summer approached its zenith, the heat in our narrow gorge became well-nigh intolerable. The mosquito, moreover, was beginning to make himself a plague, both by day and night; but we were reluctant to leave our quarters, where an' incipient birch-forest flourished on the turf-thatched roof, for a rushing river, almost at the door, daily yielded a beautiful basket of trout. We had, moreover, discovered some new water within an hour's drive; so, for some days longer, we continued fishing in breathless, blistering heat. The newly-found water consisted of a succession of deeps separated by 
strong rapids, and commencing immediately above a barrier of grey granite, which some old-time convulsion had hurled athwart the glen, thus damming up the stream above. Here the trout all ran of a nice size, and hardly a day but yielded a few big ones. The fishing, however, was difficult, the best pools being broad and much obstructed by trees, hard to work save by aid of a breeze to raise a curl on their dark surfaces. A breeze, however, was a thing to pray forto dream of. For that rock-girt ravine, reflecting every ray of the summer sun, was too abrupt and tortuous to admit of any continuous current of air.

The hay-harvest had already commenced. On "Waterloo day" we first noticed the natives beginning to hang the cut grass to dry on their stake-fences as the Norsk custom is. Under the alders by the river, and along its damp, shaded haughs, flitted brilliant butterflies-commas, fritillaries, and many more; but we were too languid to catch them, and decided to move a thousand feet higher.

Our next quarters were selected after long and careful study of the Ordnance maps. They appeared to form the focus of a network of lake and river, and took two days to reach by the easy-going system of posting - some stages by water, where a woman usually formed one of the crew, and pulled as hard as any. Part of the journey lay over an elevated table-land-desolate heaths, somewhat monotonous, though the serrated peaks on either side were fantastic and striking in the extreme.

In the descent we encountered the cariole spill that is inevitable at intervals, and I only mention this 
particular one as the situation was awkward, the road being a mere shelf on the mountain-side with a rockwall on the left; on the right, some hundreds of feet below, an unseen torrent thundered in its deep-cut bed. Luckily, we all remained on the shelf, though sliding perilously near the brink.

For the last nine miles there was no road, and we proceeded on foot, the baggage deftly roped on ponies; but we had to wait a couple of hours while the said ponies were being caught in the woods.

Our new home, a hamlet of three log-huts and some hay-sheds, each propped on rough stone pillars, stood at a considerable elevation, commanding an infinite prospect of pine-forests stretching in alternate rise and fall to the distant horizon, where snow-capped ridges marked the borders of Sweden. All night long the chorus of redwings serenaded us, and in the small hours willowgrouse began to "bee" and cackle in the birch-scrub above. By day, the drawl of the brambling and the wild carol of ring-ouzel, far up the hill, enlivened the solitude, while, by the riverside, the warble of willowwren and sandpiper was incessant.

Half a league beyond, commenced a long narrow lake, or rather a chain of linked lakes connected by intervening lengths of river-it was difficult to say where lake began or river ended, so imperceptibly did they merge one into the other. The lake-like parts were too broad to fish from the bank, and wading proved unsatisfactory; but each at its upper extremity, towards its confluence with the river, afforded one of these ambrosial stretches that one may dream of, but seldom finds. Here, as the width contracted, it was possible, by 
rather deep wading on a good bottom, to reach well across.

Never did water more surely foretell success than did those moss-dyed streams that now glanced in the sunshine before us. A steady, gentle breeze, moreover, ruffled the surface, and a dark-green and golden trout, of just under the pound, soon succumbed as first blood. Four more of exactly similar size, besides two grayling, followed the first in rapid succession-all these being

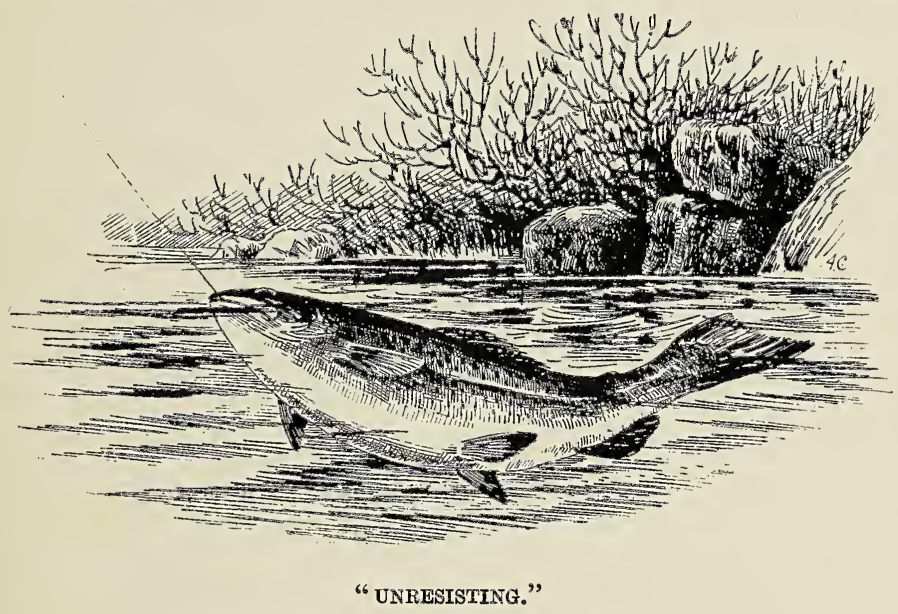

killed in mid-water without going ashore. Towards the neck, a big island-boulder deflected the current in long brown swirl towards the opposite bank, with its lichenclad rocks and shaggy fringe of birch. A yard below that boulder, the fly was arrested under water, with a sudden dead resistance that left no room for doubta big fish and fast hooked. This trout ran off twenty yards of line straight, the thin gut cutting an index trace of spray along his course. Then he raced back, 
slacking the line, and jumped twice within ten yards. I had his measure and gave it him hot, though it was minutes ere the middle hickory began to tell, and quite ten before he was under control. And then there were yet ugly rushes and final struggles ere the big trout could be towed, unresisting, towards the pebbly shore.

This was my first big fish in Norway, and a handsome fellow he was - a yellow trout of $4 \frac{1}{2} \mathrm{lbs}$. weight, $22 \frac{1}{2}$ inches in length, and in the pink of shape and condition. Truly such a prize, as he lies still gasping on the dark-green moss and in the fresh radiance of his rainbow hues, forms a picture one does not soon forget.

We have landed many a good trout since then; twopounders from a score of Scandinavian streams and lakes; two-and-a-half, not seldom; three pounds and upwards, more rarely. But never yet have we beaten our first record of $4 \frac{1}{2}$ lbs. in that grand trout of Tyrisletten.*

Of the sport these streams have afforded, and the contests they have witnessed between a lusty trout on the one side, with gossamer gut on the other, it is needless to descant. Hardly a fight, but where conditions everlastingly vary; but the result is mostly the same. Given a good hold and careful handling, the finest of gut will carry the day, and ere it is time to reel-up in the cool evening, the creel is full. There is no night here, and as the cariole jogs homeward under sunlit skies seen through a mountain-setting, one is really inclined to believe, for the moment, that

* I leave this as written some years ago ; but it will presently be apparent to the reader that the "record" has since been beaten again and again. Ay! twice-over, and once thrice. 
we have attained the acme of mundane bliss, and to wonder if anything better remains to be found

We were young then. In later years, as experience broadens, the ecstatic mood is apt proportionately to pale. That is, perhaps, inevitable; for not even the angler has yet discovered the ingredients of perennial youth.

To sum up:-The first consideration is the season, which is always later than at home. May is useless; and in the high-lying regions (through which the tourist routes mostly lead), the trout have not regained condition till quite the end of June. July is the best month, with August in a rainy season. In average years, the waters are apt to run fine during the latter month, and by mid September, the trout are all going back, and some almost ready to spawn.

Next as to locality :- I hope I have made it clear that good trout-fishing is not as a rule to be found within half an hour's walk of tourist-station or hotel. What constitutes good trouting is perhaps a matter of opinion. Those who are content to cram, say, eight or nine dozens of troutlets into a $10 \mathrm{lb}$. creel, will hardly get wrong anywhere in Norway; but to that, the epithet would not apply. Norway is not "played out"-as one often reads-and never will be. There is abundance of trouting-water, good, bad, and indifferent; it is not really difficult of access, but the best is not, as a rule, right before the tourist's nose.

One constantly reads in the sporting papers, this question :- "Where can I get good trout-fishing, free?" I have endeavoured to answer it-though in general terms-in the foregoing chapter. If the querist expects more, verily he will be disappointed. 


\section{CHAPTER XI.}

\section{TROUTING IN THE TELEMARK.}

The Telemark lacks in grandeur of scenery as compared with cis-alpine Norway. It is a province of pines, akin in character and contour to those of Dalsland and Wermland beyond the borders of Sweden. Yet the Telemark is instinct with individuality in its pastoral people and customs, its stave-kirks and staburs, the dwellings of a primitive peasantry, full of local colour and characteristics, beyond the average in the north.

But such matters do not concern us here, nor will I stay to describe the glories of Gausta-fjeld and the Rjukanfos--though the latter impressed me as few of the great "show scenes" in Norway have succeeded in doing. Perhaps it is the mystery of the unseen abyss into which the waterfall hurls itself in a thousand. foot leap; perhaps it was merely the fact that on those beetling crags that all but encircle the fall, I made a new and notable acquaintance. From every cleft clung tufts of wild-flowers-purple aconites, toadflax, and campions, ladies'-finger, vetches, and wild geranium, with saxifrages, harebells, and the rock-loving cotiledons. Over these flitted brilliant butterflies, conspicuous 
amongst which, one in particular instantly attracted attention. This was the great crimson-ringed Apollo, soaring through space as an eagle-now high overhead, anon sweeping on set wings a hundred feet down the rock-face, towards some tuft of aconite or oxeye. To capture such high-flyers was no easy matter; till I discovered a rock-ledge across which the Apollos crossed and recrossed at intervals, and where, in the landing net, I secured nine specimens of this magnificent insect, whose thick, hairy bodies (almost moth-like) and tenacity of life deserve remark. Besides Apollo, I captured here the following fritillaries:-Paphia, Adippe, Niobe, Eris, Aglaia, Lathonia and Euphrosyne ; together with Cratægi, Virgaureæ and others, so that I enjoyed that day on the rocky ledges above Krokan.*

Before the windows of our log-house, the ice-scalloped arrête of Gausta-fjeld, rising to 6184 feet, filled the prospect; while slopes so steep shut in the valley that one enjoyed a sort of bird's-eye view of a vertical earth-such, as it were, as an eagle must have while soaring over more normal geological formations.

Fifty yards from our door, sped the Maane-elv in swift crystal current of that green-blue tinge that often betokens a glacial origin. But this river, we knew (having been to its source), was not born of a glacier, and its pools, we soon proved, were paved with small trout.

The Maane-elv in the latter days of June, in an exceptionally hot summer, ran at lowest level, while

* Another splendid insect, characteristic of southern Norway, is the Camberwell Beauty (Vinessa Antiope) which, though we did not meet with it to-day, appears in this district as early as mid-May, and in central Norway ('Trondhjem's Amt) during the first week in June. 
its tributaries were stone-dry-arid and parched as though no water had occupied them for centuries. In water so low and bright, success partly depends on finding pools to which the larger fish have fallen back, and in which, as sanctuaries, they will be congregated. To me, weary of throwing back troutlets, an ancient, grey-haired farmer kindly pointed out a wooden footbridge-formed of four long pine-trunks, resting on a central pier-which spanned the river hard by. Beneath

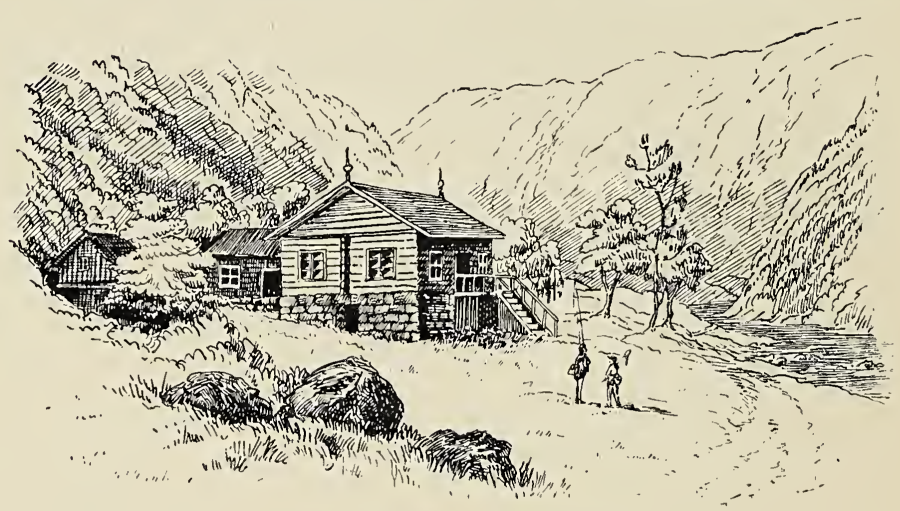

OUR QUARTERS IN TELEMARK.

the bridge the stream ran eight feet deep, but so clear that every stone in its bed was plainly distinguishable. From among these stones of infinite hues, as my flies reached the surface, I observed a heavy trout leave his holt and ascend directly towards where I stood, twenty feet above him, on the central span; up, up he cameit looked as though he would never reach the surface. Then a sharp turn, and a wave of a broad tail, and he was gone; but a blue-dun was fast in his maxillaries, and a singular struggle ensued. Had the captive 
elected to bolt upwards, beneath the bridge, nothing could have saved a smash. Instead, he essayed to fight it out from his lair among the stones, which no doubt afforded some illusory shelter; then he fell back, downstream (the current being strong), till it became necessary to check him. Presently he was back beneath the bridge, rolling, and in visible distress. There remained the task of piloting him round the projecting buttress, and across the strong stream under the shore, towards my landing-net among the shelving rocks below, and soon a brown trout of $2 \frac{1}{4} \mathrm{lbs}$. was safely basketed.

Many good fish we afterwards killed off that old bridge, and the landing-net was kept frequently employed on the lichen-clad ledge below. Yet the full resources of the river remained to be discovered. At another point, on the farther shore, where the stream ran swift and unruffled-too placid, one feared, for flywere a series of deep embayed pools literally alive with fine trout. By mere chance I discovered them; for, carelessly walking round the point of one of these bays, from my very feet darted away a whole shoal of startled trout. Then I observed that these rock-spurs were more than mere projecting promontories; each was part of a continuous rock-stratum dipping far across the river. Above each shelf the sloping rock dipped gently away into deeper water again, and there was merely a slight swirl to show the spot where the current poured over the submerged ledge into the deep cauldron below. It was here, just behind this rock-face, that the best of the speckled beauties lay poised, awaiting the flies which the stream carried to their mouths.

There was a series of these bays, all precisely alike, 
and whatever their geological history may have been, it was obvious that they formed a regular set of trouttraps : and, ere one had finished the last, the first was ready for a second time of asking.

So intense was the sun-glare and the midday heat, that fishing was only practicable early and late. Life in Telemark thus divided itself as follows:-At some early hour, according as I awoke, I turned out, and after a dip in the home-pool, continued fishing till the sun got on the water, about half-past seven. Then came frokost, a simple affair, commencing with a long. pull of milk, followed by fried trout, eggs, fladbröd, and delicious coffee. The heat of the day was spent either on the fjelds above, or collecting some of the brilliant insects that abounded in the flowery bræs and sunny woodland glades of our valley. Many of the strongflying fritillaries, Apollos, etc., could indeed only be captured during the noontide heat, which meant warm work. Then, lying on a mossy bank carpeted with wildflowers, I could count a dozen species almost within reach of the net. Each tall head of scabious or purple. knapweed was surmounted by the green and silver lustre of Argynnis paphia, or by the burnished orange of the high-brown, pearl-bordered, Niobe, or Queen of Spain fritillaries. There were sombre ringlets and tortoiseshell contrasting with the dazzling radiance of the Golden-copper (Virgaureæ): heaths and skippers abounded, and the dark Argus flitted in the shade; while Apollos on soaring wing, and strange ghost-like Cratrgi swept across the open meadows.* Dragon-flies. and grasshoppers also abounded.

* A note on the birds observed in Telemark may be inserted 
At five o'clock we dined on precisely the same lines as we had breakfasted, plus a dish of delicious wild strawberries, whose bouquet resembled that of old Bourgoyne, and on happy days öl replaced coffee; then, as soon as the shadow touched the lowest pines on the fjeld behind, we proceeded to despoil the pools. The trouting on this lovely Telemarken river almost equalled the best enjoyed in western Norway; but, on the whole, the fish averaged less-chiefly because " monsters" were here relatively scarcer. There was no difficulty in filling a sixteen-pound basket twice a day, morning and evening, leaving off at ten o'clock; and as the numbers ran from five to six dozen, the average weight was half-a-pound apiece. But we found it necessary to limit the takes; otherwise (the bulk of the villagers being away at this season at their sæters on the fjelds) there would, after feeding ourselves and the rest of the hamlet, have remained a surplus of waste-albeit the old women salted the fish down in tubs. But by ten o'clock it was dark enough, and we returned to our hut to enjoy a deep draught of milk and a final pipe on the portico, watching the flickering flight of bats and nightjars, till the vicious mosquitoes fairly drove us to bed.

here. In this valley very many of our British summer-migrants were breeding, including whitethroat, garden-warbler and blackcap, Icterine, chiffchaff, and willow-wren, wheatear, whinchat, and white wagtail, redstart and pied flycatcher, the black and white plumage of the latter harmonizing prettily with the variegated bark of the silverbirches they frequented. Corn-buntings and larks (as usual) absent, but yellow-hammer and ortolan not uncommon : found nest of latter with four eggs on June 28th, and one of woodlark (at 2200 feet), a day or two before. Among common birds may be named: chaffinch and greenfinch, the usual tits, night-jar, dipper, blackbird, woodpeckers (green and lesser spotted), corncrake, magpie, Siberian jay, raven, grey crow, and buzzard. On the high fjeld above, a pair of golden eagles, and several of the red-throated diver, etc. 
One evening our old friend, the farmer, brought two large trout, caught in some diabolic trap, for which he asked a kroner. My basket was nearly full, but it is best to pay one's footing when fishing like this is free, and for all I knew, I was trespassing on the kindly old gentleman's property and rights.

It is, in my opinion, the trout of rather under the pound that affords the best sport on a light rod. Your three-pounder, it is true, pulls hard and fights in his own dogged way. But his tactics leave him little real chance; it is a case of "hold him hard" for so many minutes, and one seldom sees him till ready for the net. The lighter fish, on the contrary, is here, there, and everywhere; beside himself with fury, he performs a dozen somersaults in as many seconds, takes line in spite of one, brings one's heart into one's mouth as he races towards the "snags," and after all his frantic efforts is still fresh for another burst when he gets a first glimpse of the net.

In colour the Maane-elv trout were pale - light green, with silvery sides, and but lightly spotted. One fine fish was an exception, being all red and orange, like a char; even the fins and tail were red, and the latter spotted throughout. An incident occurred here which is unique in my experience. As the flies swept over one of these rock-ledges, there ensued a tug and a commotion that led me to expect something exceptional; yet there followed no far rush, and on getting round the point and working the quarry into a quiet bay, I found I had three trout fast, one on each fly. "Doubles" are everyday affairs, but a treble with three large trout, graded in size, the heaviest at the end, was a novelty. 
These fish had the sense to swim free, thus rendering it necessary to kill them in detail. To land No. 3, while two beaten fish already encumber the intervening line, needs some little care.

Ten miles down the valley, near its confluence with the Tinsjö lake, the river divides into several rushing streams, separated by wooded islets and beds of shingle. Here the trout ran larger, but the water was deep and strong, and many beautiful streams were inaccessible. The thick trees along the banks also rendered casting difficult, especially as the best time was after dusk. Trolling on the Tinsjö produced some heavy fish, large flies proving more attractive than spinning-baits. One night I went out to see the "otter" in operation; but after witnessing the massacre of eight noble trout at a single haul, I had had experience enough to last my lifetime. It was, nevertheless, very delightful on the lake at midnight, with its soft subdued light, and the faint rosy blush in the north, which never entirely died away. About one o'clock each morning the low soliloquizing croak of the mergansers was heard as they Hew to and fro across their fishing-grounds. Shortly afterwards the small birds commenced their version of the Benedicite, and then came the tinkle of the goatbells far up on the fjeldside.

There were beautiful lakes and large trout on the higher fjelds above, and we enjoyed one memorable evening up there; but suffered several blanks, when a blazing sun and rippleless surface forbade hope. On one of these nights, while returning, we came on the spoor of two elk, one a big bull, quite fresh, the moisture still oozing into the deep shafts that the heavy beast had 
cut into the peat. My Norsk companion, Ole, became excited : and, quite oblivious of law or of forest-rights, wanted to follow up the spoor, assuring us the elks had not gone far. I was most anxious to get a glimpse of the big game-beasts (never, at that time, having seen an elk in life); but on some rocky ground beyond, we soon lost all trace, and, it being nearly midnight, we proceeded to climb down the steep two-thousand-fivehundred feet which still separated us from our home in the valley.

The torments of the insect-scourge, above mentioned, finally drove us from Telemark rather earlier than we had intended: by day and night it ceased not, and even our happy al fresco life became a minor burden. We moved to Bolkesjö, which is prettily situate, but the fishing proved blank. The Gwynniad is said to exist in Folsjöen, but I neither captured it, nor anything else in that lake of water-lilies; but in the marshy pine-woods hard by I was pleased to meet with a new insect, a small fritillary, its under hind-wings of a curious blood-red hue, which I have since identified as (?) Argynnis pales, var. lapponica (Stgr.). At Kongsberg, several commas (Grapta C. album) were feeding on the lilacs in the garden; but I failed to capture these active insects, and spent a day scouring the neighbouring country without seeing another. The whole land was burnt up by the heat and long drought; the pastures brown, and flowers dead. Wherever a patch of vegetation survived, were butterflies in scores, the golden copper notably numerous here, on the tansies. But all now show signs of wear, the smaller fritillaries especially being washed-out and threadbare, and all sorts more or 
less broken and faded. At the falls of Labrofos, on the Numedals Laagen, that evening, we finished a grand season's sport with two dozen trout, completing the tenth century (namely, 820 trout and 180 coarse-fish, the latter, mostly caught in Sweden, including ide,

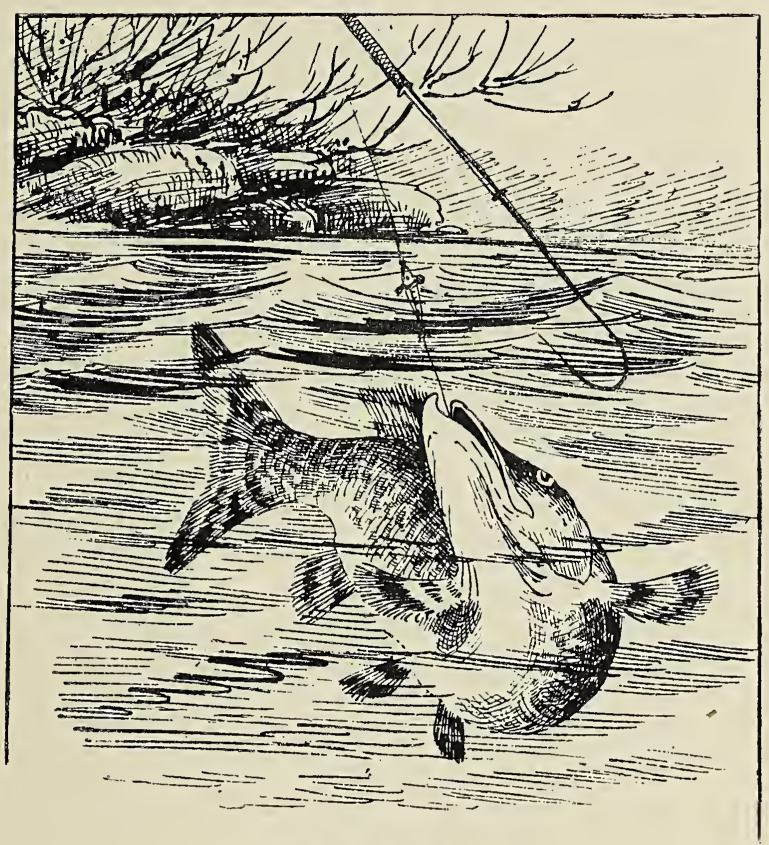

READY FOR THE GAFF.

rudd, roach, chub, pike, and perch). Nightjars dashed to and fro in the gloom of the pines, what time we drove home in the cool midnight.

Next morning we left Christiania by the Wilson liner Rollo for Hull. 


\section{CHAPTER XII.}

\section{AUTUMN IN NORWAY.}

\section{The Sequence of Seasons.}

THE northern summer is over; the long days when a delicious twilight melts into dawn, are a memory for another year. They are replaced by normal hours of light and darkness. The last lingering patches of snow have long disappeared from the crests of the fjeld, and for nearly a month the rivers have run at lowest summer-level. Not a salmon has been taken for a fortnight; you can see the fish lying red and lethargic in crystal depths, whence no lure (save perhaps the prawn) will entice them; while the big sea-trout, that in July afforded such abundant sport, now run daily smaller, till they scarce average a pound apiece. The angling season, in short, has gone by. The rod may be laid aside and reliance again transferred to gun and rifle.

Already the harvest is in full swing; all over the steep hill-slopes are minute, unfenced corn-fields, and the oat-sheaves hang in golden groups from poles, drying and ripening in the sunshine-or rainaccording to the curious custom of the country; one seldom sees the grain gathered into "stooks," save on the flatter lands towards the coast. The second crop of hay is also won in August and September- 
the first being cut in June-and the swathe hangs drying in masses along the stake-fences. No microscopic patch of grass which may find roothold on ledge of crag is overlooked. Each blade is cut with tiny crooked scythe, and the bundles of hay, along with faggots of firewood collected from the same crags, are despatched to the valley beneath by the long wires, familiar to Norwegian tourists, which stretch heavenwards beyond sight. In Norway nothing is wasted. Natural products may be few and poor, but they are utilized to the very last blade, or grain, or stick. Potatoes are impressed to make bread, or what serves as such; while even their "tops," which the British farmer burns as refuse, are here dried and stacked to provide winter provend for the cattle. Almost each farmer grows a tiny patch of hops to flavour his homebrewed ale, and inside his house is heard the rattle of the loom, as the womenkind industriously transform the coarse fleeces of the hill-sheep into cloth for family wear.

The extension of steam-navigation in the fjords and improving means of transit will, no doubt, in time alter this patriarchal simplicity; but at present each valley, indeed almost each house and hamlet, is largely selfsupporting and independent of external supplies. Such minute economies and intense dislike of waste are, however, at times apt to be a nuisance. Thus, for example, when encamped on the fjeld, one finds on the third or fourth morning that one's stock of iron plates and cups, always limited, seems to have vanished; and on inquiry discovers that the missing crockery is all carefully put aside, one plate containing fragments of cold trout, the remnants of yesterday's 
breakfast, others the discarded extremities of tinned meats, and so on-not one scrap of which will our frugal hunters either throw away or convert to their own use till specially bidden.

One crop there is in Norway which might perhaps be better utilized - the wild mountain-berries. The cloudberry, it is true, as well as the cranberry (tutibær) and bleaberry, are collected both for eating fresh (and delicious they are) and for preserving; but the enormous crops of other wild fruits, especially the krak-bær, which in September cover the fells, seem to deserve more attention than they receive.

By mid-August many of the lower fells become as purple as our own moorlands-perfect seas of blooming heather extending down to the fjord levels. There is as yet, on the lower levels, but little sign of autumnal conditions : but on the higher fjeld, beyond where heather grows, the scant grasses and alpine plants have already in August begun to assume the sere and russet tints. By mid-September the forest-foliage is attaining the full glory of its splendid autumnal colouring. Amidst the quivering green of the birch-woods appear streaks and great patches of orange and pale gold-the brilliant "irridescence of decay"-a perfect blaze of colour, contrasted with the dark evergreen of the pines. The grasses, ferns, and many-hued mosses lend the hillside the warmest tones of russet, red and brown ; the mapleleaf fades to a brilliant crimson, set off by the glossy green of the alder and the emerald of the new-mown grass beneath. It is a beautiful season, the northern autumn; but contemplation alone suffices not-it must be the concomitant of action. 
Reindeer-stalking and grouse-shooting both open on August 15th. But the beasts are still in the velvet at that date, and the "store bocks" remain in hiding amidst crags or stony strongholds; each woebegone old recluse ashamed of his defenceless state, and awaiting in solitude the day when, in all the pride of widesweeping antlers, he can again take his place as monarch of the herd. The latter days of August have afforded the best of sport with the deer on the high fjeld; but in the mean time we must be patient and content ourselves for a while with the grouse.

\section{Grouse-Shooting.}

Norway possesses five species of grouse, all more or less abundant in their respective zones, which are as follows :-

Capercaillie (Tjur). In low-level pine-forest.

Blackcock (Aurhahn). Wooded moors, as at home.

Hazel-grouse (Hjerpe). The densest birch-forest.

Willow-grouse (Dal-rype, Skovs-rype). Among the woods on the lower fjeld, and as high up as scrub can grow.

Ptarmigan (Fjeld-rype). High fjeld, above limit of scrub.

I should preface my remarks on this subject by saying at once that, owing to the prohibition of English sporting dogs, I have never gone in seriously for grouseshooting in Norway. One can, of course, in the interminable birch-forests that clothe the slopes and lower plateaux of the fells, without a dog, find and kill many brace of grouse in a day; they offer, too, smart and difficult shots as a covey springs in thick covert, some dodging low through the trees, the majority rocketing vertically upwards till clear of branches. There is hard work in plenty, lovely surroundings, and the charm of novelty in thus shooting the willow-grouse. 
But this is not grouse-shooting. The glory of grouse-shooting lies in its pride of power over bird and beast alike; in the mutual sympathy and interdependence between man and $\operatorname{dog}$ which it calls into play; in the sportsman's personal skill and mastership in directing his dogs.

Self-hunting, on the other hand, is merely blind work, and every one who loves and understands the hunting-dog knows that, without his assistance, the gunner (work as hard as he likés) must leave ninetenths of the game behind him. Watch him, with his beaters, all stamping out that heathery knoll where they have just marked-in a covey. Beneath the bilberries and creeping-willows squat a dozen grouse, literally among their feet. The men know the birds are there, somewhere, for they were accurately marked; but not a feather can they flush, and nothing remains but to start and hunt afresh for another covey. 'The gunner then gets his right-and-left; and the same melancholy fiasco is repeated-plus having probably lost one of his grouse - a runner.

Let me give two or three instances of typical days among the grouse in South and Central Norway, illustrative of the makeshift methods to which Norwegian law has reduced the foreign sportsman :-

August 18th. - The first three days were too wet and stormy to go on the hill, but it cleared yesterday at noon, and this morning we were on the fell-ridge, one thousand four hundred feet above our quarters, by 9 a.m. We had no dogs, but six beaters, mostly boys, whom we disposed thus-two in centre between the two guns, with two on either flank. The orders were 
to maintain a good line with regular twenty-five-yard intervals, thus sweeping a breadth of a hundred and fifty yards; to beat hard, and when a grouse fell, the two nearer boys to be at the spot as soon as the bird. The result was we only lost two runners all day. The day was gloriously warm and sunny; the ground mostly open moor, moderately level, with low thick scrub, but intercepted by frequent ravines, precipitous and flanked by bog and birch-forest. When we stopped at six o'clock, we counted nineteen grouse, an old blackcock, and two teal. Of the grouse, ten were old cocks, though broods were numerous! Had we had dear old "Rap" or "Nell"-now pining at home-it is obvious that the above bag would have been trebled. Coming down the fjeld at night, shot at two woodcocks and bagged one.

August 23rd.-On same fjeld, one gun, working hard with four beaters, got seven grouse (in seven shots) and a golden plover.

August 30th.-Started early for Brökvas-fjeld with Helmar and Hjumpe-the professional avocation of the latter being that of an elk-hound. From among the lowest pines an old caper-cock clattered away, wild: shortly afterwards the clamour of fieldfares attracted attention, and a big brown buzzard sailed by within long shot. The trees were thick, and I must have missed him, for a minute later a pair were soaring at safe distance. During the climb-out, a piebald hare was bagged, and then Hjumpe flushed an old grey-hen, which flew clucking into a tree and sat watching the dog baying beneath. The correct course was to shoot her there, but I refrained, and presently persuaded Hjumpe to hunt-out the rough heather whence she had risen. 
Here we found five of her brood, three of them cocks, which I shot, fine forward birds, nearly half black. In a densely-wooded corner we heard hazel-grouse whistling ; there were high rocks, and we could walk all round the place, spying down into the trees, but nothing was visible, so we climbed down into the hollow which was fairly choked with small firs, birch, and rowan trees, jostling the life out of each other. We heard the birds rising and settling again; but though Hjumpe bayed them twice close by, not a glimpse could we get.

We now separated, W. going down to the lake, while I kept the fell-ridge, and soon fell in with an exceptionally good bit of sport. The ground was wild and rocky, with open pine-forest, and from a heathery hollow hard by sprang twenty willow-grouse. I was not ready, having no sign from the dog, and only got one. The rest sped away through the pines, and, just as we were losing sight of their white wings, wheeled sharp to the left into a small glen. I walked them up and got a brace, marking them again into a ravine a considerable distance forward and higher on the hill-indeed at one time their flight was well over the tree-tops. Made a long detour to get above and beyond the birds to leeward, and on approaching the head of the glen, which was deeper and with stronger covert, Hjumpe (on the leader) indicated game. The grouse rose rather wide, but all scatteredly and in separate lots, some on either side of the gully, so that I managed to drop five with four barrels, Hjumpe retrieving two runners most meritoriously. This time their course was down-hill, but through thick timber, and we could not mark them. Knowing their twisting, devious flight, I never expected 
to find them again. It was impossible to conjecture which way they might have turned after leaving view ; but a bit of genuine luck came to our aid. I was following up a gentle sinuous hollow, which, it seemed just possible, might have attracted their flight, when Hjumpe (still on the leader) almost snapped a single grouse that rose within three yards. In an instant I realized that $I$ had them. And a most curious bit of sport ensued. The grouse lay scattered all up and down that glen for a hundred yards or more, each bird squatting singly among rough heather and fern, demoralized, and ready to "lie like stones." Hjumpe, on being let go, speedily found bird after bird; but as he utterly declined to "stand," it became necessary for the gun to keep within shot of his dog! This meant rushing hither and thither at racing speed across rocks, bogs, and deep scrub, jumping, bumping, shooting, and reloading at a run. Hardly a breath of "wind" remained when we luckily caught Hjumpe, and, having lashed him to a tree, enjoyed a respite. Then the wild chase was renewed, and ere the last bird was found, Helmar had gathered in his bulging pockets three brace more, making a total of sixteen out of the original twenty-and this with only a half-bred elk-dog.

It was long past dark ere we reached our sæterhome. Besides a basket of trout, W. had got a brace of hazel-grouse, and the manner of their death was characteristic:-After firing a "flukey" snap-shot at one through dense branches and foliage, he saw another fly up and alight. Having "potted" this, he found both birds lying dead together. Beautiful as he is, I fear the hazel-grouse cannot boast a good sporting character. 
W. had also found four old capers, which rose, just out of shot, from a patch of rush on the open fell. The next day we rested, preparatory to opening a month's campaign with the elk on the morrow.

The best grouse-shooting I have had in Norway has been on open moorlands above timber-level-say two thousand feet, where the fjeld is patched with clumps of birch-scrub about six foot high, with low heather between. Here the grouse can generally be marked in ; or, otherwise, in such scattered and defined covert, they are easier to find again, when two guns, with three or four beaters, "half-mooning" and surrounding each birch-clump in turn, and taking the birds as they come out beyond, will soon demoralize and dominate the wildest grouse. On such fjelds a few blue hares vary the bag, as well as a chance woodcock and a couple or two of snipe.

From the above extracts it will be apparent that the Dal-rype is a game-bird of the first-class. He is, indeed, a true grouse, identical with our own, save for a few unimportant climatic variations. The northern latitude, with its more severe winters, drive him from the fells to the sheltering birch-woods below, and impel him to don snow-white quills and breast, with a winter garb of white; but, otherwise, in all essential points of plumage, voice, and habits, the two forms are alikeas regards voice, though the notes are the same, that of the willow-grouse is pitched in a distinctly higher key.

Probably our friends, the Norwegians, know their own business best, and it would be unwise for an outsider to question their arrangements. Still, it does 
seem strange that, with their vast ranges of moors and abundant crop of grouse, they should virtually prohibit foreigners from renting those moors, and enjoying the Norsk grouse-shootings as they already do her salmon fishing. Under the present régime, Norway only receives (from foreigners) the market value of her grouse as food, say, one shilling a brace; whereas the sporting value, as game, would probably amount to five times that sum were the importation of dogs (under reasonable restrictions) permitted. I am aware that English dogs are introduced by various means into Norway. Some are advertised for sale every August. But that is nothing. The man who loves shooting over dogs will have none of the "rag, tag, and bobtail pack," and, unless he may bring his own dogs with him, he will prefer to shoot his grouse at home.

The hazel-grouse, or hjerpe, as already hinted, is deficient in true sporting attributes. Dwelling in the thickest forest, where a clear shot is rarely possible, he springs away with a dash and clatter that should carry him for miles; but he perches incontinently on a tree hard by, where he will sometimes sit, or climb, parrotlike, among the branches till a fifth shot from our schoolboy's catapult lays him low. He has splendid speed of wing, and it is almost impossible to kill him as he dashes off his perch in the pine; but the perching habit is fatal to his reputation as game. He is, nevertheless, a beautiful bird, and associated with pleasant memories of days passed in the primeval forests of Scandinavia.

Of the blackcock, too, little need be said. $\mathrm{He}$ is found in open forest and marshy moorland-the same 
places as, mutatis mutandis, he occupies at home. He, too, is an old love; but his habits and haunts are set forth in "Bird-life of the Borders," and they do not differ beyond the North Sea. This clears the ground in regard to three of the five Norwegian grouse; as regards the fourth, the ptarmigan, I have already

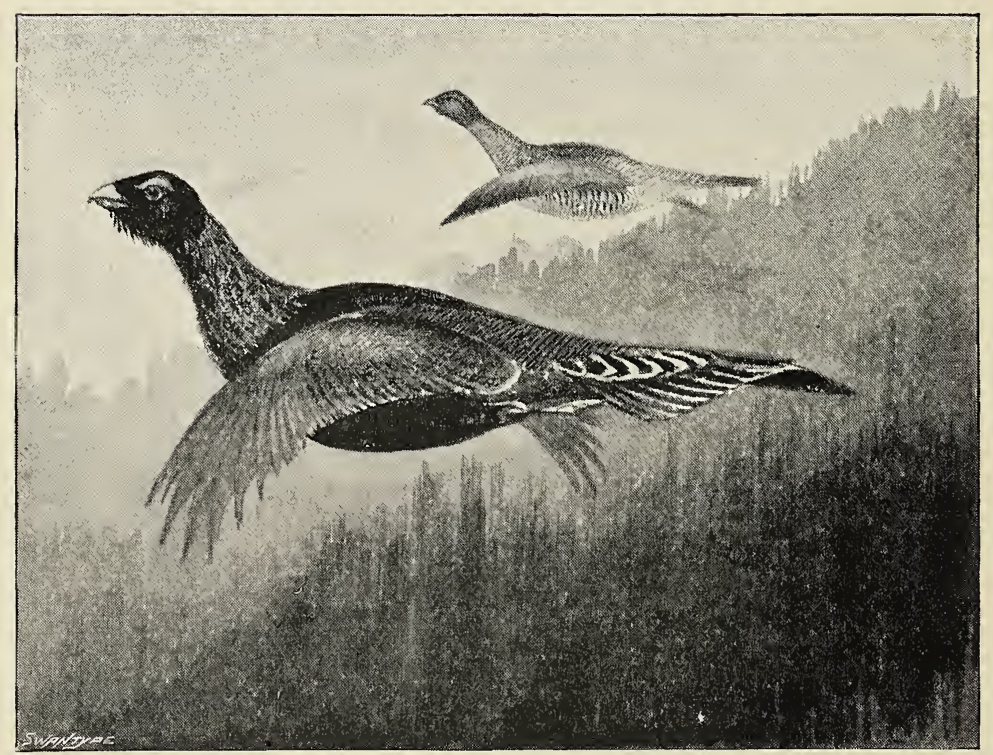

SAILING ON SET WINGS OVER THE TALL SPRUCES.

(Capercaillies.)

described elsewhere his haunts, habits, and sporting character.

And now remains, fifth and last, but largest and most imposing of all the grouse-tribe, the great capercaillie, or tjur, in Norsk. What am I to say of him? I must think it over.

After two more years' study of the Tjur, since 
writing the above, I am still unable to place him in the first rank of game-birds--reluctant as I am to do even unwitting injustice to a truly noble species.

The "quality" of any game must depend on the degree of sport it offers to skilled and systematic hunting. But with the caper in the endless Scandinavian forest, no system whatever is available or possible. A wild bird amidst dense trees, he is altogether too scarce to be worth following, and "driving" is here out of the question. In winter the case is different-he then offers a fine mark for the rifle-but in autumn (bar mere flukes and lucky chances) the only way I see to kill him is the haphazard and unsatisfactory one of chancing charges of mould shot through perhaps seventy yards of intervening branches. And, even at that, in all the years I hunted those forests, I do not think I could ever have had six shots in a day-often only one or two. That is not sport, nor worth the trouble of trying. Hence I refuse to include the capercaillie as a gamebird of any real value in Norway.

There is the native method of shooting the capercaillie (and all the other forest-game) that should not be omitted, though it is not sport. Most of these birds, on being sprung by a ranging dog (and not suspecting human presence), will "tree" hard by. The dog is trained to bark beneath, thereby monopolizing the attention of the game till the gunner has time to come up. A pot-shot then results. We have not ourselves been wholly above adopting this plan when shifting camp in the backwoods, and meat was scarce. The game being often most plentiful along the roadsides, we sometimes secured several brace, besides beguiling the weary hours 
of travel. Sitting in the cariole, it was amusing enough to see six or eight blackcocks and grey-hens crowded into a little Scotch fir within fifteen yards, and all intently gazing downwards at the baying hound beneath; while Bengt and Johannes manœuvred behind the adjoining trees till they got the greatest number in line.

Another point in favour of the capercaillie I should not forget. In September, when feeding on the mountain-berries, he is splendid eating; and I consider that even the old caper-cock-tough as he is, or is supposed to be-has then a delicate and delicious flavour that is not surpassed by any other game-bird. But he must be skinned first, and wants a lot of cooking after thatI refer to old cocks. On one occasion, having killed an elk betimes, I was back in camp before noon, and soon afterwards committed an aged tjur to the pot. All the afternoon he simmered and stewed. My companion did not turn up till past eight, and we dined about nine. That bird was simply magnificent; we remember his flavour to this day, and he was tender, too.

III. Specific Notes on Grouse and Ptarmigan.

Ptarmigan.-The Scottish and Norwegian races of this bird are identical, though slight local variations occur, tending towards a generally darker summer plumage in the southern parts of their range. Some examples from South Norway are almost black in breast and back-a phase I have never seen in Lapland specimens ; while the Icelandic form is lighter still, showing no trace of black whatever.

The latter (Lagopus rupestris) I have not seen in 
life, but the full descriptions given in the Ibis for 1885 , p. 386 , and 1886 , p. 49 , leave no room to doubt that it is a true ptarmigan, agreeing in note and frame with those of Scotland and Scandinavia, but differing therefrom in the absence of a lavender-blue autumnal dress, in which characteristic lies its chief title to specific differentiation.

The (so-called) ptarmigan of the higher arctic region -that is, Lagopus hemileucurus, of Spitsbergen-is totally different, and is not a ptarmigan at all, but a true grouse. The points in which ptarmigan differ from grouse are very distinct, and may be described (apart from plumage) thus :-(1) The guttural croaking note, like that of a frog. (2) The weak and comparatively slender beak and claws. But the beak and claws of the Spitsbergen ryper are remarkably strong and thickstronger than those of the willow-grouse, indeed its claws resemble those of badgers-while its note is a distinct grouse-like " bec, bec," lower and more subdued than that either of our bird or its Scandinavian representative, but in no way resembling a croak. Its plumage also coincides in colour with that of the willow-grouse, and it further agrees therewith in frequenting the valleys and lower grounds.

Since I first made the acquaintance of Lagopus hemileucurus in Spitsbergen, in July and August, 1881, I have had more extensive experience of this family, and am now sure that the big brown Spitsbergen ryper are not ptarmigan at all, but merely the hyperborean variety of the willow-grouse, bearing precisely the same relationship to the latter as it, in turn, holds to our own red grouse. To make the relative distribution 
of this group more clear, they may be put in tabular form, thus :-

True Grouse.

Habitat (in North Europe).

1. Lagopus Scoticus-Red grouse-British Islands only.

2. $\quad$ subalpina-Willow-grouse-Scandinavia only.

3. " hemileucurus-Arctic willow- Spitsbergen and the grouse $\}$ higher Arctic region.

True Ptaruigan.

1. Lagopus mutus-Ptarmigan-Both Scotland and Scandinavia.

2. " rupestris-Rock-ptarmigan-Iceland and the lower Arctic region.

Another important point in this connection is the relative size of the two forms. Ptarmigan, generally speaking, are distinctly smaller than grouse; yet two adult Spitsbergen ryper, shot by me in Ice-fjord on July 26th, weighed $30 \mathrm{ozs}$. each, while three shot by Mr. Arnold Pike, on Danes' Island, in October ( $79^{\circ} 55^{\prime \prime}$ N. lat.), scaled exactly one kilo, or 2 lbs. $3 \frac{1}{2}$ ozs. apiece - that is, far heavier than the biggest red grouse on record.

It will thus be seen that, though the ptarmigan affects greater altitudes, the grouse is really the stronger and hardier bird, and survives at far higher latitudes. 


\section{CHAPTER XIII.}

HUNTING-CAMPS ON HARDANGER VIDDEN.

Reindeer-Stalking.

I. Under Difficulties.

The Highlands of Hardanger, as the words Hardanger Vidden may be translated, must count among the larger areas of land that still survive in Europe absolutely barren and uninhabited. Measured roughly upon the map, the Vidden stretch eastward from the wellknown Hardanger fjord, some seventy or eighty English miles before the valleys of Numedal or Hallingdal are reached; while from its southern limits on Haukelidfjeld, abutting on Telemark, no break occurs up to the neighbourhood of the Sogne-fjord, upwards of one hundred miles distant in a northerly direction.

The whole of this space of seventy by one hundred miles is a mountainous table-land of a mean general elevation of 4000 feet, traversed or dotted with hills of much greater altitudes. Thus, on the north, the icefields of Hardanger-Jökul reach 6467 feet, Hallingskarver 6000 feet; Haartieg, in the centre, 5390 feet; and on the southern verge, the Stor-fond and Nŭps-eggen exceed 5500 feet.

The landscape of Hardanger Tidden may be likened 
to some great ocean, storm-tossed and turbulent, suddenly arrested-petrified in all the grandeur of its wildest mood. High ridges, as those of Hallingskarver and a hundred more, cloud-flecked and snowcapped, resemble broken foam-crested billows; while between opposing rollers shoot up single waves-angry pyramids, as the cone-like peak of Haartieg. Between are valleys, great and small ; gorges, ravines, and rolling fjeld; mostly rock, but diversified with tawny downs, with glaciers and the glint of water-lake, river, and foss. In summer, a few hardy squatters push out advance-sæters and graze sheep and goats on the pasturage of moor and corrie; but autumn soon drives these to lower levels. Then the Vidden are left to the reindeer, the ptarmigan, and the hunter.

To the Hardanger Vidden we have twice organized sporting expeditions. On the first occasion good weather prevailed and sport resulted ; but I do not here propose going into merely sporting details, the system and practice of reindeer-stalking being already touched upon in a former chapter. The second venture was in another district, in the southern Vidden. The summer had been wet, but in mid-August a break in the monotony of rain-charged skies welcomed the opening days. It was but transient. The first week had yielded three deer, and prospects looked bright enough when, on August 21st, we pitched our second camp on Hellevas-fjeld-a day-and-a-half's journey from anywhere. But Dieu dispose. The next fortnight brought in a spell of the very worst and wildest weather I have ever experienced, and the like of which I earnestly hope I may not see again. Words must fail fully to describe that series of 


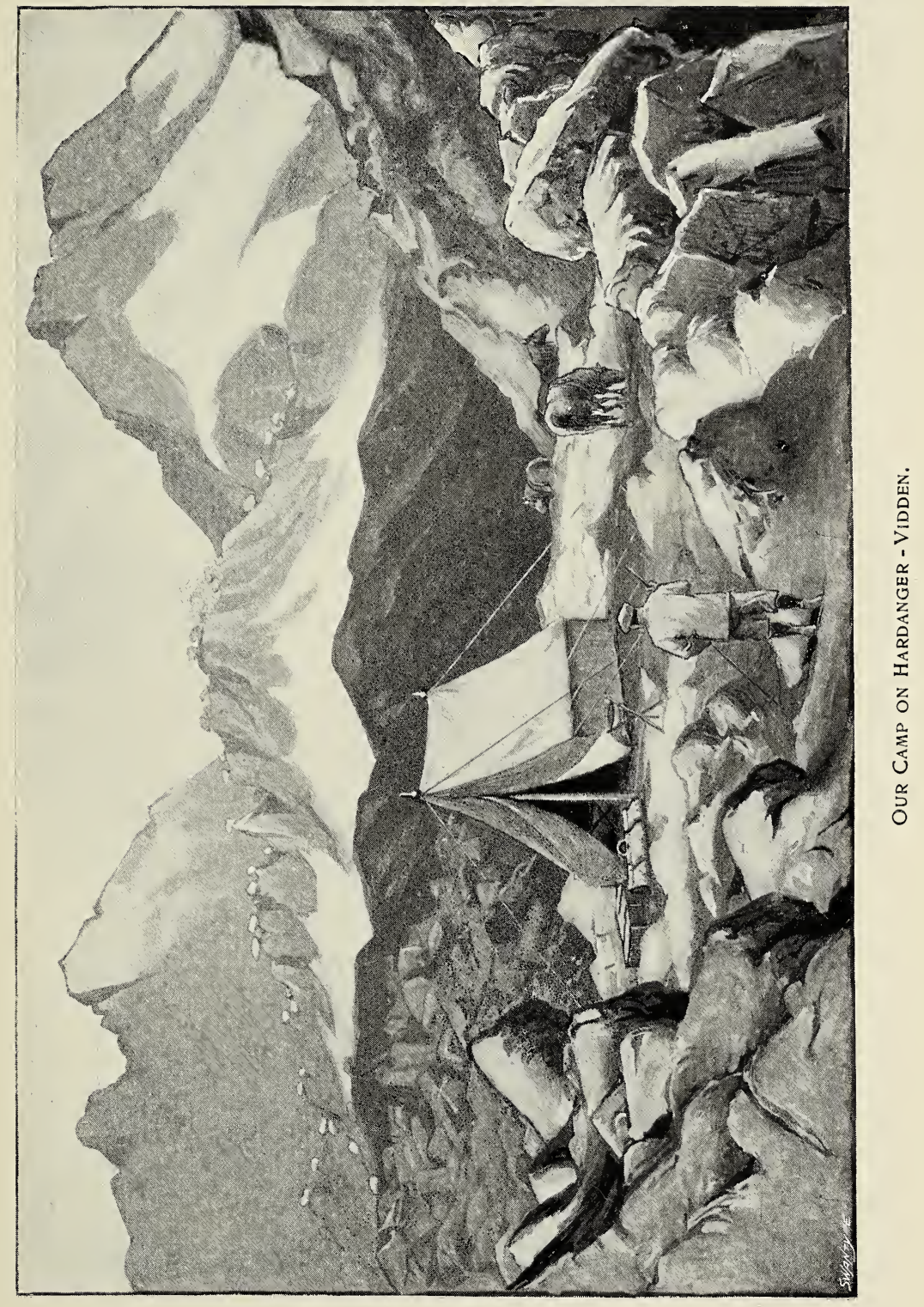



hurricanes from every point-snow-blizzards, rain, and driving scud in turns; or our own position under canvas, unable to hunt, cut off by swollen torrents from retreat. Superlatives sound but tame, and posthumous expletives offend alike both good taste and sound philosophy.

The following extracts from a diary kept on the spot will convey some idea of this experience; premising first that our abode was a canvas tent- "Explorer" pattern, single roof, size six feet by eight, which just afforded space for our two tressle-beds, with about a foot to spare between.* Our hunters were berthed in a steinhuset, or cave-dwelling dug out of the brae, some thirty yards below. The altitude of the tent was just under four thousand feet.

August 22nd.-Ere the last star had paled we were astir, boiled coffee, and got away by 5.30. An hour later it was raining-fine rain at first, but growing worse, with scud on hills. Nils, my new hunter, pleased me by "spotting" a fox at long distance, scampering about on the edge of a snow-brae, but I declined the shot, as we were in perfect deer-country. Near midday found fresh spoor, and knew by the "sign" that we were within half an hour of deer-a certain find! But just then the rain and sleet came away solid, and in the blinding scud nothing could be seen beyond fifty yards. Waited an

* After trying various patterns of hunting-tents, I prefer the rectangular, for convenience, before the bell-shaped form-albeit the former necessitates carrying double uprights and crosspiece (all jointed), instead of a single pole. This tent was made by Messrs. Piggott Bros., of Bishopsgate Street. The tressle-beds (Salisbury pattern) and Pandora sleeping-bags are supplied by Messrs. S. W. Silver, Cornhill. 
hour till we were benumbed, when nothing remained but retreat. Reached camp at 3 p.m., W. arriving same time without having seen deer. Strong gale towards night; hung clothes out on guy-ropes to dry, in hopes the wind may blow rain over. These, alas! proved illusory. August 23rd.-After a terrible night of wind and rain, the outlook this morning was dismal in the extreme -all idea of stalking abandoned. At noon a thunderstorm, with deluges of rain-all hands digging drains and strengthening guys. At 4 p.m. weather cleared a little, so sent men to set net, while we went up the north valley. The country out there is all high, desolate mountains, five thousand feet by aneroid, but we saw no deer. On way down, descried two men, who suddenly disappeared. Fearing they were poachers who might have rifled our camp, we searched the spot, but saw nothing of them till we reached camp, where we found them smoking their pipes! They had brought up my rod-box, which I had forgotten.

Very wet and stormy again-wind S.W.-but last thing the sky cleared, rosy hues appeared, and hopes rose like rockets.

August 24th.-Wehad made up our minds this was to be a fine day, so turned out at 4.15-only to find solid rain falling; yet W. went out alone, returning at seven, without result. An hour later we made a second start, but rain grew worse and worse, and fitful rays of sunlight, very transient, only heightened the gloom. Again I found quite fresh spoor (including two first-rate bucks) near Ure-vand; but again we were driven back, at the critical moment, by rising wind and incessant sleet, which it was impossible to face. Into "sleeping bags" 
by 4.30 . Tent beginning to leak in places. While I write, another misfortune is reported: the net has caught no trout. Why? "The thunder."

August 25th.-Bitterly cold all night, and this morning the ground is white and snow falling. Called at six, but "laid in." Sent men to draw net-result, one halfpound trout, not enough for breakfast. Heavy snow all day; stayed in "bags" till midday, coffee and bread in bed; then twice attempted to start, but both times were driven back by furious snow-squalls from $\mathrm{N}$. At night wind shifted to S.W., with heavy rain.

Five days have passed since we entered the wilds, and not a shot has been fired nor game seen. For this we have to thank the weather. Reindeer-shooting is dependent wholly on the weather-next on luck; but without weather you can't have luck.

The cold, too, for August, is intense. Snow-fonds. and glaciers impend our camp-one of them is twenty miles long. Swollen torrents surround us (there were only three at first, but new ones commence business every day, and the originals have trebled in size), and the roar of the cataracts blends day and night with the creaking of guy-ropes, the flapping of the tent, and the rattle of rain and hail on our canvas roof. We have not a dry rag left ; five days' rain has drenched everything, and we must perforce turn in at four, not having a change left. Moreover, having killed no game, we are reduced to living on bread-and-cheese and the last tin of corned beef; the only hot thing we get is coffee. The "brandy" we brought proves to be aquavit; our butter and literature are exhausted, though not our patience-but oh, for a change in the weather ! 
August 26th.-After a night of rain, glass rose and sky cleared towards dawn. The wind veered to N., and at last we had one fine day, though bitterly cold. Sent Aasmund at 5 a.m. to the valley for supplies, and W. and I hunted together; but though we worked fourteen hours in lovely deer-country, with miles of tawny grass and pasturage, we saw no living thing except a few buzzards, kestrels, and a falcon waiting on a covey of ptarmigan. There are very few of the latter this year, and the only other birds of the fjeld are merlins, ravens, wheatears, titlarks, and a pair or two of dippers. Lemmings abound, as do field-mice and foxes, and we have seen one alpine hare, a stoat, and the spoor of a bear.

August 27th.-Hard frost: our water-buckets and basins all frozen, and sponges hard as rocks. Started at six, Nils and I going up Vasdals Eggene. We had just got nicely climbed out to five thousand feet, when it began to snow, and in ten minutes we were driven to shelter. Waited till nearly frozen, then abandoned idea of going higher, and tried what looked a fine ravine towards N.E. But weather went from bad to worse, snow lying six inches deep and driving on a whole gale Could not see ten yards, so " chucked it," and made for tent, arriving benumbed and blue at 1 p.m., only a few minutes after $\mathrm{W}$. This afternoon proved the stormiest of all, rain driving in horizontal sheets. The tent leaking badly, there are pools of water all over my bed-cover, and a steady drop from a score of places on the windward side.

August 28th.-Morning again broke in deluges of rain, and the wind had threatened the stability of our abode all night. Obliged to abandon intention of 
shifting camp, as we had arranged, beyond Great Bear Lake, for we cannot now cross the flooded riversindeed, we are fixed here, cut off alike from advance or retreat. The tent is full of spiders, large and lethargic.

Towards midday started in heavy rain, Nils and I climbing out to the high ground on N. (five thousand three hundred feet), thence along a chain of lakes, one shore sandy, the other all high snow and glacier-ice; but though there was plenty of old spoor, we saw no deer.

Coming down Vasdal glacier, Nils slipped, and being above me, knocked me over, and we both slid down to within a few yards of the lake-an anxious moment, but all ended well.

August 29th.-Deep snow around tent and arctic conditions. Dressed treble, but the day turned fine, and even hot at noon. We had to catch the ponies to get across the rivers. Nils and I hunted by Mid-Nuten to Simlertinder. Just before noon, Nils suddenly pulled me almost on to my back, and at last we were in sight of deer. About six hundred yards away was a herd of between thirty and forty, but all going at speed, and I feared they had seen us. No! half a mile ahead they settled down to feed on a grassy slope. We meanwhile had been running at top speed to keep them in view, and on the rough ground-all broken gorges and corries-I was getting pretty well "pumped" ere the deer eased down. During the next two hours, I three times tried to "get in," but so fast did the deer keep feeding forward, and so scattered were they, that I only succeeded in coming up with four or five, and these all small beasts. The deer were now scattered 
up and down a steep shale-slope that covered the base of higher crags; and spying them with the glass at four hundred yards, I made out three very good bucks (one in velvet), besides one enormous old bull carrying a grand head (see p. 6), and another heavy beast, pure white all over, but with inferior horn.

Once, during those two hours, we had all but "cut them out." While the deer crossed a broad ridge, by a short cut and hardish running, we commanded the whole herd at little more than two hundred yards as they crowded through a narrow rock-pass. The forest of horns, all jammed together, was a fine sight-we could hear antler rattle on antler, and even the curious "clacking" of the hoofs. This was a golden opportunity for the meat-hunter, with his 1000-yard repeater. But no separate shot was possible: and the big bull was covered quite three-deep.

It was now two o'clock. The deer had ceased to "feed at a run," and for half-an-hour, preparatory to their siesta, grazed leisurely on shale. I state this as I was watching them keenly with a powerful glass, and afterwards satisfied myself that there was not a vestige of vegetable-growth on that pile of dark detritus.

At 2.30 several deer laid down on a grassy shelf above the shale, but below the higher crags above. The big bull, with his snow-white friend always in close attendance - the two were always lethargic and lastmounched slowly about the shale for some time longer, and then, moving our way, lay down among some nearer rocks.

We crept forward with extreme care till we lay within three hundred yards of the two. I saw clearly 
that the big bull could be stalked without any great difficulty to within sixty or seventy yards-but for those deer above! These, overlooking the whole scene,

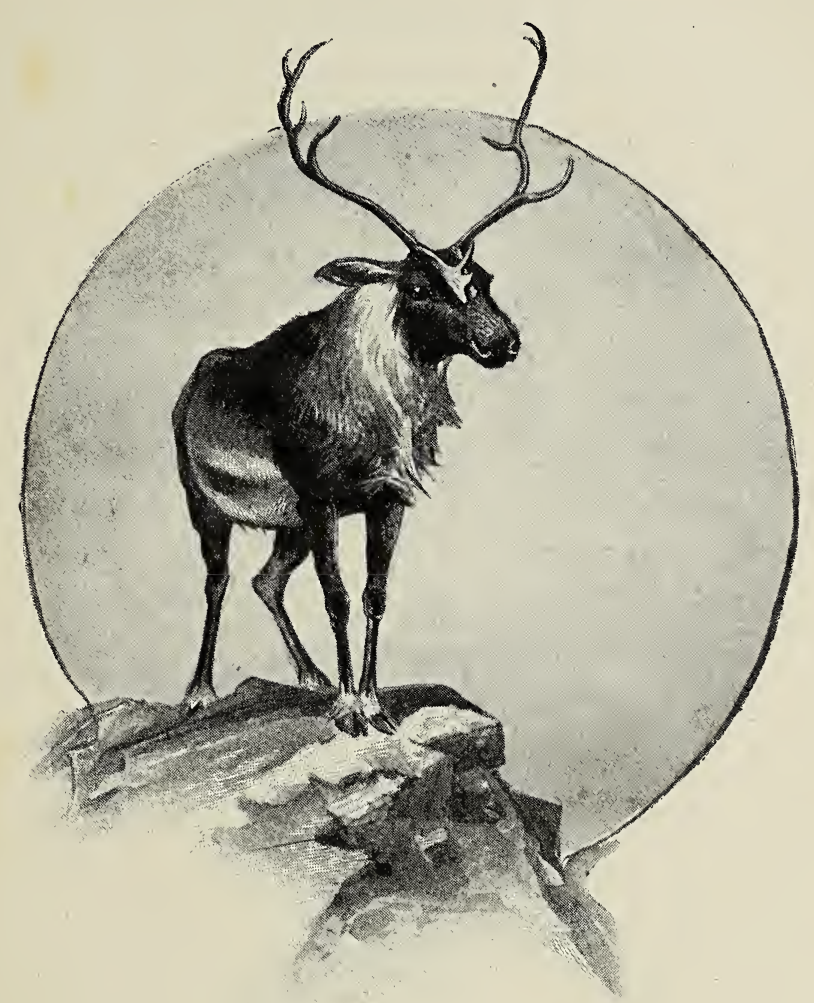

ON SENTRY DUTY.

and with sentries thrown out, not only at either flank of their shelf, but doubly secured by a pair still posted on the centre of the shale, commanded the whole position from the front. Advance in that direction was impossible. 
As an example of shrewd animal-instinct and strategy, their dispositions were magnificent, and revealed true generalship. But, after all, to man is the dominion; and, speering the deer from behind my boulder-really revelling in this rare scene far more than in its prospective promise of sport-I at once perceived that (regarded merely as game) I had them in hand. For the hanging crags above, and to the right, commanded all the deer on the shelf, quite clear of wind, and at less than fifty yards. With the glass I worked out every detail of the route-it was safe. I could reach that crag-edge in twenty to thirty minutes, and knew the deer would not move for at least an hour. To man, as just said, belongs the dominion; but civilized man does not always push that advantage to the utmost, since sportsmen are not butchers, and there the beasts score one! For no inducement on earth would to-day have availed to persuade me to take those smaller deer on the shelf, while the grand old stor-bock lay full in view before me. $H e$ could not be reached from the crag, and him I had resolved at all costs to make my first target, come what might afterwards. Nils implored me, almost with tears, to make sure of mad (meat) by taking the certainty on the shelf; but I remembered Breiava (see pp. 37, 38), and meant to do that again. A coldness arose between us-I felt it and grieved for it-as we sat and ate our lunch together behind that boulder.

Punctually to the hour, the first deer began to get up. One by one they arose, and ten minutes more were spent in stretching, shaking, and little friendly greetings, which displayed poses and attitudes of infinite grace. 


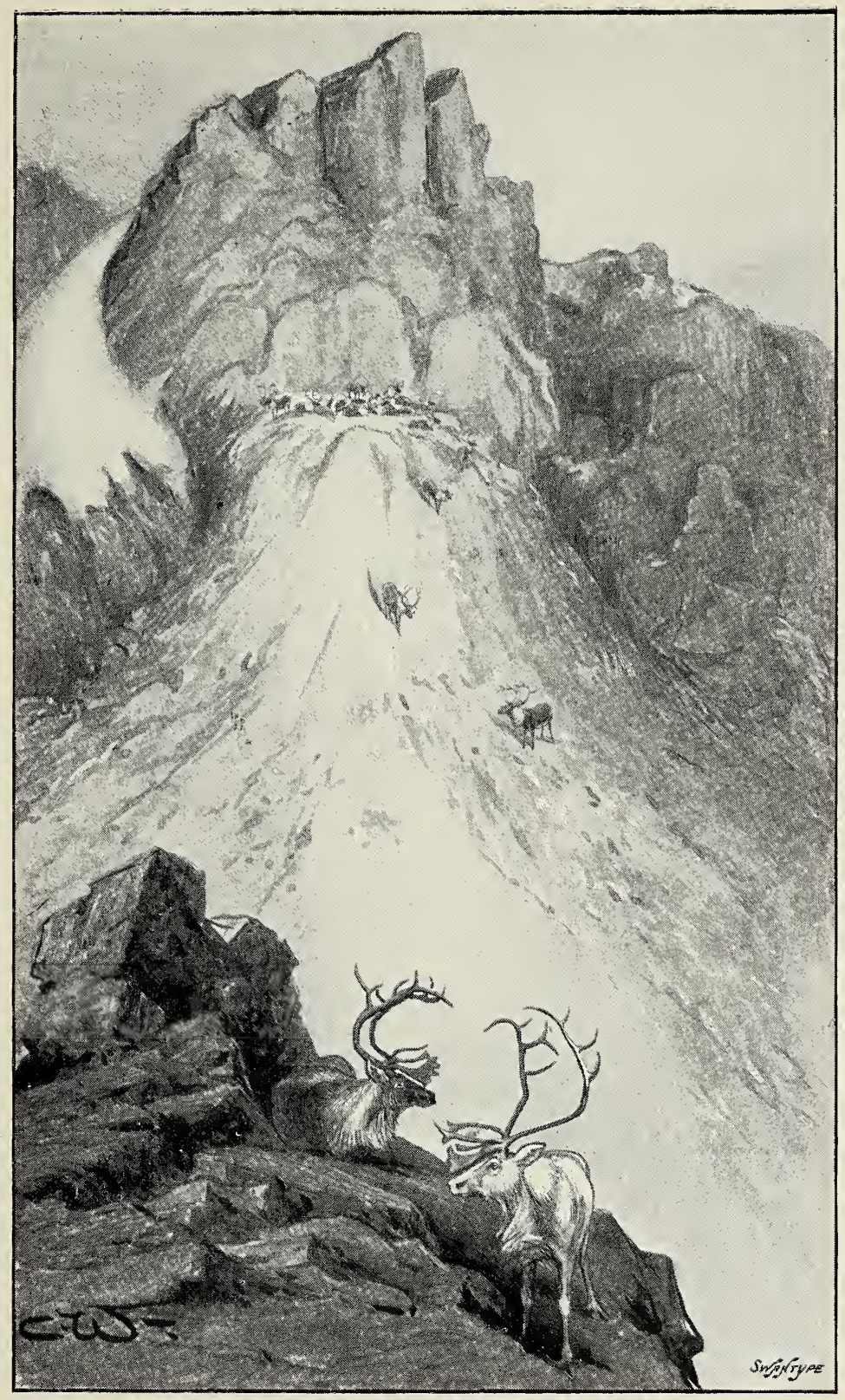

ReINDEER REsting AT MID-DAY.

(The shale-slope of Simlertind.) 

Then they started off on the serious business of feeding. Had they elected (as we were hoping) to continue their former course, along the base of the crags, the herd must have passed our position within long shot; but, instead, they held north, filing up a snow-filled couloir that led over the sky-line, several calves bleating maa! maa! as they disappeared. We followed fast. Beyond was a deep basin. Here laggards lingering behind the herd delayed our advance full half-an-hour; thence, over the ridge, into another valley, with a lake filling its floor and a glacier blocking its extremity-a lovely spectacle as those forty agile deer skipped playfully across the icy barrier. Then a narrow "pass" to the left led out on to a boggy plateau-the final scene!

On reaching the crest of the pass, I observed the deer all scattered, feeding on the boggy flat below, many within seventy to a hundred yards, one big bull standing statuesque on a rock at three hundred. But the lowering sun was now direct in our eyes, glinting and obscuring detail; colour had vanished, and outlines were difficult to distinguish. The bull fed slowly, leisurely, towards us; at intervals he halted for minutes at a time, rubbing his horns on the rocks or pretending to drink at the moss-pools. At length I recognized him for certain (by his one big back-tine), and decided to take the shot when next he showed his broadside. The distance was well over two hundred yards-probably two hundred and forty-and I rested the rifle over a flat rock, one of the semler (hinds), only sixty yards away, looking up as I got into position.

For some seconds after the shot the bull stood still, and I thought he had it true, though I had felt the 
rifle jump. Then he went off full-swing, sending the water flying like flashes of flame as he. ploughed through the bog. The second shot was a miss-the merest trifle too high. The ball passed between his horns, almost grazing the head, as he went away, endon. Nils meanwhile had managed to miss the white bull, and, reloading one barrel, I missed a third shot, galloping at near three hundred yards. We raced hard across the flat, but on reaching the slope beyond, it was clear that all was over-the deer were then crossing the river half-a-mile below, all sound, the two heavy beasts (as usual) bringing up the rear.

It was a long shot and the light was bad; still I ought to have made sure of it, and would have but for one fatal mistake. To avoid "stampeding" the watchful hinds, hard by and already suspicious, I had relied on resting the rifle on my cap on the rock, instead of holding her firm forward with the left hand. The result was she "jumped," and the ball went anywhere. We watched those deer some two miles, and then turned homewards in silence and self-reproach.

Here was a hotch-potch of mixed sensations! First, eight blank days without seeing game or firing a shot; then, to-day, a grand stalk lasting near five hours, during which we often held the winning card; finally, taking a hazard and scoring a miss. Where now was our boasted dominion?

Nils made one remark. After tramping for an hour, he said, "After all, he was ikke saa meget, meget stor! Not so very, very big!" It was kindly meant; but he was big, and we both knew it. Mentally, I had already taped those grand antlers (no photo annexed) 
at well over four feet, and put their points at nearer forty than thirty! The "tops" were specially fine and branchy, while there was an unusual development of the backward tine on the left horn. The white bull, though bulking as big in body, carried only a poor head. He appeared to be snow-white from stem to stern, and was probably an albino.

Next day (August 30th) was the wildest and stormiest I ever weathered on the fjeld. We sighted two deer, but stalking was out of all question, and such was the force of the wind that in attempting to climb the "Horse-shoe glacier," W. was lifted off his legs, and had we not had the ponies with us, I doubt if he could have reached the summit. But the reader's patience may well be exhausted by this weary catalogue of difficulties and disappointments; so I will conclude, by way of variety, with an episode of the other sort.

\section{A LuCKy Wind-UP.}

Our last day, for another year, in the glorious freedom of the fjeld! Weeks of hard work tend to toughen muscle, but they tire limbs, which it now requires some little effort to withdraw from the cosy depths of the "sleeping-bag," while stars yet glimmer through the open door of the tent. Wiry little Knud brings hot coffee and cold venison cutlets at 6 a.m., and soon we are off to spend our final day in the corries beyond Værungs-vand.

From the northern verge of this wild fjeld-tarn open up a succession of grassy glens leading away into the mountains behind. Its southern shores are occupied by 
one vast snow-bræ, or incipient glacier, which rises from the water in a thirty-foot face all furrowed with cavernous crevasses, brilliant in opal and emerald. From this face break off huge masses, which float like icebergs in rippleless water that reflects each detail of its wild environment as in a mirror. The day was still young, when, far away up the glen leading from the eastern end of the lake, something moving caught my eye. A glance through the glass showed this to be a deer-two deer, both small-then a third, and a fourth, the two last good-sized bucks, followed into view, all four feeding three-quarters downwind towards the lake. Tactics were simple enough at first. By retreating a few yards till we had "sunk" the deer, we soon gained the water's edge, and then, sheltered by a terraced ridge, ran all we knew along the level shore.

Towards the head-water more care became necessary. We must then be moderately near our game; moreover, parallel with the shore protruded a plutonic ridge that had apparently welled forth from the molten bowels of earth and cooled there. No deer, it was very certain, would seek pasturage on that naked granite; but we could not guess along which side of it they might elect to feed. I took the risk, and kept along the ridge alone, leaving Knud behind. Now bare bed-rock is not favouring substance to hide upon; still it has folds and rounded crevices; and, more important far, there are the "erratic blocks," or balanced boulders-I forget their correct name-that always seem to have had an affinity to pitch on plutonic surfaces. This strip of granite was plentifully bestrewn with them, and 
by cautiously advancing from one to another, we had already approached within one hundred and twenty yards of its extremity ere the first of the smaller deer showed up in sight. He was feeding to the right-that is, towards the lake; and soon afterwards the second small beast was seen, moving down the left side of the ridge.

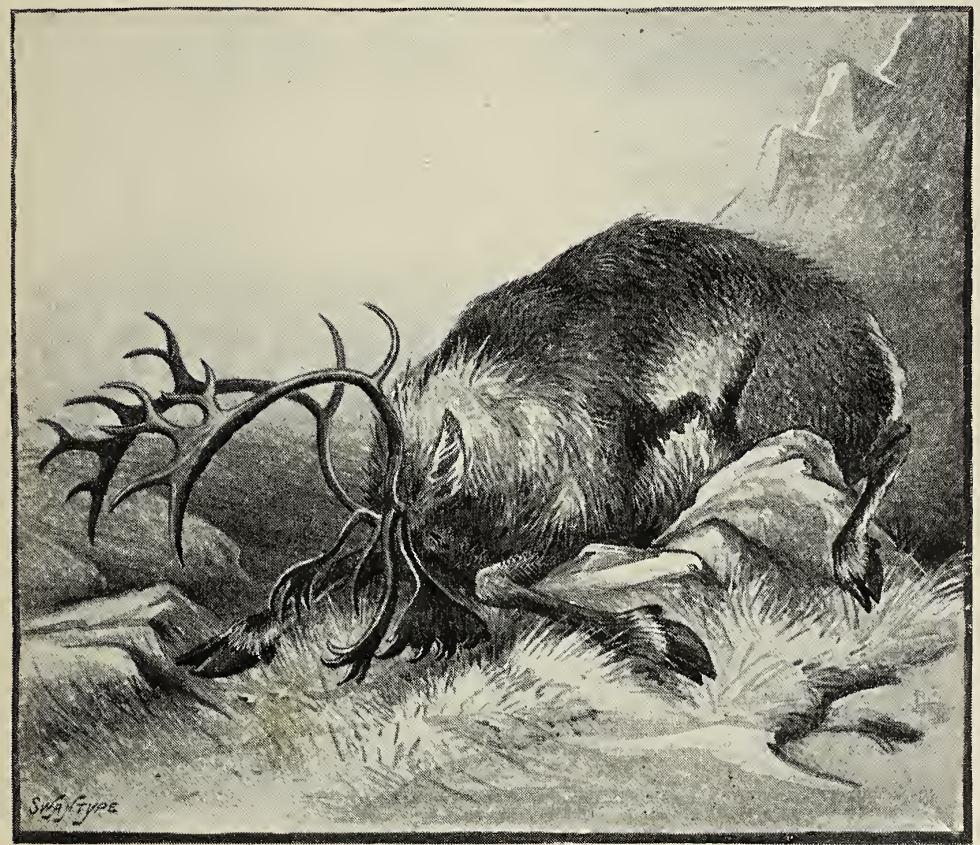

“STRUCK STIFF"-(THIRTY-THREE POINTS).

Minutes now elapsed without any sign of the two more desirable deer. What was delaying them in that hollow ahead? Both the smaller reins were already in shot, but the larger lingered. Besides, the little spike-horn on our right front was coming forward so fast on the barren ground that he must soon pass us and 
come dangerously near our wind. With intense relief I saw No. 3, a fine buck with good clean head, rise the ridge and follow No. 2 towards our left. Soon

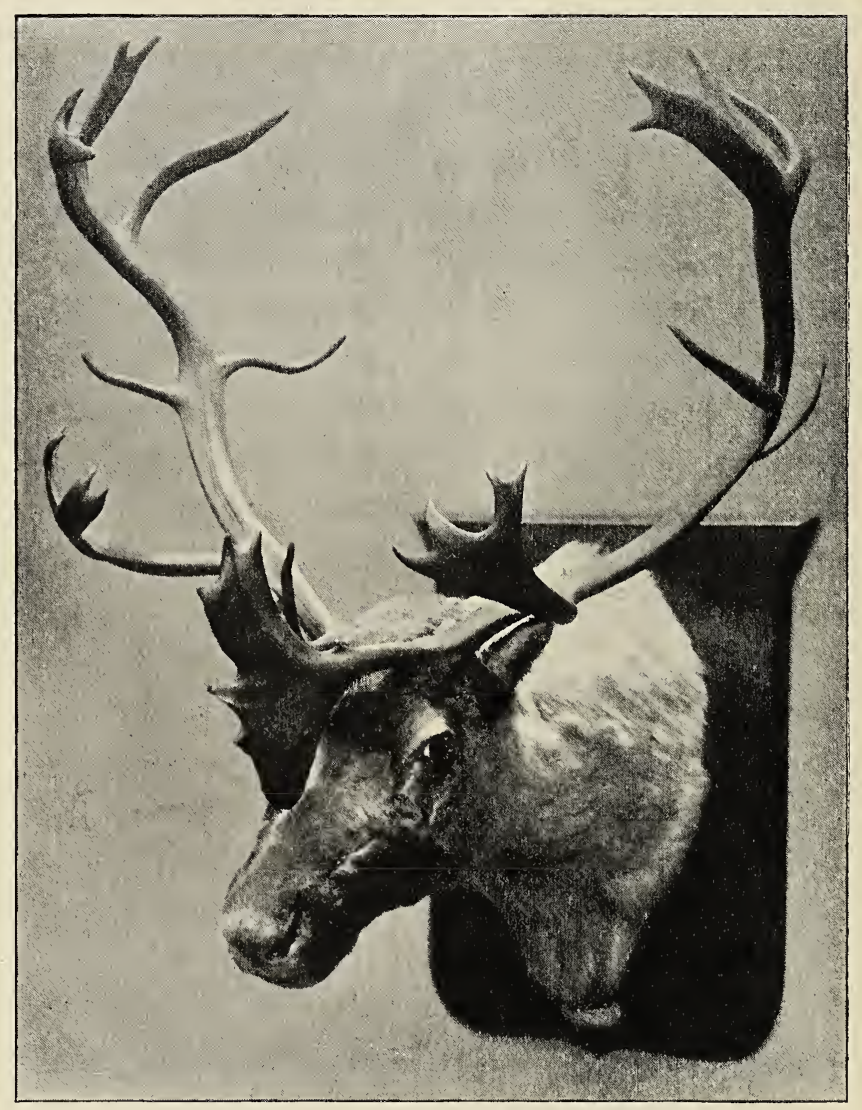

REINDEER-A VERY OLD BULL.

he was within a hundred yards, petulantly pawing the moss with hoof and snow-plough by turn, but I hesitated to fire before No. 4 had appeared on the scene. Another anxious minute passed. The position was growing 
critical ; for our friend on the right (No. 1) was now nearly abeam of us, not sixty yards away, and we had to wriggle round the stone to keep out of sight. I had waited as long as I dared-another twenty yards and that intrusive little beast must come below our wind. The sights now lay very true on No. 3-just behind the shoulder as he stood one-third from us, at seventy yards-and he fell so dead I never saw him drop.

Now it was that luck stepped in. Both the small deer had dashed off-the spike-horn actually going behind-and, in that instant, No. 4 bounced up on the ridge, took this in, and stood for a second "on gaze." I had only one barrel loaded; but felt that that ball had gone true, though the deer disappeared at the shot. There was blood hard by, however, and within a hundred yards, he lay dead on the rocks, with a tiny hole full in the centre of his shoulder.

This deer carried a really pretty head, shapely and regular. Though taping less than three feet, the horns carried over thirty points: while, on the first deer, we counted seventeen-both clean.

\section{Hints on Staliking.}

The Reindeer I regard as ranking quite with the first of European big game. Both his haunts and his habits combine to place him among the best of all beasts of chase. For he feeds by day and frequents open fjeld, where he is ever amove, and that in full view, from dawn till dusk-save for one hour, or possibly two, at midday, when the bunter will be well advised to 
share his rest.* The reindeer never hides in scrub or dense forest as does the elk; he has no nasty nocturnal or crepuscular habits like bear and boar, ibex, and some other kinds of deer. The broken character of his haunts is, moreover, all in favour of the stalker. The pursuit, indeed-once game is viewed-is largely a matter of hardish running, so as to keep in touch while out of view. There is but little climbing and still less of the creeping and serpentine progression usually associated with the term "stalking;" though it is often necessary to worm over an open bit, or to crawl a few yards to gain a shelter or cross a sky-line.

EQUiPMENT. - Where the stalker is lodged in a hut or sæter, he can of course have attendants who keep fires going, dry clothes, and make things generally comfortable. But huts are rare on the highlands, and a tent has an advantage in portability, for camp can thus be shifted at will all over the wide range of the fjeld. Tent-life, however, demands some forethought, or grave discomforts may ensue. I offer the following hints to those about to essay it for the first time :-

1. Remember that the cold and wet on these heights are apt to be far more severe than one would imagine possible while packing (in a hot sun !) at home, or even in the subjacent Norwegian valley. Bring, therefore, what may appear a superabundance of the

* The only other game-beast in my knowledge that so entirely fulfils the stalker's ideal is the chamois; but then his haunts arewell, any self-respecting biped (other than a hunter) would be ashamed to be "found dead " in such spots. The fjelds of Norway, with their break-neck gorges, snow-fields, and miles of stone-heaps, are bad enough going; but they bear no comparison with the Riscos and steepled rocks of Biscay, where the chamois flourishes above the clouds. 
warmest clothing-all flannel or woollen, including caps, gloves, stockings, etc., both for day and night.

2. Remember that nothing can be dried in a tent. Always, therefore, hold back in reserve at least one full set of clothes solely for sleeping in. Keep this reserve in the "sleeping-bag," and you are then sure of a dry change when you come in, wet, at night. In the morning it does not so much matter putting on damp clothes, but it is of vital importance to be dry and warm at night.

I use the word "dry" in a relative sense, since, after a week of rain under canvas, nothing is actually dry-wooden matches won't strike, and 'baccy hardly burn. After a fine dry stalking-season the year before, one is apt to forget these dangers, and to neglect sufficient provision against them.

3. Wear waterproof clothing, as far as possibleI have found Gabardine very useful myself-and a short macintosh skirt runs the rain clear of one's knees. Provide plenty of waterproof ground-sheets as a protection for beds, baggage, etc., during the day.

4. Never leave camp without a compass and the sheets of the Ordnance map for twenty miles around in your pocket. These sheets can be bought for a shilling apiece.

5. Commissariat.-(a) Solids.-Corned beef, tinned ox-tongues, and the like, are portable, and serve the purpose till you have stocked the larder with venison, ptarmigan, and trout. A piece of ham can be bought at the last Norwegian town, and a few tins of preserved peaches, pineapples, etc., supplemented also by fellberries, will help to atone for the absence of vegetables. 
(b) Liquids.-The coffee in Norway is magnificent; tea just the reverse. With these are required a few tins of condensed milk, with chocolate at discretion. Beer is far too bulky for transport by pony, and must be definitely barred. But the hunter must have his grog, and both whisky and cognac can be bought good and cheap in Norway, and these go in small compass.

(c) The canteen need only include enamelled metal cups (no saucers) and plates, frying-pan (with lard), gridiron, and kettle, with a few knives, forks, spoons, etc. A small hunting-hatchet is indispensable, also a spade for trenching; for light, a block-tin lantern and supply of wax-candles will serve, while a little diachylon plaster and bottle of Elliman's embrocation come in useful for minor accidents. On most reindeer-fells, fire-wood must also be brought, or sent up. But this, and other similar requirements, the local hunters will arrange. 


\section{( 207$)$}

\section{CHAPTER XIV.}

ELK-HUNTING IN INDERÖEN.

Our Forest of Furudal.

Aт length the happy day had arrived when the good ship Haakon Jarl, of the Nordenfjeldske fleet, cast off her moorings in the ancient harbour of Trondhjem, and steered a northerly course towards the forest-region which forms one chief stronghold of the biggest of European big-game-the elk. Then the fierce joy of the hunter possessed one's soul ; imaginations, not perfervid, pictured scenes of forest-triumphs, and one's thoughts dwelt with loving confidence on that beautiful and perfect battery that now lay stowed in "Cabin D."

The haunts of the elk are remote and access laborious, the penultimate stages often involving a day or two's journey in carioles, or row-boats, or both, besides the final portage by pack-animals, or carriers, into the hills. By comparison, the North Sea passage comes to appear but a trivial detail. On this occasion we had, inter alia, some eighteen miles of fjord to traverse, and had chartered a small steamer for the purpose, but, owing to the breakdown of her screwshaft, she never arrived; so we engaged a row-boat with four stalwart oarsmen to cover the primary stage, 
passing by old-time haunts of sea-kings like Herlaug and other heroes of the Bersaker Saga.

These old sea-kings, so the Norsemen aver, discovered North America, and were at the sites of Boston and New York five hundred years before Columbus crossed the Spanish main.

Luckily for our heavily-freighted craft, the sea was smooth, though frequent waves lapped threateningly over the gunwale. Starting at five o'clock next morning, we carioled from the head of Lyngen-fjord under pouring rain, as far as track led in the desired direction; then from the upmost farm we "packed" our kit, and taking ourselves a wider course, to stock the larder with a few brace of grouse, we were encamped by nightfall in our log-hut-height only six hundred feet-in the heart of that upland forest.

Furudal, with Finvolden adjoining, formed ideal hunting-grounds. Saucer-shaped, and fifteen to twenty miles across, the lower forests were encircled by ranges of higher fjelds, while the floor was occupied by two series of lakes, from around whose darksome shores stretched away pines in everlasting undulation-here dense forest, there broken by patches of tawny bog or moorland with scattered trees. Forest-growth extended to some fifteen hundred feet up the fjeld-sides; above that, timber gave place to dwarf-birch and willow, and higher still, to the stunted, mossy flora of the fjeld. Though steep places and rugged were not wanting, yet the general contour lay fairly even - that is, for Norway - the hills rising gradually from the lakes, with many upland plateaux and gentle slopes, where forest and mountain-meadow alternated. Goat-herds have summer 
sheilings out here, and wood-cutters by the streams; but by September these are deserted, and the whole wild region left uninhabited.

The feature of Furudal, which had attracted us to this corner of Inderöen, was that the elks were reputed large. There are forests in the Nordenfjeldske where

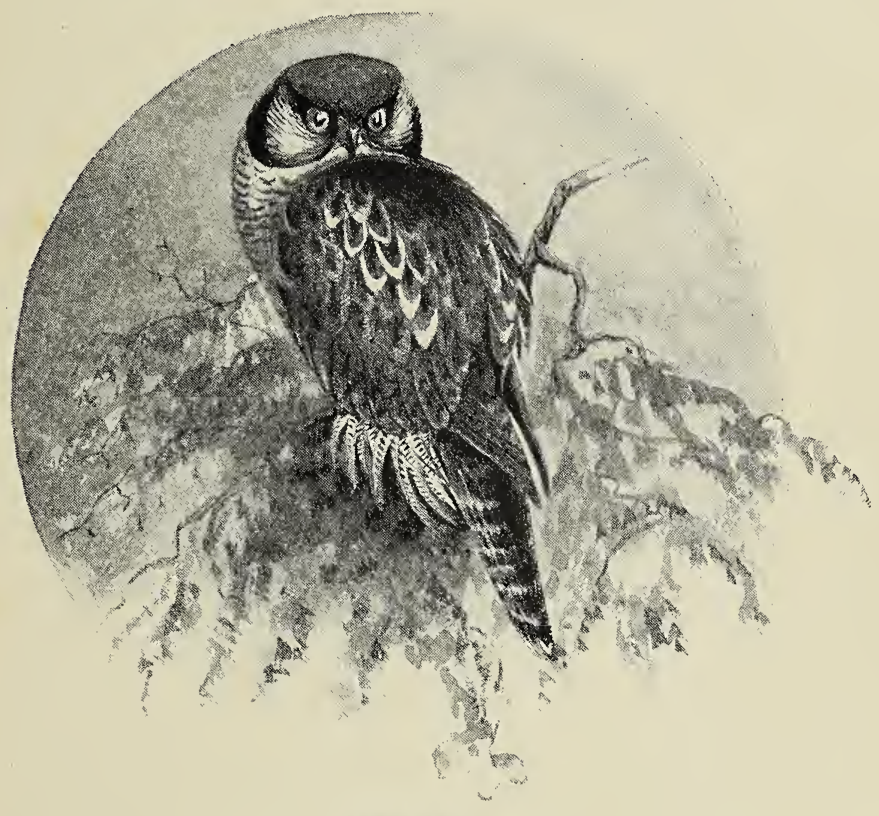

HAWK-OWL.

elks are more numerous; but nowhere are bigger heads obtained than among the woods of this sea-girt peninsula-heads both of many spears, and also those of fewer points, but of the massive "gnarley" type. The elks of Inderöen, though large, are both scarce and shy, being ever harassed by lawless Lapp hunters from the coast. These facts we understood beforehand; and I 
may here add that information received has been fairly corroborated by subsequent experience. Furudal con tained, moreover, some excellent bear country, and two bull-elks, estimated as carrying over twenty spears apiece, had made the lonely shores of Troll-botn Vand their summer home. No craven doubts or afterthoughts of vaulting ambition deterred us. It was our first attempt : yet we joyously backed our tyro skill against the shy elks of Inderöen in general, and this veteran pair of forest-monarchs in particular.

Now, whereas the reindeer loves the highest fjeld, far above tree-growth, barren of covert, but broken by innumerable corries and ravines, which afford the stalker full scope for his craft and skill, the chosen home of the elk, in the reverse, is found amidst dense pine-forest, wherein stalking, properly so-called, is impossible. The mean elevation of these elk-holding forests may be put at a thousand feet, on an average; the timber-line seldom much exceeds two thousand feet, and above the trees the elk is not seen, save in the hot summer days when he seeks higher levels to escape the torment of the mosquito.

These conditions naturally all make against the stalker. Opportunities to stalk elk-that is, to see the game at a distance-rarely occur except, as indicated, in the early days of the season, while the big deer may still linger in the higher regions of their range. Later, in mid-September, with cold nights and coarser weather, they move downwards, spending the autumn in lowlying forest, and in winter often coming almost to the valley levels.

The pursuit of elk is therefore conducted, not by 
stalking, but by hunting. There are two systems-that of the loose hound, and that of spooring, or still-hunting with the hound in hand-the salient points of which have been so well described already that I will not attempt to repeat them in detail. Suffice it here to say that in loose-dog-hunting I found the pace too hot. After a certain age-call it forty-some of us would need new machinery for that work-triple expansion, with forced draught and two-hundred-pound pressure to the inch.

To return to our log-hut, the skov-huset of Furudal. Our first week's hunting, full of excitement and the novelty of new experience, nevertheless yielded neither result.nor sequence of incident. Incidents there were in plenty. Not a day passed without learning something or making some new acquaintance. Bears in some parts of our beat abounded-to judge, that is, by "sign," by ant-hills despoiled and rowans uprooted. Here Bruin had revelled in a resinous feast of pinebark; in a dark ravine was unmistakable evidence of a fight between bear and elk-the long bristly hair of the deer lay strewn around in handfuls, and the earth was scored with footprints, cloven and plantigrade. The elk was a full-grown bull, but the result was not indicated. Another day, under the hanging woods of a rock-scaur, we came on an elk-calf piteously moaning. "Bjorn" (bear), whispered Voda ; and we crept forward towards the sounds in momentary expectation of seeing murder in perpetration; but only to view the poor calf (which, by the way, was of the size of a carriage-horse) departing in strides of five yards apiece. Some days later, passing near the spot, but higher on the hill, we 
had clear evidence that the bear had actually been disturbed on the former occasion, and that his flight had been precipitate and undignified. These things should have given us a hint; but the experience to glean it was yet lacking.

Twice we came on new spoor of lynx, but that

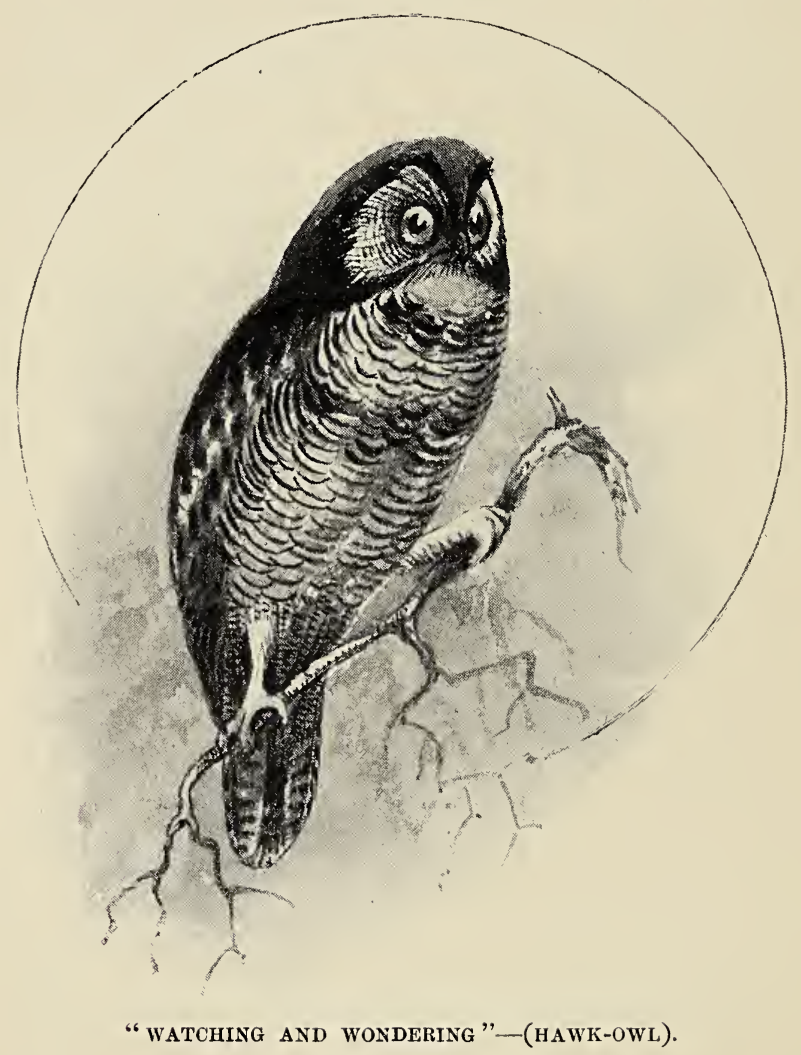

wariest of beasts we never saw, and bears but once-a family-party of five. Game-birds were conspicuous; capers clattered, like turkeys, from the pines, while 
grouse of three kinds, * woodcocks, and white hares were frequently observed. Sometimes the Kongs-örn (golden eagle) treated us with majestic flight, soaring across some glen; buzzards and goshawks hunted the hillsides; now the domestic cares of mergansers, or redthroated divers, teaching their youngsters to catch trout, engaged attention. Anon an aggressive hawk-owl menaced us and our dog with outstretched claw, wheeling around within arm's-length, and perching on the dead limb of a pine.

Then, and beyond all, there was the forest itself. What written words can convey even a feeble conception of its pristine glory, the impress of that primæval scene, its strange juxtaposition of life, death, and decay? Here no axe intrudes - the living and the dead stand side by side; dead giants, centenarians perhaps, still erect though blanched and rotten to the core. Others halfdead, dying from the top downward-weather-bleached skeletons, their white bones gleaming in the sunshine in contrast with the living greens of the survivors of the forest that surround and protect them. Here a longdecayed trunk, though thicker than one can span, may be overthrown with one hand, and the very ground is a graveyard. The dead lie piled one upon another, the older corpses already half-hidden in long mossy sepulchres-for nature provides her own sexton, and moss and lichen fulfil their office in concealing evidence of what is past. Such is the home of the elk; to convey an initial idea of the habits of the beast, and of

* Namely, blackgame, willow-, and hazel-grouse. The hills immediately around our camp were not high enough for ptarmigan, which, however, were found on the higher ranges towards Finvolden. 
the business of elk-hunting, we turn to our diary of a week later.

September 8th.-Hazel-grouse whistled in the birches not ten yards from the hut as we turned out before dawn for ablutions in the burn, and a pair of inquisitive Tengmalm's owls watched the performance, each perch-

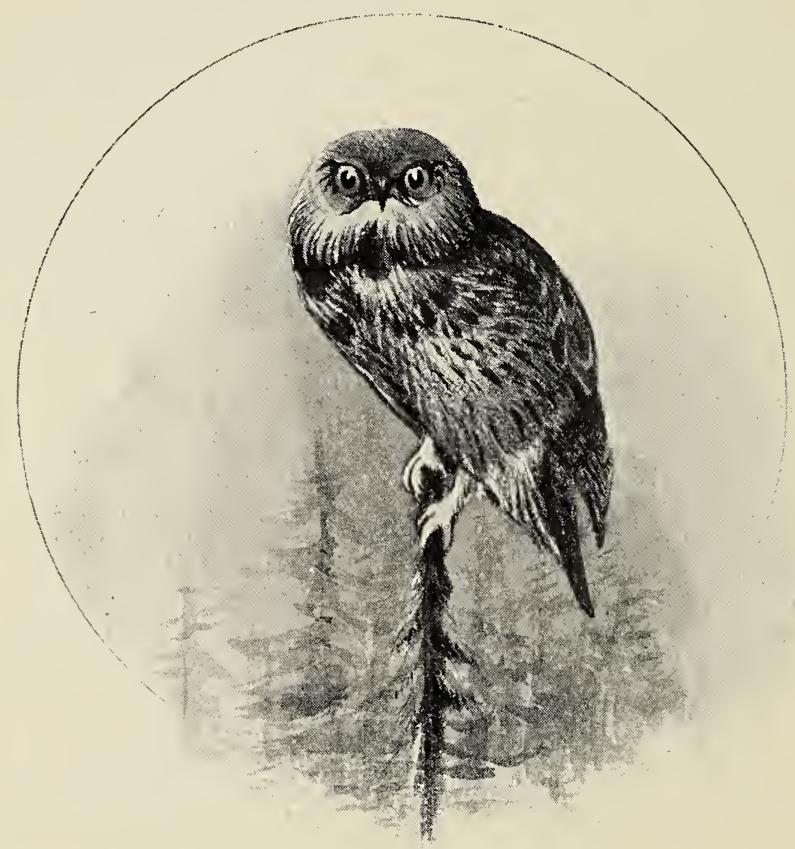

PERCHES ON THE TOPMOST SPIKE OF A SPRUCE-(TENGMALM'S OWL).

ing on the apex of a spruce-sapling, our other notable neighbours being large field-mice. We started together, intending to separate beyond Troll-botn Vand. On the way, by the shore of a small tarn, "Passop" took a hot scent, and led us a long dance at top speed. No spoor 
could be seen, and the nature of the game puzzled us. The yielding sphagnum retained no impress, but at length, on a patch of peat, big round pugs showed that the quarry was a lynx. For another hour the beast led us up-hill and down, twisting and doubling through the worst ground he could find. As these tactics must give the game our wind, "Passop" was let go, when the pace soon became too hot to last, and it was almost a relief to find, on a densely-timbered and almost perpendicular face, that the scent was lost. I imagine, from experience of the lynx in Spain, that this acute beast would never be secured by spooring with the dog in hand.

During the three-mile row along Troll-botn, sundry trout were captured. Sitting in the stern, it was amusing to watch the anglers' faces as another two-pounder seized the spoon. The bilges swam with big fish before B. and I, with Ole, whom we had brought from Namdalen, and his elk-hound "Bengel," landed to hunt the south shore. The wind to-day (and every day) was very light and variable-conditions almost fatal to success-yet already, from the boat, "Bengel" had touched a faint luft (scent), and within six hundred yards we came on fresh spoor of a bull. By the trail it was evident the elk was on the alert; he was moving at a canter, though not fast. It was still early, and for four miles we followed a straight-away spoor through moderately open forest and bog. Then the beast had settled down; he had commenced tracing that erratic course to right and left-often almost doubling on his tracks-that is characteristic of the elk, and necessitates the utmost caution on the hunter's part. Again and 
again Ole left the direct spoor, taking wide casts to right and left, to save the wind-or rather, to avoid the risk of getting to windward; but always recovering the lost thread and working it cautiously forward.

At midday we stopped for lunch, to windward of a wide fell-meadow, where we thought ourselves quite secure, having cast wide on either flank. But at that same moment our bull, having skirted back through the timber, was himself making a noontide couch almost directly to leeward! The fact we, of course, discovered an hour later, on resuming the trail and following it round to the point where the bull had lain down beneath a pine, a mile behind us. Thence, the great splashing spoor-prints six yards apart, ploughing up the peat-plainly told that he had gone off in alarm and at full gallop. This burst lasted full five miles straight, before a sign of slackening was observable, and even then the elk kept travelling. We stuck to him, however, and towards five o'clock were aware by "Bengel's" increasing excitement-the dog now straining hard on the leash - that we were again overhauling the deer. The ground here, overlooking the headwaters of Furudal-vand, consisted of sloping rock-ridges with heather and fairly open timber-highly favourable for approach-and anticipation soared high. Once more luck played us false. For hours we had not seen a grouse; but now, at the critical moment, when within some two hundred yards of our game, up clatter a brace of ryper, cackling and becking for all they are worth. The deer was gone in the same instant.

Considering the favouring ground, and the fact that the beast was travelling fairly straight-these two 
circumstances enabling us to overhaul him rapidly, direct on spoor and without aid of wind-Iffelt convinced that, had it not been for those grouse, we should, bar accidents, have sighted the deer within six or eight minutes more.

The day being now far spent and the hut three to

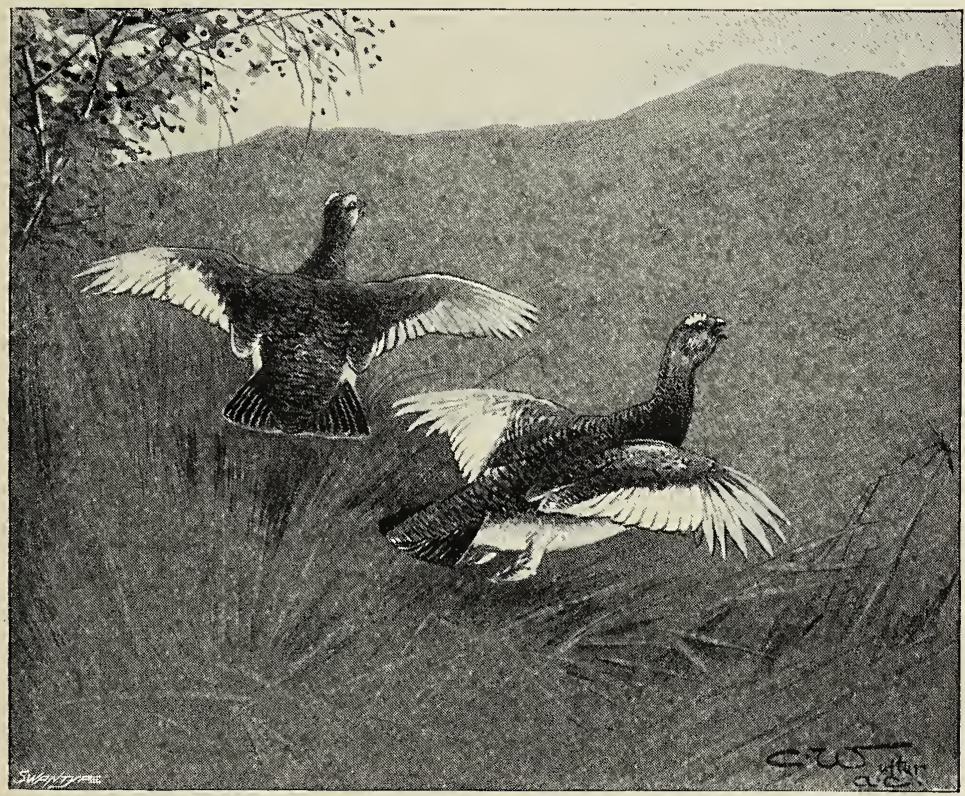

"CACKLING AND BECKING FOR ALL THEY ARE WORTH."

four hours distant, it was useless attempting to follow further a thrice-scared deer. But, leaving B., I went forward with Ole just to ascertain the course the elk had taken after clearing the head of the lake, so as to fix our route for the morning. A strong-running river, we found, flowed in, and through this the elk had swum. We had to go a mile further to find a fordable spot, and 
at once, on the other side, struck new spoor of another bull-elk, which, even to my untrained eye, was conspicuously larger than that we had followed all day.

The spoor of an ordinary bull-elk, I may here say, is a gigantic affair-huge ragged hollows like sepulchres sunk in the peat. The annexed photo shows the relative sizes of the hoofs of a bull-elk, of a reindeer buck, and of an average red stag of ten points, all of

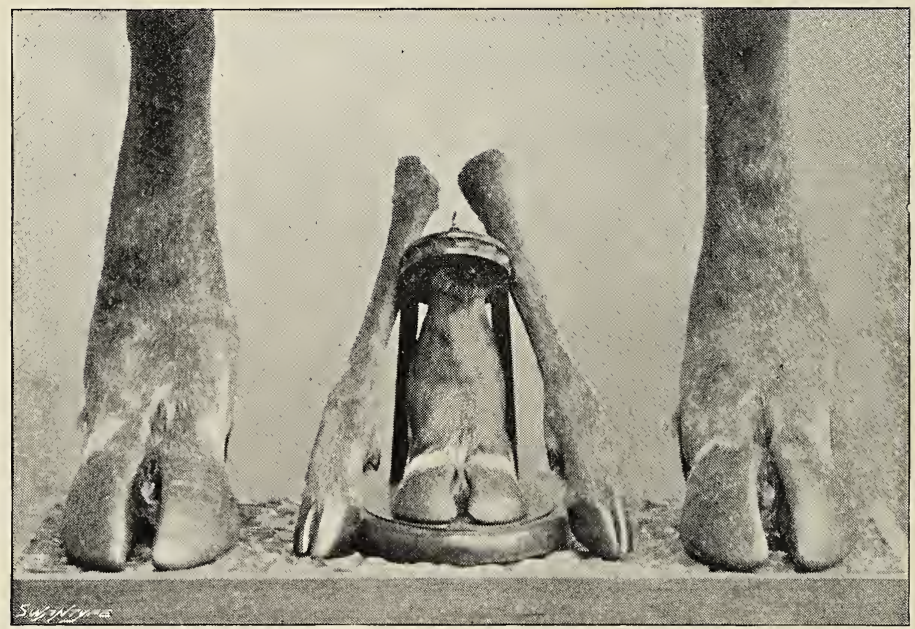

HOOFS OF ELK, REINDEER, AND RED DEER.

which I shot this same season. The latter weighed sixteen stone, the reindeer twenty-six, and the elk eighty or ninety, while some of the big old bulls reach a hundred stone. Never, whispered Ole, in his twelve-years' experience, had he seen a spoor the like of that now before us. We followed it a short distance, then returned to the first. Both tracks pointed eastward - our first beast had doubled the head of the lakeleading to higher forest beyond. We returned to B., 
sitting by a fire of pine-cones, and commenced the long tramp homewards in the dark.

We felt that we were now in touch with one at least of those two big bulls of Troll-botn, of which our Norsk friends-always optimistic as regards our shikar skillhad so confidently foretold the downfall.

The wind, though still exasperatingly light, having shifted during the night from N. to N.E., forced us to take higher ground, above timber-line and beyond the presumed route of the elks. Hence we had five hours' walking before recovering the big spoor. We followed it for some hours ; but towards midday were close up to the game, which kept turning, twisting, and doubling, but ever moving on through thick forest or birch-wood, now uphill, now down vertical faces regardless of limits to limb-power. But he never stopped or seemed to remember the midday siesta. The climax occurred early in the afternoon, when, for a couple of miles, "Bengel" strained furiously on the leader, and we raced forward across rough ground. There was a deep and broad ravine, its flanks strewn with rocks, amidst sere grass and scattered pines. Here every yard we advanced seemed to offer fresh promise, and eyes strained ahead intent on catching the first view. We crossed the open at a run, and had already regained the thicker forest, when Ole dropped to his knee and held up a hand. I was alongside with rifle cocked. Fifty yards above was a fallen pine, its uptorn roots outstanding in broken array-truly, in the half-light of the forest, those twisted spikes might well be mistaken for the coronet of an antlered elk.

In a moment we realized the mistake and pushed 
ahead. The real elk, I feel assured, was then no further than a hundred-and-fifty to two-hundred yards in our front, and had there been but a breath of air to enable "Bengel" to advance direct on scent-instead of having to follow out each turn and twist of the spoor-the beast was ours. As it was, there came back to us the faint crack of a breaking branch, a rustle as of displaced pineboughs, and not another sound broke the stilly solitude.

The spoor showed where alarm had been conveyed. The deer had gone off on a bee-line. Fortunately this led towards our hut: so we followed till dusk, the elk then going along just under the higher fjeld and among the upmost scattered trees, where already he was snatching a passing bough. There we left him for the night.

Early in the morning I was on the trail again, and for several hours in touch of the bull. To-day at length we had the long-wished breeze, with driving rain. Firmly did I now believe in an ascendant star, when newfallen "sign" lay warm and smoking, and anticipation verged on certainty. The bull, in crossing a high bare ridge (two thousand two hundred feet), had joined a cow and calf. "Will you shoot all three?" asked Ole, such was his confidence. Twice the triple spoor crossed high fjeld, descending to dense pine-forest beyond; but though the wind favoured all day, and the trio were never once skrœempt (alarmed), yet never a glimpse rewarded us -never did they stop or change that unvarying course, travelling slow but straight, as though bound for a specific spot. Twice, if not thrice, we were close up (once we actually heard them) and must have been almost within shot, could only one clear glimpse have been obtained amidst those thickly-crowded trunks. 
Here again the smoking "sign," and those huge slots in soft sphagnum, with water still trickling-in, gave clearest evidence that we followed on their very heels, but the density of that dark forest proved fatal-never was hunter so near and yet so far.

At dusk-being then many miles beyond our boundary *-we were constrained finally to abandon this grand bull, after following him, during three days, some fifty miles, and with sick hearts we set out hutwards, having no small trouble in finding a way, for we were far beyond our sheet of the ordnance map.

Luck seemed to have sunk to zero. Six different times during three days a feather might have turned the balance in our favour, and given us the first prize of the forest; but wind and viewless wood alternately combined to defeat us. Besides, these elk never stopped - never ceased that unending forward trail. We could not understand it then; it was contrary to all their known habits. But we know the reason now, and it will presently be explained. I could hardly have followed a fourth day, and we put in an "easy" with the trout, of which we caught over forty, some weighing two pounds, but few retain condition in mid-September -all are going back, and many ready to spawn.

Several times, during succeeding days, we fell in with recent spoor, on two occasions with burning scent; but the same breathless atmospheric conditions continued

* By Norsk law and custom, spoor can be followed without regard to boundaries, provided, of course, that the game is found in the first instance on one's own ground ; but the hunter, if challenged, is liable to prove his right by the "back-trail." This is, of course, only possible on soft ground, and the penalties are heavy for killing an elk illegally, or on unauthorized land. 
day after day, and, use all the caution and woodcraft we possess, a luft always betrayed us ; though, one evening, one of us came close enough up to hear the trio (a bull, cow and calf) tearing down branches through dense timber, where no clear view could be obtained beyond a score of yards. It was on the eleventh night, when returning hutwards down-wind, that I saw my first elk. From the midst of a tawny mountain-bog, on rising a ridge, we "jumped" a huge black beast, and as the elk trotted with mighty stride through scattered pines at about a hundred and fifty yards, the foresight already sought a flying shoulder, when a shout of "Coo, coo !" from Helmar Finvolden restrained the errant ball. Despite bad luck with bulls, during my first twenty-four days' hunting, I six times refrained from firing at cows, nor have I yet sent a bullet at the wrong sex, though they are considered, in Norway, legitimate game.

A word here on the mode of living while in hunting quarters. This is rough enough, but compares favourably with the rigours of reindeer-stalking. There, on the high fjeld, one is lucky to have a wooden hutch to crawl into; there is no firewood nor fireplace bigger than an average kettle. Wet clothes cannot be dried; the hunters each night must light their own fire and cook food in precise accord with their culinary lights or darkness. Distances and difficulties of transport forbid anything being brought beyond the barest necessaries. These difficulties, in elk-hunting, are less. In some cases, the furthest sæters and sheilings are accessible to ponies ; in others, baggage must be conveyed on human shoulders, but the weight a Norsk mountaineer can bear 


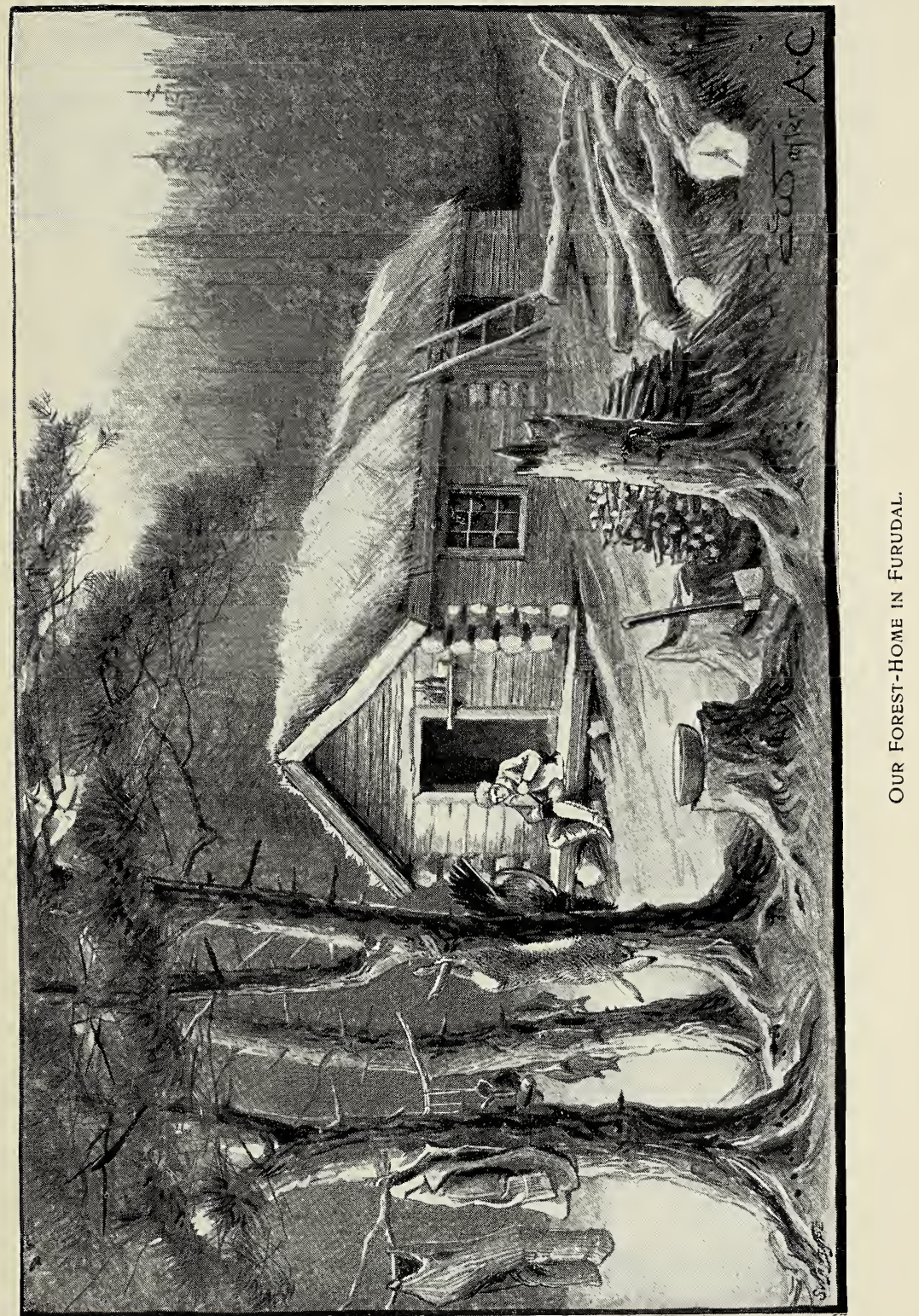



is surprising. Thus at Furudal, we managed to drag up things of which the stalker on the ice-riven plateaux of Valders or upon the "hinter-land" of Hardanger will dream in vain. There was an iron camp-kitchen and canteen, cases of comestibles-solid and liquid-there were tressle-beds and blankets. Moreover, there was Lota-Lota, the flaxen-haired damsel who before each dawn awoke us with a modest poke in the ribs, and a brave effort at English, thus, "Pease!" as she brought a luxurious cup of tea and biscuits. Lota gave us excellent breakfasts, lunches in our cartridge-bags that were quite too varied; while dinners of several courses (on a table-cloth, too) stood ready each night on our return. As a counter-balance to these comforts, Lota caused us some anxiety. On the first evening she came up with a face full of fears, and bleated, "I cannot sleep to-night-there is no place for me!" The six baggagebearers, unable to return that night, and declining to sleep outside in the rain, had perforce to be accommodated somewhere; there were also our two selves, our two hunters, and Anton, an old man who spent whole days out in the wet, accumulating a stock of cut faggots as though we proposed wintering here-in all, eleven men, besides Lota. How and where were all to be stowed for the night in a log-hut measuring fifteen feet by ten ? One-third of this space we had partitioned off for our separate use by hanging rolls of thick bark-paper from the rafters, and hesitatingly suggested that Lota might prefer our side of the screen after we had retired; but she demurred, and eventually perched on two pine-logs that formed a kitchen-shelf, the men lying on the floor beneath. That she slept we do not say; but she 
appeared to be reconciled to her' lot, for, so long as we remained conscious, she kept chortling and clucking, like a caper-hen on a pine-bough, to the eleven subjacent males. There is safety in numbers.

The end came, and the big elks had beaten us. Later on, we learned the reason of this failure in Furudal. It was those Bears we had to thank. For some cause unexplained, bears that season roamed in quite unusual numbers over Inderöen. From our first morning's hunting onwards (as above recorded) we had constant, daily evidence of their presence on all parts of our beat -on two occasions of their actual violence towards the deer. The tainted atmosphere had told the tale. The startled elks travelled hither and thither, never settling down, never daring to rest, or remain for a single day in their wonted haunts. Had we but realized this fact in time, and devoted ourselves exclusively to BEARs, instead of persevering in an almost hopeless stern-chase after elks already scared and restless, the result might not have been a blank. Even without specially seeking for bears, it was curious that in all the hundreds of miles traversed on the Inderöen fjelds, early and late, the writer never once had the luck to fall in with these ursine intruders. At least ten bears were seen, within our own knowledge, by others, and of these three were bagged-but not by me.

The whole incident presents a curious and interesting phase of wild-life. The lesson it conveys cost us too dear; but it may one day prove useful to others, as illustrative of the possible coincidences or combinations in forest-hunting in Scandinavia. 


\section{CHAPTER XV.}

ELK-HUNTING IN NAMDALEN.

The White Bull of Rognvas-fjeld.

ANother wet morning--this we recognized directly on turning over in our hay-filled bunks, by observing our Norsk retainers all standing about in their shirt-sleeves outside. Rain, indeed, was falling in solid earnest with half-a-gale from N.E.-real elking weather; but for several days we had hunted hard in incessant rain and perhaps welcomed an excuse to ease up.

Our quarters were a log-hut situate in the backwoods of Namdalen, and the hills around, though of no great altitudes, were of rugged contour divided by deep, abrupt ravines, and with little or no extent of open moor or fjeld-meadow-in short, it was all climbing, treadmill, up and down in turn. Per-Sæter, our home, albeit inaccessible to ponies, ${ }^{*}$ was a rather more commodious abode than the skov-huset of Furudal, having a verandah and three small rooms, besides an upper region, whither our handmaiden, Sigrid, retired by a ladder through a hole in the rafters. The continuous

* The hut lay about twelve miles back from the valley, and the route thither included a two-mile row by boat along one of the hill lakes. 
rainfall had reduced our surroundings to a swamp, and the verandah aforesaid afforded the only dry spot outof-doors.

By nine o'clock, encouraged by a brief pause in the downfall, which presently started with renewed violence, we were under way-our normal hours of business, it should be mentioned, commenced at 3 a.m. An hour's march through dripping forest with increasing wind; then an hour's pulling down Rogn-vand, where

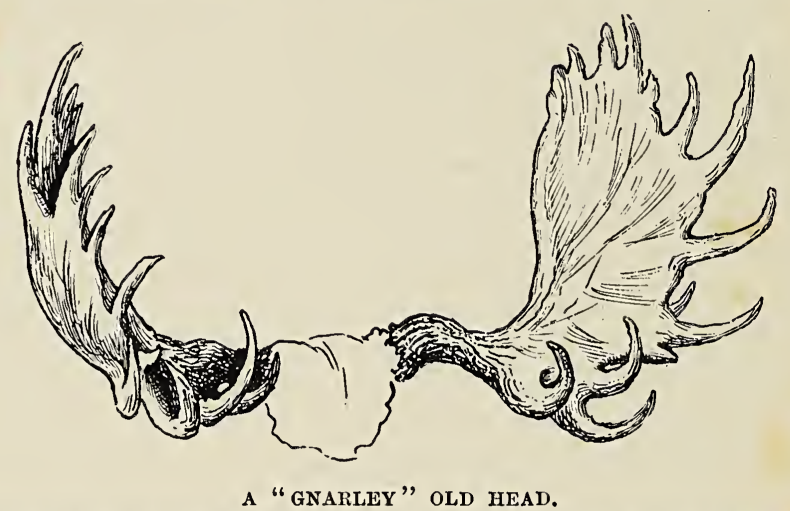

(Sletched from a single cast-antler, which had 14 spears, set in a double row.)

spray flew high over rocky islets, and we landed, not without difficulty, at the southern point. Hard by we picked up a grand cast antler, carrying fourteen spears in a double row (circumference $7 \frac{1}{2}$ inches, nearly), but unfortunately spoiled as a specimen (as is usually the case) by the points having been gnawed by lynx or fox.

Hunting first to the westward, but gradually swinging to south as the wind eastened, before noon we had picked up a good spoor, quite fresh. Two miles further, and the bull had laid down on the crest of a wooded 
knoll ; but the change of wind had shifted him, and he had sought more sheltered quarters in a steep wooded face where (though twice we thought we heard him) the dense timber made it unsafe to follow. Ole reckoned that the beast would not stay here. Having once been disturbed in his siesta-though by the change of wind only, not by us -it was improbable at that hour ( 2 p.m.) that he would lie down again, but would keep on moving.

By a detour we avoided the thick timber and gained the higher ground. Here our hunter's forecast was amply verified. The spoor showed that the deer had passed on, and was proceeding slowly but straight, as though travelling. The trail led through ravines which written words would fail to describe - suffice it that we sometimes fell back a mile to leeward in order to cross places where the great deer had gone straight ahead. Presently the spoor led across a high shoulder (two thousand three hundred feet), the top barren fjeld, and while descending the reverse slope, Ole dropped on his knee, and we knew he had sighted game. In front was a wide valley, its floor, five-hundred-feet below, occupied by a string of black-looking tarns. The elk was on the opposite face, at least a mile away, and in the midst of a chaos of crags, waterfalls and scattered trees.

Little time was allowed for contemplation. Hardly had I focussed the binocular exactly upon that indistinct and distant object-a, mere point amid the shade of rocks and trees-than down came the hail, and a blinding storm, driving up the glen, shut out everything from view. Off we set, helter-skelter down that rough slope, trusting to the cover of the hail; but 
during that mad scamper I was torn by doubts as to the wisdom of relying on so transient a blind. Down we flew, over banks of blaeberry and ling-clad ledges, then through forest intercepted by scrub and young pines, across two swollen burns-how, I know not-till we gained the valley-floor.

Still, to my surprise and dismay, Ole held his course, though we were now on open bog, not six hundred yards from the game, and the hail almost ceasing. But when at length we pulled up to reconnoitre from the shelter of some broken hummocks, all doubts were resolved. For there, on the opposite face, slowly feeding to leeward (that is, on a parallel course with our own), we descried, not one, but three elks, about five hundred yards away. The strategy of our hunter was also apparent. His dash, though seemingly risky (it was risky, but less so than I had feared), had now secured to us advantage both of wind and position. And the elks-we could now pause for a moment or two and watch them at leisure! Slowly and deliberately the great beasts moved to and fro on that terrace-like ledge of the opposite fjeld, now disappearing in the gloom, their position only indicated by the shivering of some birch or rowan' as a succulent bough was torn down. Two were bulls, the third a cow; but what struck us at once was the extraordinary colour of one of the former-as Ole put it, En er ganske hvit = "One of them is quite white."

Without difficulty we crossed the intervening flat, sheltered by scattered trees and broken ground, and commenced the ascent beyond. The elks were on a hanging ledge, flanked above and below by crags-one 


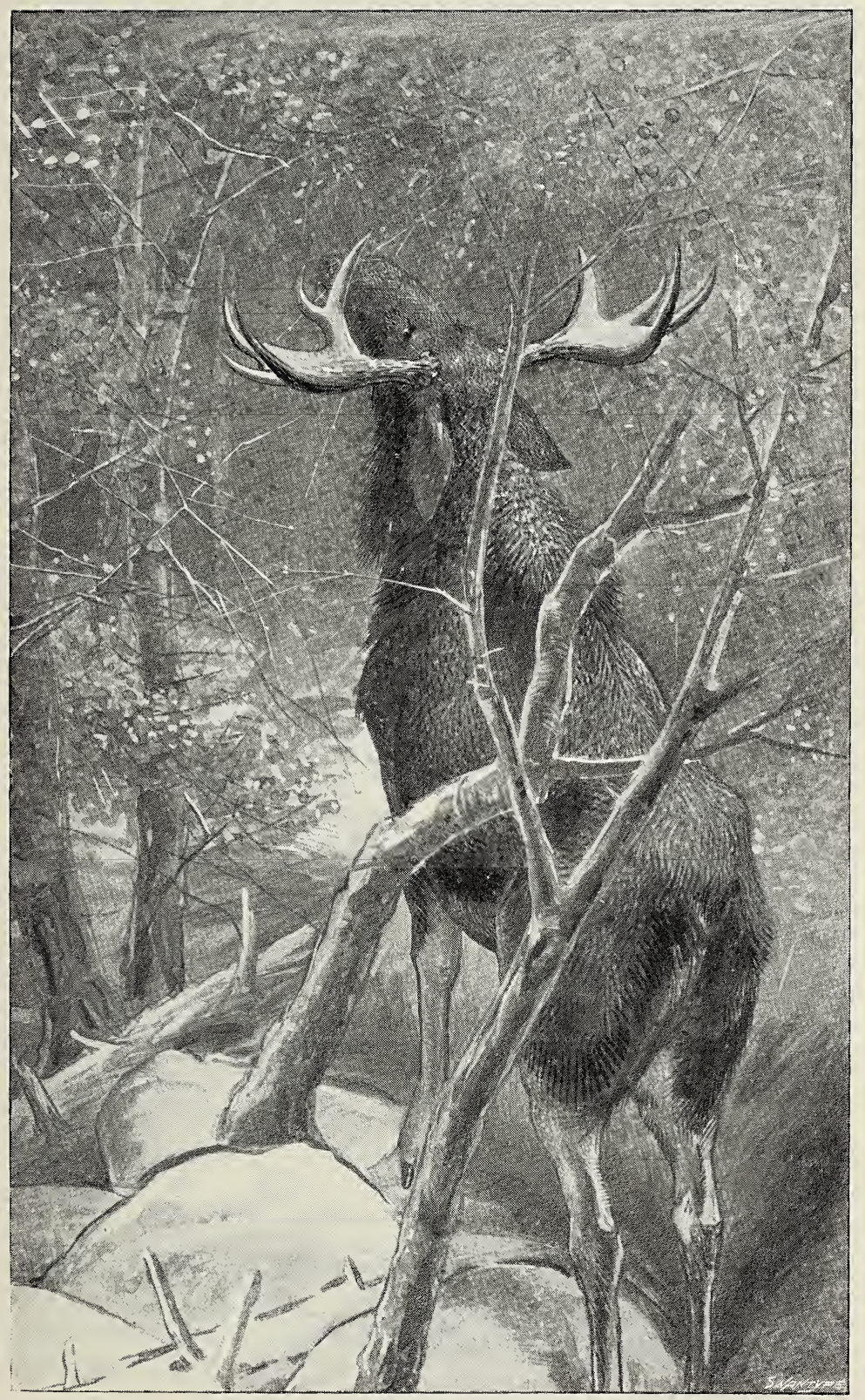

BULL-ElK, BROWSING. 

of several such on that face. These crags gave some trouble to scale, but in half an hour we had gained the terrace above that along which they were feeding downwind towards us. Walking upright along this heathery slope (for it was out of sight of that below), "Bengel" soon gave us intimation of the proximity of the game. At first the dog drew straight ahead; then turning sharp to the left and straining on the leash, he led usor dragged us-direct towards the ledge of our terrace. Then I knew I had them. Crawling to the verge and peering through its fringe of shaggy heather, I found myself within easy shot. Right below, scarce fifty yards away, yet dimly seen in the shade of the trees, loomed a mysterious form. It was the black bull. He stood upreared and stern-on, his forefeet on a ridge, while his huge head stretched up among the branches of a birch above. Two thin trunks covered his body, and amidst hanging foliage and chequered shade it was difficult exactly to distinguish outlines. It may seem strange that difficulty should exist at so short a range; but big as he is-an old bull stands seventeen hands at the shoulder-the elk assimilates in marvellous degree with the changing forest-tones. In the bad light and drifting scud, it was chiefly the white legs and the curious white patch on the ever-moving ears that enabled us to make him out.

Selecting the 12-bore Paradox in preference to the Express for close quarters, I waited for the bull to turn and expose the shoulder, though Ole the while kept whispering, "Shoot, shoot - can't you see him?" Presently the elk turned a quarter to left, and I placed a ball in line, as I reckoned, for his heart. He dropped 
to level ground, still covered by trees, and the second ball struck the ribs rather far back. He moved away, though evidently "done," and staggering over a dip received a third bullet in the region of the tail as he disappeared. At that moment, the cow dashed out from under the crag, right beneath us, and offered an easy shot, which was declined, B. simultaneously whispering, "Look out, there's the white bull!" Again a great mysterious form loomed, phantom-like, among the shadows, and stood rigid as a grey rock but for those tell-tale ears which twitched every way as the bull hesitated, seeking the cause and the seat of danger. Again both shoulder and flank were protected by intervening trees, till I had crept a yard or two through the heather, and even then no clear view could be obtained. The first ball, though it struck fair, failed to stop him, but the second, beautifully placed behind the shoulder as he bounded forward, dropped him direct, and the white bull, plunging forward with resounding crash, next showed all four legs in air.

Ole, with Bengel, had disappeared. Our hunter, skilled in the arts of spooring and of woodcraft, was yet apt, at critical moments, to lose that "level head" which it is just then so essential to preserve. At any rate he was gone, so B. and I sought a way down the crag to examine our game. Though in extremis, the white bull still held his head up, and we were at a loss how to finish him, having due regard to the sweep and power of his hoofs. We therefore proceeded to look for the black bull, when Ole returned and told us that that elk had gone right away and left no blood-trail! This I well knew was impossible, having seen a fore-leg swinging 
useless from the shoulder as the sick beast staggered from sight, and, unless we quite misunderstood our friend, concluded he had, in his haste, followed on the track of the cow.* At any rate the black bull lay there safe enough, not fifty yards below the ridge, having, in fact, fallen to the shot and rolled so far down the steep face. I had bagged my two first bull-elks, right and left; an ambition was achieved and a vow fulfilled. Standing, a month before, on the gangway of the Capella, alongside the Tydskebryggen at Bergen, I had stopped amid clamour of touts and porters on the quay, to register a mental vow not to quit Norwegian soil till the bull-elk had fallen.

Both elks were huge animals, afterwards estimated by our hunters at nine hundred and one thousand pounds respectively. The lesser was rich glossy black in pile with warmer undertones, the other light iron-grey. The first carried nine points, the bigger beast only seven, though the size and sweep of horn warranted a greater palmation, and by the spoor Ole had anticipated a twelve or fourteen-pointer.

The normal colour of the elk is very dark, smokegrey, with glossy sheen; but the warmer shades of the under-fur, showing through the outer bristly hair, give the pile its rich appearance. The lower legs and inner parts of flanks are white, and this contrast between the dark and light colours is accentuated by a band of shorter hair of a deep dull black adjoining the line of demarcation. As mentioned, there is a curious white

* It is probably much easier for the shooter to keep cool than for his companion, who finds himself in presence of game, but without a rifle. 
patch on the upper front of each ear, and under the chin depends a thick tufty beard, though there is no mane or ruff on the neck.

The iron-grey variety of Cervus alces I understand to be of scarce occurrence. Locally no one had ever seen a beast of this colour before, and I afterwards learnt from Hr. Bruun of Trondhjem, who set up this head for me, that in a long experience he had only received two or three similar specimens. They are invariably defective in development of horn-growth and palmation.

It will be noticed that the concluding stages of the operation just described were of the nature of stalking, not hunting. Two other points are noteworthy. The first is the lack of respect paid by hunters to the optical powers of elk. But it will be obvious that denizens of dense forest, where for mile beyond mile no clear view is ever to be had, must in time come to rely more on other senses than that of sight for self-protection. That the elk can see-and see far-in the open, I have had evidence; but am equally sure that he does not habitually maintain that ceaseless, vigilant look-out that is the essential complement of mere eye-power, and that invariably characterizes denizens of open plains, such as bustard, black buck, gazelle, etc., or of barren mountain plateaux, as reindeer and ibex. The elk, though his sight is good enough when used, relies more on scent and sound, and those who have hunted him realize the keenness of those two senses in him, and the intense astuteness and sagacity with which an old-world beast brings both into full bearing against the modern hunter. The elk is no fool, or he would never, under difficult 


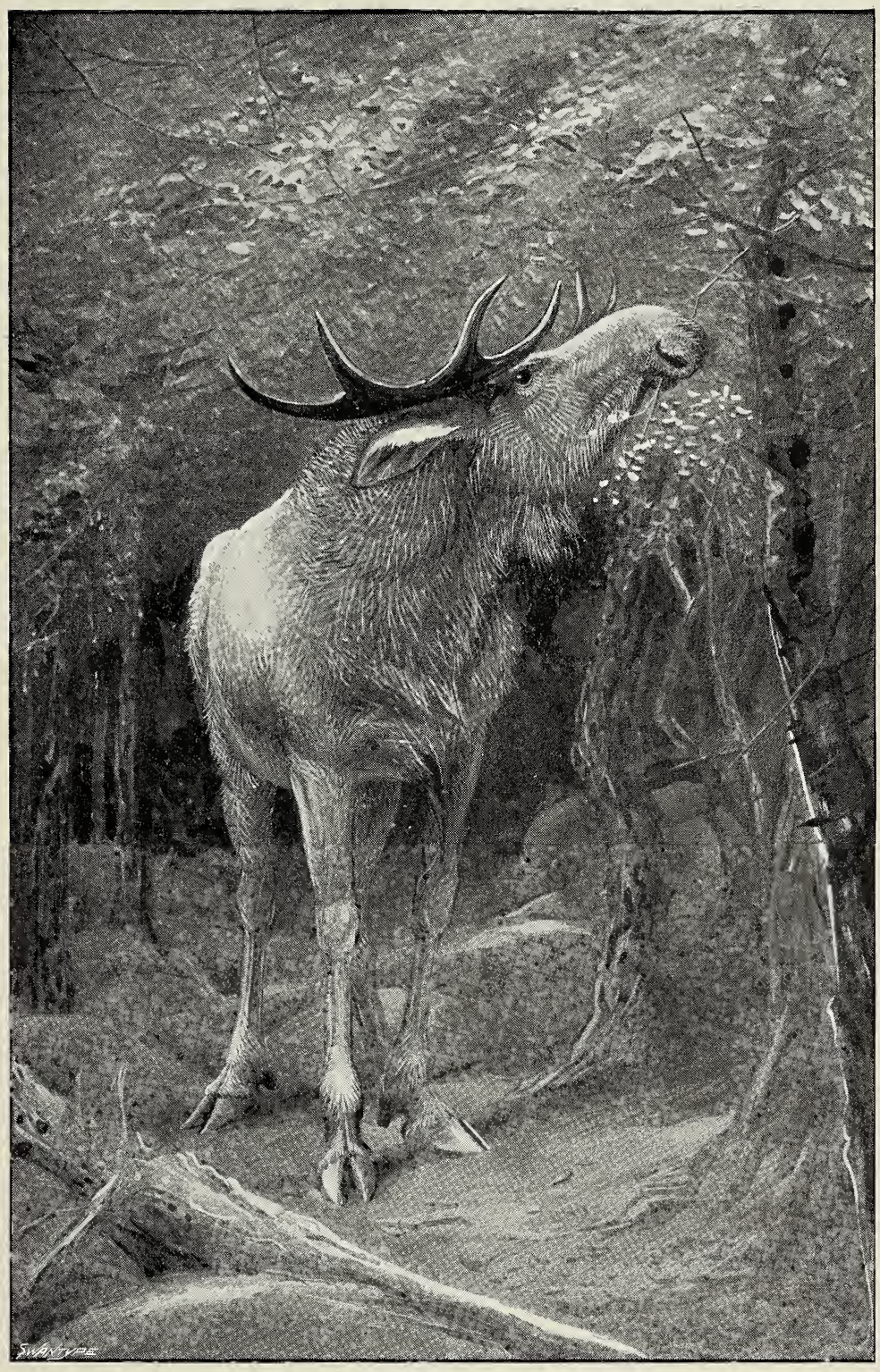

The White Bull of Rognvas-Fjeld. 

conditions, have preserved his giant personality till near the dawn of the twentieth century.

The second point is the apparent apathy with which elk receive an attack-or it would be more correct to say, their apparent tardiness in realizing the point and source of danger. Thus the white bull pulled up and stood deliberating within seventy yards, immediately after I had fired three shots into his companion. But such incidents, it must be remembered, invariably occur amidst crags and high ground where echoes confuse the senses, and the roar of wind and waterfalls drowns minor sounds. It cannot, therefore, be deduced that the elk is lacking in wit or wile-quite the reverse. I have seen wild reindeer equally at fault, and only a few weeks later had a similar experience with a red stag, and that on level ground. It was, however, blowing hard, with heavy rain. I missed this deer, crossing a narrow glade among thick forest, at about eighty yards. He stopped short in the tiny opening, facing the other way. A second shot as he stood, stern on, dropped him dead.

In big-game shooting, especially in stalking and still-hunting-but the same applies, though in less degree, to driven game-it is a mistake to assume that the first shot fired must be the most effective, or that it necessarily prejudices the chance of third, fourth, or even fifth bullets. It is the impulsive sportsman who prejudices his own chances by prematurely showing in sight under a false impression that the game is already disturbed. Disturbed it is, no doubt, but the exact point of danger may not yet have been disclosed; and I would urge on young riflemen the expediency of 
remaining closely concealed, using all expedition in reloading, and awaiting second or third chances.

Consider the matter from the standpoint of the game. They have been feeding, resting, and otherwise enjoying life out on those wilds-be they fjeld or forest, sierra or alp-undisturbed by man for weeks, it may be months. Suddenly from some hidden point amidst crag or timber, from some ridge above or rocks below, resounds the "ping" of a rifle. Mind you, it is a hundred, or a hundred-and-fifty yards away. The big buck, or bull, or ram falls dead, and in the same instant come echoes reverberating from a dozen crags and corries. Nothing is in sight; the tiny puff of smoke has vanished or floats along the hill, mingled with the light mists of the mountain. Doubt and confusion prevail ; the beasts for some seconds-pregnant seconds for the hunter-hesitate whither to direct their flight. They may even move his way.

Clearly this is no moment for the rifleman to show in sight. Let him rather crouch lower than ever behind that sheltering bush or boulder, the block of ice or fallen pine, whatever it may be that conceals him, remembering that now a search-light of alarmed eyes plays in tenfold force upon his hill. But with care he may find opportunity, for all that, to pick out the second-best beast, whatever the game may be-possibly also a third or a fourth.

This, to some, may sound bloodthirsty, but I emphasize the point because (in Europe) the big-game hunter deserves his chances. He works harder for his sport, and often, probably, fares worse than any other human being. For days, for weeks, he toils on, never 
despairing, but, it may so befall, never getting a chance to score. But the dominion is in him: sooner or later pluck and perseverance prevail, and it is then-when he finds himself at length three points to one better than the wildest beast on earth - then he should bear in mind this humble bit of advice and make the most of a hardearned opportunity. Depend upon it a cool head at critical moments, and calm judgment, represent more points even than the most brilliant rifle-practice.

Next morning early, while powdery snow still clothed the heights, the men were off at dawn to skin and cut up the game, and the usual meat-traffic commenced. A half-way camp was established where coffee simmered on a pine-cone fire, and for a week to come men, setting out with sacks and ropes, or returning with gory burdens, traversed those leagues of forest, fjeld and lake, till every ounce of those two thousand pounds was safely housed.

On cutting up the elks, all my five bullets were recovered-three in the black bull, two in the white. All but the second fired (which was a foot too far back) had struck within an inch or two of the points selected. The first ball had traversed both shoulders of the black bull and broken his far foreleg. The elk is a tough beast, and requires a terrible blow.

The flesh, I should explain, belongs to the proprietor on whose land it was killed, only the head, horns, and such meat as he may require for his own use being retained by the hunter. Elk-beef is of excellent quality, brown, but tender and of delicate flavour, with strata and lines of fat. We had been well supplied, for on the 
first day of the season, B. had here secured a nine-pointer. They were after a bear in a deep ravine, when, among the pendent woods of the opposite face, the form of the deer was seen, and a clean shot at two hundred yards with the Paradox, raking the elk from chest to stern, promptly settled the business and stocked our larder for half the season.

Leaving the gruesome work to those interested, we climbed the steep south slope of Rognvas-fjeld, where the golden eagle yearly breeds. The two nests (used alternately) project, huge masses of sticks, from crevices of the crag, and though inaccessible from above or below, could be approached within forty yards from the side. The nests, as is usual with this species, are placed in the lower series of the precipice. While we were there, both eagles passed overhead; and we also observed to-day one black woodpecker, and discordant parties of Siberian jay. Fieldfares, titlarks and finches were seen (September 19th) packing into flocks.

On the berry-clad ridges of Rognvas-fjeld, "Bengel" took a luft (scent), and with a strong breeze, following direct on scent, soon took us to game. Forty yards beneath us stood an elk, unluckily a cow with her calf. For half-an-hour we enjoyed watching them browse on the birches. The cow was very black, carrying a long beard, while the sleek pile of the calf looked hairless, almost toadlike. They had just laid down when we gave them our wind, and both went up the opposite face, the calf hardly losing a yard, either on the steep rocks or while crossing the black moss-hags above, where both sank half-knee deep in the peat. After witnessing their departure, we ceased to wonder that elks had 
sometimes kept ahead of us for two or three days on end.

The elk is essentially a browsing animal, and the long pendulous upper lip is provided by nature for seizing and pulling down branches. Yet in autumn, when the forest-vegetation is at its height, the elk certainly arazes to some extent. In many places, whole beds of fern were seen stripped of their fronds, leaving only the naked stalk, and where tall sedge-grasses grew waist-deep, the prehensile lip had here and there snatched an armful of flowering tops. I remember my old friend, Mr. Clive Phillipps-Wolley-as hard a hunter, by the way, and as keen, as ever walked the woods-being bitterly criticised for a similar statement in regard to the moose, though in the case of elk it is certainly correct.*

The normal habits of the elk are as follows:-He is astir with the first signs of dawn and moves about, feeding, till near noon : covering an immense extent of ground, but, owing to his circling, devious course, seldom getting very far away from the original spot. Towards midday he lies down for a siesta of uncertain duration-from two to five hours-usually under the shelter of trees; but when the weather is hot, and mosquitoes torment, in the midst of open boggy moorland, or a moist fjeld-meadow, where his ponderous body speedily converts the bed into a tepid bath. In every case when we came upon them thus, the wily beast had circled well round to leeward before couching, thus ensuring to himself timely notice by the wind of any

* Had I then known as much as I now know of the habits of elk and some other big-game, I would not have allowed an absent man to be attacked with impunity by anonymous critics. 
hunter following on his track. Hence hunting during the midday hours is apt to be unprofitable, the most favourable times being early morn, and again towards evening, when the elk recommences to feed, continuing till dark.

During the midday interlude the hunter will do well thoroughly to spy-out with the glass every inch of open country within his ken, together with loose forest, the crests of wooded knolls, as well as the lower slopes of the fjeld. On the latter, his survey may be rewarded by a sight of Bruin, busily shovelling down pawfuls of crowberries.

Here is a note on elk-country, which was made on the spot:-The "going" in the forest is every bit as bad as on the high reindeer-fjeld. There is a lot of "tooth and claw" work. One can seldom "let one's self go" or rely on a second foothold. Hollow snow-gullies, shoe-piercing flints, ice, or loose rocks in the one case ; and in the other, rotten stumps, moss-hidden holes, snags and windfalls like spelicans, are but a few of the hundred and one treacherous traps and pitfalls that ever waylay an unwary step, that daily jar one's system and yet further lacerate sore-wounded shins. The lash of a released pine-bough in one's face is not pleasant, and a straight one in the eye will not help to get the foresight well down in the nick. Nor is a mile or two of fallen pines, each with uptorn roots and a hundred splintered spikes sticking out in every direction, any sort of relief from the previous hour over tumbled rocks, or scrambling on crags where the rifle must be shifted from shoulder to shoulder thrice a minute, and where the only handhold is half-inch heather or prickly juniper. 
Towards the end of our time we arranged a "slapjack," or drive (properly kilap-jagt). There were many miles of forest in which we had not set foot, by reason of the dense growth of the trees; and the inner verge of this sanctuary, we had observed, was commanded by a range through which two fairly-defined passes had long suggested the possibility of a drive. The wind favouring, we started at dawn with four beaters. B. and I occupied the two passes, and there, for four hours, waited expectant in steady rain, while the men completed their enormous circle. Anticipation rose high when a distant baying was succeeded by repeated shots, but nothing was seen by us all day.

According to our men's account, several elk were roused, two of them bulls, of which the biggest had made direct for my post. On examination, this was found to be correct. His spoor came to the verge of a forest-opening (on which I had kept a constant watch) not five hundred yards away. Unluckily, in the earlier part of the drive, it appeared that a bear had crossed our front diagonally at that point, and the elk, coming on his scent, had turned sharp off. An effort to overhaul him with "loose hound" was a failure. The bear had passed me within three hundred yards, but not in sight.

The "slap-jack" thus ended blank, and the season finished with our own score standing at four elks, besides three bears (a female and two cubs), shot by one of our hunters as he journeyed homewards across the fjelds. In the same week our friend Ole bagged a lynx, of which incident the following is his account :- "It was almost dusk; I was sitting down to rest, when I saw the beast 
trotting towards me through the trees. At first I thought it was a hare, but when it came within fifty paces, I knew it was a Goup. It fell when I fired, but recovered, and I fired four more shots. Then it was dead. It was a male, with beautiful skin, and larger than a goat."

Sad is that final morning when camp is broken up, when beds and baggage are rolled in their canvas-covers, the kit piled on packhorse or human shoulders. We have come to love those lonely little huts. Thence for thirty mornings we have set forth full of keen hope and eagerness; for thirty nights their flickering light has been the hunter's welcome beacon. 'To-night Per-Sæter will be but a memory. Passing the well-engineered bathing pool, we note that thick ice this morning covers the dam. A last turn through the woods for a few grouse or a stray caper, then guns are encased and the homeward journey is begun. Less easy, this, than the outward, for midnight suns and tourists have long departed, and with them fast yachting-steamers and frequent services, with reliable connections. Fjord navigation in the dark is precarious, and fogs frequent; the big boats on through-routes are often a day or two - sometimes a week-behind time, and the small craft that ply on the "inner leads" (not lighted) must anchor nearly every night and await the dawn. He who seeks. sport late in this northern land, must lay his account for delays, and some little roughing-as when the choice lies between sleeping on the table of a coaster, or making a forced dash of forty miles in the dark, under solid rain or snow : carioling all night to catch a weekly 
steamer at daybreak in the next fjord-with alternative of "seven days."

Such, however, are but trifles-items in the costs we willingly pay for glorious weeks in forest or fjeld, and only mentioned to complete our sketch of elk-hunting. And let us gratefully remember those delicious autumnal nights when, long after the equinox, we have sat beneath quivering foliage smoking our cigars at midnight by the moonlit Lungegaard's Vand, listening to an alfresco concert, and enjoying a scene as pretty as it was animated. 


\section{CHAPTER XVI.}

THE HIGHLANDS OF THE SIVEDISH DIVIDE.

The scene of this autumn's campaign lay in the nethermost backwoods, as wild as it was extensive. Our eastern boundary for upwards of fifty kilometres marched with Sweden, the frontier being indicated on the mountains by cairns, in the forests by an endless straight-cut ride. Deep coniferous forests filled the valleys and climbed the hillsides up to timber-line, where they gave place to a zone of open wood, and above that to bleak moor and barren fjeld. Lakelets and tarns studded the uplands, while huge sheets of water (sjöen, or "seas" in Norsk) separated the main ranges. These seldom exceeded three thousand feet in elevation; but a leading feature in the physical configuration of our domain was a great cordillera that protruded far through its centre. This was the Mœrrafjeldetn, the highest peak of which (Hartkjolens) reached four thousand five hundred and fifty feet. The whole territory belonged to the Crown, and carried a nominal right to kill eleven elks, though there were not that number of bulls on the ground. During hard winters the wolves from Hartkjolens play havoc with the deer. Our aim had been to penetrate truly virgin ground, 
and in that we succeeded. No English sportsman had ever before invaded the solitudes of Muru. We had left behind those hunter's horrors-population, cultivation, and so forth; but in passing beyond the line where even the hardy Norseman, inured to unequal strife, ceases to wrestle with impossible odds, we found ourselves confronted with a new and unexpected terrorthe Lapp. These savages wander at will over the North Scandinavian backwoods and highlands, pasturing their herds of deer regardless of private rights or property, and innocent of the nature or existence of law. I do not infer that they deliberately break the laws. They are many degrees too low down the seale for that.

The mere propinquity of these nomads would not have injured our prospects but for the combination of another circumstance-an early snowfall. Already, in the first days of September, the heights of Hartkjolens lay white as Soracte. The snow drove the Lapps and their deer-and with the deer, their ever-attendant wolves-earlier than wont from the hills into the lower forest. Their advent was notice to quit to the solitudeloving elk, which moved off into denser woods beyond.

Our first morning in Nordli the wind blew strongly towards our best ground. Accordingly, to gain the leeward, we proceeded together down-wind to the base of the big hills, twelve miles distant, there separating and swinging back in wide circuits to left and right respectively. Before that preliminary walk was completed, the key-note had been struck. First our dogs, Jeta and Jagt, took a scent which, on crossing some peat-hags, was seen to belong to three reindeer, going at speed. Following from curiosity for half a mile, we 
were struck by a quantity of hair scattered along the course ; presently there was blood, and not much further on, the scene where wolves had that morning pulled down a reindeer-calf. Little remained but shreds of skin ; even the bones, except two hoofs, had disappeared. Then, a few miles further on, we descried to the right five reindeer, including three large bucks, feeding beyond a small loch. To have stalked and shot a couple of these would, we reflected, still barely put us level with the Lapps; but our hunters strongly opposed any idea of so adjusting matters, and we rather reluctantly proceeded.

We covered that day an immense area, each of us swinging with a cheek-wind on a homeward circuit. The forest was open and mostly deciduous-a perfect elk-country-and there blew a strong steady breeze that gave a three-mile scent. Yet not a sign did either of us see of garne or recent spoor, and before we finally reached our boat after a fifteen-hours' tramp, we had each separately decided that not an elk remained in that tract.

Acting on this, we next day shifted camp to Muru, distant twenty-four miles, on the Swedish frontier. W. went with the horses, Bertie and I taking the hill. At first we "played ourselves"-driving the smaller patches of wood, where a few brace of blackgame or a stray caper-cock came bounce on the bent, or walking the bogs for a casual snipe; then pushing forward up the rising ground. On clearing the trees we fell in with grouse. A pack of five-and-twenty, rising wild, went forward : two others, wheeling back, "becc-ed" down above the ridge. These last we promptly gathered, 
rising from short heather: then followed the main lot. At first they were wild enough ; but by lining-out in a crescent, the guns closing in forward while the beaters closed the rear, we soon had them demoralized. Surrounding the birds thus in each patch of dwarf-birch, we took them coming out in face-en pico, as the Spanish say-and in less than forty-five minutes, by this simple plan of half-mooning, had two-and-twenty willow-grouse and a blue hare in the bag, when "cease firing" became imperative as time pressed and but four cartridges remained. It was short work and sharp while it lasted : moreover, it established our repute as marksmen with our simple hunters. This initial repute is of the utmost value in foreign shooting, encouraging one's jagers, who then know their hard work will not be wasted. They will then find excuses for one should even an inexcusable miss occur later. To have to make excuses for one's self is worse than useless.

It was amusing to see our friends' undisguised amazement at a few smart, incoming " doubles." " $\mathrm{Oh}$, meget slem dag for ryper!" = A real bad day for the grouse! repeated Johannes as he gathered them in threes and fours.

The final stages of that day's journey were completed in silence. Ridge beyond ridge of sterile fjeld, miles of deep forest-weary men mechanically tramping forward. Hardly an ounce of going-power remained when at last, about 9 p.m., we lit a mighty bonfire on the Muru-sjoën as a signal to send the boat.

Our new quarters commanded one main and one minor forest-tract, mostly lying on steep acclivities, but broadening out westwards into a moory plateau which 
forms the main watershed, the streams on the near side flowing into Sweden, those beyond into Norwaythe head-waters of the Sandöla. Here, amidst miles of dark forest, we had got beyond the Lapp, for no broadantlered deer could traverse these woods; but their very density was a new obstacle-it was often impossible to see fifty yards. The favourite lying-grounds of elk were not in the spruce-wood, but in the depth of those dank, dark thickets, where sallows, birch, and willow crowded in, a million to the acre, shooting upwards from an undergrowth of hazel, juniper and fern. My first day here I saw four elk, but never fired a shot. Here is the record.

Started by boat, 3 a.m. We had hardly entered the woods when we struck fresh spoor: but the elk (a fiveyear bull) having gone down-wind, we left him and within half-an-hour walked right into another good bull. At the moment we happened to be crossing the wind, and therefore had no notice. There was but a single crash among dense birch-saplings forty yards ahead, a glimpse of one horn, and a patch of grey stern-that was all. He was gone: a rabbit could hardly have vanished more suddenly, silently, invisibly. We followed the spoor to get his line for future guidance, and two hours' later came on game again. This time a bark-stripped pine was the index. White and naked, the tree stood by an open bog, skinned clean to a height of seven feet. Strips of "velvet" lay mingled with the chips and shreds of bark below, and by the spoor we saw that a truly enormous bull, accompanied by a cow and calf, had that morning cleaned his horns against the pine. This trail we followed all day, mostly through very 
heavy ground, steep and intercepted with interminable ravines. The trio wandered aimlessly upward ; for some reason they never laid down - at any rate, not for more than an hour-and at 4 p.m. they had turned and commenced feeding back, down-wind. This, of course, trebled the work on our part, owing to the endless detours now necessary; but we stuck in, and late in the evening knew by Jeta that we were coming up. The elk were then (we assumed) feeding down-wind towards an abrupt crag that rose like a Gibraltar in the forest. A treeless bog flanked the erag, and by a hard run around this (nearly a mile), skirting the forestfringe, Johannes reckoned we should gain the weathergauge and so meet the game, coming in, face to face.

All this we actually performed; all that we had anticipated and striven for actually occurred.

We accomplished that terrible sprint, gained the wind, and climbed the steep. Half-way up that crag, in a hollow amphitheatre of rocks, we had all three elks within fair shot. But we did not know it. The light shifting air in a confused ravine now played us a trick as false as ever hunter suffered; not only did the traitor breeze refuse the required scent to Jeta right in its course, but it conveyed it to the cow-elk directly to windward and a hundred feet above us. She went off with a crash, followed by her calf. I just distinguished the hornless heads, and sank down on a rock, "pumped' with the long run and hard climb. The bull at that moment stood even nearer-within eighty yards, and on the same level. Something like a great grey patch of the mountain-side began moving-within the instant the rifle was at my shoulder, covering the next opening. 
But never another sight did I get. There was the same single crash, as before, and the bull dashed headlong down those broken rocks, strewn with fallen trunks, studded with boulders and thickly-growing pinesvanishing in silence and strides six yards long!

The day was ours, but the spoils were denied us. By all the rules of hunting-craft and fair play, we had won. The grandest of elks had lost his coronet to superior intelligence, and his head should now hang in my hall with the rest. There remained, you suggest, the chance of a miss? Aha! but a holy calm possesses one in these final, crucial moments, and a combination of confidence and common sense serve to steel nerves when the labour of days and weeks depends, for realization, on keeping, for less than thirty seconds, a cool head and a steady hand. Here a double run of bad luck, that would outwit an archangel, deprived us of a hard-earned trophy, and human craft came in a bad second.

As a climax to the disasters of the day, we now mistook our bearings, under a false impression that the wind had changed, and for an hour walked in the wrong direction. The compass, in the hurry of an early start, had been forgotten. But nature came to aid where forethought had failed. The ant-hills of the forest are her compasses, being invariably placed due south of the tree that protects them. An ant-hill having corrected our error, after three more hours' toilsome tramp through dark forest and pouring rain, we reached the hut, deadbeat, at ten o'clock.

A fortnight later, I had another interview. Bengt and I, by an extra early start, reached the summit of Roeberg-scar (Gibraltar aforesaid), eight miles distant, 
ere the pale dawn spread itself over the forest. Our hope was that from this high peak we might view elk moving at daybreak across some forest-opening. But we saw nothing and, descending, struck a good spoor. This we had followed for some miles-at times in momentary expectation of "view" - when, without notice from $J a g t$, we came suddenly on our three former friends. The cow rose from her bed and stood, flicking her heavy ears, not forty yards away; the calf beyond her. Then, between the spruces, the great bull strode into sight. It was a matter of a moment. But one may see much in a moment. What I did then see remains fixed on my mental retina as an instantaneous photograph-that great wild beast, bulking huge in the subdued light, with his high withers and sloping quarter. His head hung. low and slouching, and the heavy clamshaped horns showed up in relief, with the double row of spears showing dark against the broad palmation behind. It was a memorable picture of wild primeval life, a dissolving view; but there was no time for a shot.*

This moment presented a most favourable opportunity for slipping the dog. But Bengt had on former occasions shown so great reluctance to using .Jagt as a "loose hound," that the idea did not occur to me in time, and the chance was lost. I never saw that elk again.

Walking homewards in sullen mood, we passed through a chattering concourse of birds at least a mile in length. They were very wild, but after some trouble I made them out to be waxwings (Ampelis garrulus),

$$
\text { * See illustration at p. } 8 .
$$


their sharp crests and striking plumage clearly defined by the spy-glass. This was September 18th; next day not one remained, nor did I ever see them again. While spying the waxwings, several crossbills were also observed, each busy dissecting a pine-cone at the summit of very tall trees. Owing to their lofty perches, their silence and sedentary habits (since each cone takes perhaps an hour to explore), and to the birds agreeing so closely both in size and colour with the cones to which they cling, crossbills are easily overlooked even in woods where they are numerous. A woodpecker with curious white band down the back, and a yellow crown, also attracted attention to-day. I shot it with the $\cdot 450$, and from the fragments gathered, identified it as Picöides tridactylus, of which we subsequently obtained another specimen. While waiting for the boat to come across, we also "potted" five hazel-grouse, all sitting on the trees. They are delicious eating.*

Enough, however, of misfortune. I have, in fact, overrun its actual limit, for happier events had occurred in the interval, and I must hark back to maintain the sequence of this narrative. On September 14th, a bonder, that is, a yeoman farmer, came over to interview the outlanders. Representing five owners of forest-land

* Forest-birds were few. Besides game and birds of prey (elsewhere mentioned), the chief were Siberian jays, Northern tits with black caps and white cheeks, which sang sweetly, crossbills, occasional bramblings and fieldfares, robins, great black and three-toed woodpeckers (both rare), and many kinds of owl. On September 14th ortolans observed at Murumöen sæter. On the lakes, most of the breeding waterfowl had departed. The last young long-tailed duck was shot on September 8th, but a few common and velvet scoters remained, and I have odd notes of scaup and tufted ducks, wigeon, teal, etc. On September 9th a black-throated diver had already completely acquired the white neck of winter. 
some thirty miles distant, he invited us to visit their domain, assuring us that elk might there be hunted more favourably than in our own dense forests of Muru. Our hunter, Johannes Norbak, knowing the ground and confirming their statement, I set out thither at once, and

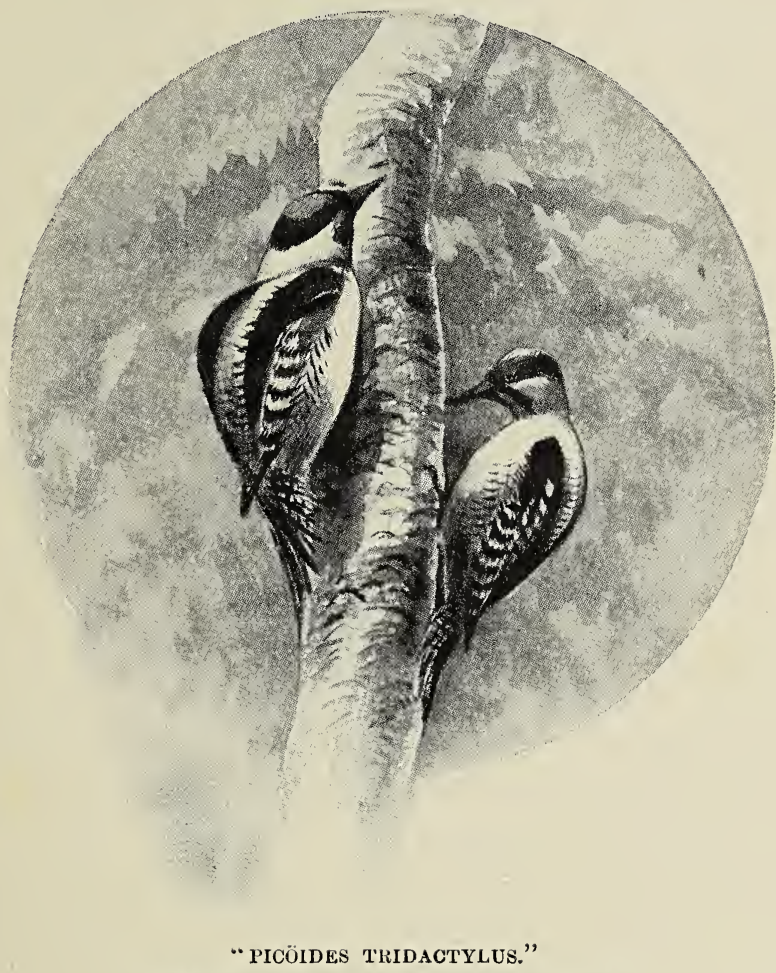

(Only three toes, but he needs no more.)

before nightfall had reached a sæter on the fringe of the fjeld. In this hurried start due attention had not been paid to provisions; hence we were reduced that night to coffee and rye-bread-bad fare for hard work.

At three o'clock next morning, when we turned out, 
the night was fine, the moon shining through driving clouds, and I observed a poacher "burning the water" far below. This explained the fact of our dogs having barked all night, depriving us, tired as we were, of a chance of sleep. Two hours later, by which time we had climbed out through dark woods to the fell-ridge, the weather had changed to mist with heavy vertical rain. By 6 a.m. the breeze had utterly died away, and the prospect was wretched in the extreme. For the essence of our venture lay in this-that on this open fjeld, we should be able to see our game at a distance, while the elks fed at sunrise. But clear weather was obviously a sine quâ non, since one cannot see even an elk in a fog like pea-soup : nor can the best of dogs scent him in a breathless atmosphere. Verily the elements seemed to conspire against us, and in desperation I gave the word, "Back to the house!" To me thus Johannes:- "Wait here one hour; perhaps the weather may change." The hunter dived beneath the spreading crinoline of a spruce, while I sought comfort in a nip of grog and a pipe, sitting shivering on a $\log$ in the pouring rain and dark dawn.

Siberian jays flopped around within arm's-length, and a caper-cock bustled noisily on to a half-fallen pine hard by. He tried to sing, but his vocal organs failed, so he descended to breakfast on blaeberries and shoots of dwarf-birch.

Precisely at seven o'clock, a rustling of leaves betokened wind-oh, the joy of it! Johannes was all action in a moment, and we pushed forward over the fjeld. By eight o'clock it was blowing hard, though rain and scud still shut out all view. Then we struck 
a burning spoor. Johannes thought it was that of a good bull; but I did not like the look of it-there was nothing big about it. "Perhaps ten spears," might prove possibly eight, probably six; so we left it, and presently Jeta indicated a breast-high scent. We advanced upon it, and her keenness increased. I had strong faith in this grand old bitch, who never misled us on fox, marten, or other inferior game. Of course we had here absolutely nothing to judge by-there was no spoor to gauge the quality of the game; it was a direct scent on the game itself, and some good genius persuaded me to take the risk. We had just refused a probable ten-point bull; now we accept an unknown quantity!

The breeze now blew half-a-gale. The sun, shining in an azure sky, lit up a glorious panorama of wild mountain-land-half Norwegian, half Swedish. The next sixty minutes were equally brilliant, viewed as an exposition of fjeld-craft. Jeta was inspired; she kept us going at a run. But hunting prudence dictated the precaution of constant "casts" to right and left in order to guard our flanks. These, with a tearing scent, and a fairly open fjeld-(merely intercepted with patches of russet birch-scrub, barely six feet high, and minor clumps of trees)-I considered, in the impatience of delay, almost supererogatory; but Johannes' method was a valuable object-lesson. It secured each yard of our advance. We had progressed some three miles beyond the point whence Jeta first took the scent, when our hound's intense excitement plainly indicated that we were close up. "Meget, meget naar nu!" (Very near now!) whispered Johannes, his 
handsome face expanded into a smile that reached from. ear to ear, as we breasted a steep rise. Straight before us began a long hog-backed ridge, narrow and birchclad, and dropping precipitously on either side to darkly tarns. A covey of grouse came swinging round the shoulder in front, and "becc-ed down" right on our course. We lay flat till the last had run out of sight; but we felt that that ill-timed flight boded nothing but mischief for us.

On reaching the main ridge and looking along it, I at once saw the cow-elk, lying, all alert and in the open, some fifty yards away. She and her calf disappeared in three strides to the right. To her I paid no attention, and in a moment my eye caught the coronet of the bull, gleaming in the sunlight over some low bushes about eighty yards distant. He, too, was on his legs with marvellous rapidity-(no doubt the grouse had put all three on the watch) - and slowly moved off, directly from us. I had not before seen a big bullelk fully outlined in the open, and admit I was amazed by his proportions-indeed the impression conveyed was far more that of one of the great pachyderms than of an animal of the deer-tribe. (See plate opposite.)

It was a straight-away stern shot--always awkward. Luckily a slight hummock lay beyond, and as the elk rose this, exposing for two strides an acre or so of darkgrey back, a Paradox bullet, well placed under the last. rib, traversed his vitals. The second I heard "whank" on his stern (hard by the hench-bone) as he floundered forward over the ridge and disappeared. No elk lay dead on the spot: but, two hundred yards beyond, I saw the beast prostrate. He tried to rise, but his quarters. 


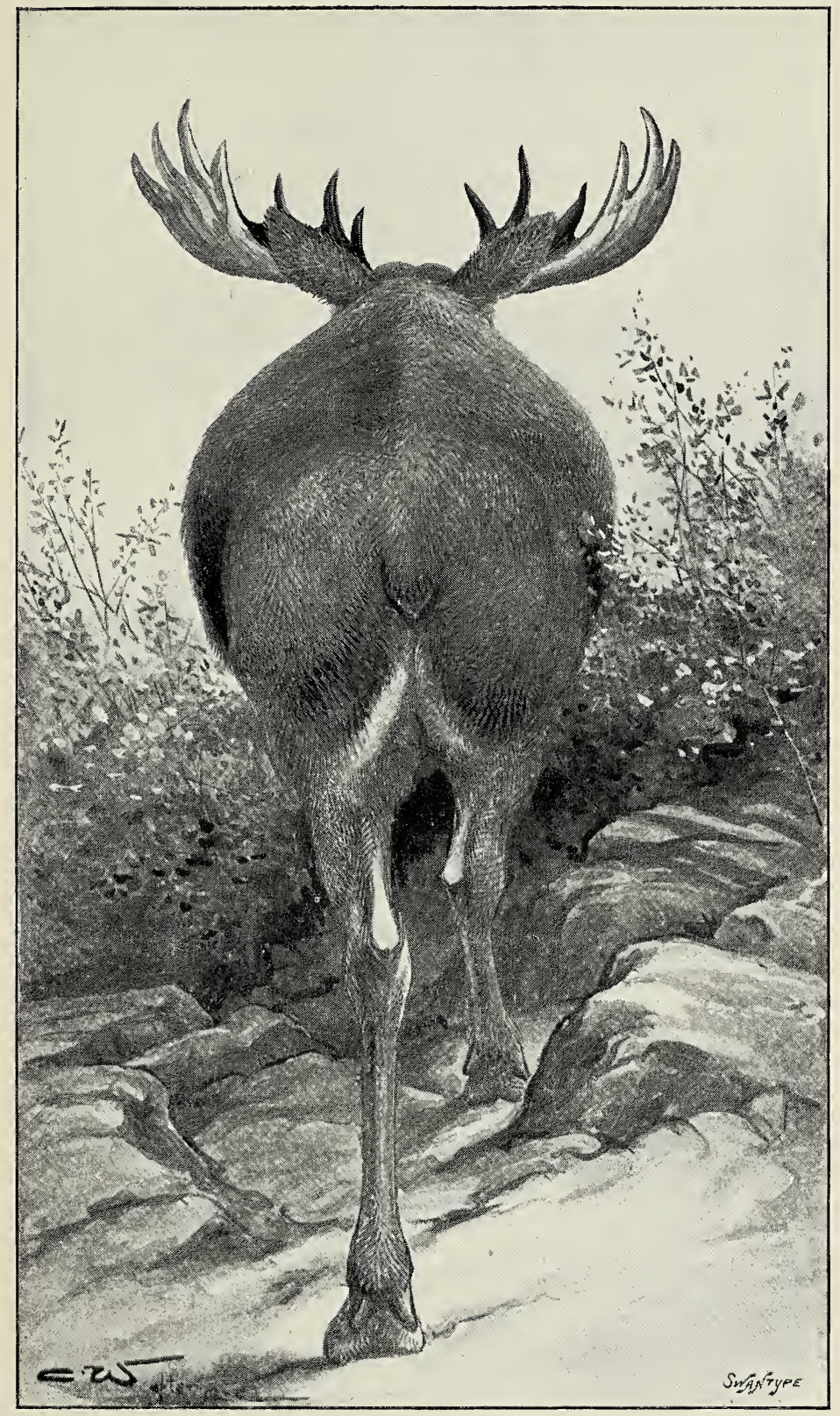

A Straight-away Stern Shot. 

were paralyzed, and a 450 Express ball behind the shoulder terminated all conscious suffering, though in the final struggle he rolled off the narrow ridge, down the wooded slope, flattening birch and brush in a common ruin, till finally brought up on the very verge of the crag. One more roll, and he would have plunged into the lake, forty feet below ; but there he lay, upside down, his back caught on a rock, one foreleg hitched high in a tree, another trunk through his jaws, and anchored by his horns to earth.

This elk, both in bulk of body and in horn, is the biggest I have shot. The span of his antlers, measured straight from tip to tip, was 46 inches; length along inside curve, 28 inches; and circumference above burr, $6_{2}^{1}$ inches. He carried 15 spears, and his general proportions will be seen in the two drawings by Mr. Charles Whymper, which translate my own rough but careful sketches made on the spot.*

Owing to the circumstance that the meat was divisible among five proprietors, I had an opportunity of obtaining some of the weights, from which the approximate live weight of this bull may be put at about 90 stone, or 1260 lbs.

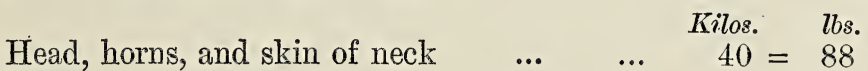

$$
\begin{aligned}
& \begin{array}{lllllll}
\text { Neck } \ldots & \ldots & \ldots & \ldots & \ldots & \ldots & 40=88 \\
\end{array} \\
& \begin{array}{llll}
\text { Two fore-quarters }(\text { each forty-six) } & \ldots & \ldots & 92=202
\end{array} \\
& \begin{array}{llll}
\text { Two haunches (each fifty-four) } & \ldots & \ldots & 108=237
\end{array} \\
& \begin{array}{llllr}
\text { Two sides (ribs) (each forty) } & \ldots & \ldots & \ldots & 80=176
\end{array} \\
& \begin{array}{lllllll}
\text { Skin (estimated at) } & \ldots & \ldots & \ldots & \ldots & \text { say } & 165
\end{array} \\
& 1000
\end{aligned}
$$

* In the drawing of the dead elk (p. 258), there is a slip in the relative sizes of man and beast. The hunter is shown quite disproportionately big : thus dwarfing the huge bulk of the bull-elk. 
Small matters now replaced great. I had brought six shot-cartridges to provide dinner in case of failure with the bigger game, and with these I had the satisfaction of securing six of the intrusive grouse in three double shots. This was an abundant grouse-season, and so numerous were the birds that year, that I imagine a single gun, without a dog, might have bagged twenty to thirty brace in a full day. There were also a few hares, with snipe on the marshy bits, and a fair lot of capers, blackgame and hazel-grouse in the woods below.

This fjeld being of level contour, mostly open birch wood and good going, was the easiest elk-ground I have yet hunted. Bertie, whom I sent for at once, secured a four-year-old bull his first day; and a third beast of fourteen spears fell within the week.

On returning to Muru, I found that W. had also come up with an elk in the birch-thickets of RoebergSkov. Bengt and he had approached within sixty yards, the bull lying protected by a fallen pine, and as the beast slowly hoisted his ponderous body aloft, facing the hunters, W. placed a 450 bullet fair in the chest, and the stricken beast took the hill, climbing out for miles through steep forest and out on to the open fjeld above. The elk having swum a considerable tarn, much time was lost recovering the spoor beyond, and from this point onwards there was no longer any blood. After six hours' tracking, the elk was overtaken, lying in a broken cleugh on the fjeld and scarce able to rise. He was not forty yards off, but unluckily W. had lagged behind, and ere he came up the chance was lost. "Don't fire--run!" said Bengt, but the wounded beast, stiff 
and stumbling, walked right away from them, disappearing over a fold in the fjeld. The trail led on to the brink of a mountain-torrent, swollen by rains, and beyond this no sign could that night be seen.

Next morning we turned out our full force, men and dogs, and for three days hunted that fjeld high and low, scouring both banks of the river (so far as they were accessible), and every spot likely or unlikely to harbour the missing game. But not a trace could be found. No spoor ever left the torrent-side, and death, beyond a doubt, had overtaken the elk while seeking safety therein, his body being swept down those yawning chasms where the stream, in clouds of spray, hurled itself down the gorge. We accepted our hunters' assurance that the trophy itself would certainly be recovered when the snow should have revealed, by the tracks of wolves and beasts of prey, the position of the carcass.

A curious incident occurred on one of these days. Both dogs were straining on their leashes, when we observed, far off on the fjeld, an unusual assemblage of birds of prey. There were croaking ravens, and at one time we counted eleven buzzards soaring around with shrill cries or alighting on the rocks. "Ulve!" (Wolves!) whispered Bengt, and we spread out silently in line, advancing on a hot scent and in high hopes of encountering both our lost elk and the carousing wolves at one and the same time. Already, in mental anticipation, we were "knocking them stiff" as the brutes crossed an open glade below. But the covert drew blank. Undoubtedly some beast moved off on our right, but nothing was seen, and the cause of the buzzards' 
concourse remained unexplained. Perhaps it was an election.

Another day we came on a pine-marten. We were following our young hound Springe, when, amidst cavernous roots of a dead pine, the yellow chest of the maar * caught our eye, not three yards distant. Close beyond, in a forest-glade, lay two newly-killed capercocks, their brains eaten, as well as part of the breast. They had evidently been caught while feeding, martens springing on them simultaneously from the spreading spruce-boughs above. Martens are quite common in these forests, harbouring in hollow trees; but they are cunning and excessively wary. In the forests overhanging Kvye-Sjöen, on September 17th, I sprang also a white fox, the only one seen, but failed to score. The wild-life of the forest, however, is too diverse to be crowded into the corner of a chapter already too long, and deserves a place for itself elsewhere.

Having received word that the Lapps had finally retired southward from the Mœrrafjeldetne, we shifted camp thither, to give that beautiful forest another trial. A single day's work satisfied us that not an elk had traversed it since we hunted the ground three weeks before. After midday, when about to exchange rifle for gun, and commence operations on the willow-grouse that abounded among the birch-scrub, Johannes drew attention to a whitish object on the distant shores of Kjœrdals-tjernen. A scrutiny with the glass showed this to be a reindeer buck lying close to the water's edge on a rocky point. The landward base of this was local.

* In proper Norsk, "marde"-the word as given above being 


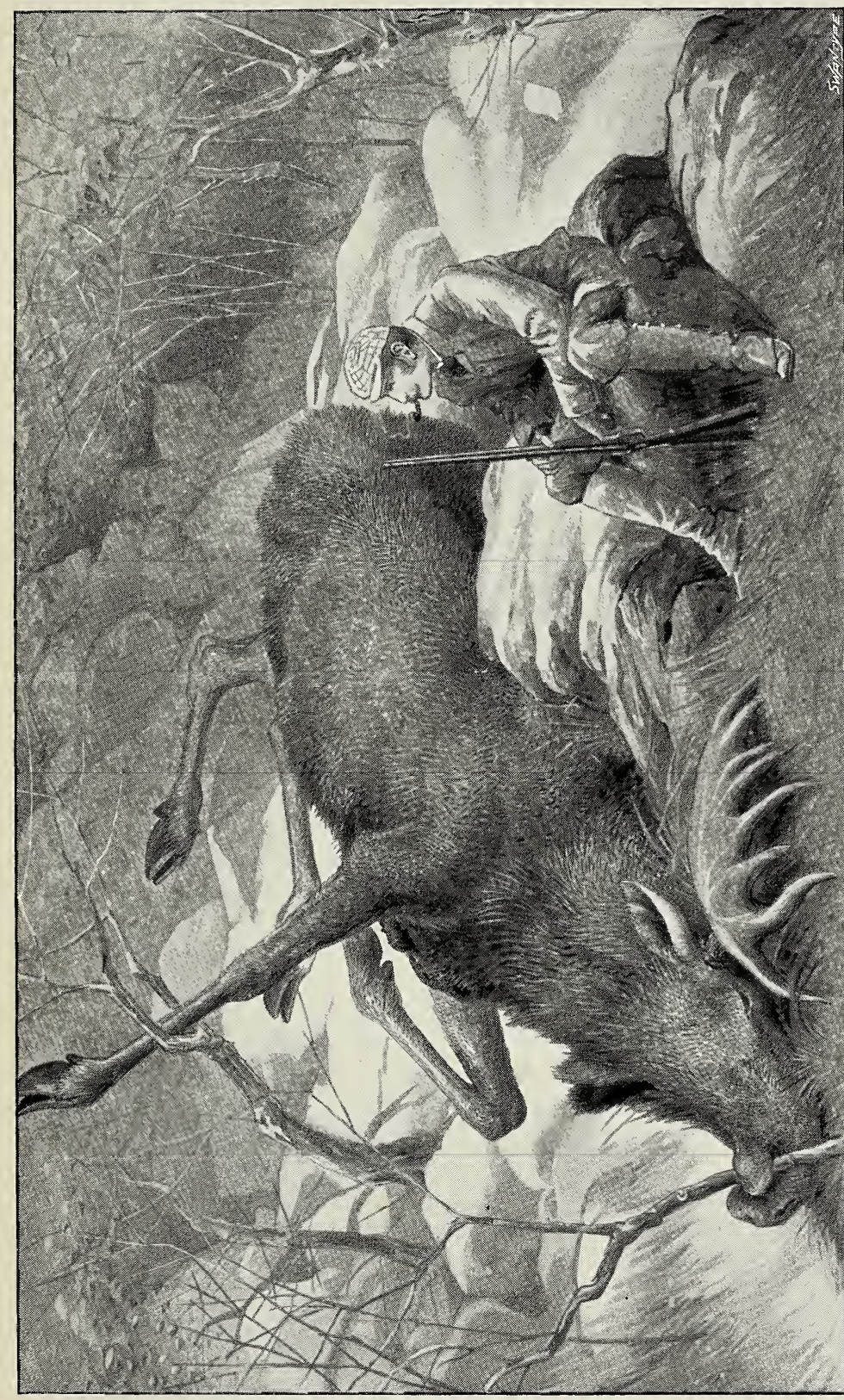

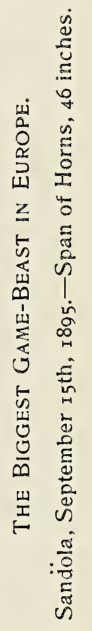



easily gained, but thenceforward the wind, being within a few points of foul, presented danger. But I was now satisfied I had a curious head before me, and crept forward along the verge of the loch. At one hundred and twenty yards, the deer got the wind and stood up, sniffing for some seconds uncertainly at the breeze. Then he moved directly away, only half his body showing above the rocks. Such a shot means five to one against the rifle, and I decided to take a bolder course and try to cut the deer off on the farther side of the peninsula. The distance to the ridge might be two hundred yards, pretty steep, and intercepted with trailing birch. Having reached the ridge, with lungs going like bellows, I rejoiced to observe that the shore beyond was within eighty yards, but-nothing was in sight! Had the deer fairly beaten me, passing by ere I had arrived? Had he taken the water, or-but doubts were resolved by the rattle of hoofs, and broad antlers, in full gallop, appeared from behind a pyramid of piled-up boulders by the shore. He had now to pass within eighty yards, and I "shot to kill," dwelling well forward on the snowwhite neck. As I pulled, the Ren-ox swerved straight in, thus receiving the 450 ball between the eyes. He tumbled "all of a heap," his head doubled in beneath the breast, dead as a door nail.

This was a very old solitary buck, no front teeth remaining, and the fact of his being alone at that date (September 20th) showed that he had probably been dispossessed in battle of his master-position in the herd, and was sulking in consequence.

The incident of course lacks in sentiment, compared with deer-stalking on the high fjeld, but that old recluse 
afforded some exciting moments, and carried rather a curious head. Though only measuring 3212 inches in length, the horns reach thirty inches in span, and are remarkably broad and massy, with thirty-two points.

Then we returned to our legitimate business of elkshooting. 


\section{$(261)$}

\section{CHAPTER XVII.}

THE HIGHLANDS OF THE SWEDISH DIVIDE-Continued.

Lövsjoli and the Luru River.

Our quarters require a passing word. The equipment included a two-man " explorer's tent," six feet by eight, enabling us to work outlying forests; but our main reliance was on the five log-huts and sæters of the backwood bonder's which lay scattered at twenty or thirty-mile intervals within our domain. No more kindly and obliging folk exist than these forest-farmers ; they are, moreover, born hunters, and we became the best of friends. Their log-huts are scrupulously clean, as were, in every case, the woolly sheep-skins between which we slept in wooden bunks.

Never " roughing it" merely for roughness' sake (though prepared to take all odds for sport), we had brought with us, besides commissariat reserve, a handmaiden whose "character" was given in these words : "Karen can cook good, she is never ill sometimes, and she can run on the mountains like a man." This we found true in word and fact. Cooking necessarily presupposes the existence of material. This condition fulfilled, we fared sumptuously; otherwise-but we try to forget those feasts on fladbröd and fell-berries. The 
death of each elk, of course, set us up for days in beef of excellent quality and surprisingly tender, seeing that only old bulls were selected. Then, one of our trio, being almost as keen of feather as of hide, kept us supplied with young caper-cocks, $10 \mathrm{lbs}$. apiece, grouse, blackgame, and, most delicious of all, the hjerpe, or hazel-hen. From six to eight brace daily, however, were required to feed us and our retinue, and the supply at times fell short. Fish never entirely failed, save when for days together it blew a gale on the lakes.

When big-game becomes the business of life, fishing must take, for the moment, a secondary place. Yet the subject will not be passed over, for in no other land have I seen so great a variety and abundance of gamefish as we here had at our doors. We had rivers and lakes of all sizes, great and small; and, though beyond the range of sea-going Salmonidæx, each swarmed with scaly denizens.

In Norway one constantly hears of monster trout that run into teens of pounds ; but when, after years of effort, one fails to land anything exceeding four or five pounds, such tales are relegated to the limbo of fiction. But Muru-Sjoen reconverted me. I don't ask anglers to believe it, but our best trout here did actually scale over seven kilos, or equal to nearly 16 lbs. avoirdupois, and measured $33 \frac{1}{2}$ inches in length by $18 \frac{1}{2}$ inches in girth. This was no lake-trout, or ferox, but a genuine Salmo fario, identical in every detail (save size) with our half-pound burn-trout at home. In colour he was a blend of darkest browns, olive, and green, shading off into gold; spots large and few, each encircled with a paler balo. 
In September, the fish are falling off in condition. With the fall of the leaf, trout and char draw up into the gravelly shallows and soon cease to take the fly. Trolling is then the only method of fishing the lakes, and was practised daily in pulling across to our different hunting-grounds. But, to feed our retinue, we did not disdain the unworthy net. One day in mid-September, having set about a hundred and fifty yards, encircling the mouth of a river, afterwards rowing inside and splashing all over the enclosed space, we had a notable haul. Five species of fish were captured, as follows :-

Trout, 18-the best exceeded $10 \mathrm{lbs}$., and several others weighed from 3 to $5 \mathrm{lbs}$. and upwards.

Char, 11-running from 1 to $2 \mathrm{lbs}$. apiece.

Grayling, 4-averaging $1 \mathrm{lb}$.

Pike, 3-running from 2 to $5 \mathrm{lbs}$.

The fifth species was a curious eel-like fish, pale sage-green, splashed with irregular dark blotches, having continuous fin-rays above and below, and a gristly beard. Its Norsk name was "lake," and this specimen measured nearly a foot in length. It was probably a species of burbot.

The orders for each day ran roughly as follows :-At 3 a.m., coffee in bed. Breakfast half-an-hour later, more coffee, fish, elk-steak and ryper. Then each, with his hunter and hound, got away before daybreak, to return at quite uncertain hours. In the event of a kill, it might be by midday: otherwise, any time up to midnight, though dinner was fixed approximately for 8 p.m. This function, as already suggested, varied in quality. On fortunate days, rich red char, frizzling in butter, preceded a pile of elk-cutlets and split grouse, all mixed 
in one dish and eaten with cranberry jelly, foilowed by "möltegrod" with cream-a thing that cannot be described in common prose.* Liquids were scarce. Beer was too bulky to bring, and the nearest store (eighteen miles distant) we had already drunk dry our first week. After that, we were reduced to our slender stock of Bordeaux and a few bottles of aquavit (cornbrandy).

On September 21st we shifted camp to the headwaters of the Luru River, distant some thirty-five miles beyond a wide stony fjeld. A ride-vei (horse-track) was available for seven miles; the remaining twentyeight had to be negotiated on foot, each man carrying, besides rifle, etc., whatever impedimenta he required for a ten-days' hunt. We had intended leaving Karen behind, considering the long march beyond her powers. But her disappointment was so obvious that, not without misgivings, we consented to her coming. She did not fail. Tricing up her skirt to the knee and donning a pair of leathern hunter's leggings, she pegged along through birch-scrub and bog, through forest and tangled brushwood without falter; she forded flooded burns, climbed those leagues of bed-rock, and tripped down the reverse slope of Hykel-fjeld (which was lofty enough to hold ptarmigan in hundreds) as though the whole was an everyday jaunt, instead of fifteen hours' solid stiff going. More than this, Karen twice during the day boiled and served out hot coffee, and when towards dusk we at length reached the huts at Græsaamöen, was so fresh that she refused to allow us even to wring out our rain-soaked clothes, but bustled about her domestic

* Ilöttegrod $=$ freshly preserved cloud-berries. 
duties while we, perforce, lay smoking on our backs in our bunks !

Græsaamöen Sæter appeared to be populated by one woman-a Swedish Lapp, who ferried us, trembling, across the surging torrent of Luru. Some dilapidated sheds hard by appeared at no distant date to have been the residence of cows, and a quantity of cheeses in our hut corroborated the conjecture. How these cheeses could ever reach a market, seeing that they lay twentyeight miles beyond the nearest road-end, appeared to present a knotty problem; but we did not pursue the inquiry, and devoted our attention to the sporting features of this new territory.

Rising in a dreary, treeless waste, encircled by higher fjelds, the Luru river flows westward through belts of pine-forest stretching upwards from either bank some three miles to the limit of timber-growth. To our intense chagrin we found that the upper mosses, whence issued the river, were already occupied by our old scourge, the Lapps. While crossing Hykel-fjeld, we had sighted a distant herd of deer, and the first object viewed in the Luru valley was a Lapp, with dog and gun, who fled at sight, like a wild beast, though full a mile away. Our first day's hunting showed that elks in some numbers had been frequenting the upper woods, but had quite recently moved off westwards, down the river. Thither it was necessary to follow.

This brought us in face with a new difficulty. For six weeks (since mid-August) rain had fallen incessantly, and the innumerable streams which, descending from the mountains, traversed our forest-belt at right angles, were now well-nigh impassable. It may read like 
exaggeration, but I will not hesitate to say that almost daily we had here to take our lives in our hands while crossing those terrible torrents. It is no child's play to ford a stream that is only knee-deep, when the bed is all loose boulders, rocking and slippery, full of holes, and with a tumultuous current swirling by. But when the depth reaches to one's waist-necessitating the transfer of cartridges to breast-pockets-then the power of the torrent and the increased resistance remove such feats from mere sporting perseverance that enjoys an obstacle, to the borders of reckless and foolhardy risk. When one's utmost strength can barely secure each new hold for the ten-foot pole, when the intercepted flood rises in a hissing wave to within a foot of one's ear, and it takes some thirty minutes in ice-cold water to make good a short twenty yards, then a single false foothold, one rolling stone, or slip on slimy water-weed may mean death, or, at the least, involve a degree of danger that should not be incurred for any sporting ambition-that is, always presuming that your life is of some value to others besides yourself.

Several of these streams which, in themselves, were impassable, we turned in flank by crossing their lakelike portions on rafts. This, of course, presupposes the existence of lake-like stretches; and also involves carrying a heavy axe capable of cutting down trees of sufficient size to bear the weight of two men. Other streams were utterly impassable, whether by rafts or recklessness, and the woods beyond these formed secure refuge for our hunted elks.

So much for our environment and its difficulties, physical and accidental. I have already related sufficient 
incidents of elk-hunting, successful and unsuccessful, to convey an idea of the practice of this grand wild sport; and will not risk wearying the reader's patience with all the details of our experiences on the Luru. The three following incidents will suffice.

Sept. 22nd.-Found several "salt-pits," indicating that the rutting-season has commenced. To-day, after following a triple trail for some miles, came up with cow and calf, lying down. The bull was nowhere to be seen, but the spoor showed that he had left the familyparty exactly at the spot where the cow was lying, and had proceeded to cross the high fjeld above-doubtless in search of fresh loves in the valley beyond. Here his trail was seen by B., who was hunting on that side ; but, meeting with no success, the bull returned the same evening to his slighted spouse.

Sept. 24th.-My average, so far, works out to less than one beast per week; but to-day I thrice came up with elk-the two first fair-sized bulls (eight and nine spears respectively), each accompanied by a cow. The third was a real big beast. We "jumped" him unexpectedly towards evening in dense forest where, though quite close, it was impossible to shoot.

Sept. 26th.-At daybreak the rattle of a black woodpecker was audible, and skeins of grey geese flew clanging overhead. While proceeding in Indian file towards one of our rafts aforesaid (intending to separate beyond it), the leading hunter dropped to his knee, and amidst dense trunks ahead a bull-elk was moving slowly towards us. At a hundred-and-twenty yards he stood, wholly covered by a spruce, except his head and neck. Through the centre of the latter I put a $\cdot 450$ Express 
bullet, and the elk, staggering a few steps, plunged headlong to earth, apparently dead. No movement was visible above the scrub; but, after crossing an intervening gorge, we found he had recovered and gone on. With a hot scent and a sprinkling of blood, we followed at top speed, but though we twice sighted the elk slowly travelling, and fired several random shots (three of which told), we failed to come up before dark.

With the dawn next morning we resumed the pursuit, taking a Lapp as a guide in crossing the rivers. Again we found the elk, within a mile or two of where we had left him, but the frequent rivers (including one passage of the main Luru, there waist-deep and forty yards wide) deprived us of the satisfaction of handling our trophy that night, though we did not leave the chase till, after four more shots, the bull had at length fallen dead on a rocky islet, to us inaccessible. This, after half an hour's struggle with a tearing torrent, breast-deep, Johannes and the Lapp succeeded in reaching and reported the bull to carry twenty-two spears.

Leaving them, we made for home under solid rain, and without the guidance of our Lapp. In the morning we had contemptuously concluded that where that little Bandicoot could go, we could follow; but the day's experience had early shaken that conviction, and now we reached an obstacle that utterly stopped us. This was a series of fosses, falls, and cataracts, varied by lakelike intervals, that looked fathomless. We followed the stream up the fjeld, in hopes of finding a fordable spot; but the further we went, the bigger and more impassable it seemed to grow. One hour before dark we were three miles up the mountain-side, nothing in 
sight but bleak barrens, rocks, and that boiling, tearing flood. Rain and sleet, driving on a westerly gale, dashed horizontally in our faces, and we realized the meaning of the word "benighted."

After council held, we decided on trying half-a-mile higher; then, failing to find a ford, to retreat to the shelter of the woods below before it grew quite dark.

Could prospects be gloomier? It was black-dark ere we regained the woods. Soaked through from top to toe, benumbed with cold, without a bite of food or a drop of grog, we had no resource but to weather out that bitter night beneath the pines. And this within sight of the Arctic circle !

One shred of luck befell. We chanced on the ruins of a Lapp hut-a bee-hive shaped wigwam of branches, without roof, and into which rain poured in torrents. Fortunately we carried a small hunting-hatchet, with which we cut down a silver-birch or two, and, by lighting the shreds of bark, soon had a big blaze in the centre of the hut. Two hours' work were needed to provide a supply of birch-logs sufficient to keep the fire going all night; another hour was spent trying to dry some part at least of our soaking raiment. But clothes in a wringing condition, we found, cannot be so dried, and in sheer weariness we rolled over asleep around the fire, curled beneath the wet garments.

Daybreak brought no relief. After a solid night's rain, the rivers ran higher than ever, and even had it been possible to cross the minor stream (which had stopped us last night), the main Luru, we knew, would now be utterly impassable, even by boat. Our only resource was to fall back on our base, twenty-eight 
miles in rear. But we had not a morsel to eat, and rather "funked" that long tramp in vacuo. Ere grey dawn stole through the pines we sent Ole to the Lapp hut, distant two hours, requesting them to supply us with bread, and to send word as early as possible to Græsaamöen, informing B. of our predicament and retreat. At eight o'clock Ole returned with a loaf, and, having breakfasted, we set out eastwards across the mountains. Among minor troubles we found that the fire, creeping outwards among the pine-needles of the floor, had consumed our drying hose, and we had to fall back on the substitute of lining our boots with wet grass. Thus "impeded," we tramped for eleven hours over the stony plateaux of Hykel-fjeld, reaching Aune-vand at 8 p.m., and the sæter one hour later. Salted trout (though rather high) and hot coffee formed, by comparison, an Epicurean feast.

Two days later, B., with Karen ever fresh, and our hunters, rejoined head-quarters in Muru, Johannes carrying the last elk-head (weight, 29 kilos $=65 \mathrm{lb}$.) over the whole thirty-five mile march. This head, though carrying twenty-two spears - the best, in that respect, that we have secured-was inferior in span (37 inches) and boldness of outline to others of fewer points. The type of head was that of an old beast that had probably, a few years before, carried a finer coronet. Of eleven bullets fired, seven had struck him. All these, however, were from the 450 Express, which (with copper-tube bullets) is rather a light weapon for such heavy game. I prefer the 12-bore Paradox for elk, but that gun had been completely disabled in a severe accident the week before. 
Pages more I might fill with sporting incident, both with leashed and loose hound-one elk we fairly ran to bay by the latter method; then, after seventy minutes through the worst of ground, she proved to be a cow! But I prefer to add only the following note on elkhunting, which, being made on the spot and while impressions were vivid, may be of more value to the tyro.

The elk, considering his environment, is one of the hardest of European big-game to bring to bag. By the expression "environment," I simply mean that his home, the primæval pine-forest, is traversable in all directions. There are neither inaccessible crags nor vast snow sanctuaries. The elk one can follow wherever he goes.* Yet, though he is defective in vision, his wondrous powers of woodcraft, and subtlety in bringing into avail every advantage of the wind to his keen nose and ear, will always secure to the elk four to one the best of the deal. Five hours out of every ten in his daily life the elk is to leeward of his own back-track. This is not accident. Is it intuition, or instinct, or is it merely inherited, developed sagacity?

Elk-hunting combines, to the fullest degree, the joint powers of dog and man. Each must depend upon the other. But another qualification is required beyond those. One learns rapidly to interpret the signs and the mind of one's hound; but these alone are of minor value unless construed by the aid of that lexicon of

* I must except the flooded streams just bewailed, for they were the result of an extremely wet season. Still, wet seasons may, and will, recur. Besides, I have hunted elk in another wet season, but in a district where there were no streams worth mentioning. 
woodcraft that is written in spoor. The art of spooring cannot be learnt in a year-nor in two, nor ten. I question if any English hunter fully understands its bearings as do the Norsk woodmen, practised from boyhood. True craftsmen, such as our friends on the Divide, going through a wood, will tell you, when you come out, its elk-story for a week past, and more. You think your hunter pays scant attention to his dog-he sometimes seems to ignore him. Yes : but that hunter knows more than his dog; for he knows not only all the dog has discovered and is telling him, but also, beyond that, all that he himself can read in spoor, and that the dog cannot read.

In power of nose, dog and elk appear about equal. Under the most favourable conditions, either will scent the other (or elk, man) up to three miles. To fresh spoor, a good dog will often draw a mile. This is almost too good, since one cannot be sure whether the dog is really drawing direct on game, or only on fresh spoor of game. Should it prove to be the latter, there is great risk that your dog's splendid nose may already have placed you to windward of the back-trending elk.

The dense forest is the home of the elk; the thicklygrowing spruce and birch-grove his protection. In a smoke-grey coat precisely assimilating to the forestshades, even his huge bulk is often well-nigh invisible, though, it may be, in full view and within fifty yards. But for these natural protections the giant deer could hardly survive. The utmost acuteness in those senses of scent and hearing - with his great hollowed horns acting as sounding-boards-would not otherwise compensate for visual deficiencies. Take him outside the forest, find 


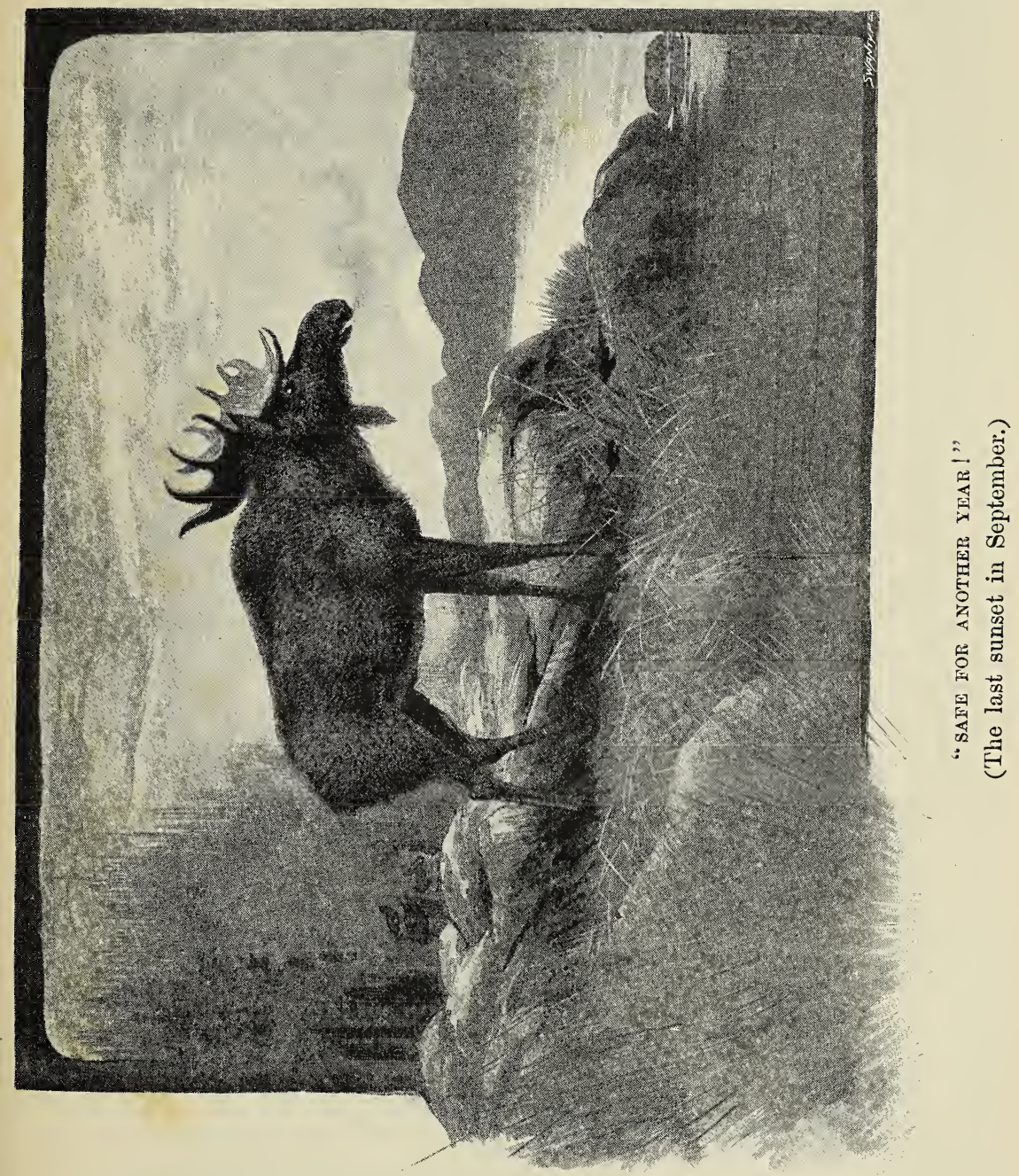



him on the open fjeld, and the elk becomes an almost certain prey.

Flooded rivers, broken bridges, banks and roadways swept away, ferries laid off-these things delayed our journey coastwards three long days; and now, to mock us, the October sun burst out in brilliance, as for seven long weeks he had not shone before, while strong dry winds from east made perfect "elking weather" now that the season was done. On the journey we heard an amusing story. Two native sportsmen in the forests that overlook the Brora, mistaking their quarry in wholly reckless zeal, had shot a grey horse instead of an elk! The owner was angrily demanding a sum of 350 kroners (nearly £20), which was perhaps tenfold more than the luckless jagers jointly and severally possessed.

When sending me the bills-of-lading the following December, our Norsk correspondent wrote: "The head of the elk that you, Honoured Sir, shot in Sandöla, is the biggest I ever seen in my life. It must have been a extraordinary big elk." The letter continues: "Johannes was here yesterday, and I gave him the axes you sent. He was pleased. Johannes and Bengt are very tru-harted, good men, and I trust [? am glad] to see how they love you, your brother, and B., and the same also with Karen. They all say there are no people existing on earth like you, Honoured Sir. I am sure they would run to the death for you, and if they should never see you again they would be very, very sorry." With this testimonial to myself (which I value), I wind up my chapters on elk. 


\section{CHAPTER XVIII.}

WILD-LIFE IN FOREST AND FJELD.

Studies of sone Few of the Chief Typical Species

Characteristic of the Scandinavian Fauna.

Great forest-areas, no less than high mountain-altitudes, are everywhere unfavourable both to variety and abundance of animal-life. The comparative meagreness of the fauna of the high-fjeld region has already been alluded to-in Chapter VIII. and elsewhere. Nor are the deep forests at all more prolific; neither in Norway nor in Sweden has ornithological research reaped any due reward in these great coniferous regions, and I will waste no space in ascribing to the Scandinavian woods an interest beyond what they do possess. True, there are forest-loving forms. There are the woodpeckers and crossbills, with tits, creepers, goldcrests, and the like; there are the birds of prey and the owls-many of them interesting enough, as will be duly noticed. Still, one may wander for days through deep forests without seeing much sign of life beyond mosquitoes and ants, whose nests stand six feet high, and spiders' webs on a giant scale that, in spring, resemble shambles.

It is where the fjeld lowers to lesser altitudes, where 
the forest opens out into coppice and glade, and in the sub-alpine belt of birch and willow, that conditions are found more congenial to a diversity of wild-life. Here, amidst the boggy plateaux of the lower fjelds, on moor and highland tarn-above the forest but below the snowfield-breed the various ducks and divers, the wading-birds and others characteristic of Scandinavia. Some of these-taking the one district of Surrendal as an example-are described in Chapter VIII. ; while, in the present, I propose briefly to notice some few of the chief characteristic denizens both of the deep forest and of the wooded fjelds that adjoin.

To begin with the forest. As just stated, one may wander for days without seeing any noteworthy sign of life. But there are creatures that are not seen. Thus one may easily spend years in the haunts of the Glutton without obtaining (in summer) so much as one glimpse of the beast; for he is strictly nocturnal and of secretive habit, lying up all day in the wildest and most rugged corries and rocky glens. I have never myself met with the least evidence of his existence, though hunting forests where we knew him to be. So I can say nothing of the glutton, and almost as little of the Northern lynx, though I have, on more than one occasion, come across the spoor of the latter, and in 1894 my hunter, Ole, shot a full-grown male, as elsewhere mentioned. Both these beasts affect the deep forest, and few of either, I imagine, are killed, except in winter, when the spoor can be followed on ski (snowrunners). The summer haunts of the bear, on the other hand, are chiefly the more open moorlands, where fellberries literally cover the ground. 
I have had no luck with bears, though at times hunting districts where we knew them to be comparatively numerous. True, I have never made the bear a special object of pursuit, nor hunted him at the seasons which are most favourable for killing him, namely, early spring and late autumn; moreover, it must be added that not all elk-hounds will follow the spoor of bear, though they know perfectly well what it is. Once we dislodged a bear from his morning bed; yet, though the scent. was actually burning, and Bengel's bristles stood on end, the dog refused to follow. Other days we have been on fjeld-slopes where one or more bears were actually engaged at the time in breaking down the berry-laden rowans: yet either the dense foliage of those hanging woods or some traitor breath of air always deprived us of a shot.

Two or three years ago, after vainly following separate elks for two days, my companion and I exchanged bulls, in the hope of thus changing the luck. Half-an-hour after we had separated, he came on five bears-winded by the hound as they shovelled in clawfuls of cranberries on the open fjeld. The shot was a long one, and failed. But it is nothing more than human nature (that is, vanity) to assume, that had we not exchanged elks, the bullet would have gone true? The bears at this season are in family parties - the mother with one or more generations of cubs, graded in size. Thus, should the mother be killed by the first shot, the cubs, even well-grown two-yearolds, will sometimes refuse to quit, and fall an easy prey. This happened to one of our hunters, who fell in with three bears-mother and two cubs-on the open fjeld, 
and killed the whole trio with four shots from his tiny repeater.

Here is a list of the noxious animals on which the Government reward was paid, killed in Norway during the last four years :-

\begin{tabular}{|c|c|c|c|c|c|c|c|c|}
\hline Species. & & $\operatorname{Pr} €$ & um. & & 1892. & 1893. & 1894. & 1895 \\
\hline Bears & $\ldots$ & 20 & oner & ... & 63 & 72 & 57 & 44 \\
\hline Wolves & $\ldots$ & 20 & , & $\ldots$ & 72 & 50 & 37 & 61 \\
\hline Lynx & $\ldots$ & 20 & , & $\ldots$ & 69 & 56 & 44 & 80 \\
\hline Glutton & $\ldots$ & 20 &, & $\ldots$ & 37 & 40 & 46 & 50 \\
\hline Foxes & ... & 4 & , & $\ldots$ & 10,758 & 11,400 & 8646 & 10,362 \\
\hline Eagles & ... & 2 & 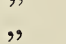 & $\ldots$ & 828 & 969 & 1081 & 854 \\
\hline Goshawks, e & tc. & 2 & . & $\ldots$ & 3954 & 4846 & 4727 & 4486. \\
\hline
\end{tabular}

ReD DeER.-Confined almost exclusively to certain islands (which are strictly preserved), and to limited areas of the adjacent mainland. The number shot in 1893 was returned as a hundred and forty-three head, eightyfour in the following year, and a hundred and forty-six in 1895. I have had no experience of red deer in Norway; but the following incident is worth relating. In 1894 a lease of the deer-rights on Oterö, a large island in the Namsos-fjord, and, I believe, the northernmost habitat of red deer in Europe, was offered me under these circumstances. For many years, owing, we are told, to long-continued in-breeding, all the calves born had been females, and the stock was threatened with extermination. Only three or four good stags remained, with seventy or eighty hinds. A lease was offered, free of cost, for a long term of years, provided I imported the needed stags from Scotland or Austria! The business had no charms for me, but I afterwards heard it was accepted by a German sportsman.

While on the subject of statistics, I will here add the 
official records of elk and reindeer killed in Norway during the years stated :-

\begin{tabular}{|c|c|c|c|c|c|c|}
\hline \multirow{2}{*}{\multicolumn{5}{|c|}{ Bulls. ${ }^{\text {ELKS. }}$ Cows. }} & \multirow{2}{*}{ REINDEER } & \multirow{2}{*}{$\begin{array}{c}\text { RED DEER } \\
-\end{array}$} \\
\hline & & & & & & \\
\hline 1892 & $\ldots$ & 686 & $624=$ & 1310 & 666 & $\overline{213}$ \\
\hline 1893 & $\ldots$ & 636 & $611=$ & 1247 & 696 & 143 \\
\hline 1894 & $\ldots$ & - & - & 1262 & 760 & 84 \\
\hline 1895 & $\ldots$ & 511 & $459=$ & 970 & 865 & 146 \\
\hline rage of & & & 89-93 & 1122 & 591 & - \\
\hline
\end{tabular}

In Sweden there are no wild reindeer, but the number of elks killed is returned as under :-

$\begin{array}{llllllllllll} & 1887 . & & 1888 . & & 1889 . & & 1894 . & & 1895 . \\ \text { Elks killed } & 2178 & \ldots & 2097 & \ldots & 1782 & \ldots & 1560 & \ldots & 1409 .\end{array}$

The Lemming (Myodes lemmus).-If his powers were proportioned to his pluck, the lemming would make things lively for the hunter. Had the bear, the lynx, or the mighty elk but a thousandth part of the lemming's aggressive ferocity, the relative positions of hunter and hunted would be reversed, and an expedition to the fjeld would require an advance guard of cavalry and a support of Maxim guns. The lemming attacks with reckless fury the harmless passer-by. One small creature (smaller than a rat) will assail, without second thought, a couple of human beings weighing a hundred-and-fifty pounds apiece; it will spring to one's knees, biting and barking, and in purblind fury fall back all-ends-up to earth, only to renew the attack again and again. To-day, while one lemming was flying at me, another from beyond a small stream joined in the demonstration, presently swimming across to get to close quarters. I was not quite sure that the first fall into the water was not accidental ; but hardly 
think so, since, once there, the beast came straight on to the charge. Even when sitting in the mouths of their holes, lemmings will as often as not come out to attack.

The lemming is a careless, happy-go-lucky creature. When he goes for a walk he seems to take no bearings or to remember his way home. Hence, if disturbed, he will either "charge home" with furious battlecry, or struggle away, squealing, through rough ling and scrub; whereas a mouse, if alarmed in the open, streaks off to his hole along a made and known highway. The abundance of lemmings this autumn (1895) had induced an unusual quantity of birds of prey. These were chiefly Rough-legged Buzzards on the higher ground, Goshawks in the lower forest: there were also Peregrines, and occasionally the white-looking JerFalcon, which our hunters assured us they had known to nest here on a pine. In a little "green-room" of spruceforest I came right upon a Goshawk feeding. So close grew the trees, that he had to come out by the same way I had come in, and I felt the wind of his wings as he swept barely two yards overhead. His dinner had consisted of a hazel-grouse, and but little remained beyond bones and feathers, balanced on a moss-clad stump.

Another day (Sept. 28th), while sitting, about "pumped out," on the end of a terribly long and rough pine-ridge we had just drawn blank, a big hawk swept down-wind, wheeled and poised for an instant at eighty yards. I "covered" the bird, merely in idleness; but, thinking the aim was rather a fine one, touched the trigger and it fell. The 4450 bullet had struck the 
centre of the breast, cutting the big hawk almost in halves, though Cullingford afterwards managed to make a specimen of it, as the photo shows. This was a female Goshawk in its second year's plumage.*

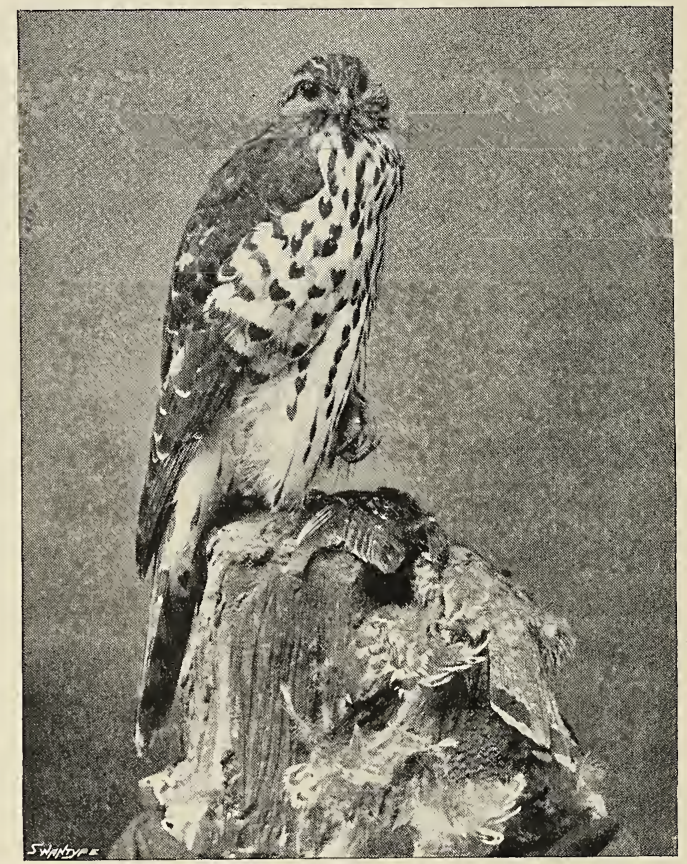

GOSHAWK, WITH HAZEL-GROUSE.

(Shot with 450 Express, September 28, 1895.)

Half-an-hour later, on arrival at the lake-shore (in no small conceit with my rifle-practice), it was necessary to

* There is a government reward equal to half-a-crown for the destruction of the Jer-Falcon and the Goshawk or hönseluöl, whereas the Buzzard, known as mūshök (= mousehawk), carries no premium, being regarded as beneficial in keeping down the swarming mice, etc. There is ornithological discrimination here that our own faunal legislation only aims at. 
fire a shot or two to attract attention to the bonfirethe signal to send a boat for us. Hard by, a Hawk-Owl perched about six feet below the peak of a pine. The bullet cut away the whole six-foot spike from just above the owl's head. He circled round, swearing at large, and perched again on the broken spike, where I missed him a second time, and pulled homewards duly humiliated.

The owl-tribe are thoroughly characteristic of the northern forests. Around his house at Lövsjoli, Bengt had persuaded a few perches of oats to grow, and over this stubble, as each daylight waned, there flew and flickered at least a score of owls, great and small, at our very door. They were mostly of the Short-eared and Tawny species, but there also appeared to be Long-eared as well. In the forests the hawk-owl predominated in numbers, though always solitary, with Tengmalm's owl second, and the tiny Sparrow-Owl (Glaucidium passerinum) rarest-at least that was the order of precedence in which we observed them. All these three at times showed an inclination to follow the hunter, often sailing around his head within a few yards, the Sparrow-Owl invariably perching on the very topmost spike of a young pine. The Eagle-Owl appeared less common in the highland forests than in the regions nearer the coast, while the Snowy-Owl even in winter confines his operations to the high snow-fjeld - and the arctic hares. The reason for these swarming owls and other birds of prey is found in the hordes of small rodents that infest both forest and fell. Besides the lemmings, voles, rats and mice of various colours, sorts, and sizes, amphihious and terrestrial, abound in 
Norway, and among a few skins brought home were included the following species :-

Shrew (Sorex vulgaris), common throughout Scandinavia.

Water-shrew (S. fodiens), do.

Long-tailed field-mouse (Mus sylvaticus), do.

Short-tailed field-mouse (Arvicola arvalis), do.

Water-vole (Arvicola amphibius), do.

Black water-vole (? sp., in Norsk "vaund"), on fjeld.

- (?) (Arvicola ratticeps), common on fjeld.

Bank-vole (Lemmus glareolus), generally distributed.

Squirrel (Sciurus vulgaris), fur very grey in autumn.

Stoat (Irustela erminea), very confiding and even playful.

The nests of the lemmings, formed of dry grass, are placed above-ground at the entrance of their holes. Those on high fjeld are conspicuous enough, though naturally less so among the tangled plant-growth of the forest. While after reindeer in August, we frequently found nests that had been pillaged by foxes. The young lemmings are blind and naked, but the dark patches of their future fur are already shown on the bare skin.

After mid-September the lemmings were beginning to migrate, all going northwards-why, or whither, none but they can tell. While crossing Müru-Sjöen at daybreak, we frequently fell in with fleets of lemmings swimming boldly across the lake, though it was more than a mile in width and full of pike and five-pound trout. After a stormy day the lee-shores were strewn with dead. On a high fjeld-lake we have seen a trout take down a crossing lemming.

\section{Notes on Norwegian Birds.}

To condense into a portion of one chapter a synopsis of the avifauna of a big country that might well occupy two volumes is not easy. The plan adopted has been 
to collate the respective nesting-dates of some of the chief species at different points of their thousand-mile range. To this, quest we have devoted many springtides, but our own notes must rank in very humble degree compared with the patient investigation and accurate observation of one of the best of European ornithologists-Professor Collett of Christiana.

First to foretell the coming spring, while an arctic winter yet holds full sway, the Siberian jay often has commenced laying in March; the Jer-Falcon by midApril ; Goshawks, Tengmalm's, and the Hawk-Owls by the end of that month-all these in Aretic Lapland. Except the Rock-Pipit, Ortolan, Raven and Grey Crow, I know of few other inland species that nest before May. I exclude from consideration the Crossbill, as it has been said to breed even in January-always by mid-February; while in March, Wheelwright, in Wermland, found more than a dozen nests, in all of which the young had perished of cold.*

The following additional species we have found nesting on or before May 20th-to wit: Golden and Sea-Eagles, Brown Owl, Great Black and Spotted

* On this subject, Mr. P. Chaworth-Musters (to whom I am indebted for many excellent bird-notes, some of which are hereinafter referred to under the initial "M.") sends me the following note : "May 13th. Left Tromsö at noon, anchored Kalsö 4 p.m., two feet of snow on shore. Found golden eagle's nest, but the eggs had been taken the previous day. Walking back across a small bog, my dog put up a curlew from a hole in the snow. By chance I went to look and found a nest with four fresh eggs; also found a hooded crow's nest with six fresh eggs in a small birch-tree. It seemed curious to find birds nesting in what appeared midwinter. On June 4th in Porsanger, I saw an old mallard-duck with young several days old, though the whole country was snowed up and every lake and river frozen solid." 
Woodpeckers, Goldcrest, Northern and other Tits, Ortolan, Brambling, Chaffinch, Greenfinch, Fieldfare, Redwing, Redstart, Rock-Pipit, Dipper, Great Grey Shrike, Willow-Grouse, Greylag Goose, Sheld-Duck, Mallard, Pintail, Heron, Great Blackback and Herring Gulls, Cormorant, Shag, etc.

The Fieldfares commence laying in colonies by midMay, and fresh eggs may be found till July, in north or south. Redwings nest separately, though often contiguously to the fieldfare colonies, and, as a rule, a week later.

The Ring-Ouzel lays in the first week of June in the same situations as at home-heathery banks and scaurs. Once only have I found its nest above the zone of scrub-built-up in the open against a stone, altitude three thousand feet. The Blackbird and Song-Thrush breed commonly up to Namdalen; and the Mistle-Thrush (rarely) up to the Polar circle. The first nest of the Northern Tit (Parus borealis) we found on May 15th, in a hole neatly drilled in a birch. The six eggs resembled those of a willow-wren, white, with large rufous blotches. There was no nest; whereas the blue eggs of the Redstart, often found occupying similar situations, are set off by the white ryper-feathers of which the nest is made, and form a pretty picture. The Marsh-Tit (Parus palustris), though merely the southern race of $P$. borealis, just mentioned, differs therefrom in also building a compact nest of moss, feathers, etc., usually placed in a naturcal hole, as distinguished from the excavated abode of its nearest relative. Both forms breed up to mid-Norway, but beyond the Polar circle $P$. borealis alone is found. 
The Brambling breeds both in pine-forest and amidst the alpine birches, laying in Nordmöre by May 20th, a week later on the Dovrefjeld; while mid-June is its date in Lapland, its nest and nesting-places resembling those of the Chaffinch. The latter, as well as Greenfinch, Linnet, Twite, and Redpole (both varieties), is common everywhere. The Siskin is decidedly scarce, but breeds.

The Woodpeckers are also early breeders, the Great Black species laying before May 10th even in the north, a fortnight earlier in Telemark. Its nesting-holes are often vertical and elliptic, those of all the other Picidæ being circular.

The Great Spotted Woodpecker lays in Sondmöre by May 15th. In Lapland, my brother A. found young hatched-out, on the Tana river, by June 16th. The Three-toed species appears to lay about June 10thNamdalen.

The Wryneck and Tree-Creeper are not uncommon : but the Nutcracker we have never seen, and our Jay rather irregularly, though the Siberian Jay abounds.

Of the raptores, I found the Common Buzzard nesting on pines in Sweden (Wenern). This was in May. Further north the Rough-legged species predominates and breeds exclusively on crags on the open fjeld. On the Dovre, eggs are laid by May 20th, while in Lapland the earliest nest found by $\mathrm{A}$. on the Tana was June 5th. The three eggs lay on a layer of solid ice, and the contents were so congealed that they could not be blown until melted in warm water.

In the forest, the Goshawk is the commonest of the larger birds of prey, building its own nest and laying its three or four eggs in a spruce by the end of April or 
early in May (four eggs, hard sat, by May 10th, Trondhjem's Amt) - a fortnight earlier in Telemark and Wermland (Sweden). The Merlin we have found with eggs by May 28th-(Bodö) - and well-grown young on June 19th (Sŭrendal), in both these cases in an

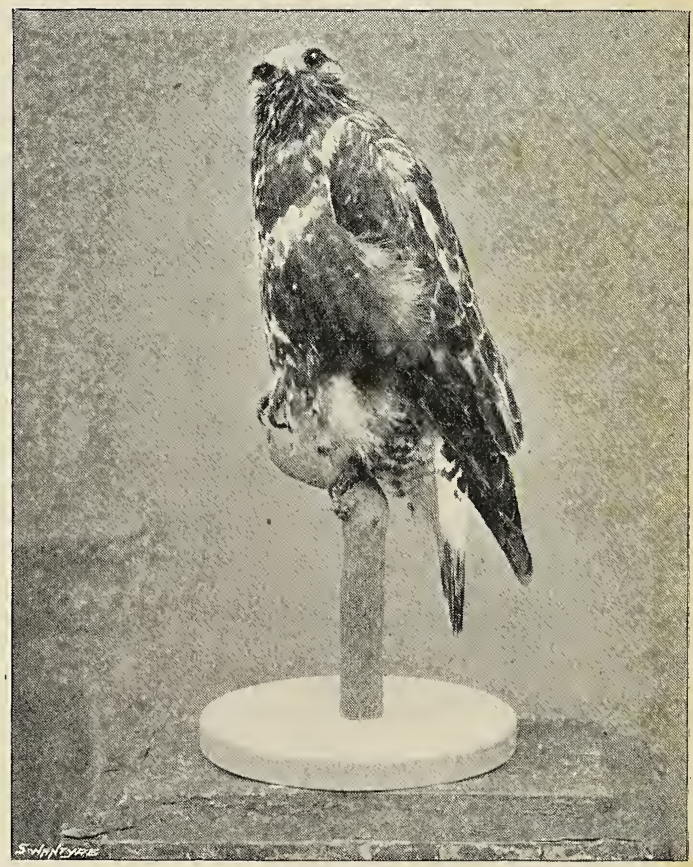

ROCGH-LEGGED BUZZARD.

(Gulholmen, June 5, 1884.)

abandoned nest of Corvus cornix. Kestrel and Sparrowhawk also breed commonly, but the Hobby is unknown.

The Jer-Falcon, on the coast (Nordmöre, Inderöen, etc.), selects sea-cliffs, or the bush-clad crags of the fjords for its eyrie, whereas in the inland forests, as well as in the far north, a tall pine is preferred. In 
Finmark, Woolley found completed clutches (three to four eggs) in two consecutive years as early as April 16 th-many by the end of that month, all on pines. Wheelwright gives June 8th as the date of a nest on the bleak highlands around Lake Wihrigaur. The Peregrine is much less numerous than the Jer-falcon.

In the south, the Ospreys also breed in the steep wooded crags of the fjords, laying in June. Nest with newly-hatched young on July 4th-Nordmöre (M.). Further north they prefer pines as a rule; but A. shot a female engaged in building on a tall rock-steeple in Lapland, on June 7th ; while Prof. Collett records finding two young about eight days old on June 25th in Folden-fjord. This nest was on a pine.

Hen-Harrier, very rare; nest with six eggs, June 4th, on marshes of Dovre-fjeld. No other harrier observed in Norway, though Circus æruginosus is not uncommon in Denmark.

The eyrie of the Golden Eagle is always in high cliffs, generally far inland; whereas the white-tailed Sea-Eagle nests indiscriminately on cliffs, trees, or on the ground. Mr. Musters gives me the following dates: "May 5th.-Took Sea-Eagle's nest on a high cliff, with two eggs, hard-sat. May 7th.- Shot eagle from nest on small hillock in the midst of a bog on Smölen-one egg, hard sat. May 18th.-Eagle's nest with three young-in-down on ledge of low cliff. Could walk into nest. Have seen many nests on pine-trees."

The Snowy-Owl breeds, on the ground, on the barren plateaux of the high fjeld, having eggs by June 1st. In "lemming - years," when stimulated by superabundant food, this species (with other birds of prey) 
continues reproducing all the summer, a single nest containing young in every stage from fresh eggs to half-fledged owlets-the latter, of course, saving the parents the labour of further incubation. This is precisely analogous to the case of the short-eared owls at home, which, during the "vole-plague" in 1892 and 1893 on the Border moors, were observed to have as many as fourteen eggs and young owls, all mixed, in one nest!

The Eagle-Owl, nesting lower (just within the timberline), appears to lay about one week earlier, selecting the hollow of the largest and gnarliest old tree that grows within its range. Eggs, four.

Of the small forest-owls, my experience is confined to the autumn, but their nesting-dates may be given thus: Hawk-Owl, in Namdalen, before middle of April, young fledged by June; in Lapland, before end of April. Tengmalm's-Owl, in Namdalen, mid-April: a week earlier in the south. In Finmark and Lapland, 1st May. Least Sparrow-Owl : Wheelwright records catching fledged young on July 12th, which makes date of laying before June 1st.

Great Grey Shrike : In Lapland, A. found a nest of seven eggs, hard-sat, on June 13th; but Wheelwright records one just a month earlier near Quickjock (Sweden).

Pine-Grosbeak: On the Tana, Lapland, my brother found three nests between June 12th and 23rd, containing two to four eggs. The species had not previously been observed beyond the northern limit of the pine.

Hawfinch: Recorded by Prof. Collett near Christiania in winter. We have not met with it. 
Coming to the "summer birds," the redstart (as stated) nests earliest, rapidly followed by the whinchat and wheatear, white wagtail, ortolan, and pied flycatcher, all of which are beginning to lay by May 25 th.

The Blue-throated Warbler is typical of Norway. Appearing at the end of May, it has eggs (Nordmöre, Dovre, etc.) by the second week in June. The nests are deep and cup-shaped, compactly built of coarse grasses and a few twigs outside, with finer lining, placed on rocky banks overhung with juniper, or on mossy burn-sides-such spots as are selected by the robin at home. The eggs-six or seven-vary from olive-green, uniform or zoned with reddish freckles, to plain brownish. In Lapland our earliest date (seven fresh eggs) is June 18th.

The Bluethroat reminds one of a wren, as he pours forth his volume of melody-somewhat metallic-with tail carried high over his back. The song at times resembles that of the Sedge-Warbler, to which this bird appears akin-flying short distances on short jerky flight, then diving into thick scrub, amidst which it runs and skulks, and is altogether most difficult to observe.

The Sedge-Warbler, just referred to, though abundant on the lower Lapland fjelds, is altogether a scarce and irregular species in Southern Norway-a remarkable circumstance in its distribution, pointing to its migrationroute being easterly; that is, it comes to Norway via Russia and Finland, and not across the North Sea. The same feature is even more emphasized in the case of the Siberian Willow-Wren-a species otherwise unknown in Europe, but which abounds in Arctic Norway, evidently 
coming from the east. Its breeding-date in Lapland is about mid-June, coinciding with that of its commoner congener Ph. trochilus, which also nests right up north as far as land goes, though quite a fortnight later there than its dates in South and Central Norway.

The Chiffchaff, Robin, and Whitethroat halt at the Polar circle; but the Blackcap and Garden-Warblers, with the Bluethroat, Whinchat, Redstart, both Flycatchers, Hedge-Sparrow, and sundry pipits and wagtails, push on to the "farthest north," nesting up to North Cape by mid-June-only two weeks later than their dates on the Dovre, Surrendal, etc., five hundred miles further south.

The Mealy Redpole was laying in Sogn by May 25th, though eggs were not found in Lapland before June 14th. Scandinavian Redpole-Mr. Musters writes: "Took two nests, each four eggs, fresh, on July 7 th. This bird is almost the size of a linnet, and has a very strong beak."

The Titlark nests on Lofoten, $69^{\circ} \mathrm{N}$., in May-earlier than on the Dovre, $62^{\circ}$, where June 6 th is an average date. On Hvalöer, lat. $59^{\circ}$ N., Prof. Collett records fledged young on June 2nd, while on the Tana, $69^{\circ} \mathrm{N}$., their laying date was mid-June.

The Rock-Pipit breeds commonly along the whole coast-line-an early breeder; many nests contain young before end of May.

The Tree-Pipit breeds up to Finmarken.

The Red-throated Pipit (an Arctic species) breeds, in Lapland, about June 20th.

The Shore-Lark about one week earlier (first nest, Tana, June 18th). 
The Skylark is a scarce and irregular species throughout non-frugiferous Norway, and the Corn-Bunting may be described as unknown, though the YellowHammer and Ortolan are common enough. The latter is an early breeder, having eggs in Telemark in May (and possibly April), while in Söndfjord, $61 \frac{1}{2}^{\circ}$ N., we found fully-fledged young by May 30th.

The Black-headed Bunting also nests from south to north, laying in Söndhordland the first week in June, in Finmark about the third.

The Lap-Bunting is another typical Norsk species. We have not found them breeding south of Surrendal and the Dovre (lat. $62^{\circ} \mathrm{N}$.), where laying commenced early in June and full clutches were found by the 6th - more abundant in Finmarken, where the date is a week or ten days later. Nests resemble in site and construction those of $A$. pratensis, but are always lined with feathers. Eggs, dull uniform brown.

The Snow-Bunting breeds commonly on the high fjelds early in June, under stones or in cracks of the rock. While reindeer-shooting in August on the highest ground, I have noticed nests both of this species and the Titlark (as well as those of the Lemming) placed quite openly among the bare stones. Nest of dry grass, lined with feathers. Found nest with half-grown young on June 23rd (M.).

The Twite is common on all the fjelds and in the willow-zone.

The Willow-Grouse and Ptarmigan both lay at the end of May. As to the other game-birds, I have no notes; but, judging from their state in August, they cannot be more than a fortnight later than at home. 
Dotterel-on high fjelds, Lapland, June 20th, eggs three.

Golden Plover-Söndmöre, June 10th. Lapland, June 20th.

Curlew - Söndfjord and Jölster, end of May. Tromsö, June 12th. See also footnote at p. 285.

Whimbrel-Sŭrendal, May 30th and June 4th. Tanadal, June 16th.

Great Snipe-Dovrefjeld, first week in June, in Söndmore, June 8th.

Jack-Snipe-seen late in June (Sŭrendal), but no nest found.

Woodcock - breeds commonly, young fledged in July.

Godwits-I have never observed either in Norway; though we found the Black-tailed species breeding in Jutland (see Chapter XIX.), and Bar-tailed Godwits in perfect summer-plumage are obtained on passage in Lapland, usually in June.

Greenshank-Sŭrendal, June 10th. Alten, June 15 th.

Redshank-Söndfjord, June 4th. Sŭrendal, June 7th. Tromsö, June 12th.

Spotted Redshank-Lapland, June.

Turnstone-All coast north of Namdal, mid-June.

Dunlin_Jutland, May 10th ; Nordmöre, May 23rd ; Lapland, June 15th.

Ringed Plover-Denmark, May 15. Sogne-fjord, May 31st. Tana, June 23rd.

Temminck's Stint-Tana, June 22nd (two nests).

Red-necked Phalarope-Dovrefjeld, early June. In Lapland, June 22nd, on Tana. In this species, the 
male is the smaller, and performs all domestic offices, including incubation, etc., the larger and handsomer females meanwhile disporting themselves, swimming in small flocks, hard by.*

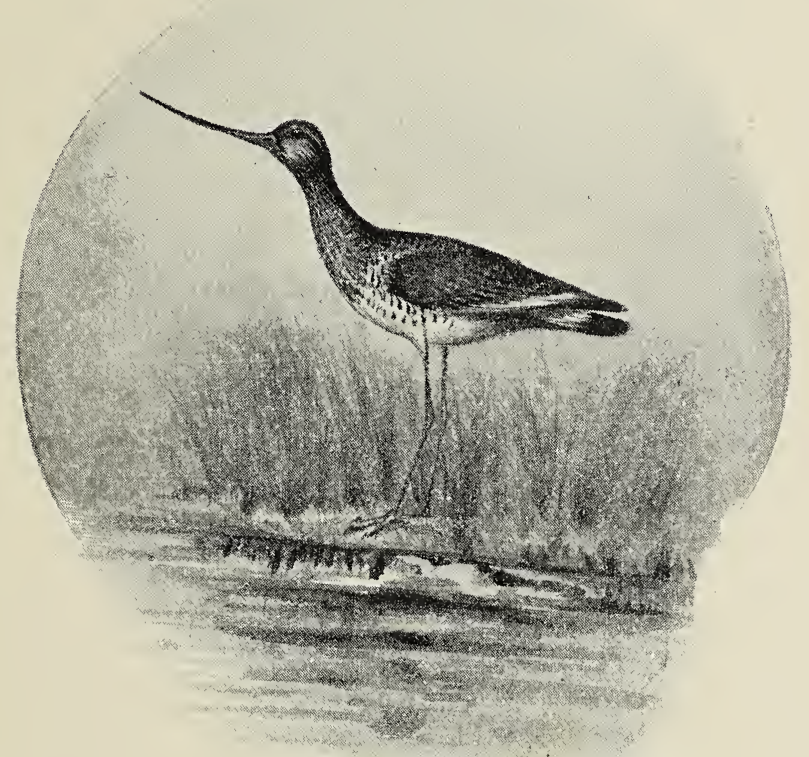

A STUDY IN VIGILANCE.

(Black-tailed Godwit.)

Ruff-breeds in Jutland by May 15th. In the Lapland morasses about a month later.

* This observation also applies, though in less degree, to several congeneric species, as, e.g., the Purple Sandpiper, Temminck's Stint, and others. 
Purple Sandpiper - lays early-in May, Arctic region chiefly, but in Nordmöre M. has found it nesting on high fjelds-four eggs, hard-sat, June 25th.

Wood-Sandpiper-eggs found, ready for exclusion, early in June; and three in nest (slightly incubated) on July 2nd (M.).

Common Sandpiper-Sŭrendal, June 12th. Departs as early as August 1st.

Broad-billed Sandpiper-Dovre, mid-June.

Oyster-Catcher, and other common species, require no remarks.

Crane-Dovrefjeld, young hatching early June.

Heron - common everywhere, nesting early in May.

In web-footed birds, Norway is naturally rich, though the true wildfowl mostly resort thither solely for the purpose of nesting, and leave the country in early autumn soon after the young can fly. Hence there is no regular wild-fowling, though a few couples of ducks may here and there be shot on marshy fjeld or hill-tarn; and in August-September the greylags, wigeon, and other true wildfowl afford a certain amount of sport as they assemble amidst the islands and holms of the Skjærgaard, preparatory to taking their departure for southern latitudes.

The two chief species of breeding ducks are the Pintail and Wigeon, which commence nesting as soon as the fjeld-lakes are clear of ice-for this reason, irregularly and rather late. In Denmark, we found Pintails laying in April, but in Norway mid-May is quite the earliest date for both species, and in the Aretic fully a fortnight later. 


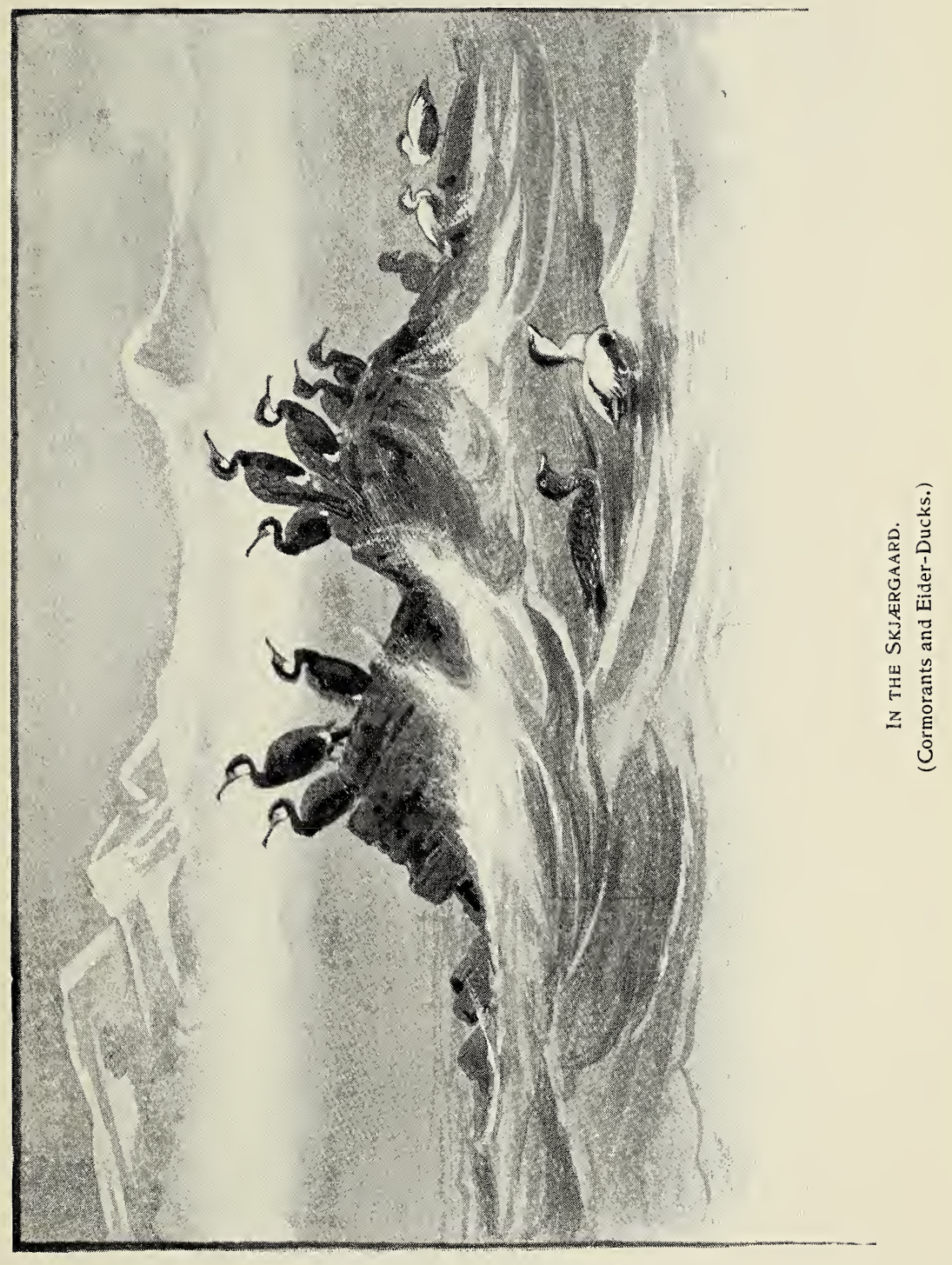



Mallard - regularly distributed, though nowhere numerous-end May. See also footnote, p. 285.

Teal-marshy moors, June 1st (Dovre).

Sheld-Duck-abundant on all low islands of Skjærgaard, laying mid-May. Young in water by mid-June.

The diving-ducks (Fuligulinæ) mostly nest towards the end of June-rather later than the game-ducks.

Long-tailed Duck-Hardanger Vidden, June 21st; Lapland, five fresh eggs, June 18th (A.). Some drakes in summer retain the white head. These appear not to breed, but molest the others which do. In this connection, I may add that I have sometimes been puzzled by observing on our own coast, young' (? two-year-old) long-tails killed end-February, assuming, at that season, the full adult winter-plumage.

Scaup-common I all nest from about mid-

Tufted Duck-scarcer $\}$ to end-June (HardangerScoter-abundant $\int$ Lapland).

Goldeneye--abundant-in south, early June ; Tana, June 16th (A.).

Velvet Scoter-mostly towards north-end June and July.

Eider-semi-domestic; and the King-Eider is not known to breed, though it occurs on the coast.

Steller's Eider-on May 27th M. shot nine out of a large flock, seven of them beautiful males. Two days later they had passed on to their far-northern breeding grounds.

Goosander-Sŭrendal, June 19th ; Tana, June 26th, each ten fresh eggs.

Merganser-Sŭrendal, June 5th.

Greylag-Goose-common along whole coast, arriving 
early in April and nesting before end of month. Later in north. Eggs four to six, rarely seven. Departs end of September.

Bean and Lesser White-fronted Geese (A. erythropus) - breed exclusively in the far north. M. caught three goslings of latter, and shot old goose, June 30th-Lapland. All other species are solely migrants ; the Brents passing north along the coast very regularly during the penultimate days of May, to nest in Spitsbergen.

Wild Swan (Whooper) — said to breed on highland lakes, Finmark.

Black-throated Diver-on islets of higher fjeld-lakes, June 20th-eggs two.

Red-throated Diver - on islets of lower fjeld, same date-eggs two : in both cases, close to water-level.

Note that both divers and grebes are exclusively aquatic-never terrestrial. The grebes, in particular, both live afloat and nest afloat, their nests being built in water often ten feet deep. The divers are also purely aquatic in habit, never even allowing themselves to be left stranded by the ebb; while their nests are on the mossy foreshore of lake-edge or islet, within a few inches of water-level. To these nests the divers scramble up the few intervening feet, by pushing along on their breasts, seal-fashion. They never attempt to walk, or to assume erect positions, simply because they can't-the osteological formation of their feet forbids this. Hence it follows that all the hundreds of divers stuffed in museums, or depicted in books as sitting upright, perched on rocks, etc., are physical impossibilities-atrocities that ought at once to be removed.

Great Skua-rare and not known to breed. 
Buffon's Skua-high Lapland fjelds, early June.

Richardson's Skua-nests on every gull-frequented islet and near the tern-colonies along the whole length of coást, laying its three eggs about mid-June.

Pomatorhine Skua-common in Lofoten in summer.

Petrels, Shearwaters-we have not found breeding on the Norway coast, though both are seen at sea.

Gannet-follows the herrings, but does not breed.

Of the sea-birds and rock-fowl I need give no details, these differing but little from those of our own coasts. The enormous aggregations that cover the "bird-rocks" of the north are well-known. Some of these colonies consist chiefly of Gulls, Kittiwakes, etc., others of Guillemots, Puffins, Cormorants, and the like. Up to the North Cape the Common Gull has eggs in May, the Terns laying about a fortnight later. The Great Blackbacked and Herring-Gulls commence laying on the islets of the Skjærgaard about May 1st-the Lesser Blackback and Kittiwake not till a month later.

A noteworthy instance of protective colouration was observed by my brother A. in relation to the Arctic Tern. A few were already, on June 14th, nesting on some hill-lochs above the Pulmak river in Lapland. One clutch of eggs (reached by walking across the ice) were of the usual greenish type. These were laid on reindeer-moss. Two other eggs, lying close by on a tussock of rich red moss, were of bright ruddy hue, as handsome as the finest merlin's eggs.

I conclude this chapter with a brief list of some few of the commoner fjeld plants and flowers, just such as would attract the non-botanical passer-by in his rambles over mountain and moor. 
Moss-Campion-Silene acaulis, "Catch flies."

Sea-Campion-Silene maritima, "Catch flies."

Red Campion-Lychnis diurna.

Ragged Robin-Lychnis floscuculi.

Bush-Vetch-Vicia sepium.

Wood Crane's-bill-Geranium sylvaticum.

Tormentil-Potentilla tormentilla.

Wood-Anemone-Anemone nemorosa.

Wild Hearts' Ease-Viola tricolor.

Procumbent Azalea-Azalea procumbens.

Marsh Rosemary-Andromeda polyfolia.

Alpine Rock-Cress-Arabis alpina.

Common Rock-Cress-Arabis petræa.

Bitter Cress (Cuckoo flower) -Cardamine pratensis.

Dwarf Cornel-Cornus suecica.

Eye-bright-Euphrasia officinalis.

Yellow Rattle-Rhynanthus crista galli.

Alpine Chickweed-Cerastium alpinum.

Jagged Chickweed-Holosteum umbellatum.

Wintergreen Chickweed - Trientalis Europæa.

Arctic Crowfoot-Rannunculus glacialis.

Snake-weed-Polygonum viviparum.

Milk-wort-Polygola vulgaris.

Borage-Mertensia maritima.

Sea-Thrift-Armeria maritima.

Mountain everlasting - Antennarea dioica.

Marsh Louse-wort-Pedicularis palustris.
Upright Școrpion-grass - Myosotis sylvatica.

Spotted Orchis-Orchis maculata.

Bird's-foot Trefoil-Lotus corniculatus.

Squill-Scilla nutans.

Bedstraw (Smooth heath) - Galium saxatile.

Common Sedge-Carex vulgaris. -Carex desicaria.

Narrow-leafed Cotton-grass - Eriophorum angustifolium.

Hare-tailed Cotton-grass-E. vaginatum.

Butterwort-Pinguicula-(? sp.)

White Stone-crop-Sedum anglicum.

Mountain Avens-Dryas octopetala.

Golden Saxifrage - Chrysosphenum oppositifolium.

Red Whortle-berry-Vaccinium vitisidex.

Bilberry-Vaccinium myrtillus.

Crowberry ("Krakbær")-Empetrum nigrum.

Black Bear-berry - Arctostaphylos alpina.

Cloud-berry-Rubus chamomorus.

Fir Club-moss-Lycopodium selago.

Interrupted Club-moss - Lycopodium annopilum.

Savin-leaved Club-moss-Lycopodium alpinum.

Hard-Fern-Blychnum boreale.

Oak-Fern-Polypodium dryopteris.

Beech-Fern-Polypodium phegopteris.

Parsley-Fern-Allosurus crispus.

-Polystichum.

-Phyllodoce cærulea.

PoST-SCRIPT.-Referring to the official lists of "Noxious Animals" killed (see p. 279), various counties separately paid premiums on the following additional species :-

5 counties paid in 1895 for 256 Eagle-Owls.

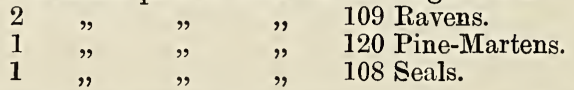

The only "hawks" on which the Government premium is payable are the Jer-Falcon and the Goshawk. 


\section{CHAPTER XIX.}

IMPRESSIONSS OF DENMARK.

I. The Cornlands and Heaths.

Denmark has been described as a country of much waste land, of wide heaths and so on ; it was, moreover, the only country of western Europe of which I had then (1889) seen nothing, and I decided to "prospect" it, en route to Sweden.

Twenty-eight hours after leaving the Tyne, the sanddunes of Jutland and the low-lying shores of the Frisian Islands rose before us from a summer sea.

It was but a flying visit to the Cimbrian Peninsula, and impressions here recorded (though confirmed by a subsequent journey in 1893) are given for what they are worth; yet in traversing the whole country, from the frontiers of Schleswig-Holstein to the Scaw, we at least enjoyed a superficial survey of the physical features and conformation of the Danish kingdom.

Denmark is a plain, flat as Holland, treeless and featureless. Save for their Himmelberg, of which the Danes are proud as of an Everest, though it only reaches five-hundred feet, the bulk of the peninsula would be submerged by a fifteen-fathom's rise in the North Sea. Worse than this-I write as a naturalist-it is all petty 
cultivation. From foreground to horizon stretches one green monotony, unbroken by fence or field, unrelieved either by coppice or spinney, or by the gleam of water. The eye wearies with the ceaseless succession of barley and oats, clover and rye-fields one cannot call them, since no hedge marks a boundary; nor, save where a few stunted poplars or maple surround some peasant's

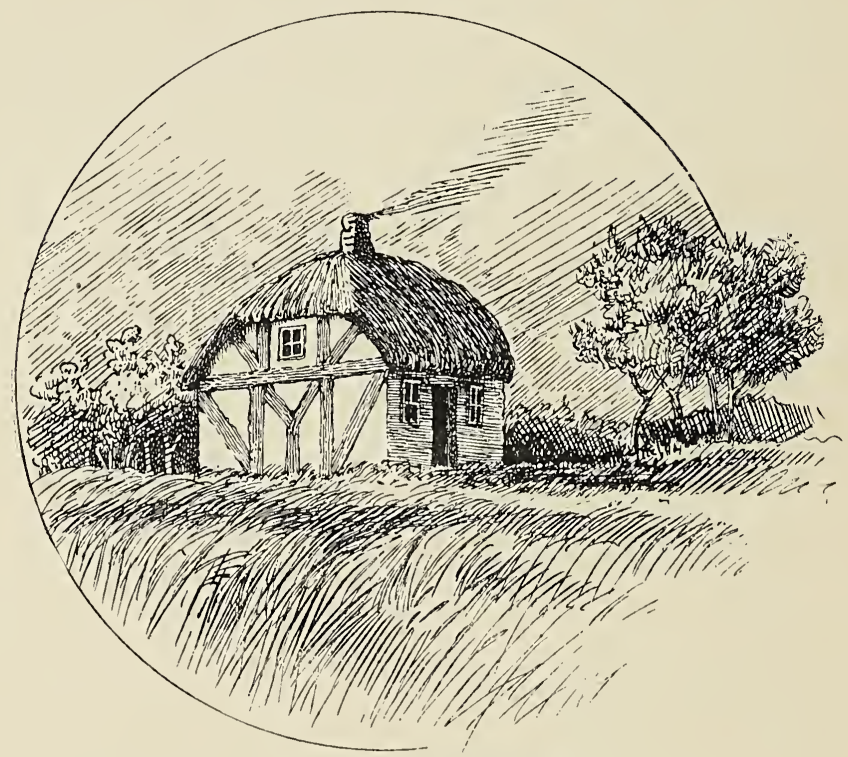

A DANISH FARM-HOUSE.

cot, is there a tree in sight. The land is cut up into little holdings of a few acres apiece, held by a peasantproprietary whose straw-thatched homesteads, heavily timbered, stud the plain.

The agricultural population must be called dense. Denmark, indeed, is fully developed on the "three acres and a cow" principle, and an ideal country if the minute 
sub-division of land is a real remedy for the congestion of great cities and general panacea. But to the naturalist, to the lover of what is broad and bold, such conditions are the reverse of attractive. With unfenced holdings so small that cattle, horses, even sheep, are all tethered, with tillage by retail, and such economy of space as to convey a sense of constriction-of ozone at so much a foot-if this be Utopia, give me the other place.

Travelling through Central Jutland, amidst rolling cultivation, the brown contour of the ahlheden, or heath-land, here and there formed the background, or we traversed a strip of irreclaimable moor. Farmlets there are in hundreds, with butter-factories systematically interspersed-these known by their tall chimney-but never a country-house. Denmark has no wealthy class, but at least she seems to have few poor; beggars are unknown, but the number of "soft folk," or half-wits, is beyond the average.

The rural villages remind one of Yorkshire with their red-brick houses and small orchards. Towards Silkeborg a few trees rejoiced our eyes-aspens and sycamores, limes and poplars (many pollarded), with ashes in full leaf on June 7th. The only pretty scenery was on the Gudenaa, the river forming a chain of linked lakes beneath hanging beech-woods, whose sylvan glades and aquatic arbours lead to embayed pools, all verdant with forest-reflection. Bevies of brightly-dressed damsels from Silkeborg did not detract from the mingled charms of wood and water; but a beer-saloon in a sequestered nook did offend, though the iced pilsener was rather delicious on a hot afternoon. 
The natives were hooking out small perch from boats moored beneath the trees. Being superior to this, I caught nothing, save a huge clam which seized a "spoon "-apparently in mid-water.

Furthur north, towards Viborg, the country is diversified with shallow sheets of water inhabited by pike and several species of grebe (Podicipes nigricollis and $P$. auritus), with a few coots, mallards, and teal. Otherwise, the avifauna of agricultural Denmark is as monotonous as its scenery. True, there are perfect myriads of the graminivorous birds, such as larks, the volume of whose chorus fills the evening air. There are starlings, too-millions, and storks, but nothing that I am here going to expend one line upon.

The heaths of Jutland present an appearance not unlike, in the distance, a flat Northumbrian moor ; but more arid, sterile, poverty-pinched moorlands do not exist on earth. Even heather can hardly grow. Wiry and stunted, poor callunc is dwarfed to the pitiful semblance of a saxifrage, and scarce plant-growth of any kind can boast a foot of height. This barrenness of the ahtheden is attributable to their geological formation. An alluvial clothing of a couple of inchesmostly gravel-lying immediately on an impermeable substratum of hard marly limestone, is well-nigh fatal to plant-life and all other. The stony moorland is spotted-not clothed-with sporadic patches of trailing heaths, between which is exposed the naked soil.* The green monotony of the cornlands is here exchanged for

* A few plants collected on the ahlheden of West Jutland included heather, needle-whin (Genista anglica), crowberry (Empetrum nigrum), and Salix repens, the creeping willow. 
an equally wearisome monotony in browns, only relieved by white cotton-grass covering some rare patch of bog. Wherever mother-earth shows sign of vitality, or where scanty fell-grass lends a tinge of warmer colour, the Jutlander has ploughed and tilled it, and is raising a crop of rye, about four stalks to the square foot. Otherwise the existence of post-glacial man is only evidenced by the peat-stacks piled up at long intervals or by bony sheep, each tethered to a peg, and literally living skeletons.

No wild-life cheers the ahlheden, not a butterfly flits across its sombre waste; nor birds, save larks, kestrels, and a few wheatears-always lovers of sterility. There is neither water nor even moisture, and one looks in vain even for the stone-curlew. Towards the verge, breed a few golden plovers and ring-dotterel-but I have written enough to give a naturalist a fair idea of these two typical areas of continental Denmark.

\section{The Fens of West Jutland.}

Anong the Marsh-Birds.

In 1889 we had "prospected" the fenlands; and, though the lateness of the season and the tropical heat had then precluded success, yet we saw enough to justify a second visit. To Denmark, accordingly, in 1893, my brother Alfred and I returned. Leaving home on May 8th, we reached our quarters on the afternoon of the 10th, and, within an hour, had set to work.

For miles around stretched marsh and fen; but our favourite hunting-grounds were focussed about the course of a sluggish river, whose serpentine stream, oft- 
divided, stagnated amidst boggy islands or bordered marsh-levels rich in sedge and jointed reed. Deep oozy channels, uncertain which way to flow, intersected the morass; here and there were larger pools and backwaters, carpeted with water-lilies and bog-bean, where shoals of obese carp plunged in sullen depths, and otters furrowed the cane-brakes with mazy tunnels. Beyond for miles, spread bouncy moss-hags and quaking bog that is neither land nor water-a mere floating film of tangled vegetation on which, as on thin ice, one may walk in safety or may as likely break through its quivering crust.

May 10th.-Our first evening.-Hardly had we left the village a mile behind than our eyes revelled in a sight that alone repaid all pains and perils of the North Sea. By the margin of a small marsh-pool, stood or splashed a dozen of the most remarkable bird-forms that nature has designed-they were Ruffs, in all the glory of their full spring plumage, with their curious frills and auricles, and their marvellous diversity of colours. It is the latter feature that at once strikes attention; no two are alike, some black, some white or cream-coloured, others bright chestnut, purple, orange, banded or brindled, or a mixture of any two of these colours. There were many ruffs scattered over these "homemarshes," but the reeves were still flying in flocks of a dozen or more. We also observed this evening Golden Plover, Peewits, Green and Wood-Sandpipers, Dunlin, Snipe, Storks, Yellow Wagtails (as bright in hue as the kingcups, Sedge-Warbler and Reed-Bunting, Black Terns, two pairs of Shovelers, and a Garganey drake, besides at least one distant pair of godwits. 
In the cool of the evening we lay on a dry knoll watching all these birds with the binoculars. The level bog in front was dotted with heads and necks, and from their actions we concluded that the reeves were not yet nesting. Presently A. noticed a larger bird running

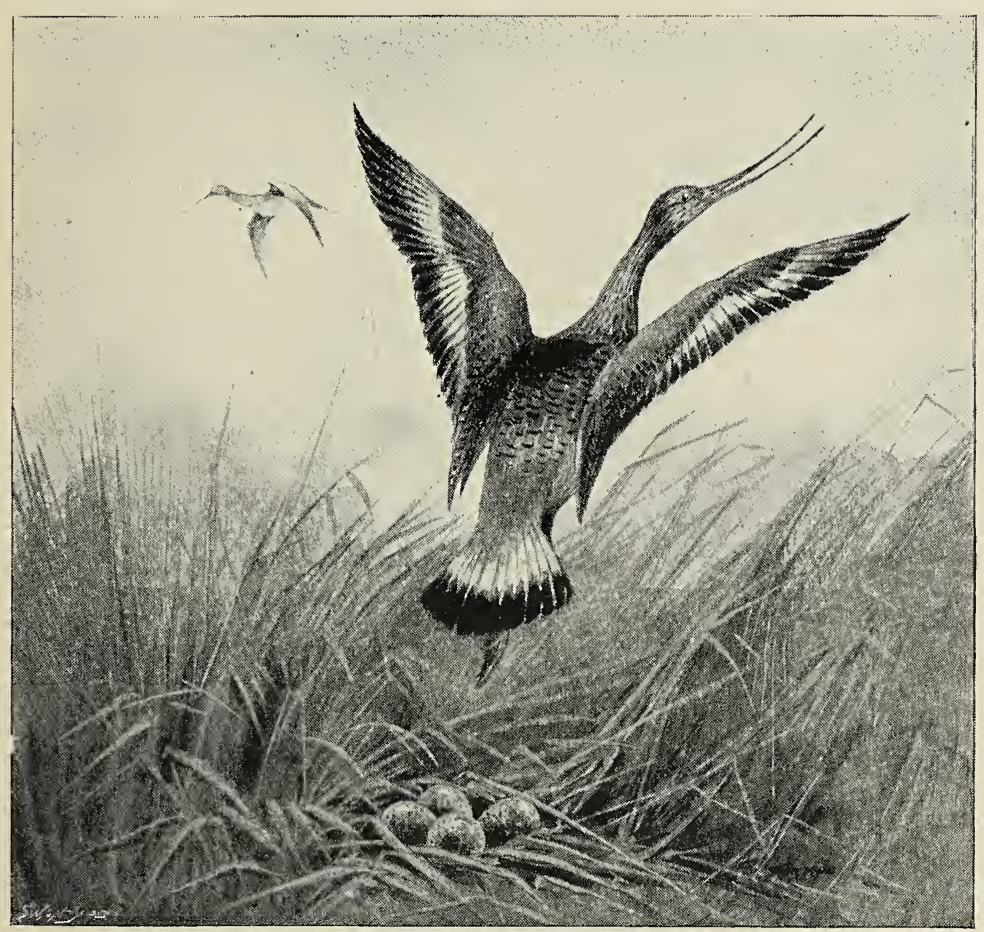

"SHOT UP VERTICAILLY FROM HER NEST.",

(Black-tailed Godwit-May 10, 1893.)

towards us and about a hundred-and-fifty yards away. It was the first time either of us had seen the Godwit in its breeding-haunts. It was conspicuously larger than all the others, and in the evening sunlight its plumage shone with a ruddy red. After running some 
thirty yards, in a moment it disappeared. Thinking the bird was on her nest, we gave her two minutes to settle, then stood up and walked forward, when she rose vertically in air, hovering around with loud cries, but always at full a hundred yards' distance. The black tail was very conspicuous, with the legs extended beyond. We had carefully marked the spot, took our lines, and in a few minutes the four beautiful pear-shaped eggs of the Black-tailed Godwit-one of the chief prospective prizes of this journey-lay beneath my eyes. This was real good work and a good start, for the godwit is scarce and the area vast.

The nest was slight, quite open, and the eggs about half-incubated, having presumably been laid about April 25th. We returned home exultant, amidst a chorus of wild bird-notes, the weird long-drawn trill of dunlins, and the croaking of millions of frogs.

That evening a curious incident occurred. It happened to be the night selected by the good folks of the village for their weekly gathering, and the sitting-room of the inn presently filled with a good-humoured company on social thoughts intent. Cards and coffee, music, chaff and comic songs were the programme, and merriment ruled; while one young fellow's singing and "break-down" dance (his long pipe hanging backwards over his shoulder) might have made his fortune at a music-hall. In simple compliment to us, the strains of "Home, Sweet Home," "God save the Queen," even "Ta-ra-ra, Boom de-ay," were several times repeated, and every one wished to be agreeable to the foreigners. There was a tall and superbly uniformed official in blue and brass, whom A., I think, 
took for a General, though I rated him a trifle lower. This gentleman, who proved to be an official on the States railway, was most attentive, and by means of a few words of German, we were able to explain to him the initial difficulty that stood in our way, in the use of a gun at this season being illegal. But all trouble disappeared before the benevolent energy of our new friend; within a few minutes he had brought from the Gendarmerie two shooting-cards (jagt-karts) available for seven days. We were also lucky in getting an excellent water-dog, and in affectionate memory of Rolf, may record that he was truly the wateriest waterdog we ever saw. The whole day long he swam alongside our punt, or pushed, plunged, and splashed through reed-bed and squash-bog in an everlasting, untiring hunt.

The total number of Godwits breeding on these marshes we estimated at seven or eight pairs, though their loud note, tritte-tue, tritte-tue, audible for miles, conveys an idea that they are much more numerous than is really the case. The first nest found (as above described) was on fairly sound ground; the next two on soft, and even dangerous quaking-bog, where the thin crust quivered and groaned for yards around beneath our weight, threatening in the frequent softer spots to give way entirely, while the imprisoned oozes beneath gurgled and hissed as they forced their way up in inky jets. But it is surprising how use begets confidence, and in a few days we penetrated the heart of squash-bogs where at first we had not dared to venture ten yards from the boat. On May 11th, after careful watching, we concluded that one pair had young, which 
fact was demonstrated on the 13 th by A. finding a downy fledgeling creeping among the bog-grass. It was buff-coloured, warmer on the neck, spotted with black, and had a short bill, but very large legs and feet. The faint cries of other youngsters hard by answered to the parental clamour. The same evening (May 13th), having observed a pair of Godwits persistently playing in.air, "kissing" each other, we landed on a specially

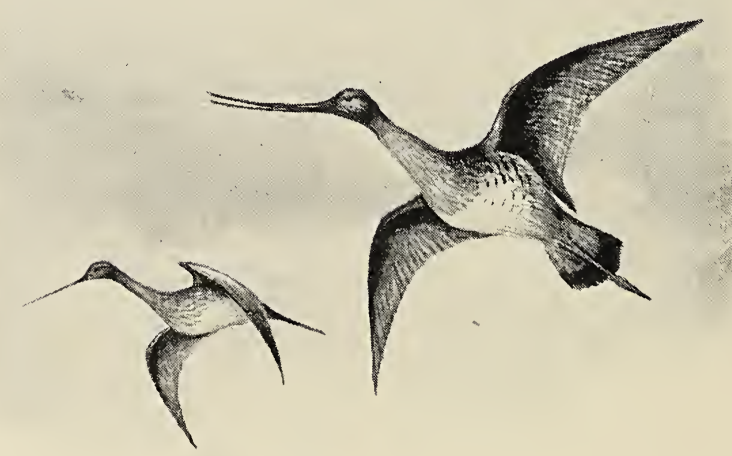

GODWITS AT THEIR NESTING-GROUNDS.

soft and squashy bog, whereon, within fifty yards, "Rolf" poked his nose into a Spotted Crake, which rose from her nest of ten fresh eggs in one of the wettest spots. The nest itself, however, was dry, supported between some dead flag-stalks. Five minutes afterwards, by sheer luck, we stumbled right into the Godwits' nest with four fresh eggs, exactly beneath the spot where the old birds had been "toying," though they had now disappeared entirely. Few birds are wilder than these 
at their breeding-stations; even when they have young, they rarely come in shot, and but for the aid of "Rolf" we should not have obtained a single specimen. The sight of a dog prowling or swimming in their domains would occasionally induce them for one instant to hover a little nearer, and we thus secured two beauties, male and female, in full summer-plumage.

Scattered here and there over these marshes were the "hills," or stands of the Ruffs where one would see a dozen or more of these eccentric birds always assembled-apparently for the sheer love of fighting. Some "hills" were on dry ground, others on grassy islets surrounded by miles of squash-bog. Poling the flat-bottomed punt up the stagnant channels, we could enjoy watching these combats within five-and-twenty yards of the trampled battle-field. Nothing more grotesque can be imagined. A dozen Ruffs of a dozen different colours dot the patch of down-trodden grass; presently, with loud clap of a wing against his side, one darts at another, wings half-spread, feathers all on end, and the long ruff and ear-tufts erected to the utmost. The champions stand facing each other with lowered necks and drawn swords-not six inches apart-like game-cocks. For two whole minutes they stand thus, immovable: then there is a sharp pass-so quick one cannot follow it-and one of the combatants darts off, vanquished, at amazing speed. That particular affair of honour is over; but meanwhile two or three similar scenes have commenced, and over the whole "hill" there is incessant movement of rival Ruffs, marching and counter-marching, scuffling and scuttling. No Reeves visit the hill, but so enamoured of war are their lords 
that, however often disturbed, they constantly return within a few minutes.

Being polygamous birds, and very abundant, we had no compunction in selecting a dozen specimens from different hills, though, had we shot ten dozen, I doubt if a match could have been found! The "ruffs" of those killed included deep bronze-black, barred with chestnut; pure white; pale cream with black ear-tufts; the same, but spotted with chestnut and with chestnut ear-tufts; deep violet-black, spotted with white; grey-brindled, and grey finely barred with black; one a lovely uniform chestnut, another orange-red with black auricles, and so on. Nor does the variation extend only to the "ruff," but includes the whole of the back, the wing-coverts and breast-plumage; * even the bills, legs, and the curious fleshy "warts" which cover the face, all varied in each specimen. Had Nature set herself to exert all her ingenuity to devise the most curious possible diversities in a single species, she could hardly have produced a more striking example.

Though the "ruff" is fully expanded when the birds are "at hill," yet it offers no impediment in flight, and indeed is hardly seen, the long feathers lying close back along the neck. A winged Ruff swimming in a pool appeared as slim in the neck as a small gull. Their note is harsh and jaculatory, and is only uttered when on the wing. We could see no sign of these birds actually nesting here up to the 14th of May.

Within fifty yards of one "ruff-hill," "Rolf" put up a shoveler duck from her nest, which contained ten fresh

* These three parts being usually, but not invariably, in harmon y with the general colouring of the particular individual. 
eggs. The nest itself was high and dry, though built in a very wet spot, which we only reached by making a sort of bridge with the oars. Shovelers were perhapss the most numerous of the Anatidx; we saw several pairs and odd drakes. One day three large geese-(apparently Anser segetum)-kept flying round the bog, and we also observed mallard, teal, and a single Garganey drake. The latter beautiful bird we put up several times, always at the same spot, but the most careful search failed to reveal the female or nest, though it must have been hard by. Of other swimming birds we only observed a few coots ; our boatman, however, introduced us to one more new species.

At midday on May 12th we had landed on the shore of a broad lagoon. Its blue waters danced and gleamed in the sunlight, and over sedges and bulrush a Marsh-Harrier, in slow flight, quartered the ground, his broad brown wings almost brushing the bulrushes as he searched for a succulent frog; hard by, a Stork with rapid blows was pommelling the life out of a big eel he had caught; and overhead hovered Black Terns, Peewits, and, further away, a pair of querulous Godwits. We were enjoying all these sights and sounds, together with the rather tasty Danish delicatessen provided for lunch, when a sudden inspiration seized Hans, our boatman, and he commenced a voluble conversation in his native tongue. This is always an ordeal, but it has to be faced; and after much wrestling with unknown gutturals and still more pantomime, we comprehended that he was describing a large bird with meget lange halse = very long neck, which dived much, and had its nest among the reeds. The name of 
this bird was "douker," which must be a grebe. Now we had already traversed these lagoons in all directions without seeing a sign of grebes, nor did it seem easy that their large floating nests could have escaped us on water only obstructed by the dead cane-stalks of last year, each cut off about a foot above-water by the winter's ice,* and by bog-bean and water-lilies. But we were not above taking a hint, and within five minutes Hans had poled us up to a Great Crested Grebe's nest containing five hard-sat eggs, and we afterwards found others. Large as these nests aregreat piles of floating canes and flags, lined with lilyleaves and anchored to the dead stalks aforesaid-yet they were quite invisible at forty yards' distance, nor (though the eggs were hot) did we ever get even a glimpse of their owners! A close acquaintance with creatures of such intensely retiring disposition is obviously difficult. We found no other species of grebe here, though, further north, in 1889, I had recognized both the Eared and Slavonian Grebes.

Up to the middle of May we had noticed a few pairs of Green Sandpipers, tame and very skulking, threading their way among the herbage close at hand, and only flying a few yards when flushed. A week later, these had all passed on northwards ; whereas the Wood-Sandpiper, which was much more numerous, remained, and some pairs appeared to be breeding. Whimbrels (on migration) were seen or heard daily, and a single pair of Great Snipes frequented a marshy meadow, though they

* A week later (May 19th) the new growth of canes was shooting up all over, the thin green stalks already a foot or two out of the water. In June these reeds were six or eight feet high. 
were not nesting up to May 20th, by which date the Black Terns had greatly increased in numbers.

Other species that require passing notice were: Sedge-Warbler, Reed-Bunting, Yellow and White Wagtails-all abundant and very pretty objects as they balanced on the point of a broken cane in mid-water ; in 1889, I thought I also recognized (in June) the Great Sedge-Warbler.* There were also Grey Partridge, Corncrake, and Golden Plovers (breeding), Common or Arctic Terns, Black-headed Gulls, and, on May 18th, a pair of Little Gulls.

Having occasionally observed rising fish in the main river, and understanding from our boatman that salmon of some kind ran up it, we put our rods together, but failed to tempt anything beyond a few small roach. That was in May; but in June I had rather better sport with the coarse fish-roach, dace, and perch, besides others unknown to me. The boatman had not before seen fly-fishing, and laughed consumedly when a couple of red-finned roach were splashing and fighting on the thin gut; nothing would satisfy him but to attempt to do likewise, with the inevitable consequence of a ravelled cast. But the laugh was all on his side when from a funnel-net he had set in a backwater he extracted a four-pound carp. Shoals of these fish-some apparently of 8 or $10 \mathrm{lbs}$. weight-we could see moving about in the depths beneath our boat; but the thick

* A Danish gentleman remarked to me on the abundance of nightingales in his garden. I ventured to doubt their being nightingales, and find I was practically wrong. Northern Germany is the utmost limit of our nightingale (D. luscinia); but in Scandinavia and Denmark that species is replaced by the larger northern form, D. philomela. 
reeds forbade all hope of rod-fishing, even had I known what lure to employ. Their curiously-compressed bodies are beautifully adapted for navigating subaquatic reedforests ; carp, in fact, among fish, seem counterparts of the crakes and rails among birds. Pike also abound here, and no doubt many other varieties of coarse fish : while the reed-brakes were tunnelled by otters.

The change from spring to summer in the fen was remarkable. The summer-heats of June stimulated aquatic vegetation. Where, in May, one traversed almost bare grassy bog, we now had to force a way waist-deep in sedge. The erewhiles open water was occupied by reeds five or six feet in height, and the insect-plague was well-nigh unendurable. Biting gnats and mosquitoes buzzed in clouds, and the reed-beds gleamed with the blue "damsel-fly," while the deadly clegg and gadfly were now in full force. In June we were fain to leave the languor-laden morass and to fly towards the cooler north. 


\section{CHAPTER XX.}

THE MARINE LAGOONS AND SALT-MARSHES OF WEST JUTLAND.

The coast of West Jutland, sandy and low-lying, is fringed with "fjords"-so-called on the map. But that name is misleading, since the Danish lagoons bear no similitude to the deep waterways of Norway with which the word fjord has become associated. Denmark, indeed, is the very antithesis of Norway, and her fjords should rather be designated "broads"-bredning in Danish.

They include wastes of mudflat, sand, and shallow of such vast area that the weak tides of Jutland rarely penetrate beyond a few deeper channels-hence landgrasses and herbage clothe islet and salt-spit. From the sea outside, the broads are only separated by those remarkable revler-narrow ranges of dreariest sanddunes, some of which stretch straight for twenty or thirty miles, yet barely five hundred yards in breadth.

A glance at the map will show that the chief of these is the Liimfjord, a hundred miles long, which practically insulates North Jutland-sometimes entirely, according as the sea-channel of Thyborön happens to be open or silted up. Southward lie the Vemb and Ringkjöbing fjords, and that north of Fanö. 
On May 14th we set out on a week's exploration of some of these. The day was Sunday, but ordinary work was proceeding as usual-ploughing and sowing, even bricklaying, while shops were not closed, the small boys were spearing eels, and two gensdarmes were shooting ! Our road lay through an arid heath, half cultivated and studded (as usual) with cottages, whereon white storks had their nests, with sparrows as sub-tenants. By the roadside were observed crested larks, wheatears, whinchats, etc. On May 17 th the country suddenly swarmed with Tree-Pipits, and we also observed a thickset, short lark, either Alauda brachydactyla or $A$. arborea; as well as one Stone-Curlew.

After a fifteen-mile drive, our Jehu pulled up before a solitary cottage, whence proceeded sounds of riot and revelry. This primitive little ale-house, literally at the world's end, and on two sides smothered up to the eaves with blown-sand, was to be our quarters. The hamlet comprised a dozen fishermen's huts scattered in the dunes, and the inhabitants were assembled here enjoying their Sunday beer. Our beds were bunks and accommodation of the roughest; but we were agreeably surprised at the fare- a fresh-caught sea-trout, beefsteaks and sweets, with good baiersköl and coffee; and when, soon after, the noisy crowd of fishermen departed to prepare for their night at sea, we felt that matters were not so bad after all.

May 15th.-This proved a memorable day. Rarely in any land have we seen greater abundance of birdlife than thronged these Danish wilds. Sea and sky pulsated with moving forms ; the dark green salt-grass was studded with marsh-birds and sea-dwellers-geese 
and gulls, ducks, terns, and waders in charming variety. Avocets hovered overhead or dotted each marsh-pool and channel, along with Sheld-ducks, Curlews, and Oyster-catchers; Ruffs had numerous "stands;" Reeves, Red-shank and Ring-dotterel (three kinds) in scores and hundreds; Terns, Peewits and Dunlins in thousands, coursed over the level plain or barely fluttered out of our way.

From the extreme point of the tipperen (salt-spit), we at once noticed, on a sandbank five hundred yards to seaward, amidst a clamorous crowd of grey geese and gulls, eight huge white birds.

"Swans," I said at once, for they were ten times bigger than the gulls, and dwarfed the geese that sat hard by. "No, not swans," said Kristian, who spoke a few words of English-" the swans have all gone weeks ago ; those are Pelicans!" Pelicans! it seemed incredible, though corroborated by the men who lived out here in some wooden huts, in charge of the government reclamation works, and who told us that, though pelicans did not come every year, the eight before us had been there for some time. They further described the pelicans as living on fish, and said they were yellow on the breast and had a long crest of feathers behind the head-which two features correspond with Pelecanus onocrotalus. There being no boat, a nearer approach was impossible, and we contented ourselves with a long survey through the binoculars. At the distance it was impossible to distinguish details; we could, however, distinctly see their enormous size, long necks, and black primaries, as well as the huge spread of their goose-like wings. See plate facing p. 20. 
Nearer at hand the foreshore was lined with grey geese, to one of which, evidently a "pensioner," we got near enough to identify it as Anser brachyrhynchus. The geese swarm here in autumn and early spring, for the plain was covered with their feathers, footmarks, etc. Everywhere droves of big webbed feet had traversed the mud-flats. We also picked up the remains of a pochard drake and a scoter, and observed many sheld-ducks, pintails, etc.

Though the salt-grass was plentifully sprinkled with nests of Terns (S. fluviatilis), Redshank, Dunlin, and Peewit-yet it was long before we fell in with anything better. At last A. walked into our first Reeve's nest, containing two of her eggs, with one of a Redshank. Next the three clay-coloured eggs of an Avocet were discovered, lying on almost bare grass, and we proceeded to walk out across dry marsh and shallows to some islands about a mile from the shore. Thereon, from afar, we perceived the now familiar spectacle of a "ruffstand" on a thistley ridge, just beyond which, on our landing, a Pintail rose from her nest of eight eggs in a hollow of the grass. A survey with the glasses having shown both Mallard and Pintail drakes feeding on the oozes hard by, we commenced a careful search, and soon my eye caught that of a duck squatting low in a hole among the grass, not five yards away. An endeavour to pin her down on the nest with the gun-barrels only resulted in breaking several eggs, hence the hateful necessity of shooting one old duck as, she shuffled along the ground, more like a wounded hare than a bird, for complete identification. In all, we found on these islands about a dozen Pintails' nests with eight to ten eggs each, all 
very hard-sat, also three Mallards' nests and many of various gulls.

Here, also, we at length got fairly among the nests of the Reeves, which had hitherto cost us so much fruitless search. They were now (May 15th) beginning to lay; of ten nests found, only two contained the full complement of four eggs, the others one, two, or three. The Reeve invariably breeds on firm grass-land (not on the squash-bogs) and the nest is well concealed, like that of a redshank, in a hollow of some tuft of grass. We also found here a nest of Ring-Dotterel.

Wandering on from islet to islet across mud-flat and oozy shallows, we were soon a long way from the mainland, while the intense heat-shimmer and mirage effects, distorting objects comparatively near at hand, were most confusing. It was difficult to say what we really did see, or how much was illusive. The whole singular scene, with its weird monotony and teeming bird-life, may remind readers of "Wild Spain," of similar descriptions of the Andalucian " marismas." Here flamingoes were replaced by pelicans; stilts and sand-grouse by ruffs, reeves, and oyster-catchers ; and, despite the heat, there was the evidence and the sentiment of the more northern latitude. Here a paternal government is endeavouring to reclaim these wastes from the sea. The whole region belongs to the Danish Crown, and the system adopted is to carry out parallel lines of turf across the flats, some of these, between islet and islet, regular raised causeways, elsewhere mere strips, about sixty or seventy yards apart. The intervals gradually silt up, and become occupied, at first by a growth of reeds and flags, but in time by grass, which slowly builds 
up a rampart against the weak tides-the rise here being only a foot or two.

The only small birds noticed on the islands were Yellow Wagtails, a pair of Garden-Warblers, and once a migrating band of Willow-Wrens. On another islet (close to the sea), Kristian called to us to say he had flushed an unknown bird, and showed us the tiny tunnel of dead grass whence it had risen. "It was like a woodcock; and that bird in Denmark," he added, "is so rare that none save the King can afford to eat it!" Kristian had once shot one, and received three kroner for itquite a small fortune. We followed to where he had marked the stranger; and there, endeavouring to hide on the barest grass, lay a Corncrake, evidently a new arrival and resting after its long sea-journey.

Leaving the islands and working our way homewards across the main salt-grass, we came on two colonies of Avocets, which, with graceful, duck-like flight, hovered around, filling the air with sharp, jerky pipes. They were rather wild, and their eggs lay strewn on the short grass, with only slight attempts at a nest, just as in Spain. Some clutches numbered four, and one five eggs, all fresh. We also fell in with an Oystercatcher's nest with four eggs, and several more of reeve, dunlin, etc. A four-mile tramp homewards along the fjord, where terns screamed and plunged, and waders in hundreds coursed along the shallows, ended a delightful day in a Danish marsh.

These tidal lagoons are, in their season, the resort of great quantities of wild-fowl. Ducks, brent, and grey geese come in thousands, and the Cimbrian broads form the winter-home of half the wild swans in Europe. 


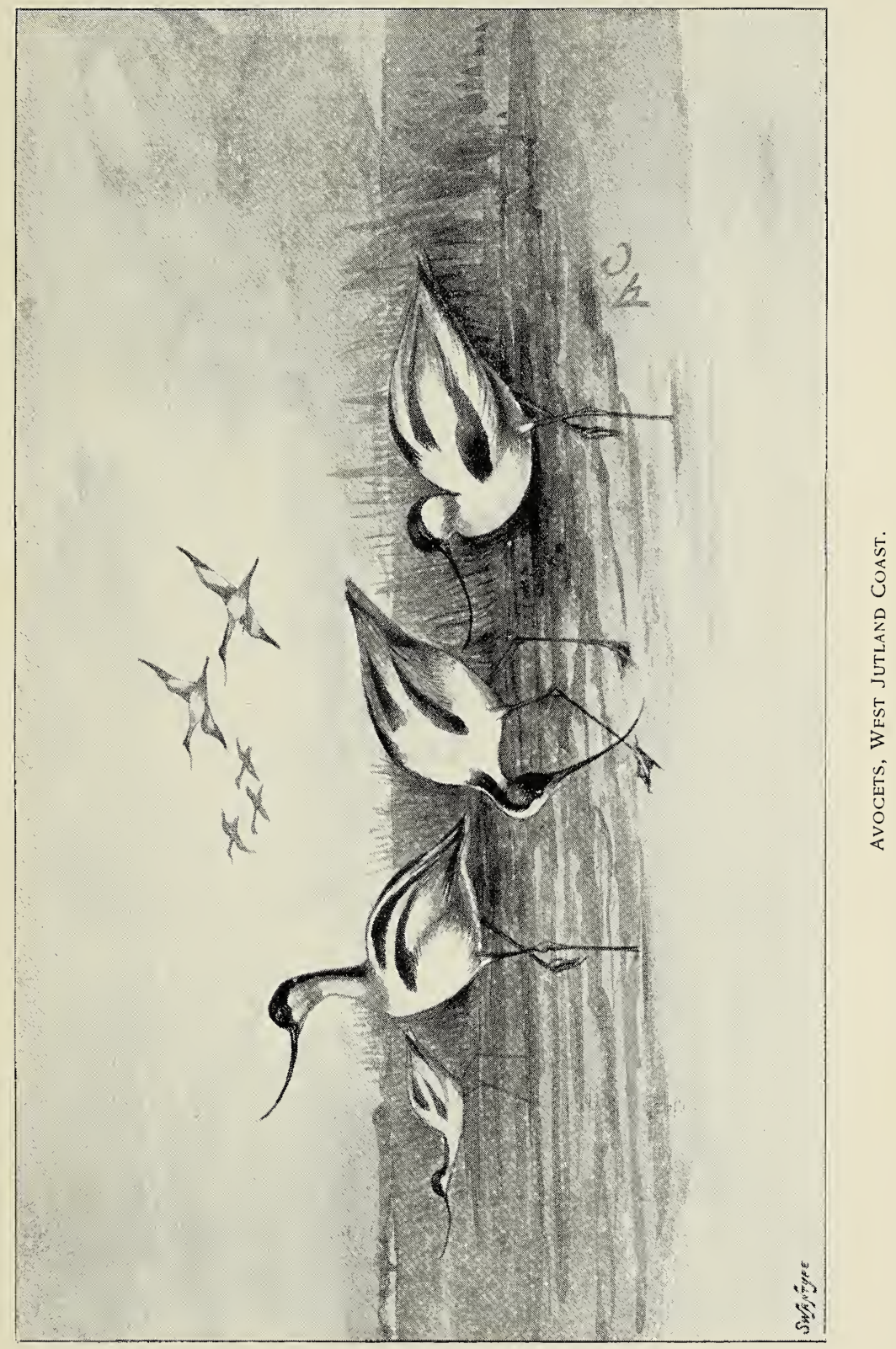



On the Liimfjord, zostera-clad oozes cover many hundreds of square miles; the voyage from NykjöbingMorsö to Aalborg occupied a whole day, passing one long succession of mud-flats and matchless feedinggrounds. But it should be noticed that these waters are usually closed by ice from about Christmas till March-exactly the period when we have the brent geese on our north-east coast.

In the Liimfjord also, we met with schemes for reclaiming land from the sea. It will be obvious, as this reclamation of the wastes proceeds, that wild-life must proportionately decrease, and in process of time fens and fen-birds will become as extinct in Denmark as they already are in England.

Among the sand-dunes, or klinten, extensive afforesting operations are being carried out by the Danish Government, by the destruction of useless ling and bents, which are replaced by young pines. This, however, affects little but the half-starved rabbits, and the work affords much highly-valued employment.

\section{Among the Sand-Dunes.}

Along the coast itself lie revler, or mountains of sand, bare of vegetation save sparse bents or palegreen sword-grass. The revler are lifeless : only colonies of terns, and a few pairs of herring-gulls, or oystercatchers, inhabit them. But among the dunes, or lilinten, occur inset patches of marshy moor, with stagnant pools surrounded by swamp and sedge, bogmyrtle, and willow-scrub.

At one such spot, where there were a hundred 
acres of water and knee-deep marsh, all trampled down by the paddlings of ducks with their young broods, we counted no less than sixteen species together. The water was alive with ducklings and anxious mothers (mallards). On a low islet was a "stand" of quite twenty ruffs; pairs of little terns plunged in the shallows, and the air resounded with the drumming of snipe and peewit and the cries of redshank, dunlin, and a pair of wood-sandpipers. These latter were nesting hard by, though the utmost care failed to disclose the precise spot. During an hour, while we lay watching them, the following were observed: a marsh-harrier slowly beating across the bog, bullied by peewits ; a merlin, mallards, and pintails; cuckoos, willow-wrens, sand-martins, and swallows. We also noticed, among the sandhills, tracks very much like those of the stone-plover, a few rabbits, a hare, and many adders, our men being unreasonably afraid of these latter.

On the shingle, nested Ring-Dotterels; and, further towards the sea, we recognized both the Lesser species (Agialitis curonica) and the Kentish Plover with its pure white chest, obtaining specimens of all three. The Lesser Dotterel did not yet appear to be nesting; but on May 17th, after watching a Kentish Plover for some time, we saw her settle down on her nest by some drift weed on the sand, and shot her, running off. The nest, however, was empty. On the shore of the fjord a pair of Little Gulls (Larus minutus) hovered overhead, and one was secured with the "walking-stick gun"-curiously, in far from complete summer-plumage, the head being only half black, the wings much mottled with black. 
The survivor, which could easily have been shot, was even less advanced, showing hardly any black on the head. Their breasts were beautifully rosy. We saw another passing pair in similar plumage.

Little Terns (Sterna minuta) fished along-shore in pairs, alighting between dives to "kiss;" and among other birds noticed here were avocets, red-throated diver, merganser, wigeon (a flight of ten), and a pair of heavy diving-ducks with white speculum-probably velvet scoters.

Two days we spent on the outer sandpit, by the verge of the North Sea-here breaking a pure pale translucent green. The feature of these outer links were the tern-colonies, which extended for miles. Bare sand and shingle alike were dotted with innumerable nests-mere scratchings, quite unlined, and all as yet empty. It was too early (May 17th and 18th). The species breeding here included Common and Arctic Terns, Little and Sandwich Terns. There were, however, other large terns whose identity we failed to make out. Cartridges had run short, and the few remaining were only half-loaded. These large terns kept a constant line along-shore, about thirty yards to sea, each carrying a silvery fish. Not one flew overland. A gravelly point projected seawards, hard by where the huge vertebræ and scattered skeleton of a whale strewed the shore. Upon this point, with our two last cartridges, I laid down flat; but, alas! neither of those undercharged shells effected its object, and the procession continued undiminished. Both the Gull-billed and Caspian Terns breed on the island of Sylt-possibly, also, the Roseate Tern-hence this failure was annoying, and we walked 
homeward with silent gun and feelings of some disappointment.

On our second visit to Denmark we were only absent from England, in all, fourteen days ; and during that short time enjoyed, almost daily, spectacles of marsh and marine bird-life that one would need to hark back some centuries to see (in imagination) on British fen or foreshore. 


\section{CHAPTER XXI.}

\section{THE NORTH SEA.}

Notes on Bird- ANd Insect-Migration, observed DURING Twenty-Four Voyages.

BeTween us and our Scandinavian playgrounds rolls the North Sea, and its four or five hundred miles of unquiet waves mean misery to many, and tax the patience of most of us. The North Sea is the scene of busy human industry, yet the spectacle of the trawlingfleets on the Dogger, picturesque as they are, avails little to vary the monotony, and perhaps induces a sense of melancholy, from sympathy with the lot of men exposed for weeks at a time in these tiny craft to the buffeting of the waves, and to every vicissitude of wind and weather on the wild North Sea.

Perhaps, however, they are, after all, in no worse case than millions of their kind on shore.

Dozens of sloops of various nationalities diligently glean the harvest of the deep, and among them bustle to and fro the busy little "steam-carriers," or hollowwelled steamers, which convey the fish to market. Further out, one passes through the Scandinavian mackerel-fleets, "harling" for these fish with big white flies on lines set from a spinnaker-boom-the bulk of 
this catch, curiously enough, being destined for transAtlantic markets.

A great phenomenon, of which one may often enjoy opportunities at sea for observation, is that of migration. The transit over wide oceans of puny creatures, such as birds and insects, is so extraordinary, its character still so mysterious and imperfectly understood in detail, as to render every record interesting, and some valuable. The following notes on this subject include observations made during twenty-four voyages by my brothers and myself across the North Sea.

To begin with the sea-birds - as every voyager knows, one sees gulls in mid-ocean at all seasons, and it is difficult to deduce any conclusions from their desultory flight. In May and June the Gulls seen are exclusively immature-young Kittiwakes with blacktipped tails, and other Gulls in that duskier plumage indicative of the second or third of the four years which nature has assigned as the period of adolescence in the Laridx. The adults at that season are, of course, engaged at their breeding-stations, and it is, perhaps, worthy of remark that few Gulls will be seen in mid-sea during the last two or three hours before dark.

Similarly with the rock-fowl-Guillemots, Puffins, and the like. These, by the middle of May, have drawn landwards, and during the rest of that month and June no sea-birds (save the gulls aforesaid) will be seen far out. But in July the Guillemots, Razorbills, and Puffins, with a few stray Gannets (mostly immature), return to their pelagic haunts, while gulls, old and young, populate the middle seas.

Thus, on July 12th, I have notes of all the species 
just named. On August 21st a Great Skua (Stercorarius catarrhactes), two hundred miles from Shetland, and twice during that month Shearwaters appear in my notes. Of course, for most of these species the open sea forms their natural home, and upon its surface they, together with the ducks, geese, and other waterfowl, to whose movements I shall presently refer, can rest when tired-not that I believe any strong-winged wildfowl are at all likely to become tired during a four-hundred-mile flight. The seasonal distribution of the sea-birds, however, is chiefly interesting to the naturalist, and evokes none of that surprise which the sudden appearance of some tiny feathered mite, such as a gold-crest or willow-wren, begets on board ship when hundreds of miles from land. That these little creatures, and others punier still, do regularly cross wide seas is, of course, a matter of common knowledge ; yet that fact in no way diminishes one's sense of wonderment on seeing them in the very act of performing the feat, and the more so when it chances to occur in the midst of a storm at sea.

Almost every voyage during spring and autumn one sees small land-birds on their passage, and not birds only, but even those feebler folk, the insects, likewise essay to cross the North Sea, as the following records demonstrate.

May 6th.-Blowing hard from north. Puffins and Guillemots observed sixty miles out; next day, wind increased with a ten-foot sea, which swept the decks and broke a seaman's leg. In afternoon a Redstart followed the ship, and tried to alight on the log-line astern, evidently exhausted, and eventually fell behind. 
On the 8th, wind S.E. ; sea calming. A Redstart and another bird (unrecognized) passed close by when one hundred and twenty miles from Norway. In afternoon a Whinchat came on deck, then a Blue-throated Warbler. In evening thick fog; another Redstart joined our two deck-passengers. Reached Bergen next morning, sixty-two hours' passage.

May 8th.-Wind N.E. ; heavy sea right across. In mid-sea, two companies of ducks, apparently Longtails (Harelda glacialis), resting on water. Two Wheatears came on board, and several small birds (not identified) seen passing.

May 10th.-Wind E.; sea rough. Whimbrels heard passing north, about a hundred miles out from Jutland coast. No land-birds seen this voyage.

May 21st.-Homeward-bound from Denmark; sea smooth, light air from east. At noon, a hundred and seventy miles out (but only forty miles from Dutch coast), two Willow-Wrens came on board, and stayed some hours, though we were presumably carrying them. the wrong way. In afternoon a dragon-fly appeared on deck; we were then only twenty-five miles from Holland.

May 22nd.--Sea calming after a five days' gale. At noon (a hundred and eighty miles out from Tyne) a small warbler and a larger bird, perhaps a Whinchat, flew close past the Kong Harald, but without alighting ; later, a single Redstart, soon followed by a pair (cock and hen), came on board and stayed, all three very draggled and tired. In the afternoon I had a very good view of a Pomatorhine Skua (Stercorarius pomatorhinus) which crossed our course, going S.E., its curious twisted tail unmistakable. Two other Skuas were seen, one 
resting on a floating log, probably belonging to the same species. Towards evening two large Eagles overhauled us, both going N.E., but quite five miles apart.

At 7 p.m., a pair of Garden-Warblers came up astern together, and lit on the after-rail; then a Wheatear strove hard to overtake us, but, failing, apparently perished in a passing squall. At 8.45, just after a glorious sunset, another Wheatear joined the ship, and the kindly captain had some bread-crumbs and a saucer of fresh water set out for his uninvited guests. This old sea-dog, nevertheless, stoutly denied the possibility of birds flying across the sea, asserting that these had come with us from England.

At daybreak on the 23rd, I was told the deck swarmed with small land-birds, but was not there to see.

May 27th.-This morning, off the Norway coast, some hundreds of Brent Geese overhauled the Norge, going due north, doubtless to Spitsbergen direct. I have already recorded this fact elsewhere, but may add that on another voyage, on June 4 th, we passed three Brents sitting on a glassy sea within a hundred yards of the ship, while yet in sight of Bommelö. The only other birds noticed on this occasion were two Swifts and a Skylark on the 26th, and a Tree-Pipit on 27 th.

I have notes of other voyages about this date, but without giving the details, which might become monotonous, will merely mention the following species seen at sea, to wit: Swallows, House- and Sand-Martins, Whinchat, Wheatear, and Willow-Wren, Jack-Snipe, Dunlin, and some unrecognized sandpipers. It should, however, be expressly added that all records refer to single birds, or to twos and threes at most. 
June 4th.-Outward-bound to Denmark. We passed a "finner" whale fifty miles east of Tyne, and had the company of two Willow-Wrens and a Garden-Warbler ; some Swifts also were reported seen. The incident of this voyage, however, was an extraordinary insectmigration observed from about two hundred knots out from Tyne (=about a hundred from the Jutland coast). About 2 p.m. I noticed a few moths fluttering about the companion-way, and soon after very large numbers, of which I caught three, which proved to be Bupolus piniarius, the bordered white. The course of the Koldinghuus was presently crowded with hosts of moths, which skimmed along the sea or rose in clouds from its surface, on which millions more lay dead. Half an hour later, larger corpses were observed, including, as far as one could see from the bows, some of the Sphingidx, a few Diptera, and many dragon-flies. In connection with the last-named, it was a curious coincidence that, on the eve of sailing (June 2nd), I had noticed in my garden at Roker a large dragon-fly, which, I now concluded, was a survivor of these adventurous Danish emigrants. The sea continued strewn with myriad relics of overwhelmed hosts all that afternoon, and, though in decreasing numbers, till within fifty miles of the Danish coast. There was at the time only a light air from the east, but a strong groundswell indicated a previous breeze from that quarter.

While on the subject of the transit of moths, etc., across the North Sea, the following note is pertinent. During the autumn of 1891 the north-eastern counties were infested by a perfect plague of caterpillars, which ravaged the turnip-fields, leaving nothing of the leaves 
but carefully-macerated skeletons. Farmers were in despair at this visitation of a new and unknown scourge. Now earlier in the year (in June) I had received letters from the fishermen, whom in winter I employ as puntsmen, mentioning having seen "clouds of small moths at sea," while they were fishing twelve or fifteen miles off the coast. "Masses of them seemed at times to alight on the water, but rose again and continued flying landward." This continued for some days, and shortly afterwards I read in a local paper of an actual invasion of the Durham coast by millions of the diamondbacked moth (Plutella cruciferarum), which appeared about June 24th, infesting even seaport towns, such as Hartlepool, whither no self-respecting country-bred insect would dream of resorting. These invaders belonged to the same species as that of which the caterpillars, during the autumn, devastated the turnipcrop - the diamond-backed moth - and to me their transmarine origin appeared obvious, though the theory provoked much incredulity at the time.

On August 18th I have another note of passing through thousands of moths of all sizes floating in midsea; none, however, on that occasion were seen alive. On the same voyage we steamed for some two hours through a belt of floating feathers, mostly chestnut, with white tip and black subterminal bar. I give the record for what it is worth.

June 4th.-Homeward from Stavanger. Shortly after passing the three Brents above mentioned, a Nightjar circled round the Mercur, and eventually perched on the coamings of the forehatch. Being disturbed, it resumed its course for Norway, the coast still in full 
view. A hundred miles out, passed through a small group of Guillemots (unusual at that season), but, except a Garden-Warbler and a Starling, we saw nothing else of note.

During voyages at the end of June and during July, few land-birds were observed, beyond some of those species already mentioned, and notes (by others) of Skylarks, Starlings, and Peewits, the two last in some numbers. While crossing the Cattegat on June 18th, a Yellow Wagtail came on board, completing his passage to Sweden free. No Wagtails, it will be noticed, occur in my North Sea notes-they probably "book through," viâ the Baltic. Three birds sent me, caught at sea in August, proved to be two Tree-Pipits and a Woodlark. There is nothing else specially noteworthy in August, beyond the diffusion all over the sea of the newly fledged gulls and the oceanic Alcidær. It is not till September that the commencement of the return-movement is really conspicuous. In the earlier days of that month, the wildfowl are all amove amidst the islets of the Norwegian Skjærgaard. Grey Geese and Wigeon, with wading-birds and other fowl, are assembling in restless packs; but this belongs rather to Norsk ornithology than to that of the North Sea. As early as September 10th we have seen big flights of Wigeon standing out due west from the coast, and on the following day, in mid-sea, observed two flights, both high in the clouds, steering S.W., as well as other ducks (not identified), divers, and mergansers.

The record this day (Sep. 10th) also includes Dunlins, Shearwaters, and numbers of Fulmar Petrels, of both the white and grey varieties. These latter accompanied 
the Capella till far past mid-ocean-indeed, up till within an hour or two of our sighting the Cheviots, rising from the grey sea. Yet the Fulmar is all but unknown on the Northumbrian coast. How narrowly do birds observe their appointed limits !

Sept. 25th.-Homeward from Trondhjem. Guillemots noticed up to fifty, and Shearwaters at one hundred miles out. Gulls observed, in twos and threes, persistently beating against a slight wind towards S.W., flying low on the water, and in very different style to the desultory flight of other gulls that followed the ship. A few ducks (probably wigeon), one finch, a sandpiper (? sp.), Richardson's Skuas, and Fulmars observed. Next day (Sept. 26th), gulls still beating to windward (S.W.) in small parties. Ducks, Skuas, Fulmars, and a finner-whale seen spouting. During the last week of September the Grey-lag Geese are beginning to move southwards: but, though one sees them almost daily in Norway at that period, I have never happened to observe them crossing the North Sea. Perhaps none do cross it.

Oct. 8th.-Homeward - bound from Bergen. A single Starling took passage towards dusk, and several packs of diving ducks (probably scaup or goldeneye) passed our ship, the Ragnvald Jarl, flying very low on the water, and mostly across our course. Next day, in mid-sea, a Pomatorhine Skua flew alongside, keeping company for some time, possibly influenced by the crowd of gulls which followed us. We saw neither ducks nor fulmars on October 9th, but the common seafowl-gannets, gulls, guillemots, etc., abounded all the way across. 
April and October are, beyond doubt, the months in which the phenomena of migration may be observed to the greatest advantage. But unfortunately, with the trifling exceptions above mentioned, I have not been on the North Sea during either of these months. The twenty-four voyages to which the record refers were all made between May 6th and October 10th.

Now, if it is permissible to deduce any conclusions from these sporadic observations, what is the most striking feature about them? Simply this. That, comparatively speaking, nothing whatever is humanly visible of migration at sea. Every voyage some few belated land-birds, singly or in twos and threes, will seek refuge on one's steamer. But what do such scarce and casual appearances amount to? Nothing. The birds seen are merely stragglers, lost wanderers fallenout of the ranks of the migrating millions that are not seen. The numbers seen bear absolutely no appreciable relation to the vast sum-total of migration. They are interesting as indices of what is passing beyond our sight, but that is all.

Consider what number of summer-birds are required to populate the one-thousand-two-hundred miles of Norway alone. From the Naze to North Cape not a wooded valley nor birch-clad slope of the fjeld but is vocal with the melody of summer-songsters. The aggregate must count up into a tangle of millions. Yet who has ever seen them come? True, they may not all cross the North Sea; * but who has seen

* I have mentioned elsewhere (see p. 15) that Norway receives her yearly influx of spring-migrants from the eastward-via the Baltic or Russia-rather than across the North Sea. 
the swallows and willow-wrens arrive in England, and they must cross the Channel? Has migration ever been seen in full swing by daylight? I mean the actual process of migration, as distinguished from mere evidences of its progress. Sitting on mild November nights in my garden at Roker, with nothing but the North Sea between us and the fjelds of Norway or the sand-dunes of Jutland, I have listened to the single pipe of the redwings (and less often the note of fieldfares, which are more silent) as they "made the land" between ten and eleven o'clock. These birds, presumably, had left the opposite shore at dusk that evening, and had covered some three-hundred-and-fifty miles in five or six hours. No one sees them start, no one witnesses their arrival. But of course the North Sea passage is merely exercise for strong-flying species. Is it the same with the feebler kinds?

In reply, I will venture on a somewhat bold opinion. I am convinced that many birds of migratory habits are absolutely incapable, under normal conditions, of flying three hundred miles, or anything like it. Among such I would include all short-winged warblers, chats, and goldcrests, quail, landrail, etc. These birds are neither "built nor engined" for long flights ; in their normal lives they never undertake such flights, and I do not believe, under ordinary conditions, that they are capable of performing them. No one who has watched their feeble, flickering flight in mid-sea can believe it. Yet, on the other hand, we have confronting us the solid fact that twice in every year these tiny creatures do traverse Europe from end to end. The solution I am neither learned enough nor clever enough to 
suggest; but it seems certain that some great facts or factors governing migration have been overlooked, or yet remain to be discovered.

The facts that migration is never observed in daylight, and that known flight-lines cross great altitudes (ten thousand feet to twenty thousand feet and upwards), point to these aërial movements being performed at heights, and perhaps at speeds, that have never fully been realized. Assuming that migration is carried on at altitudes of twenty-five or thirty thousand feet, it would follow that the conditions of air-resistance, buoyancy, etc., in a rarefied atmosphere, would there be entirely altered. What those altered conditions may be, or their precise effect on flight, it must be for more scientific pens to define; but, in my view, it can only be by virtue of some such changes, assisted by the option of selecting favouring wind-strata, that the feebler and short-winged travellers can make their distances.

An obvious advantage of high-level travelling would be the extension of the field of view. Allowing for the convexity of the earth, but not for mountains or other obstructions, the figures work out roughly as under-

Altitudes. 25,000 feet 30,000 feet
Tangential extent of vision.

$$
\begin{array}{llll}
\ldots & \cdots & \ldots & 225 \text { miles. } \\
\cdots & \cdots & \cdots & 245 \quad,
\end{array}
$$

Thus, at the first-named altitude, birds would, in daylight, see England long before losing sight of Norway: while at the higher level, when crossing Spain, they would see Biscay before sinking Africa.

In doubting whether migration has been seen in 
actual progress, I do not wish to be taken too literally, for I have myself (as herein recorded) occasionally witnessed it, but always in that limited and relative sense in which exceptions go to prove rules.

Thus, in southern Spain, in spring, I have observed whole hosts of swallows to appear suddenly, as from the clouds. The plains, the marshes, the vineyards, or mudflats swarm with them. One night they roost in thousands under your thatched eaves and in the trees hard by. Before the morning's light every bird has gone. This may, perhaps, be explained by the assumption that migration is performed at altitudes determined by the height at which a favouring air-current is found; that, in this case, the air-current had ceased to flow, and (no other being found within available limits) the migration in question was necessarily suspended, awaiting a renewal of the required conditions. Fortunate birds to have the land beneath them. Should such suspension occur at sea, it would involve the destruction of the entire host.

Except by aid derived from the operation of physical laws, the nature and extent of which are unknown to me, and by taking advantage of "trade-wind" circulations in the upper air, I believe that migration is impossible for short-winged forms of sedentary habit, such as those above-named. But that aid, and those advantages, may vastly facilitate, and perhaps vastly accelerate, a process which is otherwise impossible. As to insects, there appears no evidence to prove that there exists any regular migration across the North Sea. Occasional irruptions--such as those of Colias edusa and of the diamond-back moth aforesaid-may be thus 
explained. But in most cases, I take it, insects seen in mid-sea are probably blown-away bands that, during some local inland migration, have been caught in an airstratum too strong for their powers of flight. Fewvery few-of these will survive to cross the sea. 


\section{$(341)$}

\section{CHAPTER XXII.}

\section{SPITSBERGEN.}

\section{Prelininary Remaris.}

SPITSBERGEN in summer is now fairly well known, which was hardly the case when I first visited the Arctic Seas in 1881, though the researches of Scoresby, Lamont, Newton, and other voyagers had left little to discover, at least in ornithology.

Of personal experience, for these reasons, I do not propose to write, albeit brief impressions remain ever vivid, and bequeath a bitter regret that I have never had the opportunity of tackling the Arctic in solid earnest.

The avifauna of Spitsbergen-marvellous as it is in the aggregate-consists, when analyzed, of but some thirty species, and these chiefly rock-fowl, such as Guillemots, Puffins, Auks, and Fulmars, with Kittiwakes, Glaucous and Ivory Gulls, Skuas, and Terns. Of landbirds there are but four-one raptor, the Snowy Owl; one game-bird, the Spitsbergen grouse (L. hemileucurus), together with Snow-Buntings and Redpolls. Of wildfowl, there breed the Pinkfooted, the Brent, and Bernicle Geese, Eiders and Longtailed Ducks, with a very small contingent of the sandpiper tribe, one phalarope, and one of the divers (Colymbi). 
I have never, in any land, seen anything that can at all compare with the vast aggregations of bird-life that in July and August throng the "loomeries" of Spitsbergen. But these bird-cliffs are abandoned early. My brother Alfred, who (in 1894) visited the west coast only a few weeks later, saw nothing of these sights. The rock-birds were then drawing out of the fjords and sounds, and by October quit the land altogether. The only other remark I shall make is that no human eye sees these birds again till the following spring, nor have we any precise knowledge of how and where those teeming millions pass the winter. Several of the predominant forms may be said to be peculiar to the Arctic, such as, e.g., the Brunnich's and Mandt's guillemots, Arctic puffin, little auk, ivory gull, etc. Yet, of them all, none, save merely storm-driven stragglers, ever appear on European coasts. All the long sunless winter they must spend in mid-ocean, amidst the dark wild wastes of the north Atlantic.

The whole raison d'être, however, of this chapter lies in the following extracts from the diaries of my friend, Mr. Arnold Pike, who wintered in Spitsbergen in 1888-89, and to whose exhaustive and elaborate notes, kept specially for me, I fear these brief excerpta do but scant justice. Many books are nowadays made with far less material.

The original scheme was to pass the winter in Storfjord, in the south, where the spring "walrusfishing" offers the best opportunities; but, the ice preventing access to the shore, the course of the Seggur, an ordinary Norwegian walrus-fishing sloop of some forty tons, was directed northwards, to the 
neighbourhood of Amsterdam Island, in the 79th parallel of N. latitude. Here, in Danes' Gat, was erected the wooden house brought out from Norway, in which Pike, with his skipper, Kræmer, and six Norwegians, spent the whole Arctic winter from September, 1888, till May, 1889. Not till the 16th of the last-named month was the Seggur freed from her frozen cradle, and enabled to resume the quest of Arctic game.

Without further comment, I will now go straight ahead with the following selected extracts from these daily journals of-

II. A Winter in the Eightieth Degree.

(SPitsbergen.)

By Arnold Pike.

Aug. 21st.-Amsterdam Island. Shot a Sanderling out of a flight of three. [Skin in my possession.-A.C.]

Aug. 25th.-Smeerenberg Bay. Several Ringplovers observed; on following day a skein of two hundred Brents passed south, also some Grey Geese. Temperature during August-Air, max. 60.12 $2^{\circ}$ min. $320^{\circ}$. Sea-water-west coast, $41 \cdot 22^{\circ}$; east coast, $365^{\circ} 5^{\circ}$; north coast, $38 \cdot 1^{\circ}$.

Sept. 2nd.-Observed what we took to be an immature Great Black-backed Gull (Larus marinus).

Sept. 10th.-Walrus (old bull) harpooned and shot. Stomach contained the "speck" of a seal (Ph. hispida). This is not usual, but the skipper told yarns of similar incidents, as well as once seeing a walrus take a fulmar while sitting on the water in King's Bay. Shot a bear 
to-day; another (a :big old male), killed on the 7 th, measured seven feet.

Sept. 13th.-Shot four reindeer-two big bucks out of velvet.

Sept. 14th.-Wiide Bay. Shot five deer and sixteen ryper, the latter as large or larger than Norsk dal-ryper. The sixteen weighed $24 \frac{1}{2} \mathrm{lbs}$, though many were birds of the year. Shot seventeen more the next day. They were absurdly tame.

Sept. 18th.-Dane's Gat. Thirty Pink-footed Geese seen. Temperature during September-Max. 36.5 min. $15 \cdot 13^{\circ}$, mean $21 \cdot 37^{\circ}$. Snow fell on twelve days; all day on six, chiefly on 21st. Rain, only a few hours on 17 th.

Oct. 5th.-Amsterdam Island. Three "ryper" weighed exactly 1 kilo $(=2 \cdot 2$ lbs.) each.* They were very fat, with dark down beneath their snowy plumage. Snowy Owl beating about Dane's Gat, and SnowBuntings seen in flocks, very wild. Purple Sandpiper still here, and Long-tailed Duck shot.

Oct. 11th.-The seals are now so fat they do not sink when shot. A bearded seal (Ph. barbata), female, shot to-day, was crammed with things like crayfish, swallowed whole, three to four inches long. The seal measured nine feet, and contained a young one three feet long.

Oct. 13th.-Eiders, Glaucous Gulls, young Kittiwakes, and Tysties, generally in flocks; also a few Little Auks.

Oct. 14th.- Snowy Owl seen, and fox caught with new white winter-coat perfect. Faint aurora commencing.

* Note that this weight, 2 lbs. $3 \frac{1}{2}$ ozs., far exceeds that of any "ptarmigan," or even willow-, or red grouse. See p. 186, supra. 
Oct. 26th.-Three young Tysties seen. Seals leaving bay.

Oct. 30th.-One young Tystie seen, otherwise the birds have all gone.

Temperature this month-Max. $38^{\circ}$, min. $6.5^{\circ}$, mean $21^{\circ} 86$, above freezing-point on three days (18th to 20th). Weather rather finer than in September. Dawn, on 14 th, at 6.30 a.m. ; lamps lit at 4.30 p.m. ; on 31st, in thick weather, lamps lit all day. Faint aurora towards end of month.

Nov. 3rd.--Snowy Owl seen yesterday for last time this year, and three Eiders shot to-day from a flight of thirteen.

Nov. 16 th.-Heat oppressive. Temp. (mean) $255^{\circ} \mathrm{F}$.

Nov. 26th.-Aurora nearly all day.

Nov. 28th.-Killed two foxes, one black, one white; former had stomach crammed with small feathers.

Nov. 30th.-Heavy swells all this month from S.W., indicating much open water out in that direction. Much phosphorescent light among slush at ice-edge. These were the chief features of the month, together with the beautiful effects of the aurora.

Temperature during November-Max. $33^{\circ}$, min. $-27^{\circ}$, mean $4.47^{\circ} \mathrm{F}$.; only once above freezing, on the 15th. A fine month generally; little snow. Only confined to the house on two days, 3rd and 23rd.

Dec. 11th. - Shot a she-bear, $6 \frac{1}{2} \mathrm{ft}$., cub escaping. Stomach contained part of a seal. Foxes abundant. A white fox, shot on 12th, was very fat, and weighed 8 lbs.

Dec. 16th.-Black, as well as white foxes about house. 
Dec. 19th.--Killed she-bear, giving suck. Stomach empty but for a moccasin thrown away by the men. Cub again escaped.

Christmas Day.-No fires; windows open, and sat outside for some time. Mean temperature $36^{\circ} \mathrm{F}$.

Dec. 27 th and 28th.-Several walrus heard blowing among the ice both days. Very dark.

The average temperature for December is the same as that for October-21. $5^{\circ} \mathrm{F}$. On the $22 \mathrm{nd}$, after four days' gales from S.E. to S.W., it rose to $45^{\circ} \mathrm{F}$.

\section{9.}

Jan. 1st. - Seals heard.

Jan. 2nd and 3rd.-Aurora. Birds heard both these days, and some seen, but too dark to distinguish species. The men thought they were Brunnich's Guillemots.

Jan. 10th.-Caught our dog Humpé, which ran away on August 11th; he was in good condition, having presumably fed on seal-bodies near the house, though no tracks had been seen for months. He evidently wants to get away again.

Jan. 11th.-Saw Tystie on water, and heard Eiders and Brunnich's Guillemots crying and diving close inshore.

$J$ an. 25th.-Twilight appreciable at noon, and four days later could then read large type. Humpé ran away again.

Temperature this month-Max. $32^{\circ}$, min. $-14^{\circ}$, mean $4.44^{\circ} \mathrm{F}$., being almost the same as in November. Weather stormy, dark, and disagreeable for more than half the month. 
Feb. 3rd.-Several seals seen.

Feb. 10th.-Ryper-droppings observed. The Spitsbergen Grouse make long burrows beneath the snow; and, since snow falls deep long before the severe frosts set in, the autumnal crop of berries, seeds, etc., is thus preserved beneath it, and provides the grouse with food. This explains the problem of how game-birds can survive the Arctic winter. The burrows are too narrow for a fox to enter.

Feb. 14th. -The coldest day so far-temperature, $\max .25^{\circ}$; min., minus $31^{\circ}$; mean, minus $28^{\circ} 25^{\circ}$.

Feb. 20th.-Many Tystie observed in small flocks, plumage very white; also three Fulmars. A glint of sunshine was observed for the first time at noon, impinging on the mountain-tops.

Feb. 21st.- Several Fulmars seen, and seals on the ice for the first time since autumn. Caught Humpé again, thin, after twenty-six days' absence.

Feb. 26th.- Sun seen for first time since midOctober.

Feb. 27th.-Bear seen, and shot on following daya big male, 7 feet 11 inches long. Stomach empty but for paper, hay, etc., blown away from house.

Temperature for February-max. $27^{\circ}$; min., minus $38^{\circ}$; mean $7 \cdot 07^{\circ}$. A windy and foggy month, with little aurora.

March 1st.-Birds seen - I think Eider and Fulmars; many of the latter flying about on 4 th.

March 5th.-Ryper were heard to-day and their tracks seen in snow. On the 11th saw four and shot two. Plumage white, black tail. 
March 15th.-Fulmars and Tysties plentiful, some of latter black. Ivory Gull seen, first this year.

March 16th.-Sunlight touched housc for first time since September. Shot thirty Tysties for food. They are not bad eating.

March 23rd.--Snowy Owl seen. It had killed a ryper and was eating it. The last was seen on Nov. 2nd.

March 26th.-Two Glaucous Gulls seen, first this year.

March 28th.-Little Auks seen and heard, also the first this year. Glaucous Gulls again seen, and Snowy Owl. We now go to bed at 10.30 by daylight.

Temperature in March-max. $32^{\circ}$; min., minus $35^{\circ}$; mean $5.05^{\circ} \mathrm{F}$. Weather generally fine and clear, with occasional gales.

During the winter, lamplight was required all day for exactly one hundred days.

April 1st.-A walrus seen off Dane's Gat.

April 5th.-Brunnich's Guillemots, and Eiders seen for first time this spring; also Ivory and Glaucous Gulls, Fulmars, Tysties and Little Auks abundant. Killed a bear at second glacier : a male, fat, with sealremains in stomach.

April 17th.-Little Auks crying from all the hills around house, and Guillemots heard on the cliffs of Amsterdam Island.

April 18th.-Two Kittiwakes seen for first time.

April 20th.-Saw walrus; killed two big, three small seals.

April 27th.-Snow-buntings arrived. Walrus seen. April 28th.-Piebald fox seen. The Seggur is 
still fast in ice four feet thick, and remained so till May 16 th.

Temperature for April-mean $6.93^{\circ}$ F. A windy, foggy month, except from 10 th to 15 th, when the sun shone for six days and nights from a cloudless sky.

May 9th.-A pair of Snow-Buntings appear to be building among some old graves, near house.

May 14th. - An old bearded seal killed to-day contained a young one nearly ready for exclusion-a precise miniature of its mother, except that it had little or no "speck" under its skin. Beard well developed, the bristles several inches long and stiff. Mother very fat.

May 16th.-Boarded ship again, having at last cleared the ice from her bilges, and sailed north next day.

May 17th.-Heard blue seals whistling under-water. The cry is audible for half a mile, not unlike the whining of a dog. The sealers say it is not uttered after early June.

May 18th-Norske-Öer-a school of about one hundred white whales seen, many of them young.

May 20th.-Returned to Dane's Gat, it being impossible to go north owing to continuous E. and N.E. gales jamming the ice on coast. Next day sailed south, rounding South Cape after a good passage of forty hours.

May 26th.-Storfjord. Grey geese seen for first time this year, flying from S.E. towards mainland.

May 28th.-Storfjord. Many walrus seen on ice and water. Killed four, also eight big seals. The walrus were all three-year-old bulls, the most difficult to tackle, and one of them drove his tusks through the upper 
strakes of the boat. Six bears were also got to-day on the Menke Islands, two old bears, and four cubs alive.

May 29th.-Long-tailed Ducks seen to-day for first time, and many geese on the mossy plain under Black Point. Eleven reindeer were killed by two Germans, but in very poor condition. The Seggur was again caught in the ice, and remains so.

May 30th.-Ice-bound. Shot two big reindeer bucks within three hundred yards of sloop: horns, about twelve inches long. Birds abundant on plain aforesaid : Grey, Brent, and six Bernicle Geese, Snow-Buntings, Purple Sandpipers, Skuas (seen for first time), and Kittiwakes rooting up moss for nesting.

June 3rd.-Terns (Sterna macrura) arrived to-day, and Phalaropes were reported seen. Two days later I shot one, swimming in a channel among the ice. Yellow buttercups (? sp.) in bloom.

June 5th.-Pair Red-throated Divers shot; also Long-tailed Ducks, and Phalarope aforesaid.

June 6th.-Dunlin (Tringa alpina) reported seen by the German naturalists. We have now been blocked here by the ice for nine days - the very time we reckoned on reaping a rich harvest among the walrus. One boat which got through to Deeva Bay secured six walrus and six big bearded seals.

June 8th.-Sailed for Norway.

I have not had the advantage of the author's supervision of these extracts. His last letter to me mentioned his being on the point of leaving for Central Asia for a year or two. 
Regarded purely as a sporting venture, this voyage of the Seggur was persistently obstructed by adverse conditions at every point. The autumn's sport was prevented, first by the ice in Storfjord, in the south ; next by adverse winds, jamming the ice-pack against the North coast. This ice-block, about $80^{\circ}$ North lat., appears tolerably constant, and it is the exception rather than the rule, when an open sea is found, and vessels are thus enabled to sail round Verlegen Hook, and enter Hinlopen Straits.

Then in the spring, the best weeks had already been lost ere it was found possible to cut the Seggur free from her icy cradle, and even then, the North route proved impracticable; while, on returning southwards, the sloop was again caught by ice in Storfjord at the very moment when the chances with Walrus, Bear, and other-Arctic big-game were most favourable.

The existence of an open sea in mid-winter in lat. $79^{\circ} 55^{\prime \prime}$ North, and the presence of birds thereon so early as January 2nd appear remarkable circumstances.

Spitsbergen possesses a fairly extensive flora of its own Arctic type, and I annex a list of plants collected there by myself in July and August, to wit :-

Ranunculas sulphureus.

Papaver nudicaule, $\mathbf{L}$.

Arabis alpina, $\mathbf{L}$.

Draba alpina, $\mathbf{L}$.

Cochlearia fenestrata, $\mathrm{Br}$.

Cardamine pratensis, $\mathbf{L}$.

Cerastium alpinum, $\mathbf{L}$.

Stellaria Edwardsii, Br. (? sp.)

Saxifraga oppositifolia, L.

, hirculus, L.

, coespitosa, L.

, cernua, L,
Saxifraga rivularis, $\mathrm{L}$.

Dryas octopetala, L.

Potentilla emarginata (?).

Leontodon taraxacum, L. (var.)

Andromeda tetragona, $\mathrm{L}$.

Polemonium cœruleum, L.

Pedicularis hirsuta.

Polygonum viviparum, L.

Salix herhacea.

Eriophorum-(? sp.)

Equisetum-traces of a small species. 



\section{N D E X.}

A

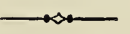

Absent bird-forms, 16, 143, 167 note, 293

Accidents in sport, $41,46-7,48,157$ 8, 193, 269-70

Adder, 103, 324

Advance (rapid) of summer, 91, 316

Albinism (in elk), 228, 232

- (in reindeer), 194 et seq., 199

Alfred C. Chapman, 136, 137 note, $145,299,305,307$

$\Lambda$ nimals, noxious (statistics of killed), 279, 300 note

Anthills (Nature's compasses), 248, 276

Apollo (Crimson-ringed), 163, 166

Auk, Little, 342 et seq.

Aurora, 344-5

Autumn in Norway, ch. xii.

— foliage, 174 275

travel (difficulties of), 240-1,

Avifauna of Norway, 14 et seq., 284 et seq.

- Spitsbergen, 341-2

$\Lambda$ vocets, $319,320,322$

\section{B}

Bats, 167

Bears, Brown, 104, 118 et seq., 211 et seq., 224, 232, 239, 277-8

_ attacking elks, 211, 224

"Benighted," 269-70

Big-game shooting (hints on), 233 et seq.

Bird-life (in general), 158, 213 et passim

- (Etne-dal), 64 note, 75

- (Evanger), 147

- (Förde-dal), 136 et seq.

- (forest), 250 note, 276

— (high fjeld), 29, 102 note, 192

- (sea-fowl), 299, 341-2

- (Surrendal), ch. xiii.

- (Spitsbergen), 341-2

(Telemark), 166-7 note

Blackbird, 167 note, 286

Blackcap, 143, 167 note, 292

Black-game, 143, 177-8, 181-2

Blue-throat, 127, 140, 291, 292, 329

Botany (notes on), 2 note, 28, 29, $126,152,300,304$ note, 351

Brambling, 103, 125, 142, 250 note, 287

Bull-trout, 100, 149

Bunting, Black-headed, 142, 293, 306

- Corn-, 167 note, 293

- Lap-, 127, 293'

- Snow-, 102 note, 293, 344, 349

- See also Ortold and YellowHAMMER.

Burbot, 263

Butterflies, 16, 17, 88, 91, 157, 162-3, 166,170

Buzzard, Common, 287

$-{ }_{287}$ Rough-legged, 129, 257, 281,

\section{C}

Camberwell Beauty, 163 note

Camp-life, 25-6, 189 et seq., 222, 263-4 
Capercaillie, 182-3, 184, 252

Carp, 315-6

Chaffinch, 142, 167 note, 287

Char, 116, 147, 155-6, 263

Chiffchaff, 143, 167 note, 292

Coar'se-fish (in Sweden), 171 (in Denmark), 306, 315-16

Coot, 304, 313

Crake, Corn-, 75, 143, 167 note, 315, 322

$\longrightarrow$, Spotted, 310

Crane, 296

Crossbill, 250, 285

Crow, Grey, 64 note, 109, 285

Cuckoo, 64 note, 113, 120, 143

Curlew, 285 note, 294, 319

Stone-, 305, 318

\section{D}

Dangers in sport, 146, 265-6, 268 et seq.

Denmark, 19, 20, chaps. xix., xx.

Dipper, 102 note, 113, 125, 143

Diver, Black-throated, 106, 107, 108, 109-10, 129, 250 note, 298

$\longrightarrow$, Red-throated, 115, 167 note, 298,350

Dotterel, 294

- , Ringed. See Plover.

Ducks (various) , 125, 129, 130, 320

- (Diving), 297, 335

- (Eider), 297

— (Garganey), 306, 313

297 (Golden-eye), 114, 115, 123,

- (King-eider), 297

(Long-tailed), 297, 250 note, 330 , 344,350

- (Pintail), 125, 129, 296, 320

- (Scaup), 250 note, 297

- (Sheld-), 297, 319

- Shoveler, 306, 312-13

- (Steller's eider), 297

— ('Tufted), 297 334

(Wigeon), 143, 250 note, 296,

Dunlin, 126, 294, 306, 319, 331, 350

E

Eagle, Golden, 167 note, 213, 236, 285,289
Eagle, White-tailed, 285, 289

-owl. See OwL.

Early dates of nesting, 143,285 note

Early-nesting species, 285-6, 291

Elk-hunting, chaps. xiv., xv., xvi., xvii., pp. 271-2

Elk-country (notes on), 238, 246

- habits and haunts of, 232-3,

237, 267, 271-2-3

— (in Telemark), 169-70 -driving, 239

280 statistics of numbers killed, 280

Etne river, ch. v.

Evanger river, 143 et seq.

\section{F}

Fieldfare, 106, 143, 286

Fieldmice (various), 192, 214, 282 note, 283-4

Flycatcher, Pied, 64 note, 117, 137, 138, 167 note, 292

- Spotted, 138, 292

Förde river (Söndfjord), 131 et serq.

Forest-scenery, 213

Fox, 116, 189, 192, 279

, White, $258,344,345$

Fulmar Petrel, 299, 33t-5, 347

G

Game-laws (Norsk), 12, 180-1, 221 note

Gannet, 299, 328, 335

Garganey, 306, 313

Gausta-fjeld, 163

Glutton, 124, 277, 279

Godwit, Bar-tailed, 294

—, Black-tailed, 294, 307 et seq.

Goldcrest, 64 note, 286, 329

Golden-eye, 114, 115, 123, 297

Goosander, 105, 111, 123, 297.

Goose, Bean, 298

— Brent, 331, 343

Grey (generally), 12t, 125, 267, $319,334,349$,

— Greylag, 297-8, 335

-_ Lesser White-fronted, 298

Pink-footed, 320, 344

Goshawk, 281-2, 285, 287-8

Grayling, 155, 263

Great Snipe, 127, 294, 314 
Grebes (various), 298, 304, 314

, Great Crested, 314

Greenfinch, 167 note, 287

Greenshank, 114, 125, 224

Grouse-shooting, 175 et seq., 178-9, 180-1

Grouse-specific notes on, 184 et seq. 250 347

Gulf Stream, 15, 16

Gull, Black-headed, 315

—, Common, 104, 125, 299

_- Glaucous, 344 et seq.

—, Great Black-backed, 299, 343

—, Herring-, 299, 328

- Kittiwake, 299, 328

-_, Lesser Black-backed, 299, 328

- , Little, 315, 324-5

\section{$\mathrm{H}$}

Hardanger Vidden, chap. xiii.

Hare, Alpine, 177, 192, 213, 240

- Brown, 113, 324

Harrier, Hen-, 289

$\longrightarrow$, Marsh-, 289, 313, 324

Harvest in Norway, 157, 172-3

Hawfinch, 290

Hedge-Sparrow, 292

Heron, 64 note, $75,143,296$

Hints on deer-stalking, 27, 45, 2034-5

267, 271-2

salmon-fishing, ch. iv., pp. 65 , 132,146

Hobby (unknown), 288

\section{I}

Icterine warbler, 140-1-2, 167 note

Ide, 171

Ill-luck (in sport), 216-17, 221, 247-8

Insect-life, 16, 17, 43, 88, 91, 147, $157,162-3,166,170$

$-193,276,316$

\section{$J$}

Jack-snipe, 127, 294, 331

Jay, Common, 287
Jay, Siberian, 167 note, 236, 250 note, 252,285

Jer-falcon, 281, 285, 288-9

K

"Karen," 261, 264

Kelts, 76, 86, 87

Kestrel, 143, 288, 305

King-eider, 297

Kittiwake, 299, 328

$\mathrm{L}$

Lapps, 12, 13, 243, 258, 265, 268, et seq.

Large Game, 10. See also, Bedr, Eı., Reindeer, etc.

Lark, Crested, 318

—, Shore, 292

- , Sky, 167 note, 293, 334

—, Tit-, 29, 102 note, 192

- Wood-, $91,121,167$ note, 334

Lemming, 123, 192, 280-1, 284

Life in hunting-quarters, 25-6, 189 et seq., 204, 222 et seq., 263-4

Linnet, 287

Lofoten, 3

Lynx, Northern, 212, 215, 239-40, 277,279

\section{M}

Mallard, 123, 285 note, 297

Marsh-tit, Northern, 138-9, 286

- British, 139, 286

Marten, Pine-, 258, 300 note

Martins (both sp.), 64 note, 91, 143, 324,331

Merganser, 116-17, 297

Merlin, 109, 129, 143, 288, 324

Migration, 236, 250 note, 291

- across North Sea, chap. xxi.

-

\section{$\mathrm{N}$}

Nightingale, 315 note

Nightjar, 167, 171, 333 
Noxious animals (Nos. killed), 279, 300 note

Nutcracker (never seen), 287

\section{0}

Ortolan, 64 note, 139-40, 167 note, 250 note, 285,293

Osprey, 76, 289

Otter, 316

Owl, Eagle-, 120, 143, 283, 290, 300 note

, Hawk-, 213, 283, 285, 290

, Least-Sparrow, 283, 290

, Long-eared, 283

- , Short-eared, 283, 290

-

-, Tawny, 143, 283, 285

- Tengmalm's, 283, 285, 290

Oyster-catcher, 296, 322

\section{P}

Partridge, 315

Peewit, 64 note, 306, 313, 319, 334

Pelican, 20, 319

People, The Norsk, 17-19

Perch, 171, 304

Peregrine, 281, 289

Petrels, 299, 334-5, 347

Phalarope, Red-necked, 294-5, 350

Pike, 171, 263, 316

Pine-grosbeak, 290

Pintail, 125, 129, 296, 320

Pipit, Meadow, 29, 102 note, 192

$\longrightarrow$, Rock-, 285, 292

—, Tree-, 142, 292, 318

Plover, Golden, 104, 177, 294, 305, 306,315

- Kentish, 319, 324

- Lesser Ringed, 319, 324

, Ringed, 294, 305, 319, 321, 324,343

Poverty of peasantry, 18

Protective coloration, 299

Ptarmigan, 23, 29, 30, 31, 184, et seq., 264,293

\section{$\mathrm{R}$}

Rabbits, 323, 324

Raven, 43, 102 note, 143, 257, 285
Reclamation of wastes, 321-2, 323

Red deer, 279, 280

Redpole (both sp.), 287, 292

Redshank, 64 note, 116, 123, 143, 294, 319

- Spotted, 294

Redstart, 64 note, 117, 167 note, 292 , 329

Redwing, 91, 106, 286

Reeves (nesting of), 320, 321

Reindeer, habits of, 27, 34 et seq., 175,194 et seq.

Reindeer-stalking, chaps. ii., iii., xiii., pp. 258-9

et seq.

Ring-Ouzel, 64 note, 102 note , 143, 286

Roach, 171, 315

Robin, 143, 250 note, 298

Rock-Pipit, 285, 292

Rodents, small, 283-4

Rudd, 171

Ruff, 295, 306, 311-12

\section{S}

Sæters, 128

Salmon-fishing, chaps. iv., v., vi., vil., ix. ; also p. 9

—, gaffing and striking, 57, 59

_- , harling, 59

"Lost monsters," chap. vi., pp. 90 et seq.

Salmon-flies, 72, 75

Salmon, habits of, 50 et seq., 73, 74, $94,153-4,172$

Sanderling, 107, 110, 111, 112, 343

Sandpiper, Broad-billed, 296

—, Common, 64 note, 117, 125, 296

- Green, 306, 314

- Purple, 295 note, 296, 344

- Wood-, 124, 125, 296, 306, 314, 324

Scenery, 2, 3, 23, 24, 103

Scoter, 250 note, 297 (Velvet, 297).

Seal, 300 note, 344-350

Sea-trout, 98, 99, 149, 172

Shearwater, 299, 334

Shrew, 284, 285

Shrike, Great Grey, 290

Siskin, 287 
Skua-Gulls (all species), 298-9, 329, 330,335

Small Game, 9, 10, 47, 212-13, 244$15,256,262$

Small Game, Norsk method of shooting, 183-4

Snipe, Common, 244, 256, 306

— Great, 127, 294, 314

- Jack, 127, 294, 331

Sparrow-hawk, 288

Spitsbergen, chap. xxii., p. 341

Spooring, 211, 220, 253, 272

Squirrel, 284

Statistics, 8, 279, 280, 300 note

Stint, Temminck's, 294

Stoat, 192, 284

Stone-Chat (unknown), 143

Stork, White, 306, 313

Summer (rapid advance of), 91, 316

Sunday customs, 31, 80, 90, 102

Surrendal, chaps. vii., viii.

Sweden, 19, 287, 290

\section{$\mathrm{T}$}

Teal, 117, 250 note, 297

Tents, Hunting-, 189 note, 204 et seq., 261

Terns (various), 299, 315, 325-6, 350

_- Arctic, 315, 325

Black, 306, 313, 315

Little, 325

Sandwich, 325

Thrush, Mistle-, 286 ; Song-, 143, 286

Titlark, 29, 102 note, 192, 292

Tits, Blue, 139,167 note

- - Longtailed, 142

--, Marsh-, 138-9, 167 note, 286

- - Oxeye, 64 note, 167 note, 139, 142

Tree-Creeper, 287

Tree-Pipit, 142, 292, 318, 331, 334

Trout-fishing, general, chaps. x., xi., and p. 263

— (in rivers), 136, 147

(in lakes), 105, 114-115, 215,

221,262

- (Norsk method), 152
Trout-fishing (in Telemark), 162 et seq.

Turnstone, 294

Twite, 287, 293

Tystie, chap. xxii., passim

\section{V}

Velvet Scoter, 129, 250 note

Voles, 283-4

\section{W}

Wagtail, White, 88, 105, 117, 143 , 167 note, 315

, Yellow, 117, 306, 315, 322, 334

Walrus, 343, 348, 349

Warbler, Blackcap, 64 note, 143, 167 note, 292 329

- Garden, 64 note, 117, 167 note, 292, 322, 331

--, Great Sedge, 315

_- Icterine, 140-1-2, 167 note

_, Sedge-, 64 note, 143, 291, 306, 315

- Willow-, 104, 117, 167 note, 292,329

(Siberian), 291-2

-. See also Chiffchaff, WhiteTHROAT, ETC.

Waxwing, 249-50

Weather (wild), 167, 182 et seq., 199 note

Weights of big-game, 40, 255

Wheatear, 64 note, 104, 143, 305

Whimbrel, 103, 115, 116, 294, 314, 330

Whinchat, 64 note, 143 note, 167, 292

Whitethroat, Common, 143, 167 note, 292

$\longrightarrow$ Lesser, 142

Whooper (Swan), 298

Wigeon, 143, 250 note, 296, 334

Wild-fowling, 10, 296

Willow-grouse, 22, 47, 175 et seq., 184 et seq., 293 
Wolves, 242, 243, 244, 257

Woodcock, 64 note , 70, 143, 294

Woodpecker, Black, 236, 250 note, 267, 285, 287

$\longrightarrow$, Green, 167 note _287 Great Spotted, 142, 236, 285,

—- Lesser Spotted, 167 note
Woodpecker, Three-toed, 250, 287

Wren, 143

Wryneck, 142, 287

Y

Yellow-hammer, 64 note, 142, 167 note, 293

THE END.

PRINTED GY WILLIAM CLOWES AND SONS, LIMITED, LONDON AND BECCLES. 


\section{THE SPORTSMAN'S LIBRARY.}

EDITED BY

SIR HERBERT MAXWELL, BART., M.P.

A Re-issue, in handsome volumes, of certain rare and entertaining Books on Sport, carefully selected by the Editor, and illustrated by the best Sporting Artists of the day, and with reproductions of old plates.

The author's text is judiciously respected in every instance, while the Editor contributes an introductory chapter, containing biographical and other observations; and, where it may be desirable to explain or correct the author's statements, editorial comments are offered in footnotes.

Library Edition, Fifteen Shillings a Volume.

Large Paper Edition (limited to two hundred copies), Two Guineas a Volume.

The EARL of Coventry writes: "I think the idea of a 'Sportsman's Library' an excellent one. So many now follow various sports, that a library of the old books brought out again will be very attractive."

Sir Ralph Payne-Gallwey, Bart., writes: "Just the class of work to be popular, whether in the shelves or laying on the smoking-room table. A pleasure to read, see, and handle."

"“The Sportsman's Library' will without doubt be found upon the bookshelves of most Englishmen devoted to outdoor sports."-Saturday Review.

"The bin is as worthy of our present drinking as it will repay keeping for those who come after us."-County Gentleman.

"Paper, type, and binding are all that could be desired."-Globe.

"Sportsmen and book-collectors will bless both editor and publisher."Liverpool Post.

VoLUME I.

The Life of a Fox, and the Diary of a Huntsman.

Volume II.

A Sporting Tour through the Northern Parts of England and Great Part of the Highlands of Scotland.

Volume III.

The Sportsman in Ireland.

\section{Reminiscences of a Huntsman.}

By the Hon. Granteey Berkeley. With the Original Illustrations in Colour by the late John Leech, and new ones by G. H. Jalland.

Cracks of the Day.

Edited by WILDRAKE. With numerous Illustrations. 


\section{THE SPORTSMAN'S LIBRARY.}

Volume I. Second Edition. Now Ready.

\section{The Life of a Fox, and the Diary of a Huntsman.}

By Thomas Suith, Master of the Hambledon and Pytchley Hounds. With Illustrations by the Author, and Coloured Plates by G. H. Jalland. Library Edition, 15s. Limited Large Paper Edition, $\mathfrak{E 2} 2$ s. net.

The Earu of Coventry writes: "A book I remember to have read with great interest many years ago, but which has been lost sight of."

Sir Ralph Payne-Gallwey, Bart., writes: "It is excellent, and beautifully produced."

"Mr. Arnold has done good service by placing in the hands of the modern sportsman a reprint of two such interesting works."-Field.

"Is sure to appeal to every one who has had, has, or is about to have, a chance of a run with the hounds, and those to whom an unkindly fate denies this boon will enjoy it for the joyous music of the hounds which it brings to relieve the winter of our discontent amid London fogs."-Pall Mall Gazette.

"It will be a classic of fox-hunting till the end of time."-Yortishire Post.

"No hunting men should be without this book in their libraries."-World.

"A delightful gift-book, and in this character we specially commend it to those of our readers who will be wondering " what they can give to a young man." "-Guardian.

"Should be in the bookcase of every sportsman."-Westminster Gazette.

Volume II.

\section{A Sporting Tour through the Northern Parts of England and Great Part of the Highlands of Scotland.}

By Colonel 'T. Thornton, of Thornville Royal, in Yorkshire. With the Original Illustrations by Garrard, and other Illustrations, and Coloured Plates by G. E. Lodge. Library Edition, handsomely bound, 15s. Large Paper Edition (limited to two hundred copies), $£ 22$ s. net.

"Sportsmen of all descriptions will gladly welcome the sumptuous new edition issued by Mr. Edward Arnold of Colonel T. Thornton's 'Sporting Tour,' which has long been a scarce book."-Daily News.

"It is excellent reading for all interested in sport."-Black and White.

"A handsome volume, effectively illustrated with coloured plates by G. E. Lodge, and with portraits and selections from the original illustrations, themselves characteristic of the art and sport of the time."-Times.

"To devotees of most branches of sport, more especially of shooting and fishing, Colonel Thornton's book will prove of immense interest."-Horse and Hound.

Volume III. Just Published.

\section{The Sportsman in Ireland.}

By a Cosmopolite. With Coloured Plates and Black and White Drawings by $\mathrm{P}$. Chenevix Trench, and reproductions of the Original Illustrations drawn by R. Allen and engraved by W. Westall, A.R.A. Library Edition, handsomely bound, 15s. Large Paper Edition (limited to two hundred copies), $£ 22 s$. net. 

